\title{
CONFORMANCE IMPROVEMENT USING GELS
}

Final Technical Progress Report, Reporting Period: September 1, 2001 through September 30, 2004

And

Third Annual Technical Progress Report, Reporting Period: September 1, 2003 through September 30, 2004

And

Sixth Semi-Annual Technical Progress Report, Reporting Period: March 1, 2004 through August 31, 2004

Principal Author: $\quad$ Randall S. Seright (505) 835-5571

Report Date: $\quad$ September 30, 2004

DOE Award Number: $\quad$ DE-FC26-01BC15316

Name and Address of Submitting Organization:

New Mexico Petroleum Recovery Research Center

New Mexico Institute of Mining and Technology

Socorro, New Mexico 87801

NM PRRC Contributors: Robert Sydansk, Richard Schrader, John Hagstrom II, Kathryn Wavrik, Ying Wang, Yin Xiong, and Abdullah Al-Dhafeeri SUNY Contributors: Brent Lindquist and Masa Prodanovic

PRRC Report 04-15 


\section{DISCLAIMER}

This report was prepared as an account of work sponsored by an agency of the United States Government. Neither the United States Government nor any agency thereof, nor any of their employees, makes any warranty, expressed or implied, or assumes any legal liability or responsibility for the accuracy, completeness, or usefulness of any information, apparatus, product, or process disclosed, or represents that its use would not infringe privately owned rights. Reference herein to any specific commercial product, process, or service by trade name, trademark, manufacturer, or otherwise does not necessarily constitute or imply its endorsement, recommendation, or favoring by the United States Government or any agency thereof. The views and opinions of authors expressed herein do not necessarily state or reflect those of the United States Government.

\section{DEDICATION}

This report is dedicated to the memory of Tom Reid. During his time with the National Petroleum Technology Office, Tom played a very constructive part in overseeing our research. We will miss his insights, his vision, his dedication to advancing petroleum engineering, and his friendship. 


\section{ABSTRACT}

This report describes work performed during the third and final year of the project, "Conformance Improvement Using Gels." Corefloods revealed throughput dependencies of permeability reduction by polymers and gels that were much more prolonged during oil flow than water flow. This behavior was explained using simple mobility ratio arguments. A model was developed that quantitatively fits the results and predicts "clean up" times for oil productivity when production wells are returned to service after application of a polymer or gel treatment.

$\mathrm{X}$-ray computed microtomography studies of gels in strongly water-wet Berea sandstone and strongly oil-wet porous polyethylene suggested that oil penetration through gel-filled pores occurs by a gel-dehydration mechanism, rather than gel-ripping or gel-displacement mechanisms. In contrast, analysis of data from the University of Kansas suggests that the gelripping or displacement mechanisms are more important in more permeable, strongly water-wet sandpacks. These findings help to explain why aqueous gels can reduce permeability to water more than to oil under different conditions.

Since cement is the most commonly used material for water shutoff, we considered when gels are preferred over cements. Our analysis and experimental results indicated that cement cannot be expected to completely fill (top to bottom) a vertical fracture of any width, except near the wellbore. For vertical fractures with apertures less than $4 \mathrm{~mm}$, the cement slurry will simply not penetrate very far into the fracture. For vertical fractures with apertures greater than $4 \mathrm{~mm}$, the slurry may penetrate a substantial distance into the bottom part of the fracture. However, except near the wellbore, the upper part of the fracture will remain open due to gravity segregation.

We compared various approaches to plugging fractures using gels, including (1) varying polymer content, (2) varying placement (extrusion) rate, (3) using partially formed gels, (4) using combinations of high and low molecular weight (Mw) polymers, (5) using secondary crosslinking reactions, (6) injecting un-hydrated polymer particles, and (7) incorporating particulates. All of these methods showed promise in some aspects, but required performance improvements in other aspects. All materials investigated to date showed significant performance variations with fracture width. High pressure gradients and limited distance of penetration are common problems in tight fractures. Gravity segregation and low resistance to breaching are common problems in wide fractures. These will be key issues to address in future work.

Although gels can exhibit disproportionate permeability reduction in fractures, the levels of permeability reduction for oil flow are too high to allow practical exploitation in most circumstances. In contrast, disproportionate permeability reduction provided by gels that form in porous rock (adjacent to the fractures) has considerable potential in fractured systems. 


\section{TABLE OF CONTENTS}

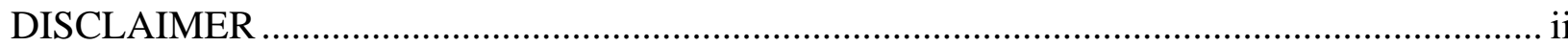

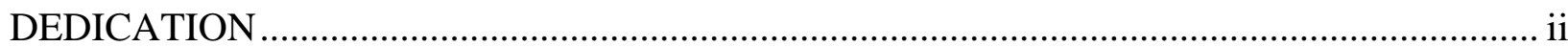

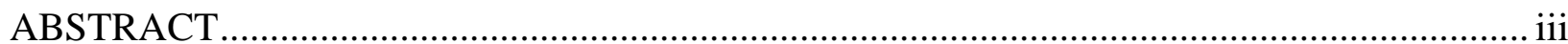

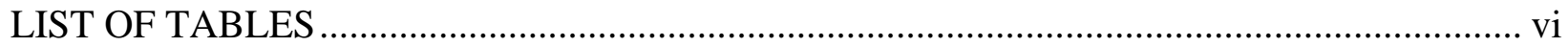

TABLE OF FIGURES ....................................................................................................... vi

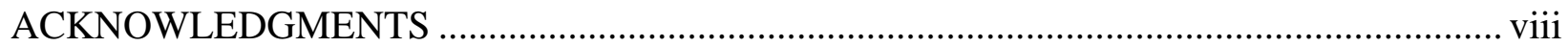

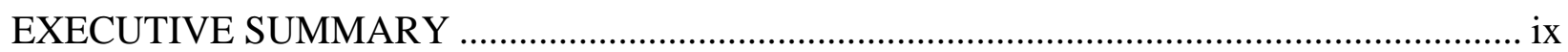

Throughput Dependence of Oil and Water Permeabilities ....................................................... ix

Mechanism for Disproportionate Permeability Reduction .............................................................

Plugging Fractures: Cement Versus Gels .............................................................................

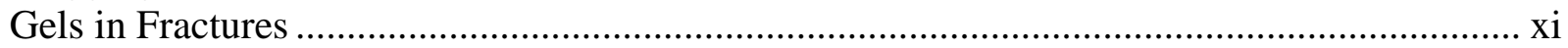

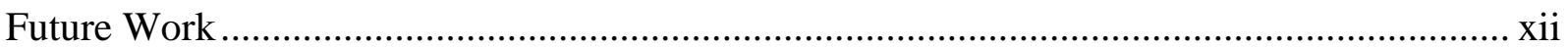

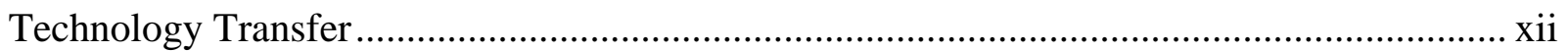

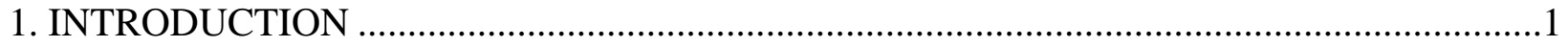

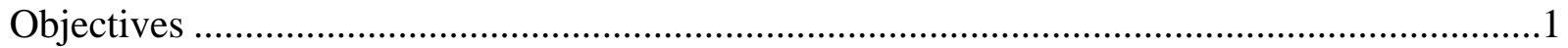

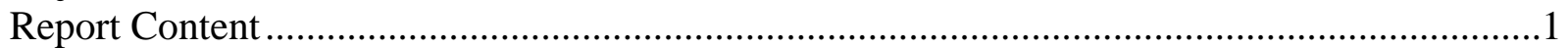

2. THROUGHPUT DEPENDENCE OF OIL AND WATER PERMEABILITIES ........................2

Permeability to Water ..........................................................................................................

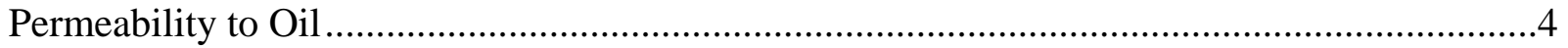

Effect on Ultimate Oil Productivity ......................................................................................

Behavior of an Adsorbed Polymer...........................................................................................12

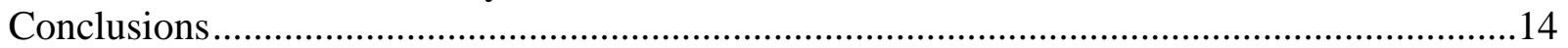

3. MECHANISM FOR DISPROPORTIONATE PERMEABILITY REDUCTION....................16

Differences between the Old and New Analyses................................................................16

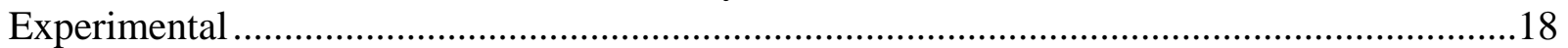

Saturations before Gel Placement........................................................................................2

20-cp Gelant Mobilized Oil in Both Porous Media .....................................................................2.

Oil and Water Flooding after Gel Placement.......................................................................2

Connectivity of Phases..........................................................................................................34

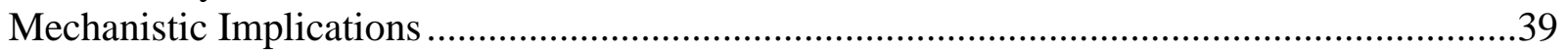

Comparison with Results from the University of Kansas....................................................43

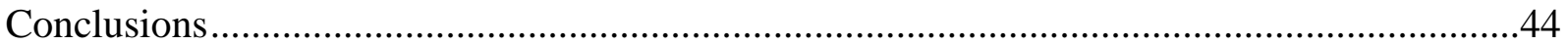

4. PLUGGING FRACTURES: CEMENT VERSUS GELS …………..................................47

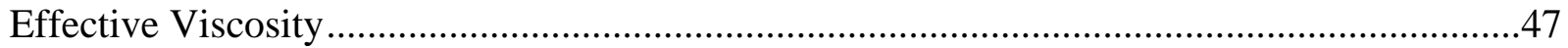

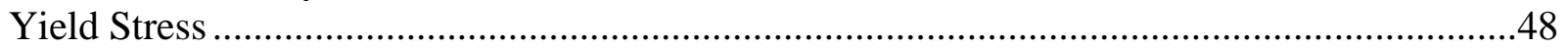

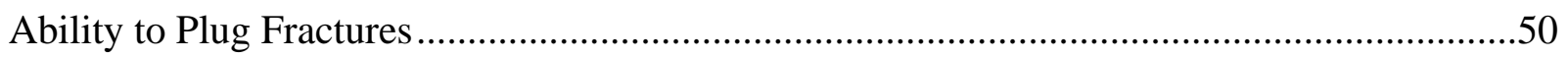

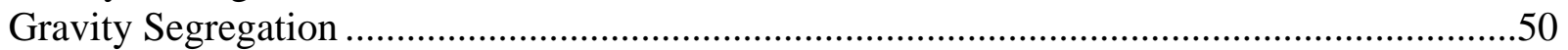

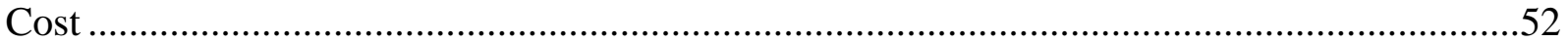

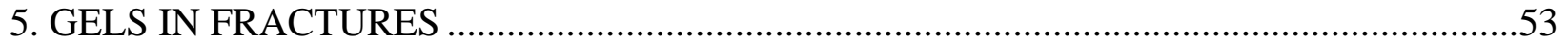

Gelant/Gel Properties during Placement.....................................................................................53

Brine Injection Displaces a Small Fraction of the Gel ............................................................59

Using More Concentrated Gels..............................................................................................66

Exploiting Placement (Extrusion) Rate ...................................................................................62

Using Combinations of High and Low Mw Polymers.............................................................63 
Using Secondary Crosslinking Reactions ...................................................................66

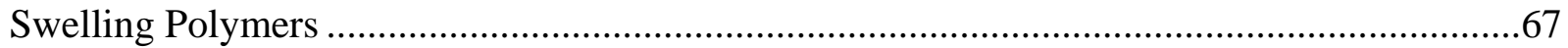

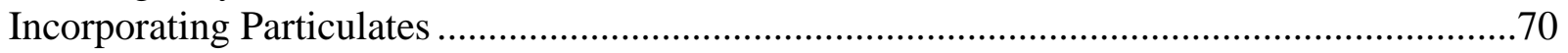

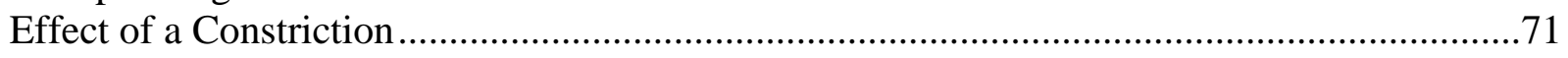

Disproportionate Permeability Reduction in Fractures......................................................72

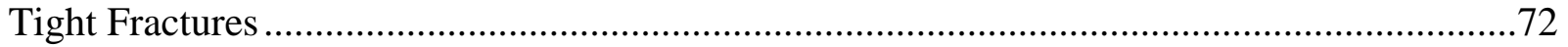

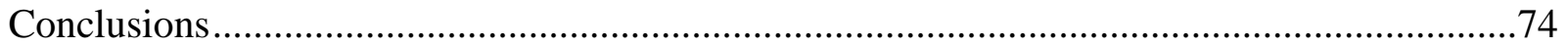

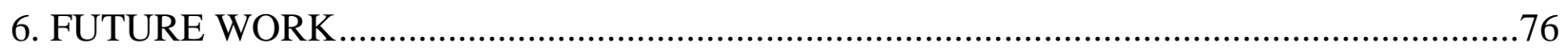

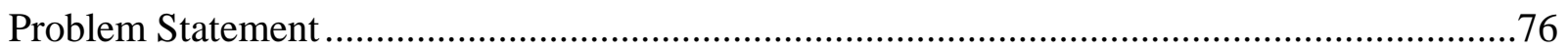

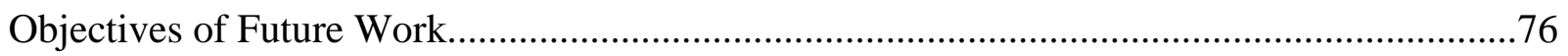

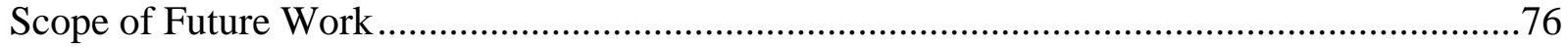

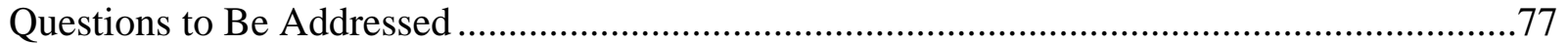

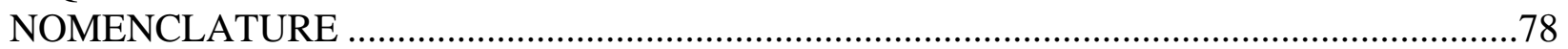

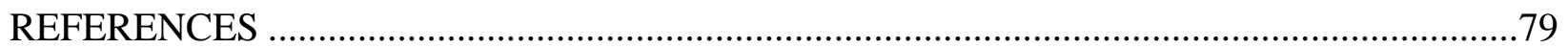

APPENDIX A: Program To Model Coreflood Results ............................................................83

APPENDIX B: Program to Predict Oil Productivity In Fractured Production Wells ...................85

APPENDIX C: Program to Predict Oil Productivity in Unfractured Production Wells................87

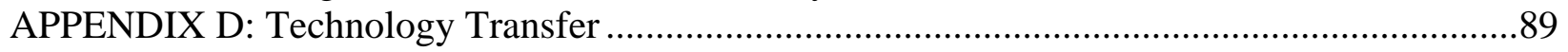

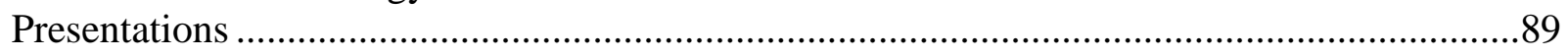

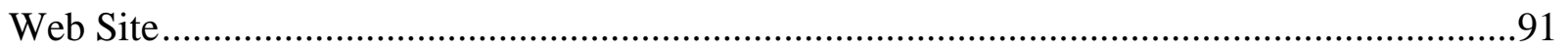

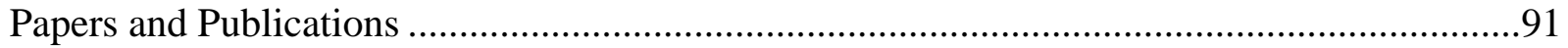




\section{LIST OF TABLES}

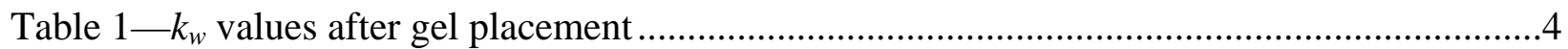

Table $2-k_{w}$ values after polymer placement in Berea sandstone .............................................14

Table 3-Average water saturations after various floods...................................................21

Table 4-Gels dehydrate during extrusion .....................................................................56

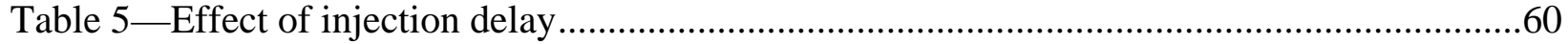

Table 6-Effect of gel polymer concentration ..................................................................61

Table 7-Effect of gel placement (extrusion) rate .............................................................63

Table 8-Use of high and low Mw polymers in gels ......................................................64

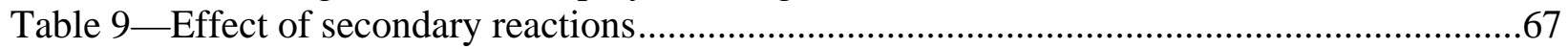

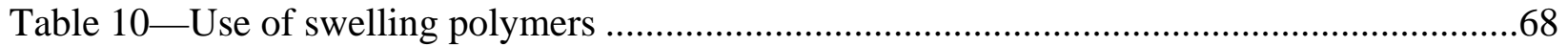

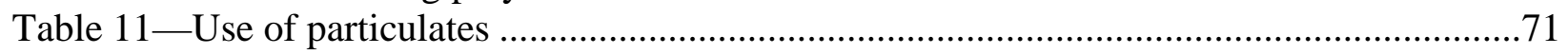

Table 12-Use of low-concentration gels in tight fractures ................................................73

\section{TABLE OF FIGURES}

Fig. 1-Permeability to oil and water after gel placement in a Berea core. .................................3

Fig. 2-Permeability to oil after gel placement during many experiments..................................5

Fig. 3-Effect of distance of gel penetration from a fracture face. ...........................................6

Fig. 4-Effect of radius of gel penetration in an unfractured well..........................................6

Fig. 5 -Cleanup time in linear versus radial flow.........................................................

Fig. 6-Effect of pressure drawdown on oil-zone cleanup. .................................................

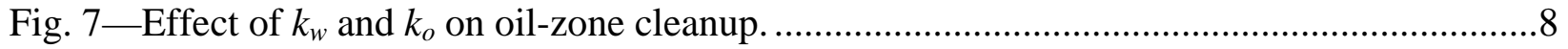

Fig. 8-Ultimate productivity after gel placement in a fractured production well. ......................9

Fig. 9-Ultimate productivity after gel placement in an unfractured production well. .................9

Fig. 10-Ultimate productivity after gel placement: linear flow, simplified correlation..............10

Fig. 11-Permeability to brine versus time.................................................................12

Fig. 12-Permeability during oil injection after treatment with an adsorbing polymer...............13

Fig. 13-Pore size distributions for Berea and polyethylene. .................................................18

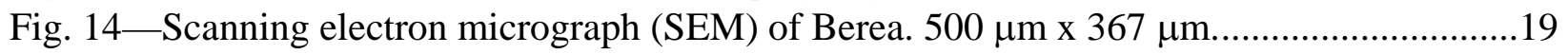

Fig. 15—SEM of polyethylene. $500 \mu \mathrm{m}$ x $367 \mu \mathrm{m}$. .............................................................19

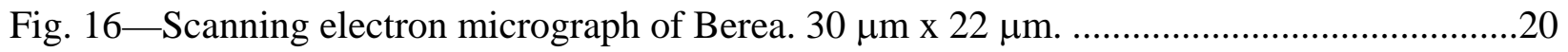

Fig. 17-Scanning electron micrograph of polyethylene. $30 \mu \mathrm{m}$ x $22 \mu \mathrm{m}$.................................20

Fig. 18_Berea @ $S_{w r}$ before gel. .................................................................................................22

Fig. 19_Berea @ $S_{\text {or }}$ before gel............................................................................................23

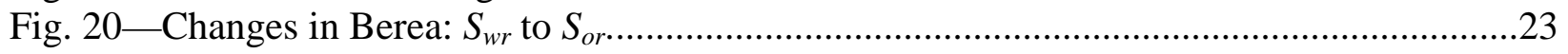

Fig. 21—Polyethylene @ $S_{\text {or1 }}$ before gel................................................................................24

Fig. 22_Polyethylene @ $S_{w r}$ before gel.....................................................................................25

Fig. 23_Polyethylene @ $S_{\text {or2 }}$ before gel.................................................................................25

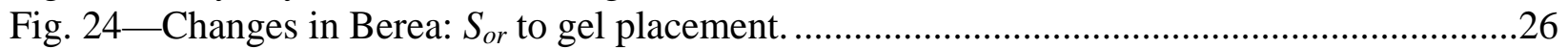

Fig. 25—Polyethylene after gel placement....................................................................27

Fig. 26-Oil flooding to $S_{w r}$ after gel placement in Berea.....................................................28

Fig. 27-Oil damaged gel most in pores that were easily filled by oil or water before gel.........29 
Fig. 28 - Changes in Berea: $S_{w r}$ before gel to $S_{w r}$ after gel.....................................................29

Fig. 29-Changes in Berea: $S_{w r}$ after gel to $S_{\text {or }}$ after gel. ............................................................30

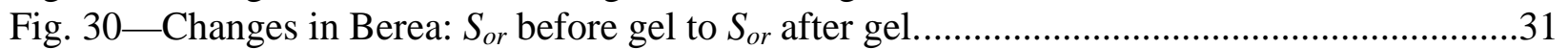

Fig. 31-Polyethylene @ $S_{w r}$ after gel................................................................................................32

Fig. 32-Oil flooding to $S_{w r}$ after gel placement in polyethylene. ..................................................32

Fig. 33_Polyethylene @ $S_{\text {or }}$ after gel....................................................................................33

Fig. 34-Residual phase blob distributions................................................................................34

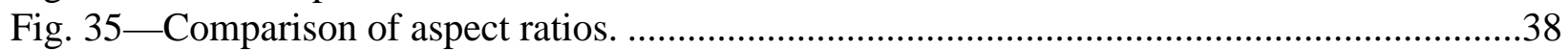

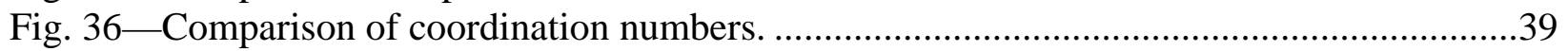

Fig. 37_Water injected first after gel placement.....................................................................

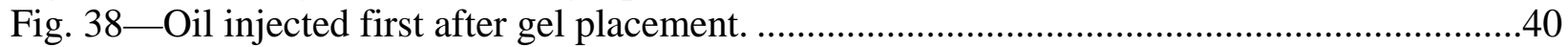

Fig. 39-Water flow following oil injection after gel placement in Berea..................................42

Fig. 40-Water flow following oil injection after gel placement in oil-wet polyethylene.............43

Fig. 41-Apparent viscosities for gelant, gel, and various cement slurries. ...................................48

Fig. 42-Minimum pressure gradient for flow for cement and formed gel. .................................49

Fig. 43-Pressure gradients during cement slurry extrusion through 4-mm-wide fractures..........50

Fig. 44-Minimum rates for viscous and gravity forces to match for cement slurries. .................51

Fig. 45-Effective viscosities for gelants and gels in 1-mm-wide fractures..................................54

Fig. 46 - Stable pressure gradients during gel extrusion.................................................................54

Fig. 47-Leakoff rates for gelants and gels in 1-mm-wide fractures.............................................55

Fig. 48-Effect of fracture width on gel extrusion pressure. ……..............................................57

Fig. 49—Wormhole pattern during gel extrusion.....................................................................58

Fig. 50—Pressure gradients in 5 fracture sections during brine injection after gel placement. ....59 


\section{ACKNOWLEDGMENTS}

Financial support for this work is gratefully acknowledged from the United States Department of Energy (NETL/National Petroleum Technology Office), the State of New Mexico, ConocoPhillips, Marathon, and the Ufa branch of YuganskNIPIneft. I greatly appreciate the efforts of those individuals who contributed to this project. John Hagstrom conducted the experimental work described in Chapter 2. Brent Lindquist and Masa Prodanovic (State University of New York at Stony Brook) were instrumental during the analyses described in Chapter 3. Richard Schrader and Kate Wavrik performed the experimental work described in Chapter 4. Several people contributed to Chapter 5, including Robert Sydansk, Richard Schrader, Kate Wavrik, Ying Wang, Yin Xiong, and Abdullah Al-Dhafeeri. I especially appreciate the thorough review of this manuscript by Julie Ruff and Bob Sydansk. Both Bob and Julie provided helpful technical comments for all chapters. 


\section{EXECUTIVE SUMMARY}

This report describes work performed during the third and final year of the project, "Conformance Improvement Using Gels." This three-year research project had two objectives. The first objective was to identify gel compositions and conditions that substantially reduce flow through fractures that allow direct channeling between wells. This goal was be reached by (1) characterizing gel propagation through fractures as a function of fracture width, length, and height, injection rate, gel composition, and temperature, (2) correlating rheology in fractures with that in a viscometer, and (3) using the experimental results to develop an appropriate model for gel placement and treatment sizing.

The second objective was to optimize treatments in fractured production wells, where the gel must reduce permeability to water much more than that to oil. Within this objective, the specific goals were to (1) determine the correct mechanism(s) for the disproportionate permeability reduction, (2) identify conditions that maximize the phenomenon, (3) find materials and methods that make the phenomenon predictable and controllable, and (4) establish a methodology to determine how much gelant should be injected in a given fractured production well.

\section{Throughput Dependence of Oil and Water Permeabilities}

Because polymers and gels can reduce permeability to water much more than that to oil, an unfavorable displacement (high mobility ratio) usually occurs in oil zones when wells are returned to production after bull-headed gel treatments. Since oil displacement through gel is unfavorable, the permeability to oil requires a large throughput to stabilize. Consequently, oil zones often exhibit a significant "cleanup time" after field applications of a gel treatment.

The oil and water throughput requirements for stabilization of permeabilities were studied for a relatively "strong" pore-filling Cr(III)-acetate-HPAM gel and for a "weak" adsorbing polymer. For both materials, permeability to water stabilized within one pore volume (PV) after polymer or gel treatment. However, as oil throughput increased from 1 to $100 \mathrm{PV}$, permeability to oil gradually increased by factors from 5 to 10 for cores treated with the Cr(III)-acetate-HPAM gel and by factors from 2 to 3 for cores treated with the adsorbing polymer.

A model was developed to predict cleanup times for both fractured and unfractured wells after a gel treatment. The time required to restore productivity to a gel-treated oil zone was (1) similar for radial versus linear flow, (2) proportional to the cube of distance of gel penetration, (3) inversely proportional to pressure drawdown, (4) inversely proportional to the permeability to water $\left(k_{w}\right.$ at $\left.S_{o r}\right)$ in the gel-treated region, and (5) not sensitive to the final permeability to oil $\left(k_{o}\right.$ at $S_{w r}$ after many PV throughput).

Although $k_{o}$ at $S_{w r}$ (after gel placement) has no effect on the cleanup time, it does have an important impact on how much of the original oil productivity can ultimately be regained after a gel treatment. Earlier work demonstrated that an acceptable gel or polymer placement can be achieved by unrestricted injection of gelants during linear flow (e.g., vertically fractured wells). However, in radial flow (e.g., unfractured wells), hydrocarbon productive zones must be protected during gelant or polymer placement. These conclusions were confirmed by 
consideration of our new results and the magnitude and variability of oil and water permeabilities and residual resistance factors for both the Cr(III)-acetate-HPAM gel and the adsorbing polymer.

\section{Mechanism for Disproportionate Permeability Reduction}

X-ray computed microtomography (XMT) was used to understand why a Cr(III)-acetate-HPAM gel reduced permeability to water 80-90 times more than that to oil in strongly water-wet Berea sandstone and in strongly oil-wet porous polyethylene. During oil flow after gel placement in Berea, a 55\% (average) reduction in gel volume occurred in pores of all detected size ranges, thus leading to a relatively high permeability to oil. In porous polyethylene, reduction in gel volume occurred mainly in small pores. Because the first oil injection after gel placement did not reduce gel volume to a greater extent in large pores than in small pores, the reduction in gel volume was probably caused by gel dehydration rather than by gel ripping or extrusion.

The overall $S_{\text {or }}$ in Berea jumped from 18.4\% before gel placement to $51 \%$ after. The greater level of trapped oil greatly restricted water flow. Before gel placement, most residual non-wetting blobs were isolated within individual pores. In Berea at $S_{\text {or }}$ after gel placement, the largest residual oil blob was 122 times larger than the largest oil blob at $S_{\text {or }}$ before gel placement. This high degree of connectivity for the oil phase explains the relatively high permeability to oil after gel placement. This large blob may exist because gel affinity for water limited the formation of water films that were needed to break the large oil blob into small blobs.

In porous polyethylene, the overall $S_{\text {or }}$ was significantly lower after gel placement than before gel placement $(0.3 \%$ versus $17.0 \%)$. Thus, oil trapping could not explain the large disproportionate permeability reduction $\left(F_{r r w} / F_{r r o}=89\right)$. Gel dehydration and rehydration provide a viable explanation. In particular, paths may open during oil injection by partial dehydration of the gel. During subsequent water injection, the paths could partially close when the gel rehydrates.

Careful analysis of results during oil injection into gel-treated sandpacks (4- to 5-darcys) at the University of Kansas indicated that ripping or gel displacement mechanisms dominate over dehydration. One would expect ripping or gel displacement mechanisms to become more important as the permeability increases for strongly water-wet porous media. Consequently, it is quite conceivable that the dehydration mechanism dominated in our 0.47-darcy Berea, while the ripping or gel displacement mechanisms dominated in the sandpacks investigated at the University of Kansas.

\section{Plugging Fractures: Cement Versus Gels}

Since cement is the most commonly used material for water shutoff, we considered when gels are preferred over cements during water shutoff applications. Our analysis and experimental results indicated that cement cannot be expected to completely fill (top to bottom) a vertical fracture of any width, except near the wellbore. For vertical fractures with apertures less than 4 $\mathrm{mm}$, the cement slurry will simply not penetrate very far into the fracture. For vertical fractures with apertures greater than $4 \mathrm{~mm}$, the slurry may penetrate a substantial distance into the bottom part of the fracture. However, except near the wellbore, the upper part of the fracture will remain open due to gravity segregation. Conceptually, foamed cement slurries with the same density as water could be placed long distances into voids and fractures and fill the void channel top to 
bottom. However, the relatively short set times of these slurries still limit their distance of penetration. Further work is needed to properly assess the potential of foamed cement.

\section{Gels in Fractures}

In cases where gels are intended to plug fractures, our ultimate goal is to identify a material that will (1) exhibit low pressure gradients and effective viscosity during placement, (2) not suffer from significant gravity segregation during placement, (3) provide a high pressure gradient for breaching of the gel during brine flow after gel placement, (4) provide high resistance to brine flow if the gel is breached, and (5) provide performance that is insensitive to fracture aperture.

Gelants and partially formed gels show low viscosities and pressure gradients during placement. Use of gelants with high concentrations of low molecular weight (Mw) polymers appears appropriate for total shutoff of both matrix and fractures with widths of $1 \mathrm{~mm}$ or less. More work is needed to establish its effectiveness in wider fractures. Concern exists about gravity segregation during placement in vertical fractures. Gelants can penetrate significantly (and potentially damage) porous rock, whereas this concern is mitigated by use of partially formed gels. With proper placement, concentrated gelants and partially formed gels can provide high breaching pressure gradients after gel placement. Gels with combinations of high and low molecular weight polymers received particular emphasis during our investigations. These materials offer advantages for convenient formulation during field applications. Like other materials, they provide mixed performance with respect to stabilized permeability reduction after gel placement, and are fairly expensive when concentrated formulations must be used.

Formed gels generally provide high pressure gradients and effective viscosities during placement. The disadvantage that this presents with respect to injectivity is partially offset by reduced problems with gravity segregation. Also, the formulations are usually in the gelant (uncrosslinked) state before injection, thus mitigating pumping problems in surface facilities (i.e., gelation does not occur until the formulation is near or in the formation). Rate control during placement has shown potential in placing very concentrated, washout-resistant gels in fractures. If high stabilized $F_{r r w}$ values are required, injection of formed gels may be the most effective approach, especially in wide fractures.

Preliminary experiments with secondary crosslinking reactions did not reveal any performance breakthroughs. However, this area is worthy of additional study.

Swelling polymers commonly showed gravity segregation and abrupt screen-out behavior in fractures. These properties impose placement limitations, especially when deep penetration is desired. Nevertheless, they also show sufficient potential to warrant further investigation.

Gels that incorporated density-matched fiber particulates showed significant potential in strengthening the gel's resistance to breach after gel placement. As with some other materials, key issues associated with their use include relatively high effective viscosities during placement and screen-outs limiting depth of penetration in fractures. On the other hand, clever exploitation of screen-outs could significantly improve the cost effectiveness of some materials in certain circumstances. 
All materials investigated to date showed significant performance variations with fracture width. High pressure gradients and limited distance of penetration are common problems in tight fractures. Gravity segregation and low resistance to breaching are common problems in wide fractures. These will be key issues to address in future work.

Although gels can exhibit disproportionate permeability reduction in fractures, the levels of permeability reduction for oil flow are too high to allow practical exploitation in most circumstances. In contrast, disproportionate permeability reduction provided by gels that form in porous rock (adjacent to the fractures) has considerable potential in fractured systems.

\section{Future Work}

The goal of our next project is to develop aperture-tolerant, chemical-based methods to reduce channeling through voids (e.g., fractures, vugs, karst) during hydrocarbon production. One objective is to develop materials that can be effectively placed and will consistently minimize flow through voids with a wide range of apertures. A second objective is to develop methods to minimize water entry into voids from the surrounding rock. This aspiration requires chemicals (i.e., gels, polymers) that predictably and controllably reduce the permeability to water much more than that to hydrocarbon.

We will fulfill the above objectives during a three-year effort, using two parallel activities. One effort will develop gel-based materials that readily penetrate a predictable distance into voids and then set up to effectively resist washout in voids with a wide range of apertures (e.g., fracture widths). Within this activity, we will investigate blocking-agent placement and washout properties as a function of (1) gelant/formed-gel composition and placement rate, (2) secondary crosslinking reactions that strengthen the gel after placement, and (3) reactive and non-reactive particulate compositions. The second effort will utilize polymers and gels that selectively damage porous rock (i.e., adjacent to the fracture faces) to inhibit water flow into voids. If water does not enter the void, it won't channel to production wells. This effort will include (1) porelevel studies using X-ray computed microtomography to confirm the mechanism for disproportionate permeability reduction and (2) mechanistic corefloods to identify conditions of maximum disproportionate permeability reduction and reproducibility. Both tasks will involve laboratory and theoretical studies. Also, both tasks will incorporate analyses of selected field applications to evaluate the efficacy and mechanism of action for different gel treatment approaches.

\section{Technology Transfer}

Technology transfer efforts for the project are listed in Appendix D. 


\section{INTRODUCTION}

Fractures (either natural or artificially induced) often cause excess water production and reduced oil recovery efficiency, especially during waterfloods and improved oil recovery projects. Fractures constitute a channeling and water-production problem that has a high potential for successful treatment by gels and certain other chemical blocking agents. Especially in fractured production wells, gels can substantially diminish water production if the gel can reduce permeability to water much more than that to oil.

This report describes work performed during the third and final year of the project, "Conformance Improvement Using Gels." Results from the first and second years are described in Refs. 1 and 2.

\section{Objectives}

This research project had two objectives. The first objective was to identify gel compositions and conditions that substantially reduce flow through fractures that allow direct channeling between wells. This goal was reached by (1) characterizing gel propagation through fractures as a function of fracture width, length, and height, injection rate, gel composition, and temperature, (2) correlating rheology in fractures with that in a viscometer, and (3) using the experimental results to develop an appropriate model for gel placement and treatment sizing.

The second objective was to optimize treatments in fractured production wells, where the gel must reduce permeability to water much more than that to oil. Within this objective, the specific goals were to (1) determine the correct mechanism(s) for the disproportionate permeability reduction, (2) identify conditions that maximize the phenomenon, (3) find materials and methods that make the phenomenon predictable and controllable, and (4) establish a methodology to determine how much gelant should be injected in a given fractured production well.

\section{Report Content}

This report describes work performed during the third and final year of the project. Chapter 2 describes coreflood studies of how disproportionate permeability reduction depends on oil or water throughput. Chapter 3 re-examines the use of X-ray computed microtomography to identify the mechanism responsible for gels reducing the permeability to water more than that to oil. Chapter 4 compares the effectiveness of cement versus gels in plugging fractures. Chapter 5 compares various approaches to plugging fractures using gels, including (1) varying polymer content, (2) varying placement (extrusion) rate, (3) using partially formed gels, (4) using combinations of high and low molecular weight (Mw) polymers, (5) using secondary crosslinking reactions, (6) injecting un-hydrated polymer particles, and (7) incorporating particulates. Chapter 6 proposes future work. Finally, technology transfer activities are described in Appendix D. 


\section{THROUGHPUT DEPENDENCE OF OIL AND WATER PERMEABILITIES}

Utility of Disproportionate Permeability Reduction. In mature reservoirs, wells typically produce more water than hydrocarbon. Reducing water production can reduce operating expenses and mitigate environmental liability. In many cases, hydrocarbon productivity could be increased significantly if the rate of water production could be reduced. For these cases, the water and hydrocarbon must flow to the wellbore through different pathways (i.e., some zones or pathways would have high fractional hydrocarbon flow, while other zones or pathways would have high fractional water flow). ${ }^{3}$ Because of physical or economic constraints, remedial chemical treatments (e.g., gel treatments) that are intended to plug water zones are often placed without zone isolation. Consequently, the injected fluids and chemicals penetrate into both hydrocarbon and water zones, and the operator must be concerned about damage caused to hydrocarbon productivity. ${ }^{3,4}$ Certain water-based gels and water-soluble polymers (after adsorption or entrapment in rock) can reduce permeability to water much more than that to hydrocarbon." ${ }^{5,6}$ Under the proper circumstances, this property could be very useful. Basic engineering calculations reveal that materials that provide "relative permeability modification" or "disproportionate permeability reduction" are currently of far more practical use when treating linear flow features (e.g., fractures) than when treating radial flow problems (e.g., wells without fractures). ${ }^{7-9}$ For these materials to effectively treat radial flow, they should reduce permeability to water by more than a factor of 10 (and preferably by more than a factor of 20). At the same time, they must reduce permeability to oil by less than a factor of two. ${ }^{7}$ In contrast when treating fractures, a significant oil residual resistance factor (permeability reduction value for oil) can be tolerated so long as (1) the permeability to water is reduced much more (e.g., >50 times more) than that to oil and (2) the distances of gelant leakoff from the fracture faces are controlled. ${ }^{8,9}$

“Clean Up” Behavior. For many field applications of gel treatments in production wells, oil productivity gradually increased or "cleaned up" during the first weeks after the treatments were applied..$^{9-11}$ To understand this phenomenon, we studied the dependence of oil and water permeabilities on throughput during various cycles of oil and water injection after gel placement in laboratory cores. The gel was our standard " $1 \mathrm{X}$ " formulation that contained $0.5 \%$ Alcoflood $935 \mathrm{HPAM}, 0.0417 \% \mathrm{Cr}(\mathrm{III})$ acetate, $1 \% \mathrm{NaCl}$, and $0.1 \% \mathrm{CaCl}_{2}$ at $41^{\circ} \mathrm{C}$. The first Berea sandstone core used was 3 inches long, with an absolute permeability of $746 \mathrm{md}$. After gel placement (6 pore volumes, PV) and shut-in, hexadecane was injected using a fixed pressure gradient of $40 \mathrm{psi} / \mathrm{ft}$. The solid circles in Fig. 1 demonstrate that permeability to oil increased gradually from 2 md to 105 md during the course of 100 PV. The open circles in Fig. 1 show the permeability when water was injected after the above oil-injection stage. In contrast to the oil behavior, permeability to water stabilized at $0.17 \mathrm{md}$ within a few tenths of one PV. During the second and third cycles of oil injection (solid triangles and squares in Fig. 1), permeability again gradually increased over the course of $100 \mathrm{PV}$. The permeability to oil followed the same trend for all three cycles (although the final permeability was $60 \%$ greater for the second and third cycles than for the first cycle). During the second cycle of water injection (open triangles in Fig. 1), the permeability stabilized at 1.1 md within $1 \mathrm{PV}$.

Mobility Ratios. The behavior in Fig. 1 depended on whether the displacement during water or oil injection was favorable (mobility ratio less than one) or unfavorable (mobility ratio greater than one). We are accustomed to considering unstable displacements when the viscosity of the 
injected fluid is significantly less than the viscosity of the displaced fluid. In our experiments, water viscosity (1 cp) was not greatly different than hexadecane viscosity (3 cp). However, after gel placement, the endpoint permeability to water was substantially less than the endpoint permeability to oil. During water injection, water mobility was substantially less than oil mobility, so the mobility ratio was very favorable, and flow was expected to stabilize quickly. In contrast, during oil injection, oil mobility was substantially greater than water mobility, so the mobility ratio was very unfavorable, and substantial throughput was needed for flow to stabilize $^{12,13}$ These expectations were consistent with the behavior in Fig. 1.

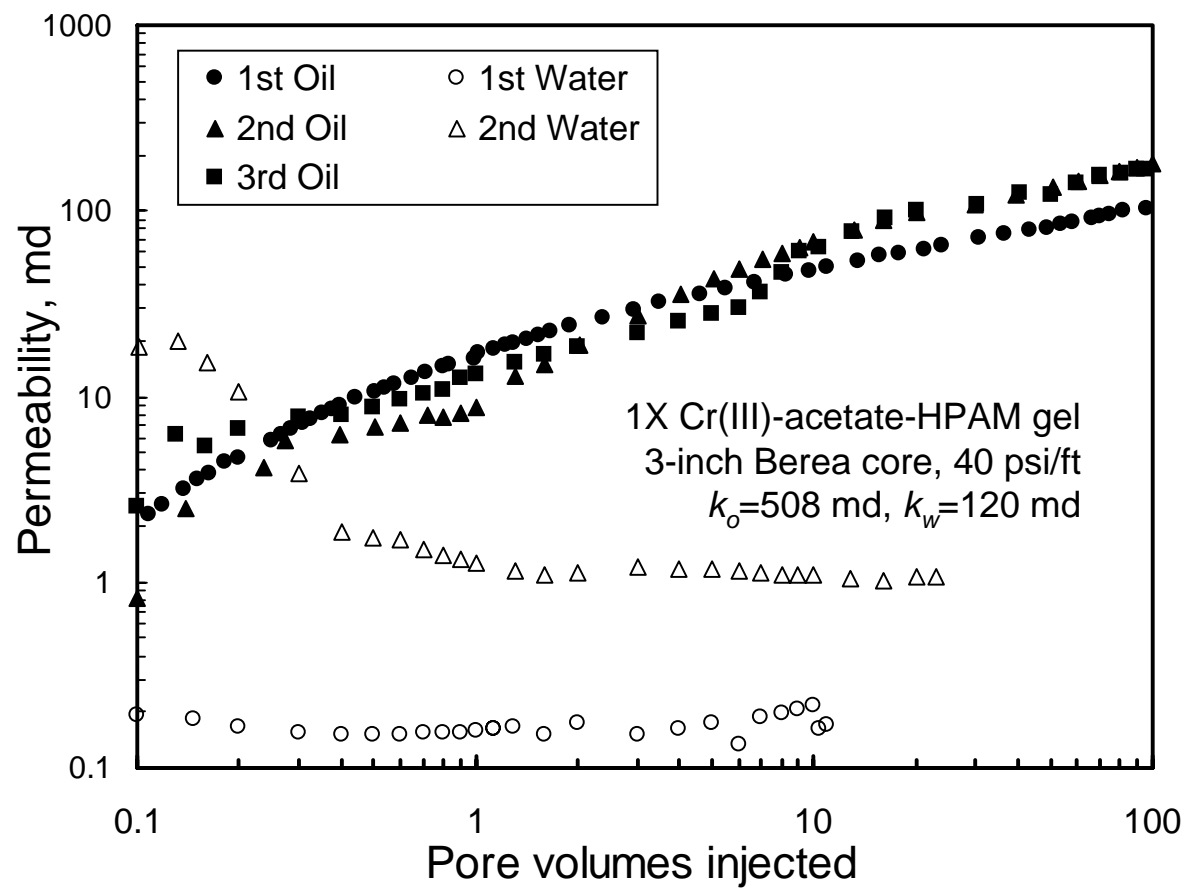

Fig. 1-Permeability to oil and water after gel placement in a Berea core.

\section{Permeability to Water}

Table 1 lists stabilized final permeability to water $\left(k_{w}\right)$ after gel placement for many experiments. Three porous media were examined, including strongly water-wet Berea sandstone and fused silica and strongly oil-wet porous polyethylene. Initial core permeabilities ranged from 738 to 15,270 md. Most cores were 3 inches long, although two Berea cores were 6 inches long. The pressure gradient applied ranged from 10 to $100 \mathrm{psi} / \mathrm{ft}$. The $k_{w}$ values were measured under several different conditions, including (1) when water was the first fluid injected after gel placement, (2) when oil was the first fluid injected after gel placement and then followed by water injection, and (3) when at least one cycle of water and oil were injected before the $k_{w}$ measurement.

For cases in Table 1, permeability to water stabilized at the reported value within one PV and remained stable for up to 100 PV. For five cases where water was the first fluid injected after gel placement, permeability to water averaged $0.26 \mathrm{md}$. This value was of the order expected if all aqueous pore space was filled with gel and water only flowed through the gel itself. ${ }^{14}$ 
For several cases where flooding occurred at $100 \mathrm{psi} / \mathrm{ft}$ (end of Table 1), $k_{w}$ values were quite high (up to $211 \mathrm{md}$ ), suggesting significant breakdown of the gel at this high pressure gradient.

For cases where at least one cycle of oil preceded the $k_{w}$ measurement, the permeability values ranged from 0.17 to $21.3 \mathrm{md}$, but were commonly between 1 and $3 \mathrm{md}$. Thus, the process of oil injection often appeared to cause some damage to the gel, but this damage usually did not result in a dramatic $k_{w}$ increase. The behavior was consistent with the mechanisms for disproportionate permeability reduction that were discussed in Ref. 5.

Table $1-k_{w}$ values after gel placement.

\begin{tabular}{|l|c|c|c|c|c|}
\hline Core material & $\begin{array}{c}\text { Core } \\
\text { length, } \\
\text { inches }\end{array}$ & $\begin{array}{c}\text { Initial core } \\
\text { permeability, } \\
\text { md }\end{array}$ & $\begin{array}{c}\text { Pressure } \\
\text { gradient, } \\
\text { psi/ft }\end{array}$ & Condition & $\begin{array}{c}k_{w} \text { at } S_{\text {or }} \\
\text { after gel, } \\
\text { md }\end{array}$ \\
\hline Berea & 3 & 746 & 40 & water after oil & 0.17 \\
\hline Berea & 3 & 746 & 40 & 2nd water after oil & 1.11 \\
\hline Berea & 6 & 738 & 40 & water after oil & 1.93 \\
\hline Berea & 6 & 738 & 40 & 2nd water after oil & 2.25 \\
\hline polyethylene & 3 & 8,400 & 10 & water after oil & 1.56 \\
\hline polyethylene & 3 & 10,000 & 30 & water after oil & 1.49 \\
\hline polyethylene & 3 & 7,410 & 100 & water after oil & 2.83 \\
\hline polyethylene & 3 & 13,550 & 10 & water after oil & 21.3 \\
\hline polyethylene & 3 & 8,530 & 30 & water after oil & 2.63 \\
\hline polyethylene & 3 & 5,440 & 100 & water after oil & 0.63 \\
\hline polyethylene & 3 & 15,270 & 10 & water 1st & 0.37 \\
\hline polyethylene & 3 & 9,530 & 30 & water 1st & 0.24 \\
\hline polyethylene & 3 & 9,530 & 30 & 2 nd water after oil & 1.17 \\
\hline polyethylene & 3 & 6,204 & 100 & water 1st & 0.32 \\
\hline polyethylene & 3 & 6,204 & 100 & 2nd water after oil & 0.74 \\
\hline fused silica & 3 & 2,390 & 10 & water 1st & 0.12 \\
\hline fused silica & 3 & 2,390 & 10 & 2nd water & 0.35 \\
\hline fused silica & 3 & 1,820 & 30 & water 1st & 0.23 \\
\hline fused silica & 3 & 1,820 & 30 & 2nd water & 0.22 \\
\hline fused silica & 3 & 1,970 & 10 & water after oil & 0.45 \\
\hline fused silica & 3 & 2,110 & 30 & water after oil & 3.1 \\
\hline fused silica & 3 & 1,330 & 100 & water after oil & 13.6 \\
\hline fused silica & 3 & 1,330 & 100 & 2nd water after oil & 211 \\
\hline fused silica & 3 & 850 & 100 & water 1st & 131 \\
\hline Average $k_{w}$ for five “water first” cases (excluding 100 psi case in silica): 0.26 md $( \pm 0.1 \mathrm{md})$ \\
\hline
\end{tabular}

\section{Permeability to Oil}

In contrast to the behavior during water injection, permeability to oil $\left(k_{o}\right)$ steadily increased over the course of 100 PV. Fig. 2 shows permeability versus PV during oil injection for many experiments (conducted in conjunction with those described in Table 1). The trends observed 
during oil injection were consistent with expectations for an unstable displacement (high mobility ratio) of oil through gel. We developed a model for predicting permeabilities and saturations during the course of stable and unstable displacements. That model is listed in Appendix A. The thin solid curve in Fig. 2 shows predictions from the model when 3-cp oil (with endpoint $k_{o}=100 \mathrm{md}$ ) was injected into a core (at $S_{\text {or }}$ after gel placement) where 1-cp water had an endpoint $k_{w}=0.26 \mathrm{md}$. The thick solid curve shows predictions when $k_{o}=1,000 \mathrm{md}$ and $k_{w}=1 \mathrm{md}$. (In both cases, $S_{o r}=0.368$ and $S_{w r}=0.432$.) The two curves provide lower and upper limits of behavior for the $1 \mathrm{X} \mathrm{Cr}(\mathrm{III})$-acetate-HPAM gel. The dashed curve provides an intermediate case where $k_{o}=400 \mathrm{md}$ and $k_{w}=0.4 \mathrm{md}$. A key question is how the variation shown in Fig. 2 impacts the predictability and controllability of field applications of gel treatments.

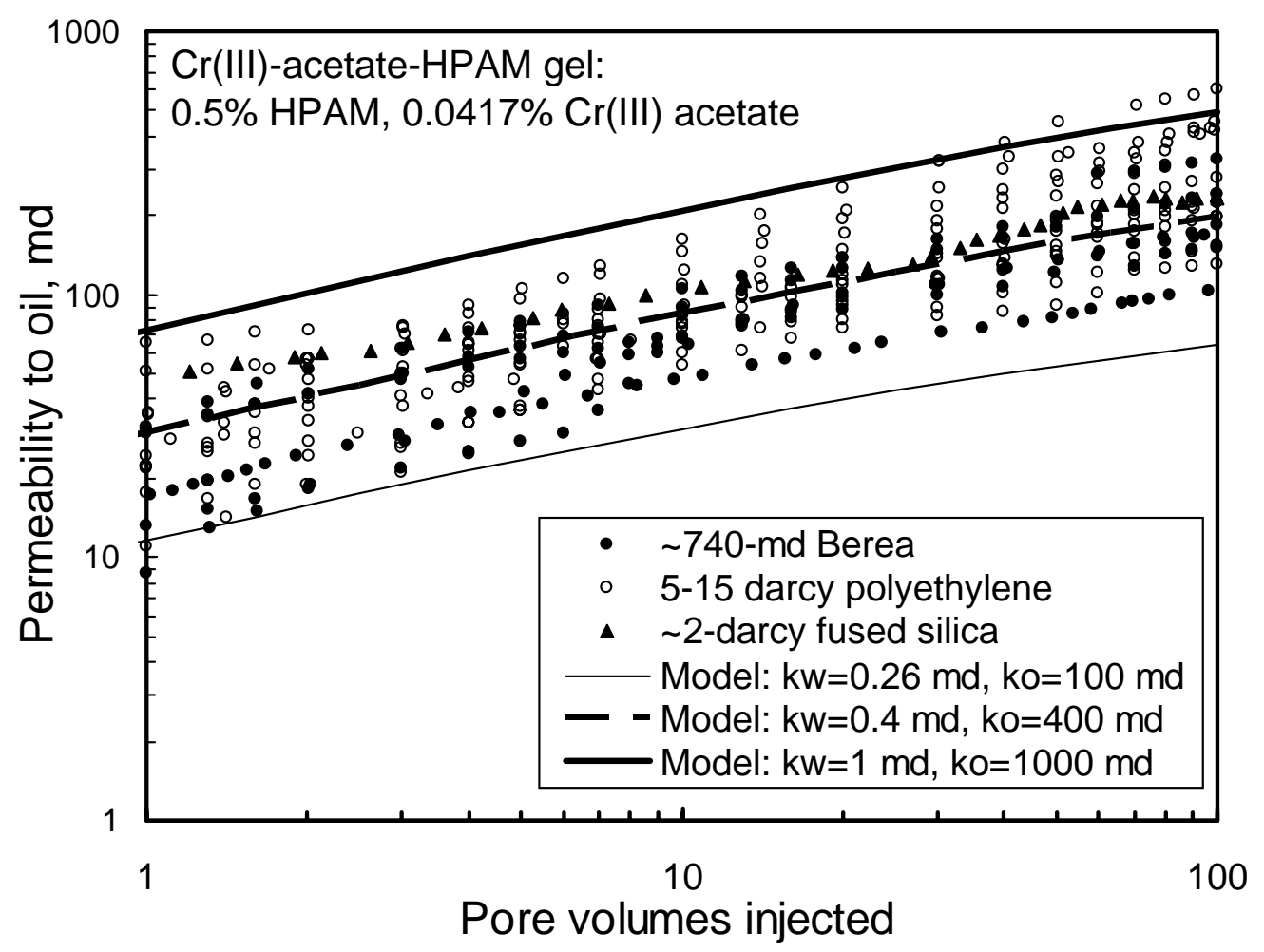

Fig. 2-Permeability to oil after gel placement during many experiments.

\section{Predictions of "Oil-Zone Cleanup" for Field Applications}

Based on the above experimental results and model, we wish to estimate how quickly oil productivity will increase after a gel treatment where gelant was allowed to invade into oil productive zones. Appendix $B$ describes a program that applies the above model for field applications in fractured production wells (linear flow), while Appendix C describes a similar program for unfractured production wells (radial flow). In all cases, the external drainage distance or radius was $500 \mathrm{ft}, S_{o r}=0.368$, and $S_{w r}=0.432$. For radial cases, the wellbore radius was $0.5 \mathrm{ft}$. For the first predictions, we assumed that the oil residual resistance factor in the geltreated region approached unity after a large volume of oil throughput (i.e., $k_{o}$ at $S_{w r}$ was the same in gel-treated and untreated rock). In the following figures, time will be plotted on the $x$ axis, while the $y$-axis will plot oil productivity (i.e., the oil productivity index) relative to the oil productivity if no gel treatment had been applied (e.g., see Figs. 3 and 4). 
Effect of Distance of Gelant Penetration. The effects of distance of gelant penetration on the time for recovery of oil productivity are shown in Figs. 3 and 4 for the cases of fractured (linear flow) and unfractured (radial flow) productions wells, respectively. The pressure drawdown ( $\Delta p$, between the external drainage distance and the wellbore) was fixed at $100 \mathrm{psi}$. As expected, the time for oil "cleanup" increased significantly with increased distance of gel penetration. For both the fractured and unfractured cases, gelant penetration distances less than $10 \mathrm{ft}$ provided the most desirable times to recover oil productivity (i.e., a day or less).

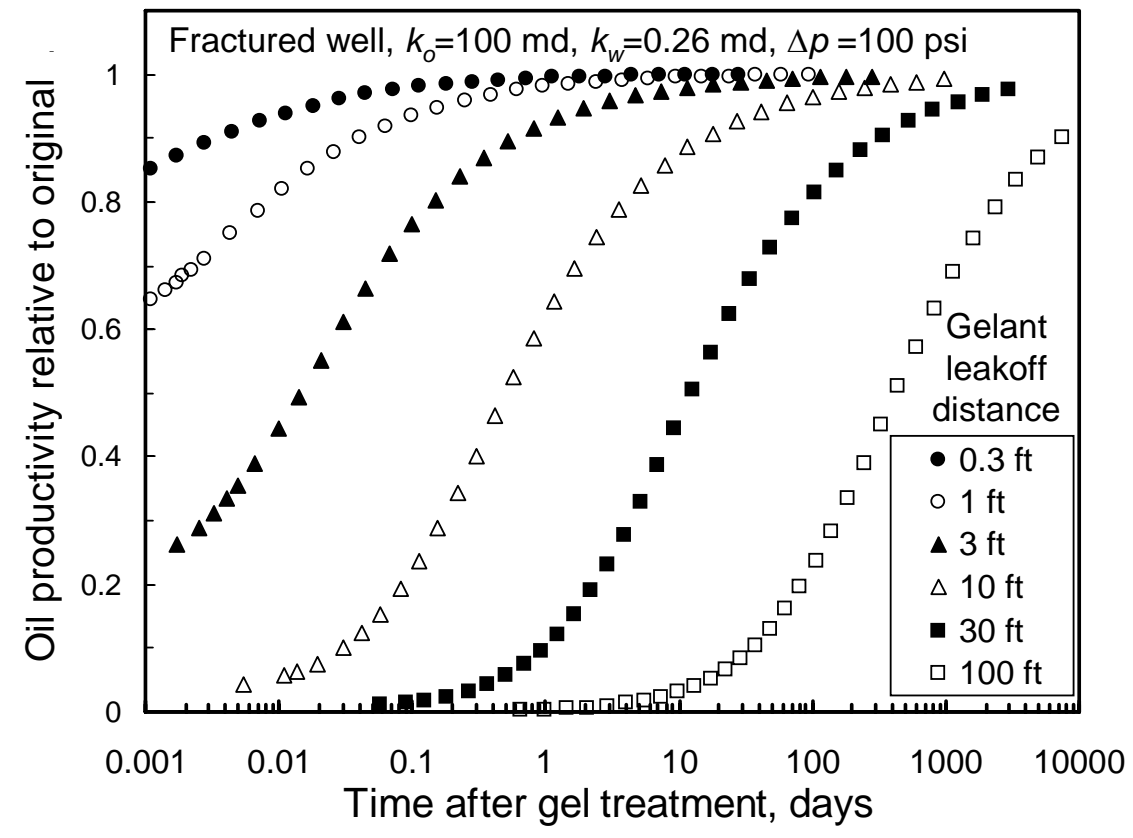

Fig. 3-Effect of distance of gel penetration from a fracture face.

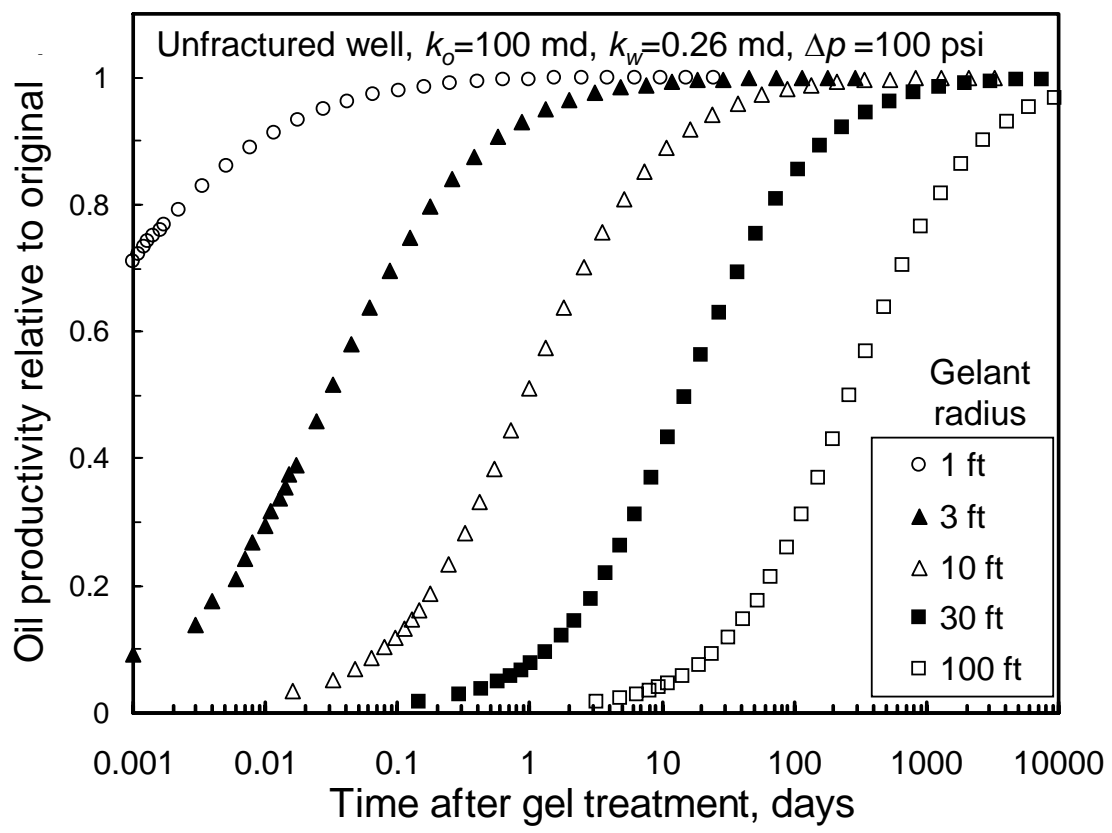

Fig. 4-Effect of radius of gel penetration in an unfractured well. 
Based on Figs. 3 and 4, Fig. 5 was prepared, showing the time required for the production well to regain $50 \%$ of its original oil productivity as a function of the distance of gel penetration. Productivity recovery was quite similar for linear and radial flow. Fig. 5 also demonstrates that cleanup time $(t)$ was proportional to the cube of gel penetration $\left(L_{p}\right)$.

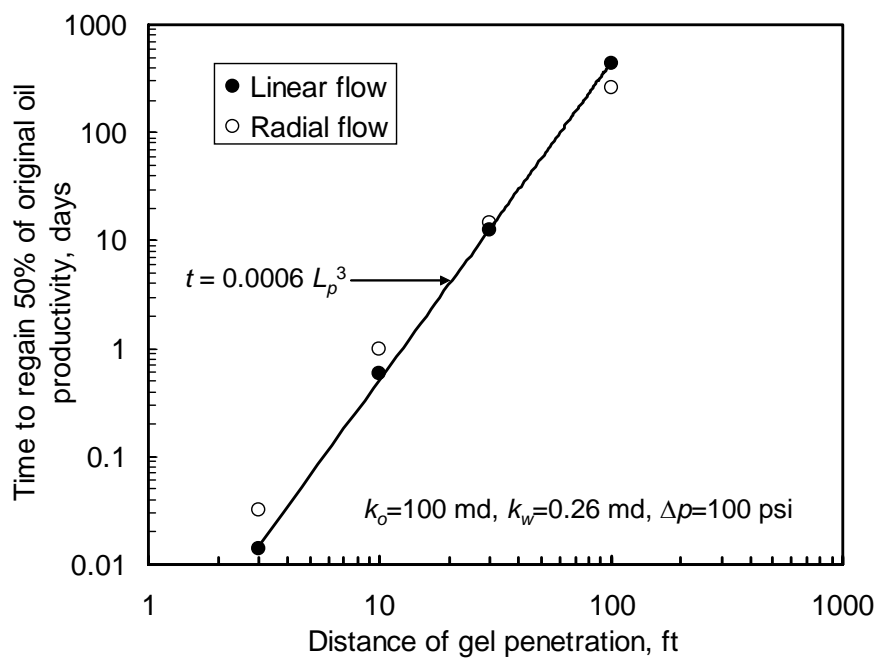

Fig. 5-Cleanup time in linear versus radial flow.

Effect of Pressure Drawdown. The time for cleanup of an oil zone was inversely proportional to the pressure drawdown. Increasing the pressure drawdown from 1 to 1,000 psi decreased the cleanup time 1,000-fold (solid symbols in Fig. 6). For unfractured wells where the radius of gelant penetration was $10 \mathrm{ft}$ or more, relatively high pressure drawdowns were needed to clean up the oil zones in a reasonable time period (solid symbols in Fig. 6). For gel treatments in fractured production wells where the distance of gelant leakoff from fracture faces was relatively small, oil zones cleaned up quickly even for low drawdowns (open symbols in Fig. 6).

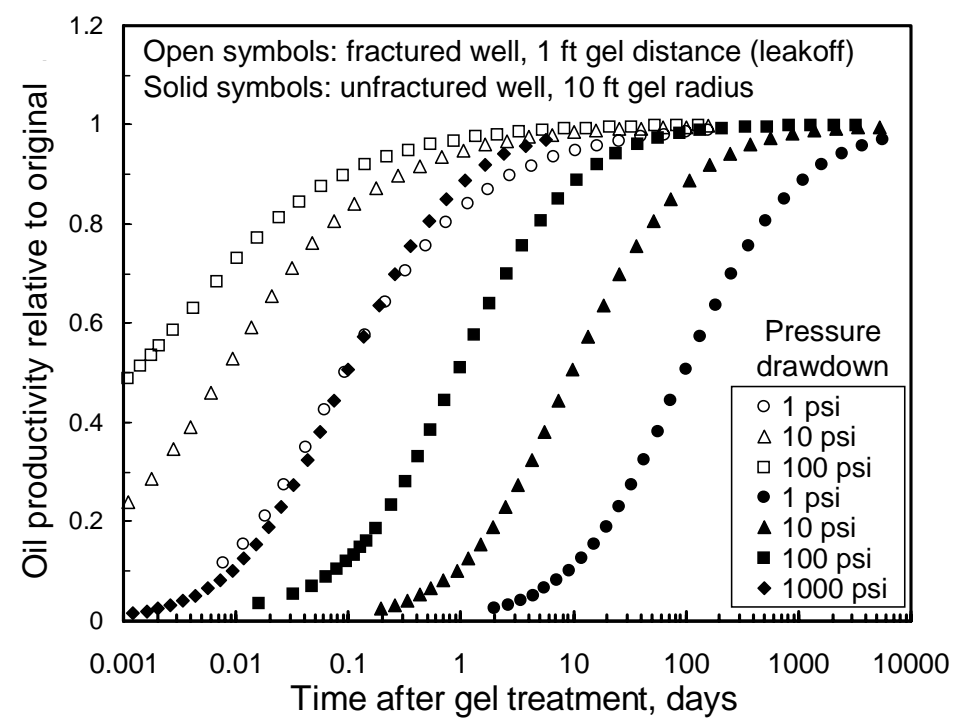

Fig. 6-Effect of pressure drawdown on oil-zone cleanup. 
Effect of $\boldsymbol{k}_{w}$ and $\boldsymbol{k}_{\boldsymbol{o}}$. The time for cleanup of an oil zone was inversely proportional to the permeability to water after gel formation $\left(k_{w}\right)$, but was not sensitive to the permeability to oil $\left(k_{o}\right)$. The solid symbols in Fig. 7 show that the cleanup time decreased by a factor of 100 as $k_{w}$ increases from 0.1 to $10 \mathrm{md}$ (when $k_{o}$ was held constant at $1,000 \mathrm{md}$ ). In contrast, when $k_{w}$ was held constant at $0.26 \mathrm{md}$, the cleanup time was basically unaffected as $k_{o}$ increased from 100 to 10,000 md (open symbols in Fig. 7).

Note that the open and solid triangles in Fig. 6 show predictions associated with the lower-limit and upper-limit curves, respectively, that bracket the data in Fig. 2. The triangles in Fig. 7 suggest a maximum four-fold variation in cleanup time for the experiments described in Fig. 2.

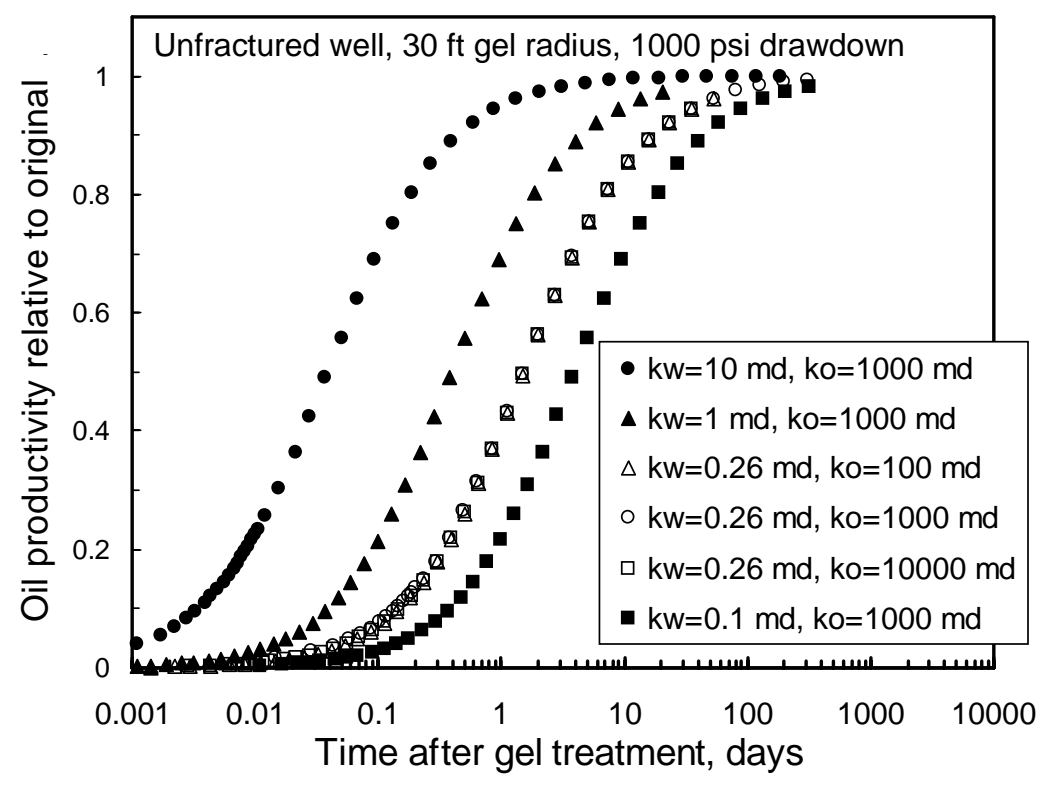

Fig. 7—Effect of $k_{w}$ and $k_{o}$ on oil-zone cleanup.

Summary. In the analysis to this point, we found that the time required to restore productivity to a gel-treated oil zone was (1) similar for radial versus linear flow, (2) proportional to the cube of distance of gel penetration, (3) inversely proportional to pressure drawdown, (4) inversely proportional to the permeability to water ( $k_{w}$ at $S_{o r}$ ) in the gel-treated region, and (5) not sensitive to the final permeability to oil ( $k_{o}$ at $S_{w r}$ after many PV throughput).

\section{Effect on Ultimate Oil Productivity}

Although $k_{o}$ at $S_{w r}$ (after gel placement) has no effect on the cleanup time (Fig. 7), it does have an important impact on how much of the original oil productivity can ultimately be regained after a gel treatment. In the above analysis, we assumed that the permeability to oil in the gel-treated region would eventually approach $k_{o}$ at $S_{w r}$ in the untreated region. Now, we consider what happens if permeability to oil in the gel-treated region cannot rise to match the original $k_{0}$.

The reduction in productivity caused by a gel treatment is described by Eq. 1 for linear flow and by Eq. 2 for radial flow. ${ }^{4}$ 
$q / q_{o}=L_{e} /\left[\left(F_{r r}-1\right) L_{p}+L_{e}\right]$

$q / q_{o}=\ln \left(r_{e} / r_{w}\right) /\left[\left(F_{r r} \ln \left(r_{p} / r_{w}\right)+\ln \left(r_{e} / r_{p}\right)\right]\right.$

In these equations, $q / q_{o}$ is the ultimate productivity relative to productivity before the gel treatment; $r_{e}$ is the external drainage radius; $L_{e}$ is the external drainage distance; and $r_{w}$ is the wellbore radius. In our examples, $L_{e}=r_{e}=500 \mathrm{ft}$ and $r_{w}=0.5 \mathrm{ft} . F_{r r}$ is the residual resistance factor (i.e., the factor by which the permeability to oil or water permeability is reduced by the gel). Figs. 8 and 9 show results of ultimate productivity calculations for linear and radial flow. These figures are applicable to either oil or water flow.

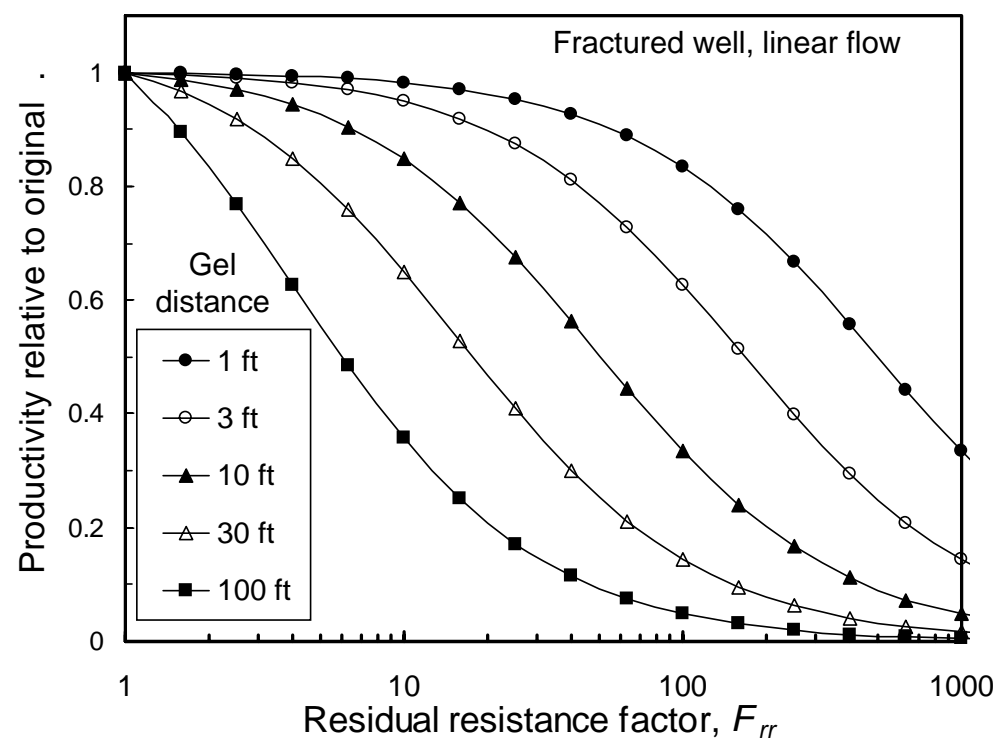

Fig. 8-Ultimate productivity after gel placement in a fractured production well.

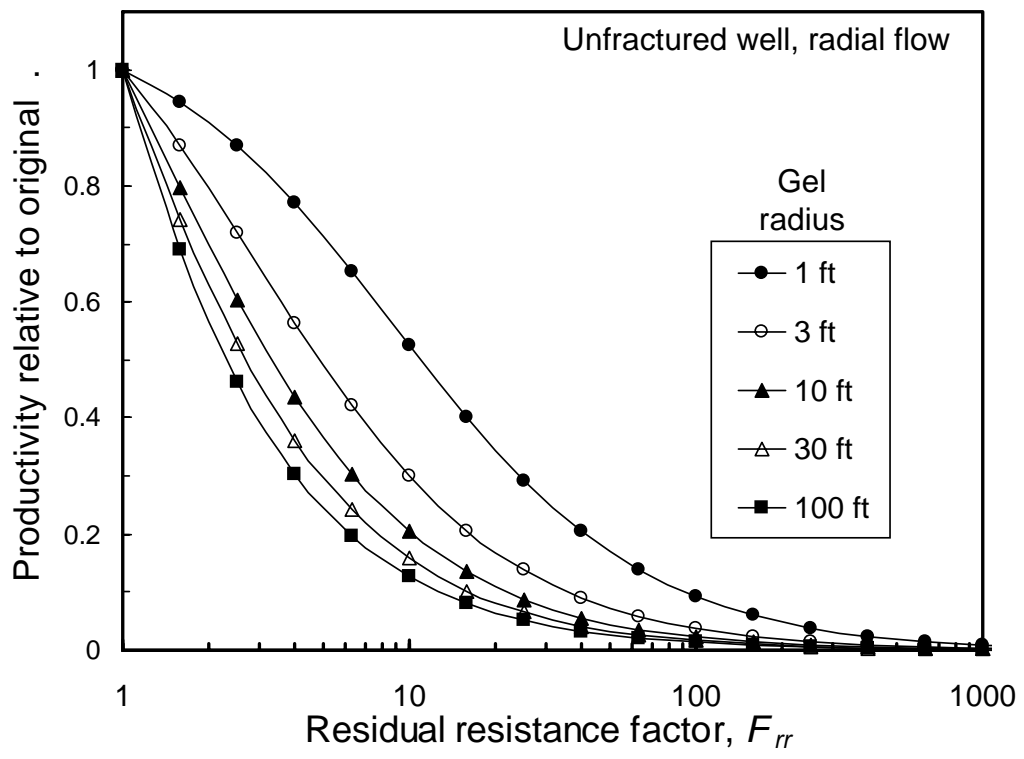

Fig. 9-Ultimate productivity after gel placement in an unfractured production well. 
Maximum Allowable Gel Penetration from Fracture Faces. Fig. 8 can be simplified considerably by plotting $\left(F_{r r}-1\right) L_{p}$ on the $x$-axis, as in Fig. 10 . This figure reveals that the key to maintaining high oil productivity in a fractured well is to keep the $x$-axis parameter less than 100 $\mathrm{ft}$ (and preferably less than $40 \mathrm{ft}$ ). Also, the key to maintaining low water productivity is to achieve an $x$-axis parameter greater than $3,000 \mathrm{ft}$. These objectives can be achieved by controlling residual resistance factors $\left(F_{r r}\right)$ or the distance of gel penetration $\left(L_{p}\right)$ or both.

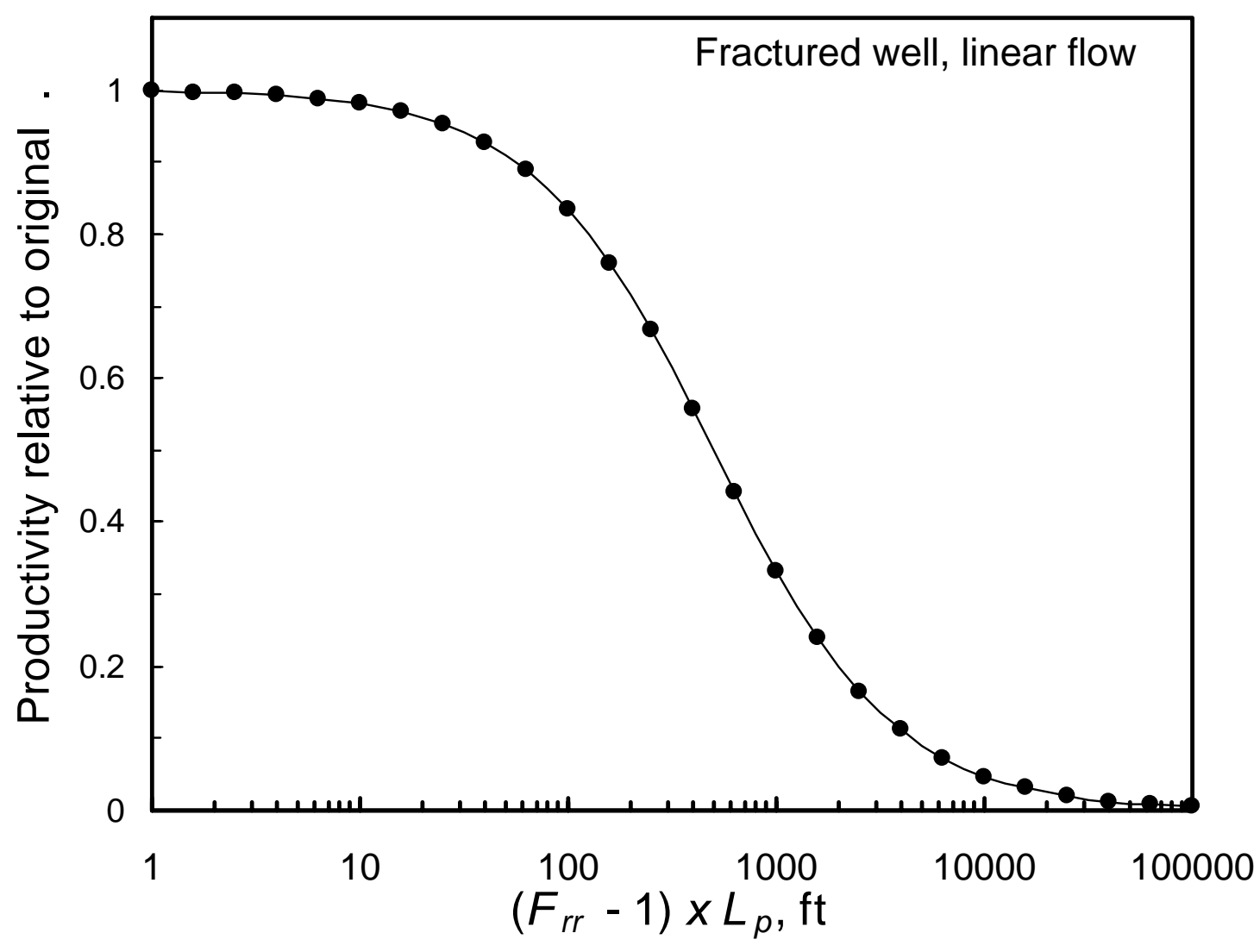

Fig. 10-Ultimate productivity after gel placement: linear flow, simplified correlation.

What range of oil residual resistance factors were observed with the Cr(III)-acetate-HPAM gel? In Berea sandstone, $k_{o}$ at $S_{w r}$ before gel placement typically was about $500 \mathrm{md}$ (Fig. 1). Given the lower-limit curve in Fig. 2, the lower limit of $k_{o}$ at $S_{w r}$ after gel placement (after many PV of oil throughput) was $100 \mathrm{md}$. For this case, the oil residual resistance factor, $F_{\text {rro, }}$, would be five (500/100). From Fig. 10, a high ultimate oil productivity would be retained [i.e., $\left(F_{r r}-1\right) L_{p}<40$ $\mathrm{ft}$ ] so long as the distance of gel penetration was less than $10 \mathrm{ft}$ [i.e., 40/(5-1)]. For some experimental results (Fig. 2), the permeability to oil in Berea (after gel) exceeded $300 \mathrm{md}$ and the ultimate permeability approached $k_{o}$ at $S_{w r}$ for the untreated rock. In these cases, the oil residual resistance factor was less than 2 . If valid, the maximum acceptable distance of gel penetration (from the fracture faces) could be $40 \mathrm{ft}$ or more.

However, higher oil resistance factors and lower acceptable distances of gel penetration were noted for the polyethylene and fused silica cores. In polyethylene, $k_{o}$ at $S_{w r}$ typically was between 
5 and 10 darcies before gel placement, depending on the initial absolute permeability of the core. Given these values and the range of $k_{o}$ values from Fig. 2, $F_{\text {rro }}$ values could range from 5 to 76 (i.e., 5,000/1,000 to 10,000/130). If one is conservative and accepts the $F_{\text {rro }}$ value of 76 , the maximum allowable gel penetration (from Fig. 10 ) would be $0.53 \mathrm{ft}$ [i.e., 40/(76-1)].

A similar analysis can be performed for the fused silica data in Fig. 2. Here, $k_{o}$ at $S_{w r}$ was typically about $1,000 \mathrm{md}$ before gel placement. Ultimate $F_{\text {rro }}$ values could range from 2 to 5 , and a conservative maximum allowable gel penetration would be $10 \mathrm{ft}$ from the fracture faces [i.e., 40/(5-1)]. Our analysis in the previous section (open triangles in Fig. 3) indicated that restoration of oil productivity should occur fairly quickly if gel penetration is less than $10 \mathrm{ft}$.

The above analysis focused on gel penetration into an oil zone. Of course, in addition to minimizing damage to oil productivity, we desire a gel treatment that causes substantial reduction to water productivity. ${ }^{7-9}$ As mentioned, the parameter, $\left(F_{r r}-1\right) L_{p}$, should have a value greater than $3,000 \mathrm{ft}$ in the water zone. To assess the appropriate distances of gel penetration, $L_{p}$, we need the water residual resistance factor, $F_{r r w}$. In turn, determining $F_{r r w}$ requires knowledge of $k_{w}$ at $S_{o r}$ before and after gel placement. Before gel placement, $k_{w}$ at $S_{o r}$ was 120 md in Berea, 4,000-6,500 md in polyethylene, and $140-640 \mathrm{md}$ in fused silica. For cases where $k_{w}$ at $S_{\text {or }}$ was 0.26 md after gel placement, the $F_{r r w}$ values would be 460 in Berea, 15,000-25,000 in polyethylene and 540-2,400 in fused silica. Achieving a $\left(F_{r r}-1\right) L_{p}$ parameter of $3,000 \mathrm{ft}$ would require $L_{p}$ values of at least $6.5 \mathrm{ft}$ in Berea. Smaller distances of gel penetration would be acceptable in the other porous media.

To summarize the significance of the above calculations, consider a vertical production well with a two-wing vertical fracture that cuts through one oil zone and one water zone. Assume that both zones are Berea sandstone where $k_{w}=120 \mathrm{md}$ at $S_{o r}$ and $k_{o}=508 \mathrm{md}$ at $S_{w r}$ before placement and where $k_{w}=0.26 \mathrm{md}$ at $S_{\text {or }}$ and the ultimate $k_{o}=100 \mathrm{md}$ at $S_{w r}$ after placement of the Cr(III)-acetateHPAM gel. Our analysis (above) suggested that the optimum distance of gel penetration from fracture faces should be at least $6.5 \mathrm{ft}$ in the water zone but less than $10 \mathrm{ft}$ in the oil zone. Of course, these distances apply only to this particular circumstance. The calculations must be repeated if the circumstances or input parameters are different.

Stability during Water Flow. Our findings to date are that gel-treated rock does not "clean up" with increased water throughput-in contrast to the behavior during oil flow. So long as the pressure gradients remained at $40 \mathrm{psi} / \mathrm{ft}$ or below, $k_{w}$ was fairly stable for water throughput up to $100 \mathrm{PV}$. Cases were noted where pressure gradients of $100 \mathrm{psi} / \mathrm{ft}$ caused significantly higher permeability to water (see Table 1) —implying substantial gel damage. Our future work will investigate the stability of water residual resistance factors for higher throughput values and pressure gradients.

An experiment was performed to test how persistently the gel would reduce permeability during continuous water flow. A porous polyethylene core (2.5 in. long, 1.5 in. diameter) was saturated with our standard $1 \mathrm{X}$ Cr(III)-acetate-HPAM gel [0.5\% Alcoflood 935, 0.0417\% Cr(III) acetate, $1 \% \mathrm{NaCl}, 0.1 \% \mathrm{CaCl}_{2}$ ]. After gelation, brine $\left(1 \% \mathrm{NaCl}, 0.1 \% \mathrm{CaCl}_{2}\right)$ was allowed to flow through the gel-filled core using a constant pressure gradient of $30 \mathrm{psi} / \mathrm{ft}\left(41^{\circ} \mathrm{C}\right)$. This pressure gradient was established by placing a 174-in. high column of brine over the core. Fig. 11 shows the 
results. Over the course of 100 days, the permeability to water remained fixed at about $60 \mu \mathrm{d}$. This experiment will be continued to assess how long the permeability to water remains stable.

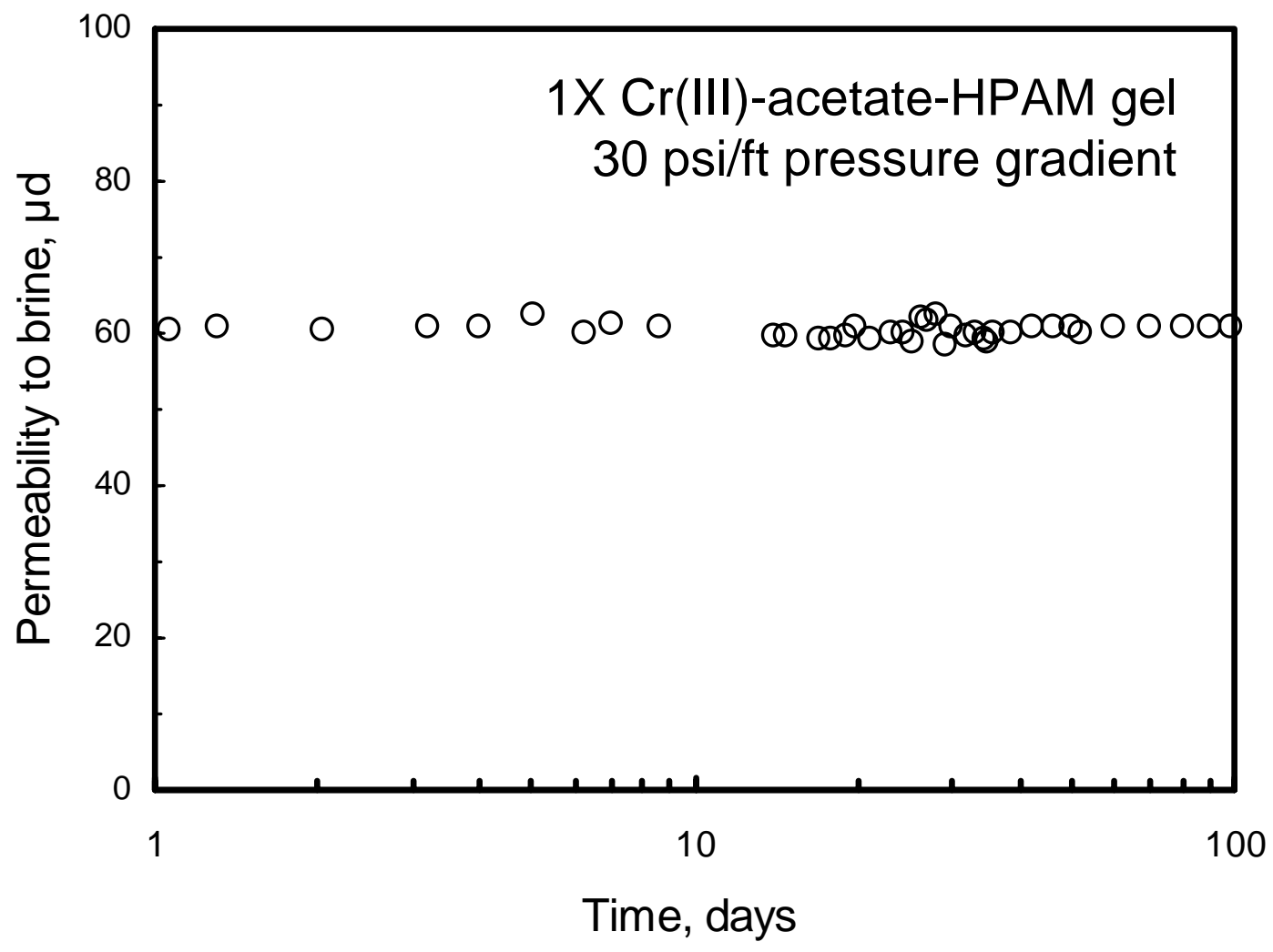

Fig. 11-Permeability to brine versus time.

Maximum Allowable Gel Penetration in Unfractured Wells. Prior to this report, our firm conviction was that hydrocarbon zones must be protected during gel placement in unfractured wells with radial flow. ${ }^{3,4}$ However, upon observing the degree of cleanup during oil flow through gel (Figs. 1 and 2), we wondered whether exceptions might be found to our earlier beliefs. Close consideration of Fig. 9 indicates that for gel radii greater than $3 \mathrm{ft}$, oil residual resistance factors must be less than 2 to insure minimum loss of oil productivity. This observation is consistent with our earlier findings. ${ }^{3}$ Can $F_{\text {rro }}$ values less than 2 be achieved reliably with the $\mathrm{Cr}(\mathrm{III})$ acetate-HPAM gel? The discussion after Fig. 10 indicated that ultimate $F_{\text {rro }}$ values might range from 1 to 5 in Berea, 2 to 5 in fused silica, and 5 to 76 in polyethylene. With the variations observed, it still seems unduly risky to inject gelant into unfractured wells without protecting the hydrocarbon zones from gel damage.

\section{Behavior of an Adsorbed Polymer}

The work described above used a Cr(III)-acetate-HPAM gel that usually fills all aqueous pore space. In previous work, ${ }^{1}$ we noted that Berea cores that were treated with an adsorbing polymer (BJ's AquaCon ${ }^{\mathrm{TM}}$ ) also exhibited permeabilities that increased gradually during the course of 
injecting $100 \mathrm{PV}$ of oil. In contrast to the Cr(III)-acetate-HPAM gel, this polymer did not occupy very much of the aqueous pore space and provided low water and oil residual resistance factors. Fig. 12 shows how permeability to oil increased with throughput for six experimental cases. In two cases (solid triangles and squares), oil was the first fluid injected after polymer placement. In these two cores, water was subsequently injected, followed by an additional cycle of oil (open triangles and squares). In two other cases (and separate cores), water was injected first after polymer placement, followed by oil injection (open circles and diamonds).

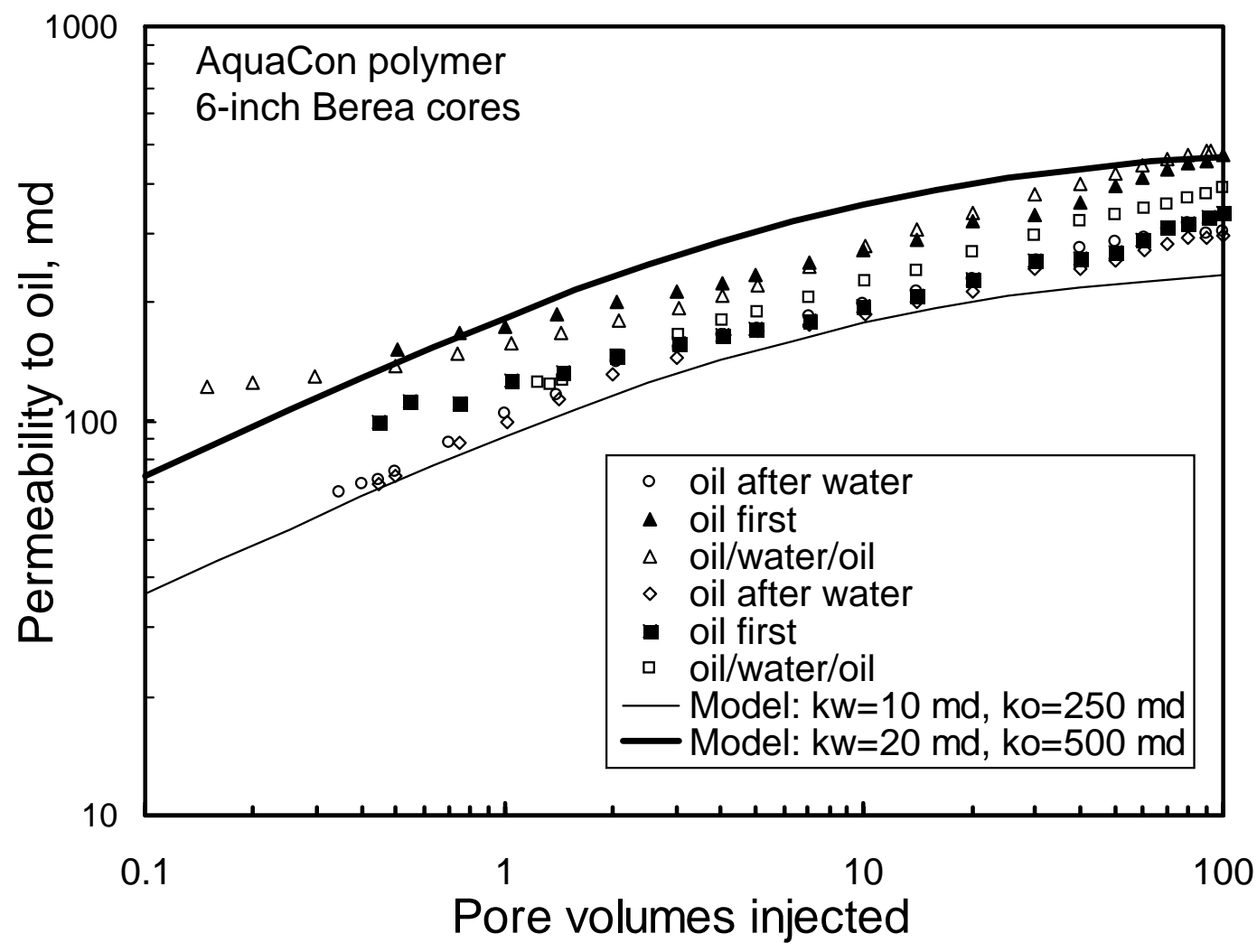

Fig. 12—Permeability during oil injection after treatment with an adsorbing polymer.

The thin and thick curves in Fig. 12 plot predictions from the model in Appendix A. The $k_{w}$ and $k_{o}$ input values used to generate the curves are indicated in Fig. 12. These curves did a reasonable job of bracketing the experimental data. However, the general shapes of the model curves did not follow the data trends as well as those for $\mathrm{Cr}$ (III)-acetate-HPAM gels (Fig. 2). The upper and lower curves were separated by a factor of seven in Fig. 2 and by a factor of two in Fig. 12. As the PV throughput increased from 1 to 100, oil permeability increased typically by factors from 5 to 10 in Fig. 2 and by factors from 2 to 3 in Fig. 12.

Ultimate oil residual resistance factors (after 100 PV) ranged from 1.4 to 2.1 for the experiments in Fig. 12. Upon first consideration, these values might seem attractive for field applications, even in unfractured wells (see Fig. 9). Unfortunately in this particular case, water residual resistance factors were roughly the same as the oil residual resistance factors. (Water residual 
resistance factors and final permeability to water after polymer placement are listed in Table 2.) Consequently, within the variability of the experimental results, a polymer treatment would reduce productivities of oil and water zones by roughly the same factor.

Table $2-k_{w}$ values after polymer placement in Berea sandstone.

\begin{tabular}{|c|c|c|c|c|}
\hline Condition & $\begin{array}{c}\text { Initial core } \\
\text { permeability, } \\
\text { md }\end{array}$ & $\begin{array}{c}k_{w} \text { at } S_{\text {or, }} \\
\text { (before gel) } \\
\text { md }\end{array}$ & $\begin{array}{c}k_{w} \text { at } S_{o r}, \\
\text { (after gel) } \\
\text { md }\end{array}$ & $\begin{array}{c}\text { Residual } \\
\text { resistance } \\
\text { factor, } F_{\text {rrw }}\end{array}$ \\
\hline water $1^{\text {st }}$ & 498 & 126 & 64.3 & 2.0 \\
\hline 2nd water after oil & 498 & 126 & 38 & 3.3 \\
\hline water after oil $^{\text {water 1 }}$ & 853 & 293 & 93.3 & 3.1 \\
\hline water oil & 469 & 124 & 84.4 & 1.5 \\
\hline 2nd water after on & 469 & 124 & 95.5 & 1.3 \\
\hline water after oil & 913 & 310 & 52.2 & 5.9 \\
\hline
\end{tabular}

In summary, after placement of an adsorbing polymer (AquaCon) in Berea, the permeability to oil increased significantly over the course of $100 \mathrm{PV}$. The polymer also provided fairly low oil residual resistance factors. Unfortunately, the polymer provided correspondingly low water residual resistance factors, so the polymer cannot be expected to provide useful profile modifications in unfractured production wells unless hydrocarbon zones are protected during polymer placement.

\section{Conclusions}

Because some polymers and gels can reduce permeability to water much more than that to oil, an unfavorable displacement (high mobility ratio) usually occurs in oil zones when wells are returned to production after bull-headed gel treatments. Since oil displacement through gel is unfavorable, the permeability to oil requires a large throughput to stabilize. Consequently, oil zones often exhibit a significant "cleanup time" after field applications of a gel treatment.

The oil and water throughput requirements for stabilization of permeabilities were studied for a relatively "strong” pore-filling Cr(III)-acetate-HPAM gel and for a "weak" adsorbing polymer. Permeability to water stabilized within one pore volume (PV) after polymer or gel treatment. However, as oil throughput increased from 1 to $100 \mathrm{PV}$, permeability to oil gradually increased by factors from 5 to 10 for cores treated with the Cr(III)-acetate-HPAM gel and by factors from 2 to 3 for cores treated with the adsorbing polymer.

A model was developed to predict cleanup times for both fractured and unfractured wells after a gel treatment. The time required to restore productivity to a gel-treated oil zone was (1) similar for radial versus linear flow, (2) proportional to the cube of distance of gel penetration, (3) inversely proportional to pressure drawdown, (4) inversely proportional to the permeability to water $\left(k_{w}\right.$ at $\left.S_{o r}\right)$ in the gel-treated region, and (5) not sensitive to the final permeability to oil ( $k_{o}$ at $S_{w r}$ after many PV throughput). 
Although $k_{o}$ at $S_{w r}$ (after gel placement) has no effect on the cleanup time, it does have an important impact on how much of the original oil productivity can ultimately be regained after a gel treatment. Earlier work ${ }^{3,4}$ demonstrated that an acceptable gel or polymer placement can be achieved by unrestricted injection of gelants during linear flow (e.g., vertically fractured wells). However, in radial flow (e.g., unfractured wells), hydrocarbon productive zones must be protected during gelant or polymer placement. These conclusions were confirmed by consideration of our new results and the magnitude and variability of oil and water permeabilities and residual resistance factors for both the Cr(III)-acetate-HPAM gel and the adsorbing polymer. 


\section{MECHANISM FOR DISPROPORTIONATE PERMEABILITY REDUCTION}

This chapter presents our "state of the art" view of the mechanism for disproportionate permeability reduction provided by $\mathrm{Cr}$ (III)-acetate-HPAM gels. In previous work, ${ }^{15,16} \mathrm{X}$-ray computed microtomography (XMT) was used to understand why gels reduce permeability to water more than that to oil. That work revealed that "strong" Cr(III)-acetate-HPAM gels formed in virtually all aqueous pore spaces. For normal pressure gradients, water injected after gel placement was forced to flow through the gel itself, experiencing microdarcy permeabilities. In contrast, even for relatively low pressure gradients, oil injection destroyed gel or reduced the gel volume so as to enhance oil permeability (relative to water flow). During subsequent water flow (after oil flow and after gel placement), the gel trapped much higher levels of residual oil (relative to the $S_{\text {or }}$ before gel placement) - thus, again providing a permeability to water that was much less than that to oil. Two major questions from the previous work were (1) how does oil injection destroy or reduce the volume of the gel and (2) how does the gel trap larger volumes of residual oil? This chapter addresses these questions using a new analysis called "indicator kriging," which was superior to our former method to distinguish between phases in a given XMT image. The XMT method and subsequent analysis were used to follow fluid saturations in individual pores during various flooding stages in strongly water-wet Berea sandstone and strongly oil-wet porous polyethylene. The flooding stages included (1) oil and water injection cycles before gel placement, (2) gelant placement, and (3) oil and water injection cycles after gel placement.

We had several motivations to re-examine our previous XMT data. First, the earlier analysis found that the smallest detected pores in strongly water-wet Berea sandstone had lower average water saturations at $S_{\text {or }}$ and $S_{w r}$ then expected from conventional wisdom. Second, especially in Berea, a newly developed method was superior in distinguishing between oil, water, and rock on a microscopic level. Third, although our first analysis obtained saturations for individual pores throughout various flooding stages, it did not indicate how extensively oil or water were connected from pore to pore. In other words, it did not indicate the sizes of water and oil "blobs". In contrast, our new analysis was able to quantify phase connectivity.

Our ultimate goal in these studies is to identify ways to maximize disproportionate permeability reduction in a predictable and controllable manner.

\section{Differences between the Old and New Analyses}

Procedural Differences. In our first analysis, ${ }^{15,16}$ assignment of the locations of rock, water, and oil voxels were made as follows. First, rock locations were identified from images of cores that were saturated only with the wetting phase. These rock locations were used in subsequent images to pin down the liquid-filled pore space. Second, fluid phase identification was made by subtracting an image having both fluid phases present (one phase of which was doped with a strong X-ray attenuating compound) from the corresponding image in which only the wetting phase was present in the pore space. A histogram of the subtracted X-ray attenuation coefficients showed a bimodal distribution-the peaks in the distribution corresponding to water- and oilfilled voxels. The subtracted image contained significantly greater overlap between the peaks than an unsubtracted image. There were several reasons for overlap between the peaks in the histogram: 
1. The finite size of a voxel means that any X-ray attenuation coefficient measured is an average over the voxel volume.

2. Variations in X-ray counting statistics result in variations in attenuation coefficients.

3. Minor alignment errors occur, of $\sim 1 / 2-1$ voxel width.

While 1) and 2) affect peak overlap in non-subtracted images, in subtracted images their influence is exacerbated. Item 3) contributes for subtracted images, but not unsubtracted ones.

In the first analysis, simple thresholding was used to distinguish water-and oil-filled voxels. ${ }^{15,16}$ The threshold was determined from the bimodal subtraction histogram, with the threshold value picked to lie in the "valley"' between the two peaks. Simple thresholding is well known to result in speculated images (i.e., apparent blobs of one phase trapped in the other). The extent of the speculation is proportional to the overlap between the two peaks in the difference histogram.

In the newer analysis, rock locations determined from single-phase flooded core images were still used in subsequent images of the two-phase flooded core to identify the liquid-filled space. However, the subtraction procedure was not used. Rather, a segmentation procedure based upon indicator kriging was used to segment the phases in the pore space only. This avoided any artificial spreading induced by a subtraction procedure. Additionally, the indicator kriging method does not rely on global thresholding, but performs local segmentation based upon maximum likelihood decisions. The result is a cleaner resolution of the fluid phases.

The basic idea of kriging is to estimate an unknown random variable (e.g., the "true" X-ray attenuation value of a voxel) by a linear combination of known random variables (i.e., measured attenuation values) plus a possible systematic shift. The data values, however, are not assumed to be independent (as in classical linear regression analysis) but are correlated spatially. The estimate is required to be unbiased, and the variance of the error in the estimate is required to be minimized. This leads to a constrained minimization problem, whose solution follows from a “constrained normal” system of linear equations known as the ordinary kriging system. While ordinary kriging estimates the value of the random variable at a point, indicator kriging gives the probability that the value at the point is greater than some threshold value. This probability then "indicates" the possible state (pore space or rock) at the point. Indicator kriging does so by capitalizing on the proportion of neighboring data valued above the same threshold, and accounts for the proximity of each datum to the unsampled location.

Differences in Results. A detailed comparison of the results from the old (first) and new (second) analyses can be found in Ref. 2. Here, we simply summarize the differences. First, the second analysis revealed larger pores in polyethylene (because a larger population was sampled-1,879 versus 308 pores). Second, the second analysis showed lower $S_{w r}$ and $S_{\text {or }}$ in Berea, which was more consistent with floods in larger cores. Third, the second analysis showed many more pores at high and low saturations in Berea than the first analysis. Fourth, in the transition from $S_{w r}$ to $S_{o r}$, many Berea pores gained oil in the first analysis but not in the second. Fifth, both analyses confirmed that $S_{w r}$ averaged less than $60 \%$ in the smallest detected Berea pores and that a wide range of saturations could be found for any pore size. Finally, other trends were the same for both analyses. The remainder of this chapter will focus on results obtained from the second analysis. 


\section{Experimental}

A detailed description of the experimental studies was provided in Refs. 15 and 16. The aqueous Cr(III)-acetate-HPAM gel used in this work contained $0.5 \%$ Alcoflood 935 HPAM $\left(\sim 5 \times 10^{6}\right.$ daltons, $5-10 \%$ degree of hydrolysis), $0.0417 \% \mathrm{Cr}(\mathrm{III})$ acetate, $1 \% \mathrm{NaCl}$, and $0.1 \% \mathrm{CaCl}_{2}$. The brine contained $1 \% \mathrm{NaCl}$ and $0.1 \% \mathrm{CaCl}_{2}$. The oil was hexadecane that was doped with either $10 \%$ iodohexadecane (used in Berea) or $15 \%$ bromohexadecane (used in polyethylene). All experiments were performed at room temperature except gelation, which occurred at $\sim 60^{\circ} \mathrm{C}$.

The Berea core (specifically, the "first Berea core" discussed in Ref. 15) had a permeability of 0.47 darcys and a porosity of $22 \%$. The polyethylene core had a permeability of 8.8 darcys and a porosity of $40 \%$. Fig. 13 compares the pore size distributions for Berea sandstone and porous polyethylene. The analyses examined 2,176 pores for the Berea sample and 1,879 pores for the polyethylene sample. The average pore size for polyethylene $\left(0.00052 \mathrm{~mm}^{3}\right)$ was $44 \%$ greater than that for Berea $\left(0.00035 \mathrm{~mm}^{3}\right)$. Interestingly, the median pore size was greater for Berea $\left(0.00016 \mathrm{~mm}^{3}\right)$ than for polyethylene $\left(0.00010 \mathrm{~mm}^{3}\right)$. The higher average for polyethylene occurred because it contained a larger fraction of pores with sizes greater than $0.002 \mathrm{~mm}^{3}$ (compare the high end of the distributions in Fig. 13). Incidentally, if the pores were spherical (which they are not), the average pore radius would be $50 \mu \mathrm{m}$ for polyethylene and $44 \mu \mathrm{m}$ for Berea. XMT and scanning electron microscope images of the two samples can be found in Figs. 14-17.

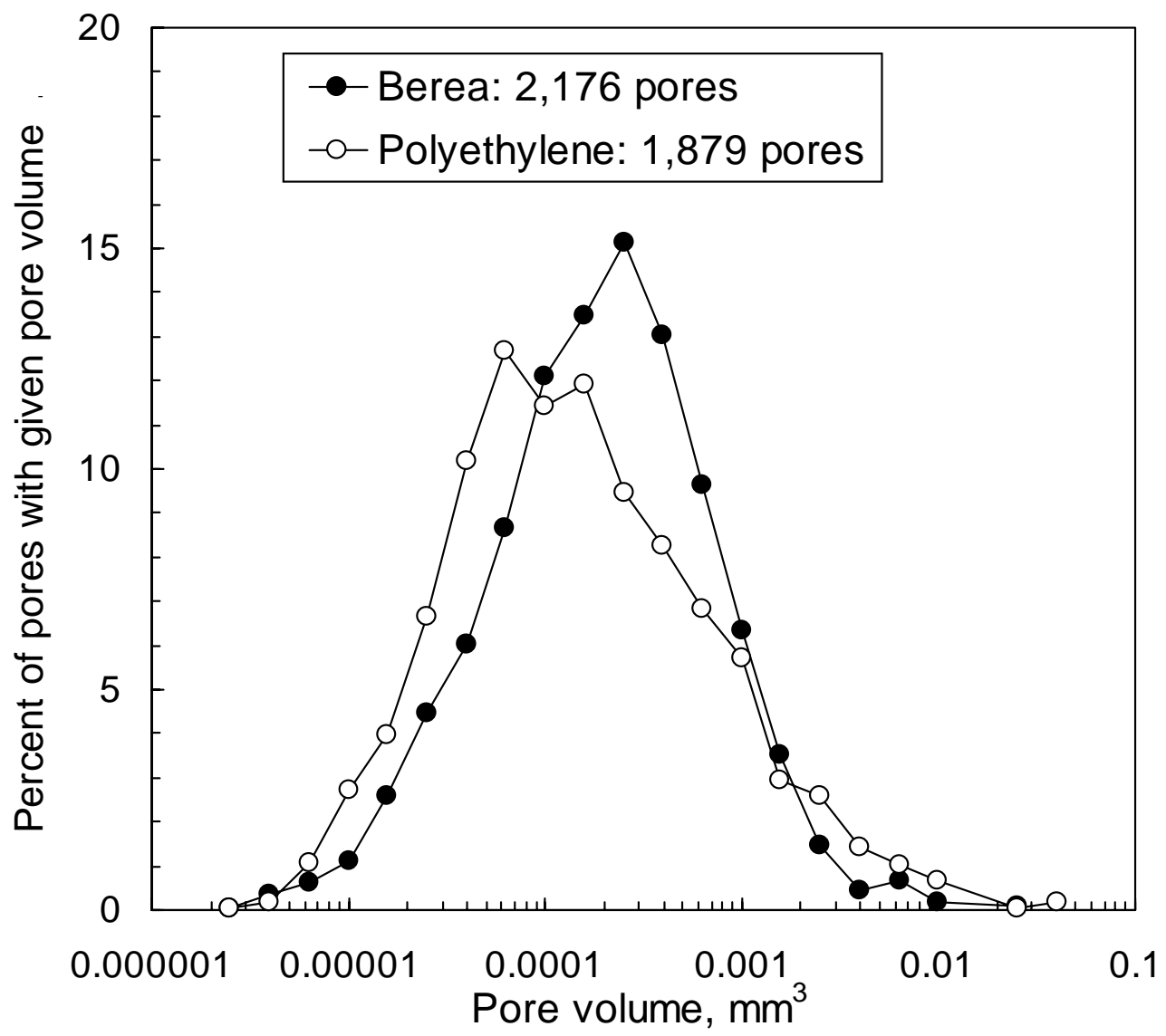

Fig. 13-Pore size distributions for Berea and polyethylene. 


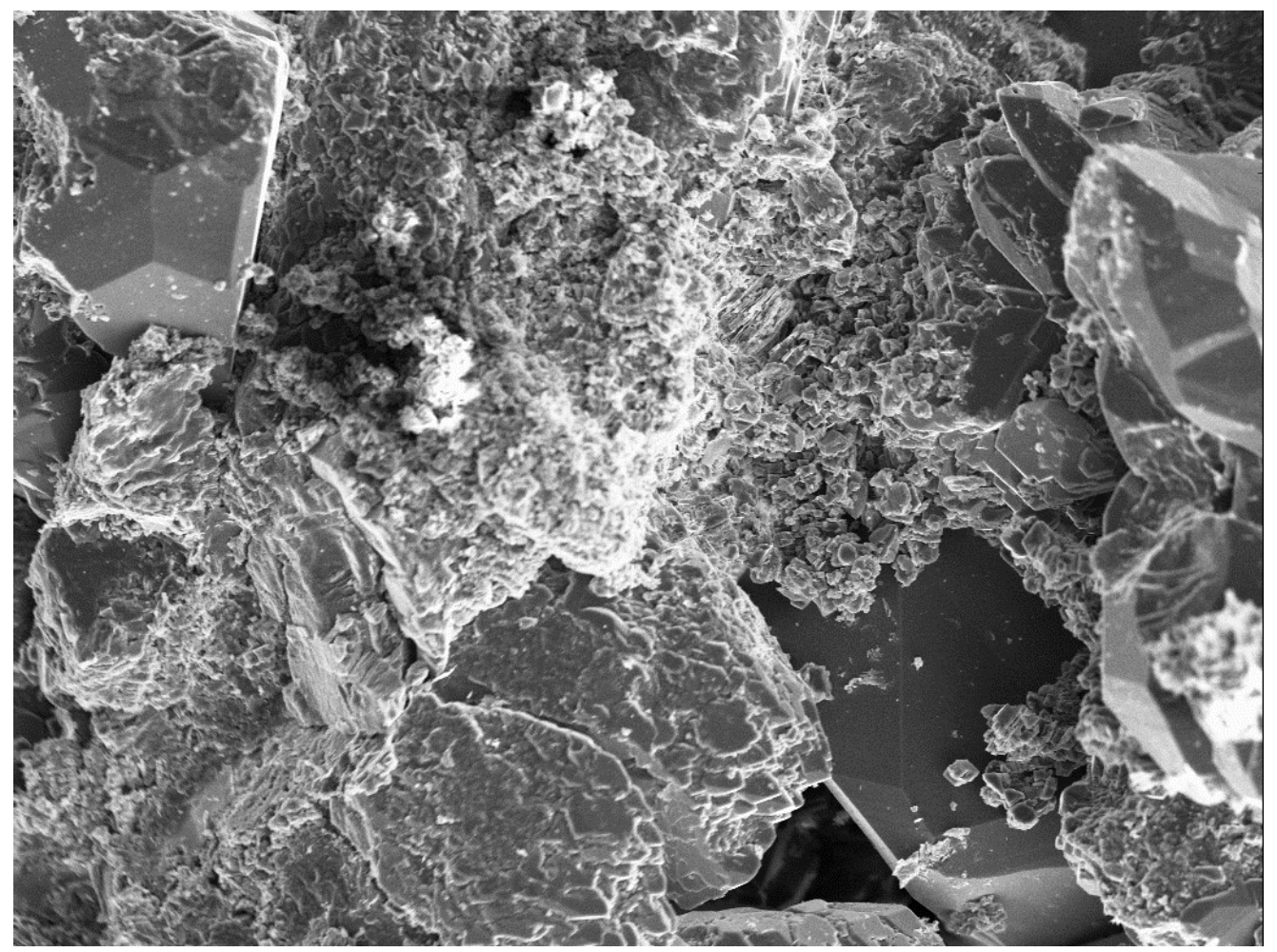

Fig. 14-Scanning electron micrograph (SEM) of Berea. $500 \mu \mathrm{m}$ x $367 \mu \mathrm{m}$.

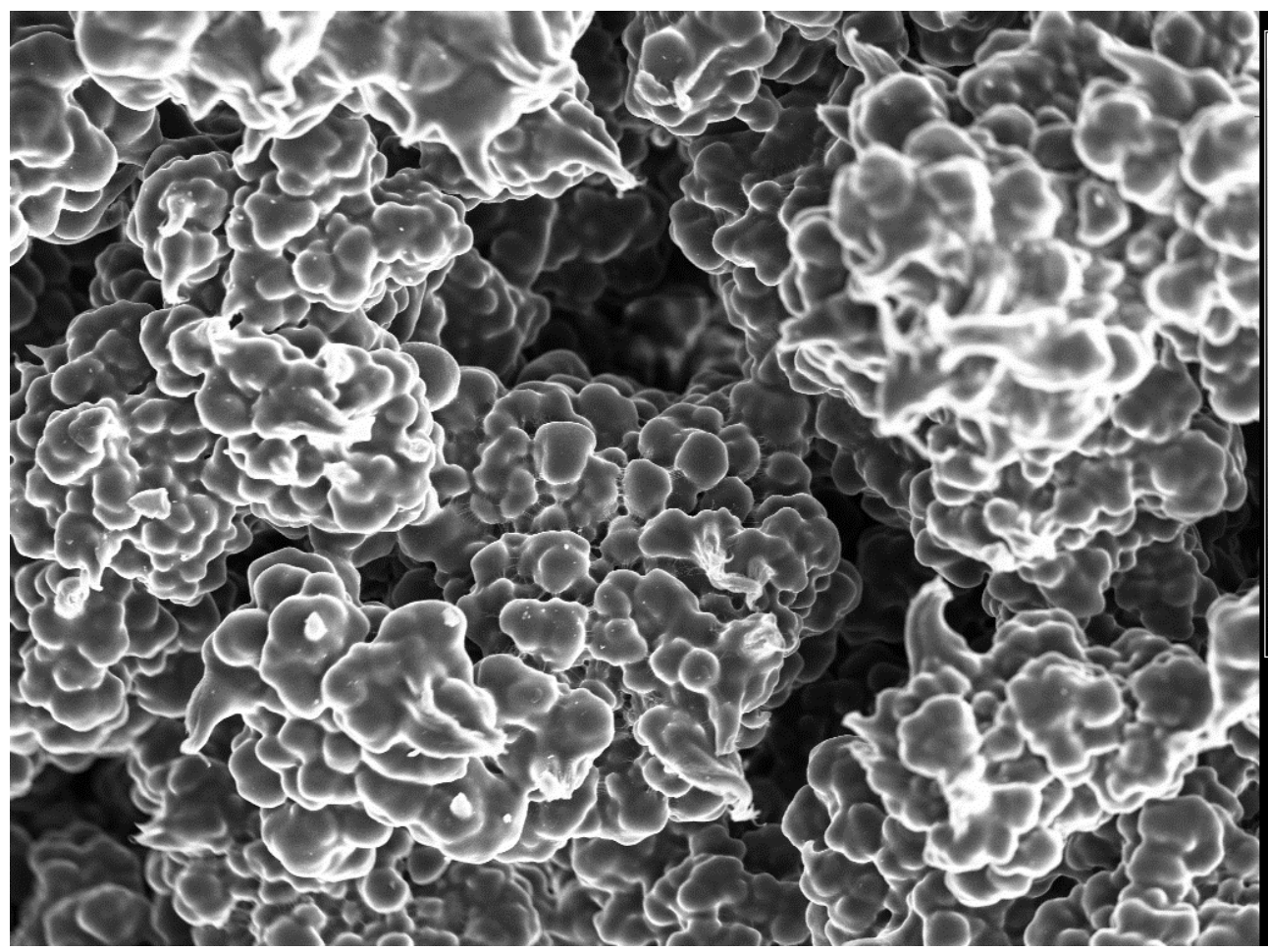

Fig. 15-SEM of polyethylene. $500 \mu \mathrm{m}$ x $367 \mu \mathrm{m}$. 


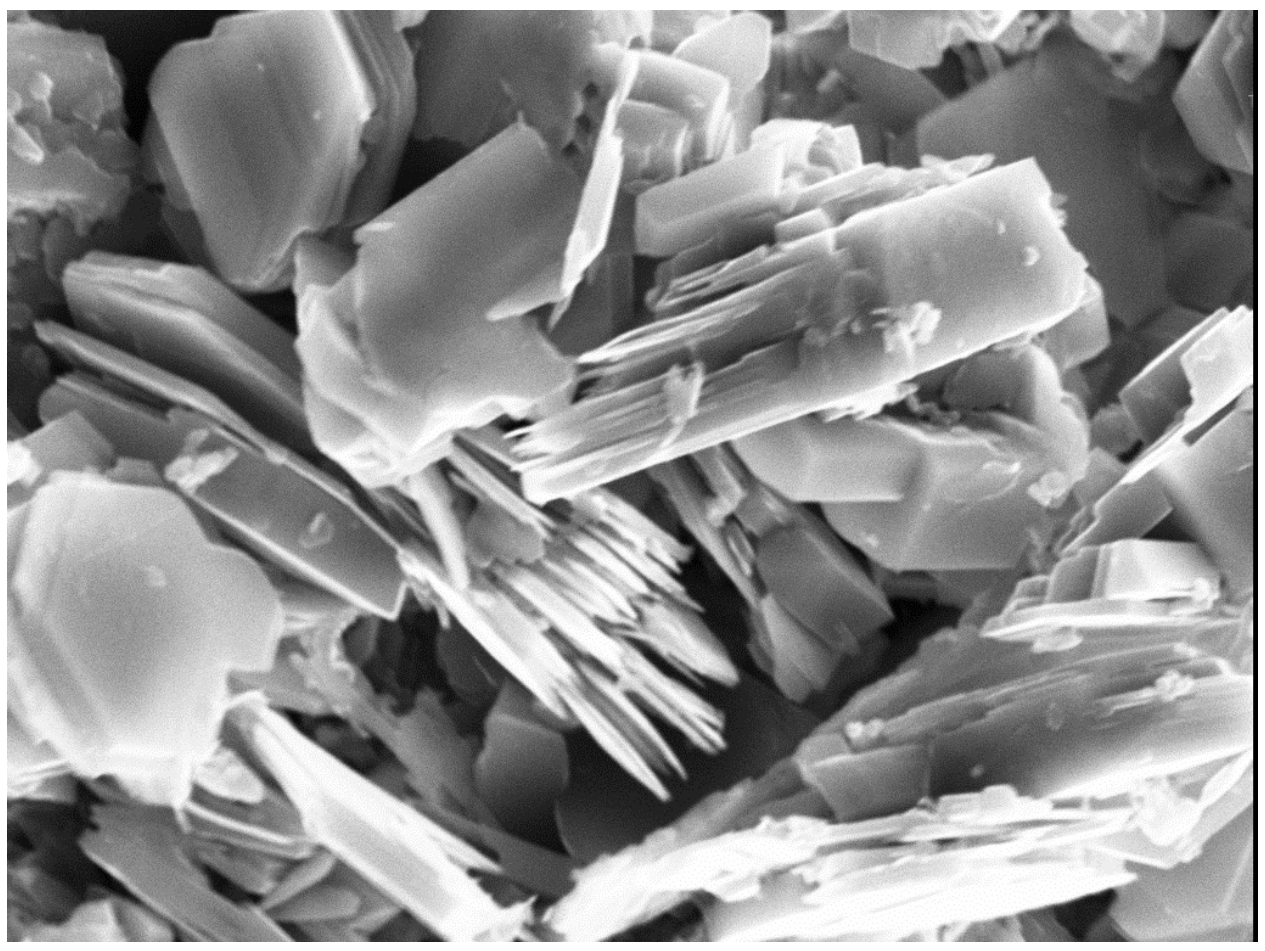

Fig. 16-Scanning electron micrograph of Berea. $30 \mu \mathrm{m}$ x $22 \mu \mathrm{m}$.

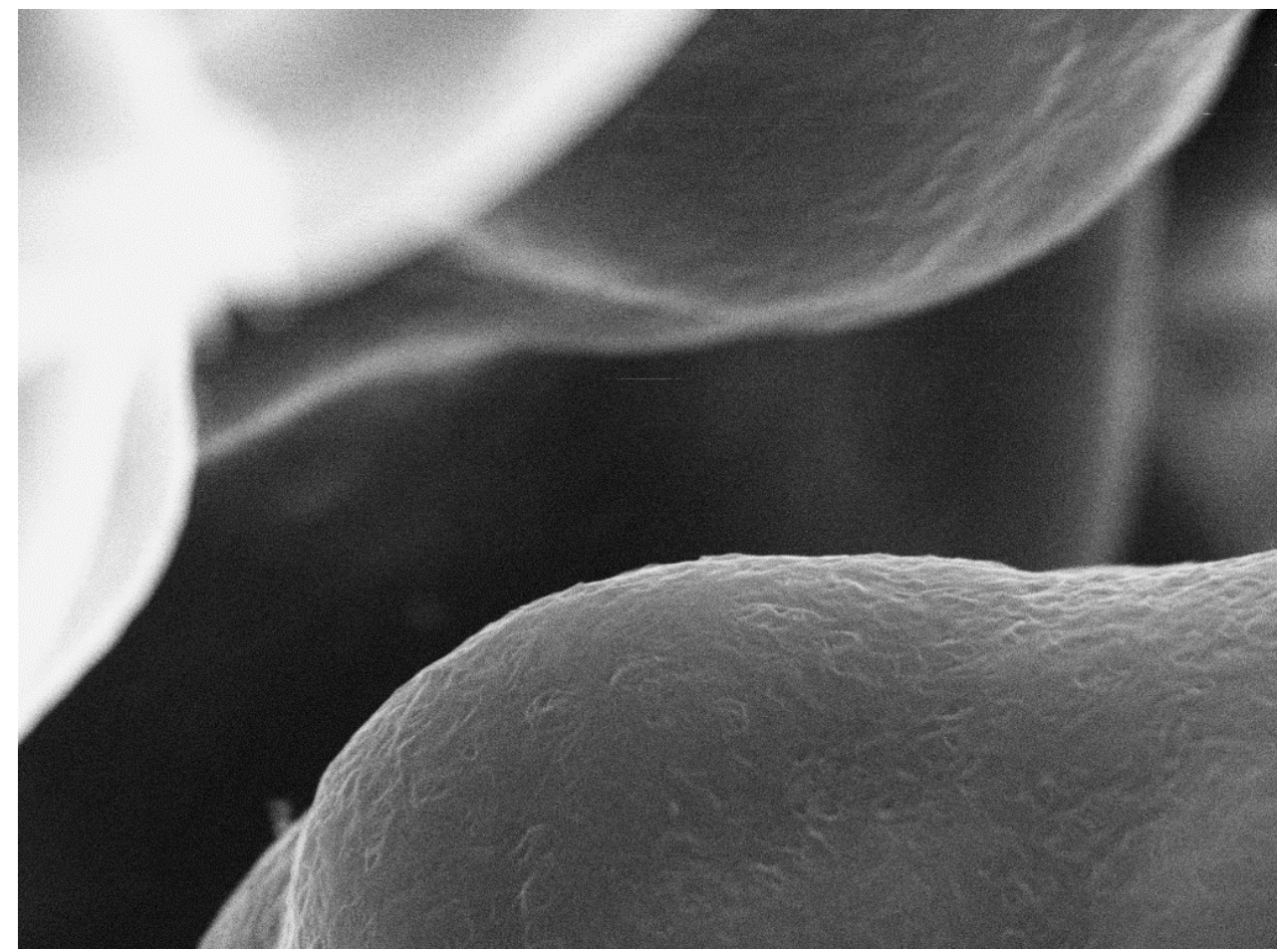

Fig. 17-Scanning electron micrograph of polyethylene. $30 \mu \mathrm{m} \times 22 \mu \mathrm{m}$. 
Pore body and pore throat symmetry. As mentioned, the pores were not spherical, and the pore throats were not circular. For Berea sandstone, we analyzed the shapes of the pore bodies (using an ellipsoid model) and pore throats (using an ellipse model) to assess their degree of asymmetry. As expected, a wide range of shapes were found. However, on average, the widest pore body dimension (i.e., the longest axis of the ellipsoid) was 1.6 times greater than the middle pore dimension (i.e., the middle axis of the ellipsoid), which in turn was 1.6 times greater than the shortest pore dimension (i.e., the shortest axis of the ellipsoid). Also, on average, the widest pore throat dimension (i.e., the long axis of the ellipse) was 1.6 times greater than the narrowest pore throat dimension (i.e., the short axis of the ellipse).

Flooding. Berea sandstone was first saturated with brine, while the porous polyethylene was first saturated with oil. Subsequently, cores were flooded with oil or water to establish residual water and oil saturations ( $S_{w r}$ and $S_{o r}$, respectively). Next, gelant was injected and allowed to gel. After gel placement, cycles of oil and water were injected to establish $S_{w r}$ and $S_{\text {or }}$ conditions. XMT images were obtained after each flood. All floods and imaging were performed without removing the core from ExxonMobil's X2B X-ray beamline at Brookhaven National Laboratory. Consequently, saturation changes can be followed for individual pores throughout the flooding sequences.

For each flooding stage, the water saturations versus pore size were compared. Table 3 summarizes the overall water saturations after each flooding step.

Table 3-Average water saturations after various floods.

\begin{tabular}{|c|c|c|}
\hline & Berea & Polyethylene \\
\hline @ $S_{\text {or } 1}$ before gel & & $86.0 \%$ \\
\hline @ $S_{w r}$ before gel & $16.0 \%$ & $16.5 \%$ \\
\hline @ $S_{o r}$ or $S_{\text {or } 2}$ & $81.6 \%$ & $83.0 \%$ \\
\hline @ Gel placement & $63.7 \%$ & $99.8 \%$ \\
\hline @ $S_{w r}$ after gel & $28.7 \%$ & $83.5 \%$ \\
\hline @ $S_{o r}$ after gel & $49.0 \%$ & $99.7 \%$ \\
\hline
\end{tabular}

\section{Saturations before Gel Placement}

$S_{w}$ Averaged $<\mathbf{6 0} \%$ in the Smallest Detected Berea Pores. In Berea sandstone, the water saturation $\left(S_{w}\right)$ averaged $16 \%$ at the connate water saturation $\left(S_{w r}\right)$ before gel placement. The water saturations at $S_{w r}$ are plotted in Fig. 18 for each of the 2,176 pores in Berea. The solid curve plots the average water saturation as a function of pore size. Note the large number of pores with very low (nearly zero) water saturation. At $S_{w r}, 54.5 \%$ of the pores had $S_{w}<5 \%$. Water saturations near zero were common for pores in most size ranges. The solid curve suggests that the average water saturation in the smallest detected pores was less than $60 \%$. However, few pores existed at the small end of the distribution, so an average value may not be particularly representative. Even so, it is clear that water saturations in the smallest pores were scattered over the entire range from 0 to $100 \%$ - just as in most size ranges. On first consideration, this finding appears to contradict those who expect the water saturation to approach $100 \%$ in the smallest pores of a strongly water-wet porous medium. In reconciliation, pores may be present (especially 
in clays) that were smaller than we can detect with X-ray computed microtomography. (Our voxel size was $4.1 \mu \mathrm{m}$.) At any rate, the smallest detected pores $\left(\sim 5 \times 10^{-6} \mathrm{~mm}^{3}\right)$ in our analysis were confirmed to average less than $60 \%$ water saturation at $S_{w r}$.

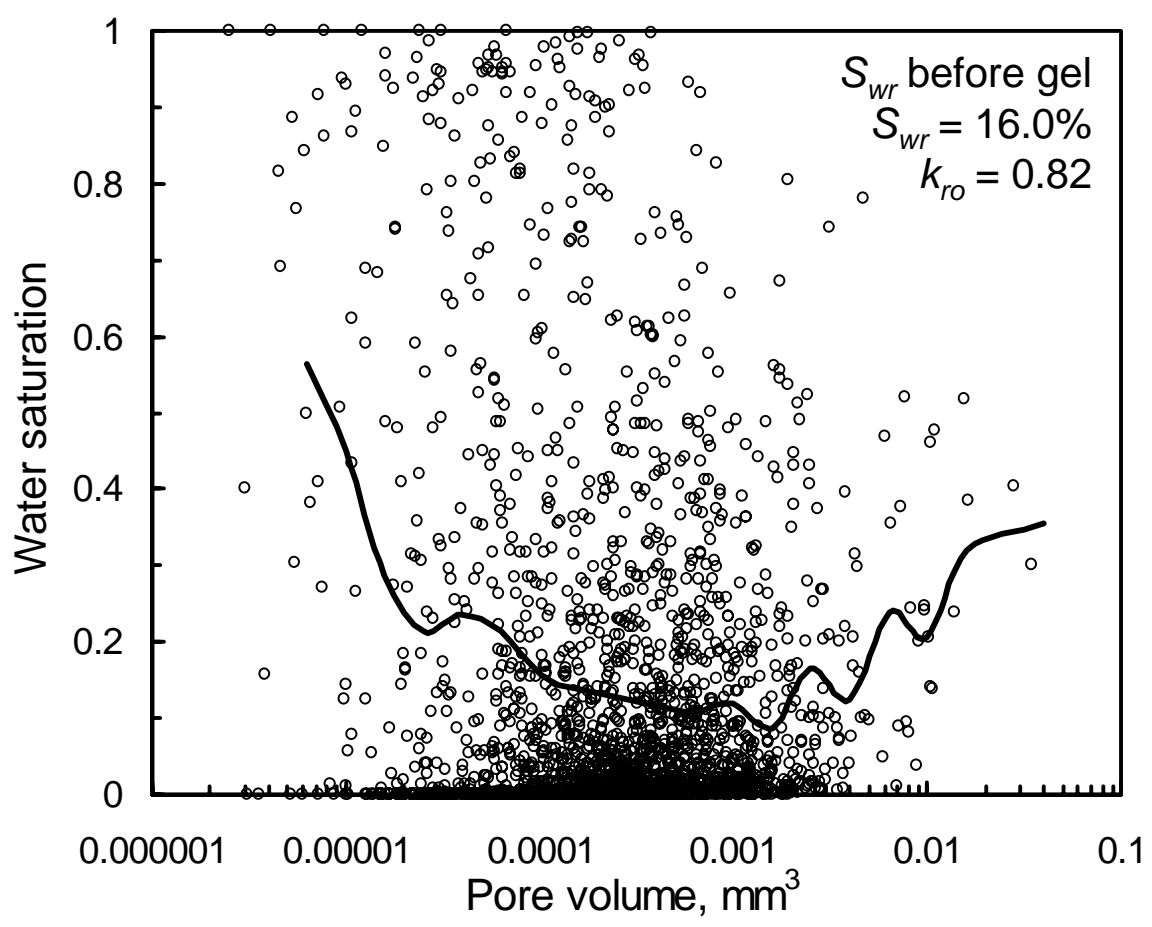

Fig. 18-Berea @ $S_{w r}$ before gel.

Saturation Changes Were Insensitive to Berea Pore Size. Water saturations at the residual oil saturation $\left(S_{o r}\right)$ in Berea averaged $81.6 \%$ (Table 3), and the average was not sensitive to pore size (solid curve in Fig. 19). For all size ranges, note the large number of pores with high water saturations. At $S_{o r}, 39.4 \%$ of the pores had $S_{w}>95 \%$. During the transition from $S_{w r}$ to $S_{o r}$ in Berea (Fig. 20 and compare Figs. 18 and 19), pores in all detected size ranges experienced significant gains in water saturation (averaging 65.6\%). Pore size did not appear to significantly influence the extent of the transition. In a strongly water-wet porous medium, one might have expected smaller pores to experience smaller saturation changes.

$S_{w}$ Averaged $<\mathbf{2 0 \%}$ in the Smallest Polyethylene Pores. In porous polyethylene at the first residual oil saturation $\left(S_{o r 1}\right), S_{w}$ averaged $86 \%$ (i.e., the oil saturation averaged $14 \%$ ). The average water saturation in the smallest detected pores was less than 20\% (Fig. 21). In other words, the wetting phase (oil) saturation averaged more than $80 \%$ in the smallest detected polyethylene pores. Recall that the wetting phase (water) saturation averaged less than $60 \%$ in the smallest detected Berea pores. For both porous media, the smallest detected pores were about the same size $\left(\sim 5 \times 10^{-6} \mathrm{~mm}^{3}\right)$. One might explain these observations by suggesting that the affinity of polyethylene for oil was stronger than the affinity of sandstone for water. However, this suggestion is counter-intuitive since polar interactions between Berea minerals and water should be stronger than the non-polar interactions between polyethylene and hexadecane. 


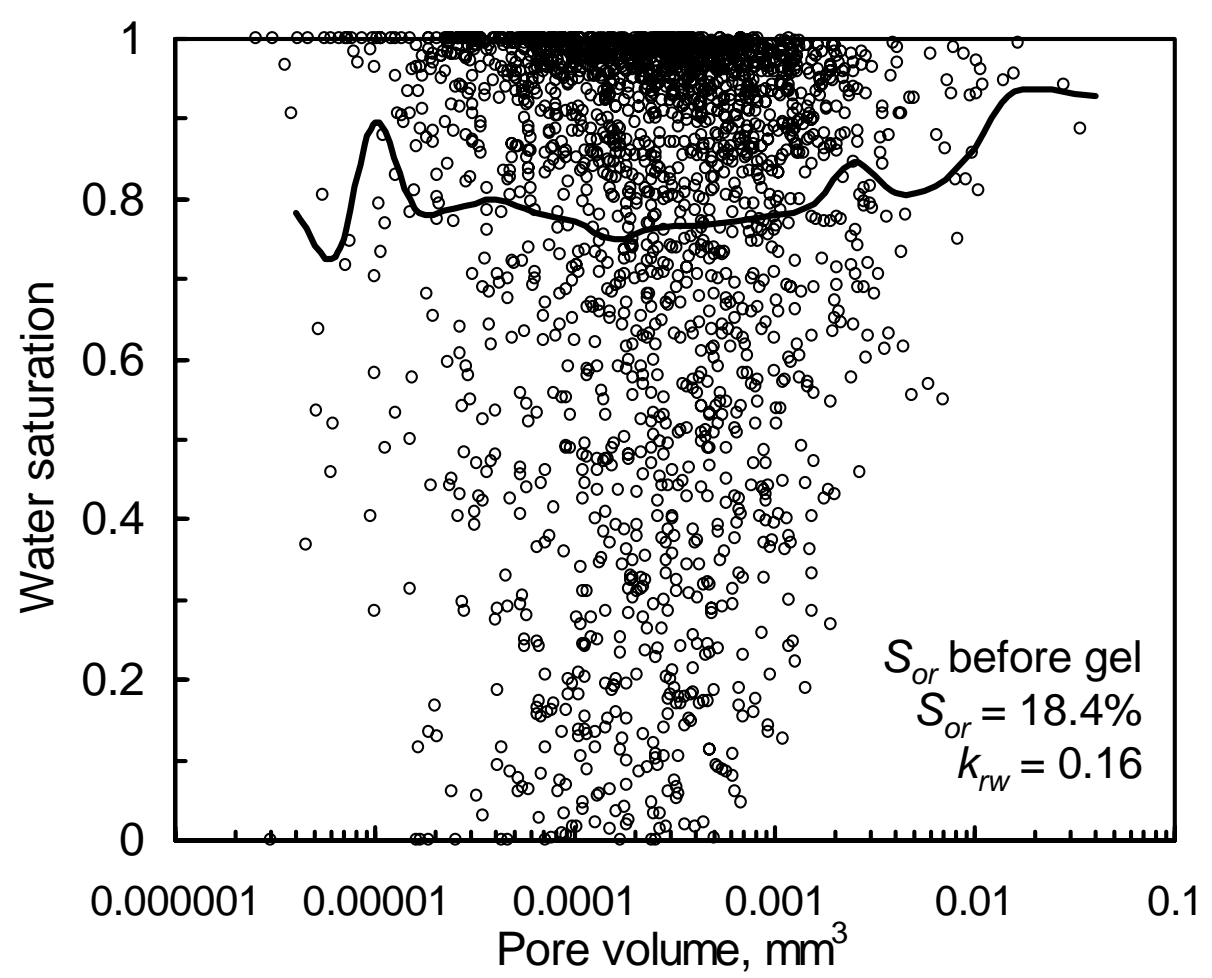

Fig.19_Berea @ Sor before gel.

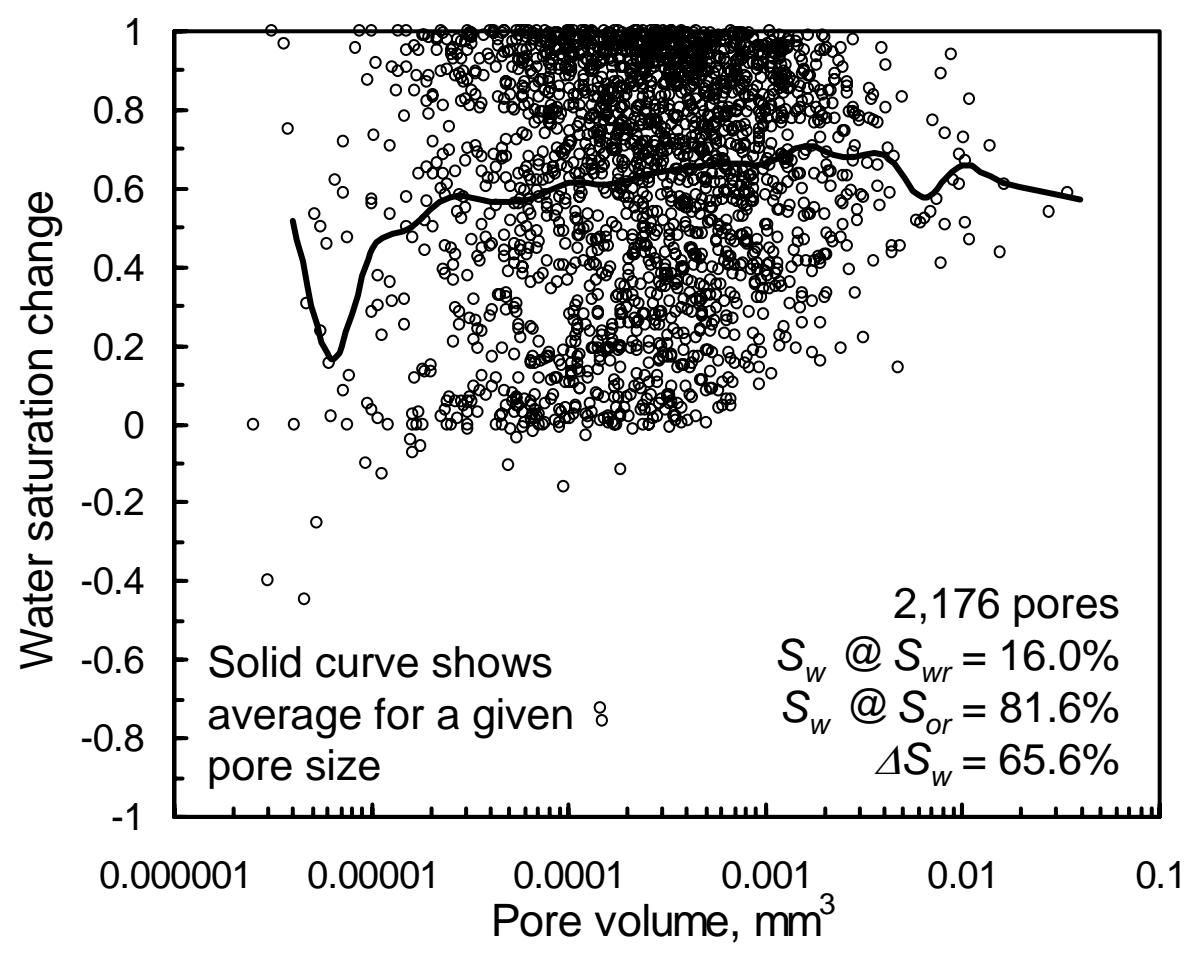

Fig. 20-Changes in Berea: $S_{w r}$ to $S_{o r}$. 


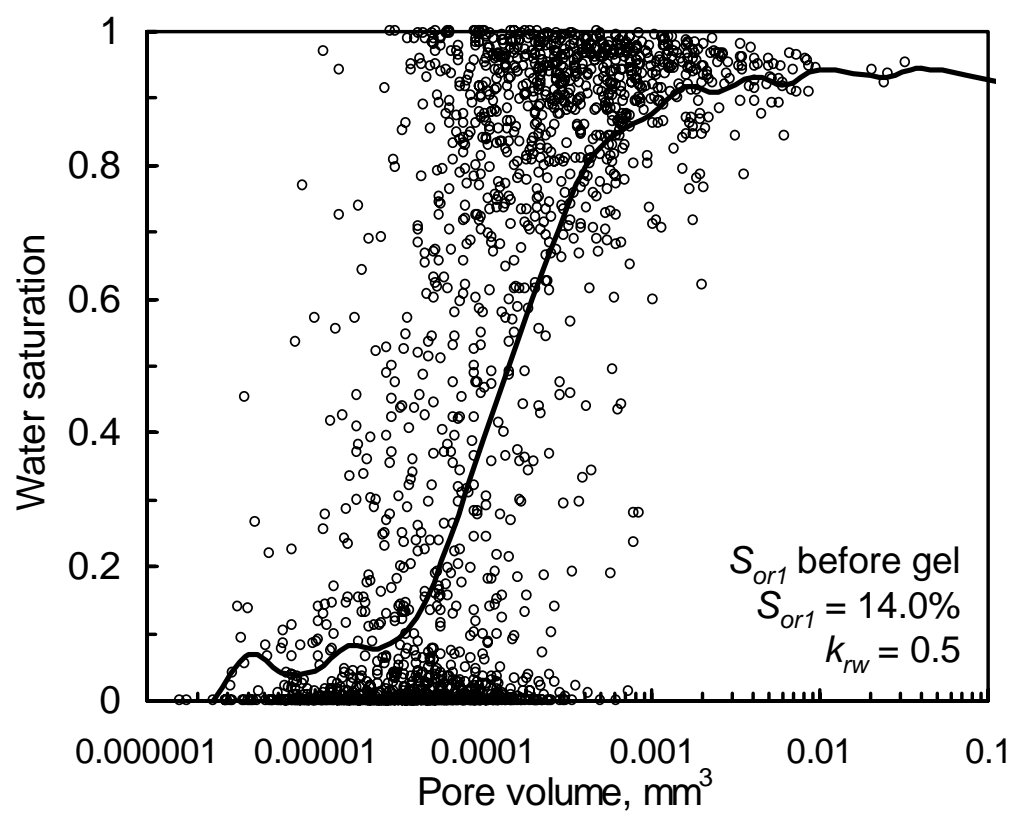

Fig. 21—Polyethylene @ Sor1 before gel.

Oil Was Largely Immobile in Small Polyethylene Pores. At $S_{o r}$ in polyethylene, most small pores had nearly $100 \%$ oil saturation, while most large pores had nearly $100 \%$ water saturation (Fig. 21). When oil was injected to drive the core to $S_{w r}$ (Fig. 22), water was displaced from most medium to large pores so that most pores ended with nearly $100 \%$ oil saturation. When water was re-injected to drive the core to $S_{o r 2}$, most large pores again filled almost completely with water, while most small pores retained high oil saturations (Fig. 23). Interestingly, a complementary behavior was not seen in Berea. The pore and throat sizes in polyethylene were no smaller than those in Berea. ${ }^{15,16}$

Norman Morrow (University of Wyoming) offered a credible explanation why higher water saturations were not seen in the smallest detected Berea pores at $S_{o r}$. Berea pores were typically coated with kaolinite that significantly increased the surface roughness of the pore walls. In contrast, the pore walls in polyethylene were quite smooth (see Figs. 16 and 17). At $S_{\text {or }}$, after oil drainage from the smooth polyethylene pore walls, an extremely thin (nanometer scale) oil film may have coated most pore walls (or possibly, no film may remain). At $S_{w r}$ in strongly water-wet Berea, the rough clay coating made the effective thickness of the water film much greater than for any oil film in porous polyethylene. (We qualitatively noted this difference visually by close comparison of Figs. 10 and 11 of Ref. 15.) With a thicker effective wetting film, water drained fairly efficiently from the smallest detected Berea pores when oil was injected-thus allowing the smallest detected pores to reach water saturations comparable to those in larger pores (Fig. 18). In contrast, when water was injected into porous polyethylene, oil usually became hydraulically isolated in the smallest detected pores because any remaining wetting film was too thin to efficiently drain oil. Consequently, high oil saturations were usually seen in the smallest detected polyethylene pores (Figs. 21 and 23). 


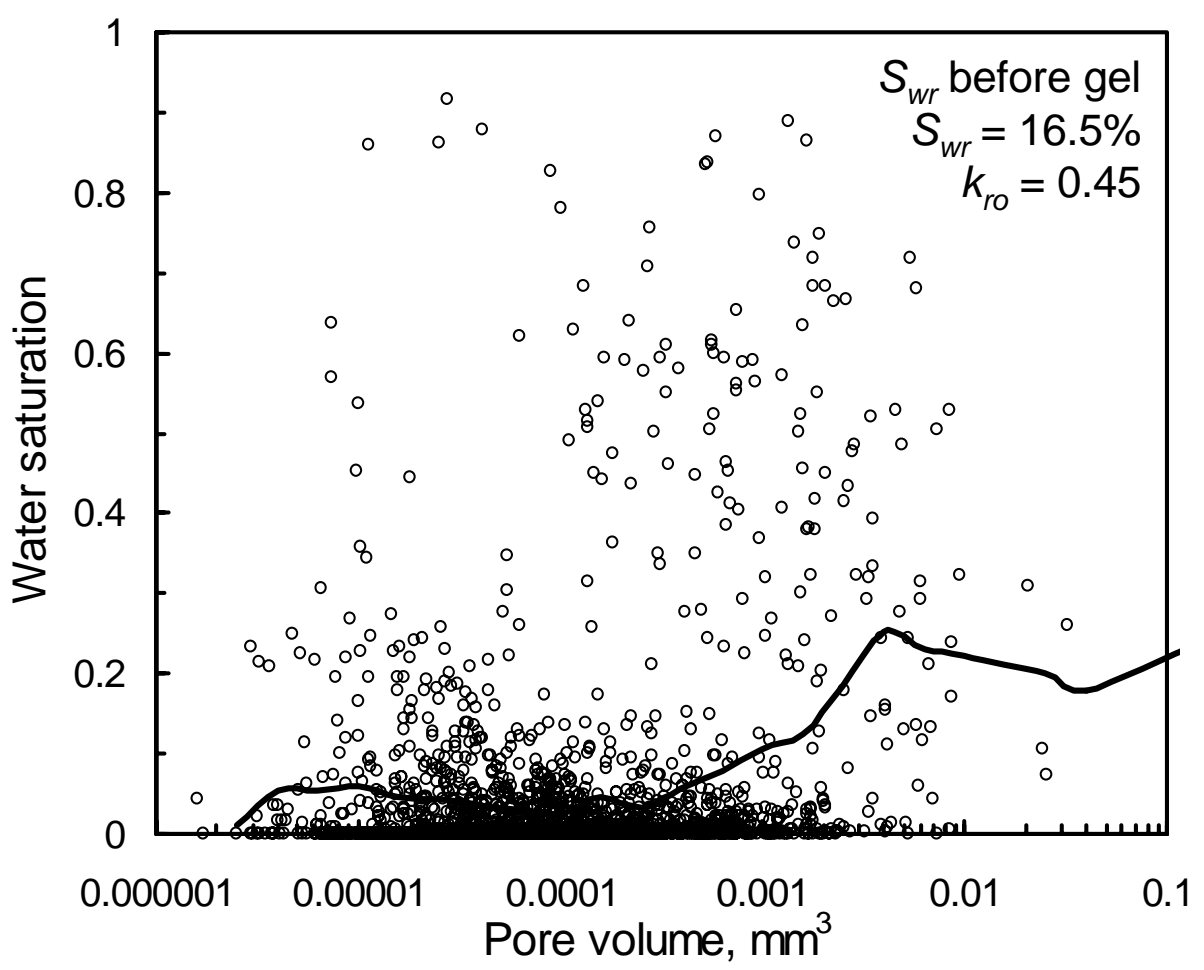

Fig. 22—Polyethylene @ S $S_{w r}$ before gel.

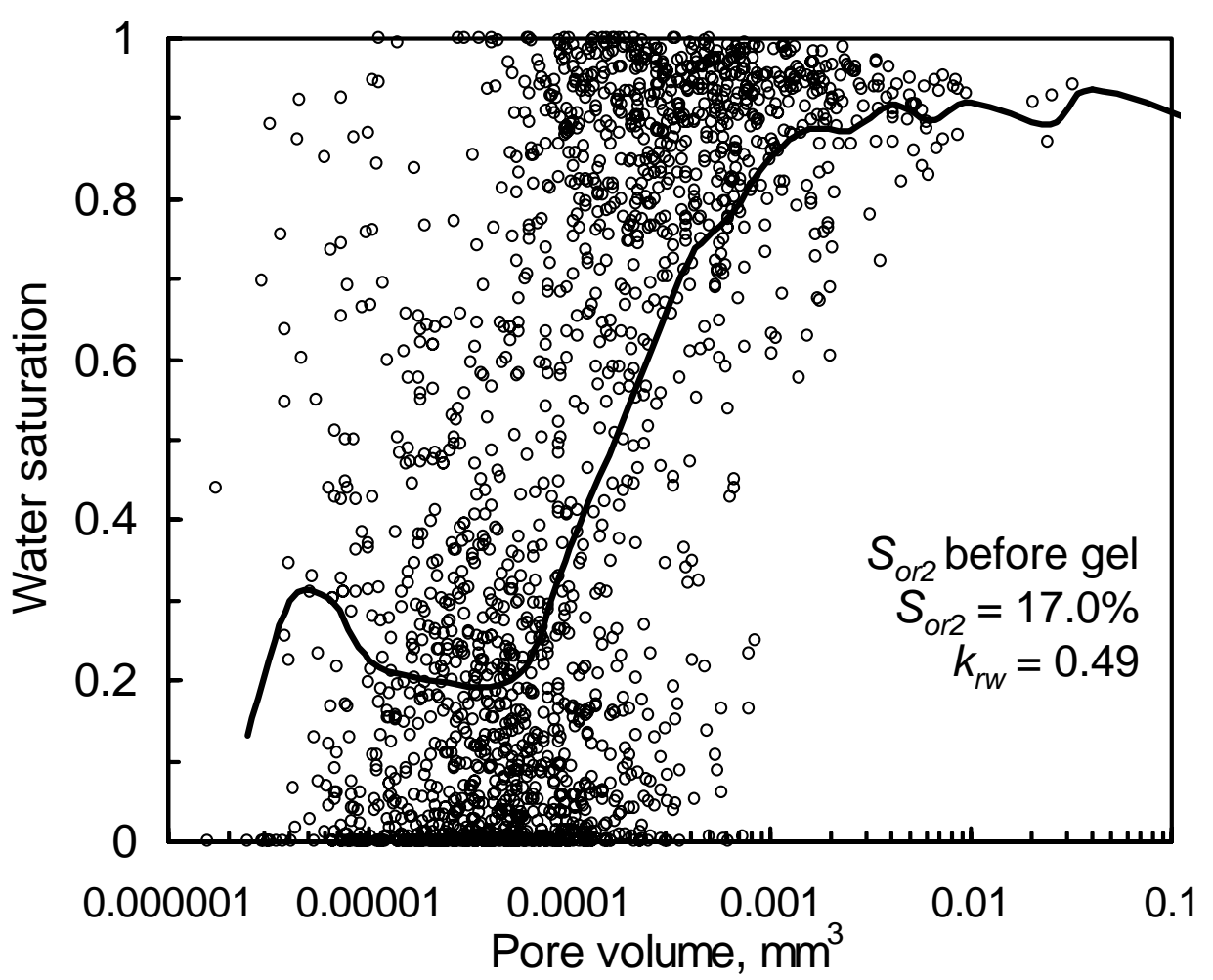

Fig. 23—Polyethylene @ Sor2 before gel. 


\section{0-cp Gelant Mobilized Oil in Both Porous Media}

During gelant placement in Berea, the image volume surprisingly increased in oil saturation (from $18.4 \%$ to $36.3 \%$ ). To rationalize this result, we note that the image volume was located in the center of the core and was small compared to the total pore volume of the core. Oil from upstream of the image volume probably was mobilized by flow of the 20-cp gelant, and that oil coincidentally lodged in the image volume. The overall oil saturation in the core did not increase during gelant placement. Within the image volume, medium to large pores $\left(10^{-4}\right.$ to $\left.10^{-2} \mathrm{~mm}^{3}\right)$ were most likely to gain in oil saturation (Fig. 24). Interestingly, the pressure gradient during gelant injection was always less than that during the previous brine or oil flows. This constraint was intentionally part of our experimental design to minimize oil mobilization. Since oil was mobilized, factors other than high pressure gradients were responsible for this mobilization.

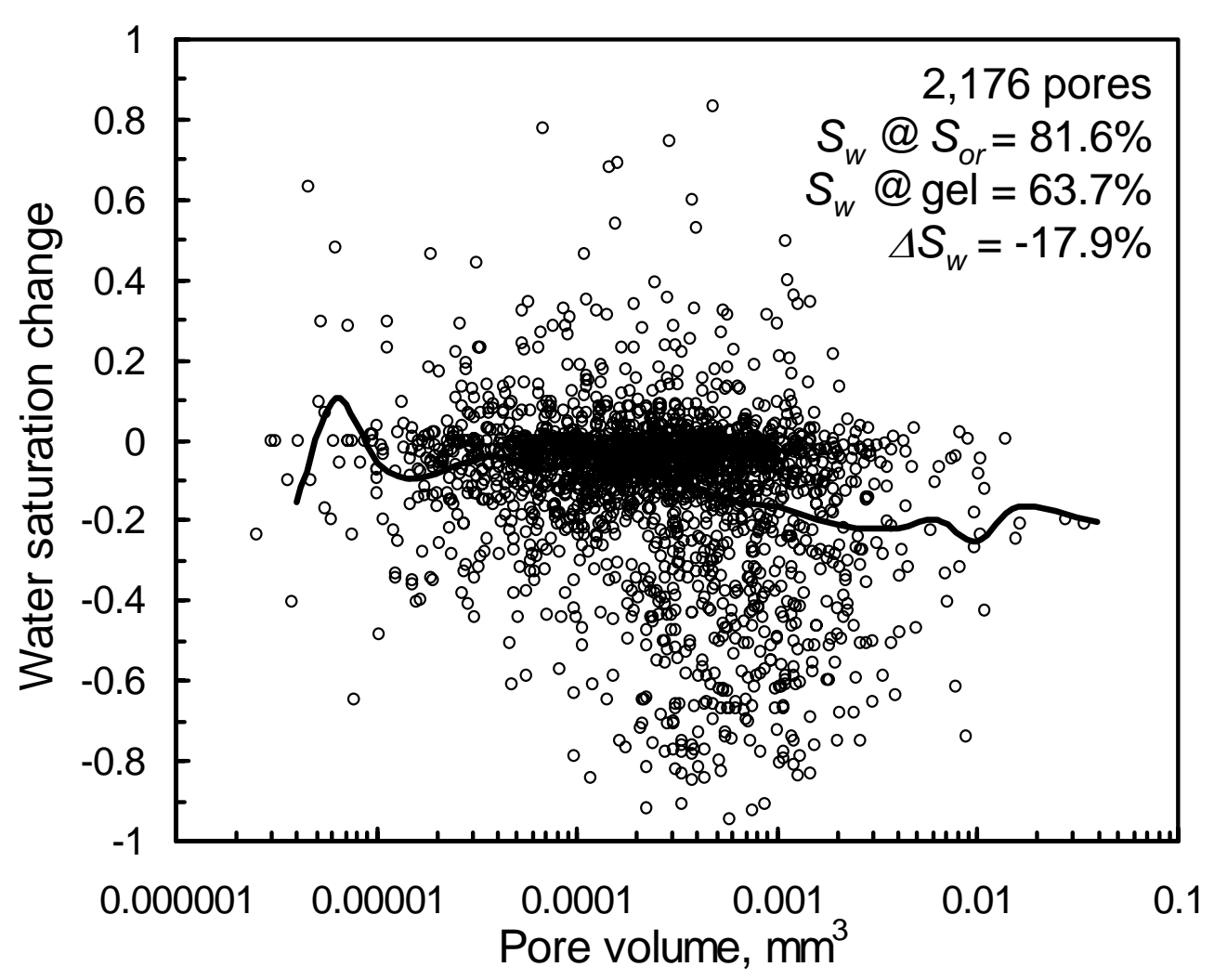

Fig. 24-Changes in Berea: $S_{\text {or }}$ to gel placement.

During gelant placement in polyethylene, most oil that was trapped in small pores was displaced, so that most pores ended with high gelant saturations (compare Figs. 23 and 25). Only a few small pores retained large oil saturations (Fig. 25). The gelant or aqueous saturation increased from $83 \%$ to $99.8 \%$ during the process of gel placement (Table 3). As in Berea, the pressure gradient during gelant injection was always less than that during the previous brine or oil flows. 


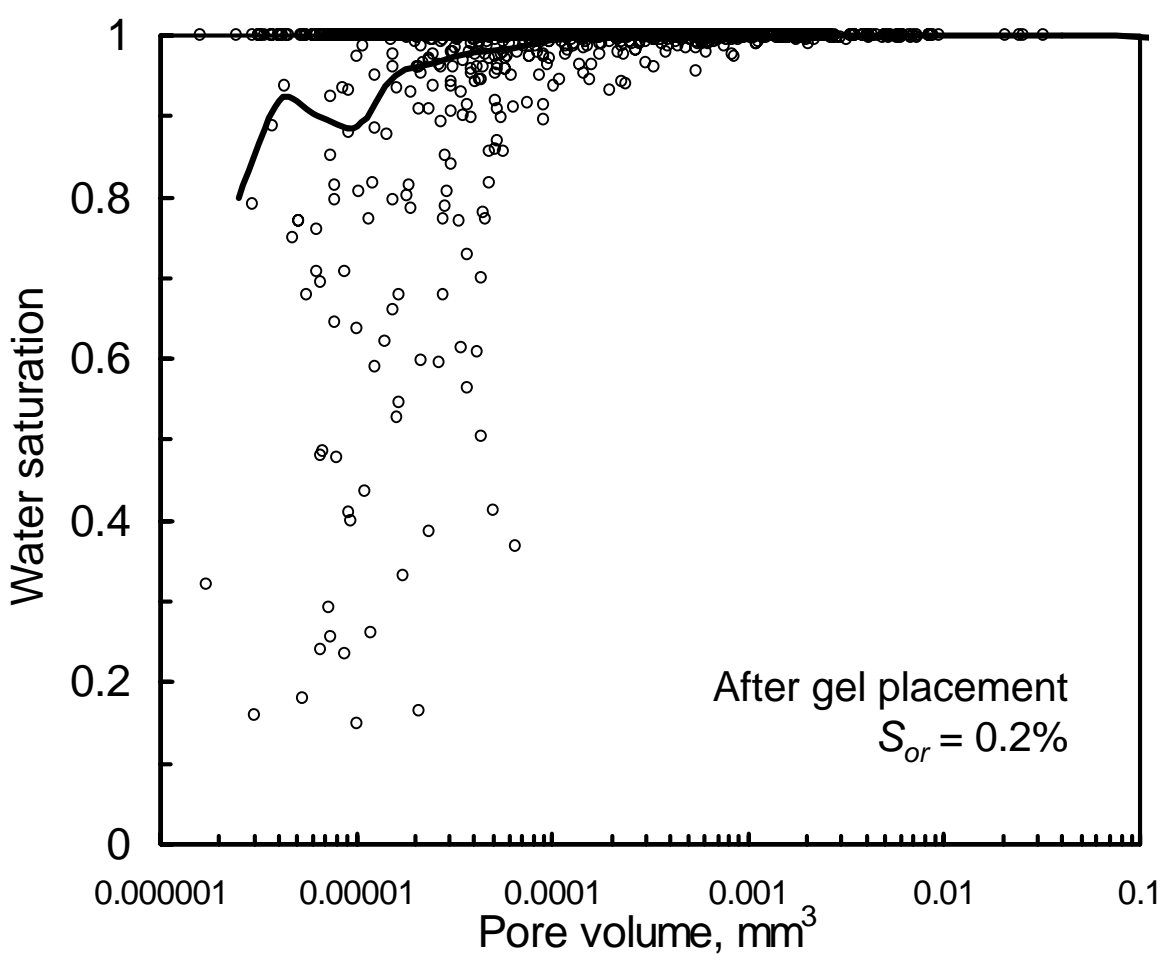

Fig. 25-Polyethylene after gel placement.

Why was oil mobilized from the small pores during gelant injection but not during the previous water injection-especially since the pressure gradient (35 psi/ft) during water injection was higher than during gelant injection? Could polymer or $\mathrm{Cr}(\mathrm{III})$ adsorption have altered the wettability (oil-wet to water-wet) of the polyethylene? This suggestion seems unlikely considering the hydrophobic nature of the surface and the hydrophilic nature of the polymer and crosslinker. Wang ${ }^{17}$ suggested that viscoelastic forces associated with flow of polymer solutions may re-distribute forces on a microscopic scale so that oil may be mobilized. This explanation may also help explain oil mobilization during our Berea experiments. More work is needed to determine if this explanation is applicable for our polyethylene and Berea experiments.

\section{Oil and Water Flooding after Gel Placement}

Oil Injection Reduced Gel Volume in Berea. Perhaps the most important conclusion from our earlier work was that oil injection effectively reduced gel volume in many Berea pathways that were utilized by oil before gel placement. ${ }^{15,16}$ This conclusion was confirmed by our new analysis. When gelant was placed, it effectively displaced all brine so that gel formed in all aqueous pore spaces. This observation was confirmed many times in previous work by noting that the $\mathrm{Cr}$ (III)-acetate-HPAM gel reduced Berea's permeability to water to levels associated with the permeability of the gel itself to water (i.e., water residual resistance factors of 10,000 or greater and final permeability in the microdarcy range). ${ }^{14,18}$

When oil was injected after gel formation, the oil saturation increased (by 35 saturation percentage points-see Table 3). Fig. 26 shows that most (95.2\% of the total) pores gained oil (lost water) when oil was injected after gel placement. The effect of oil on the gel was not 
sensitive to pore size, since the average water saturation (solid curve in Fig. 26) decreased by about 35\% regardless of pore size. Considering that the water saturation was $63.7 \%$ immediately before oil injection and $28.7 \%$ after oil injection, and assuming that gel occupied all of the aqueous pore space, the oil apparently destroyed (or reduced in volume) 55\% of the gel. The pressure gradients during these experiments were limited so that they never exceeded those applied before the gel was placed. Therefore, it seems unlikely that the reduction in gel volume occurred because of exposure to excessive pressure gradients (i.e., extrusion of the gel from the core).

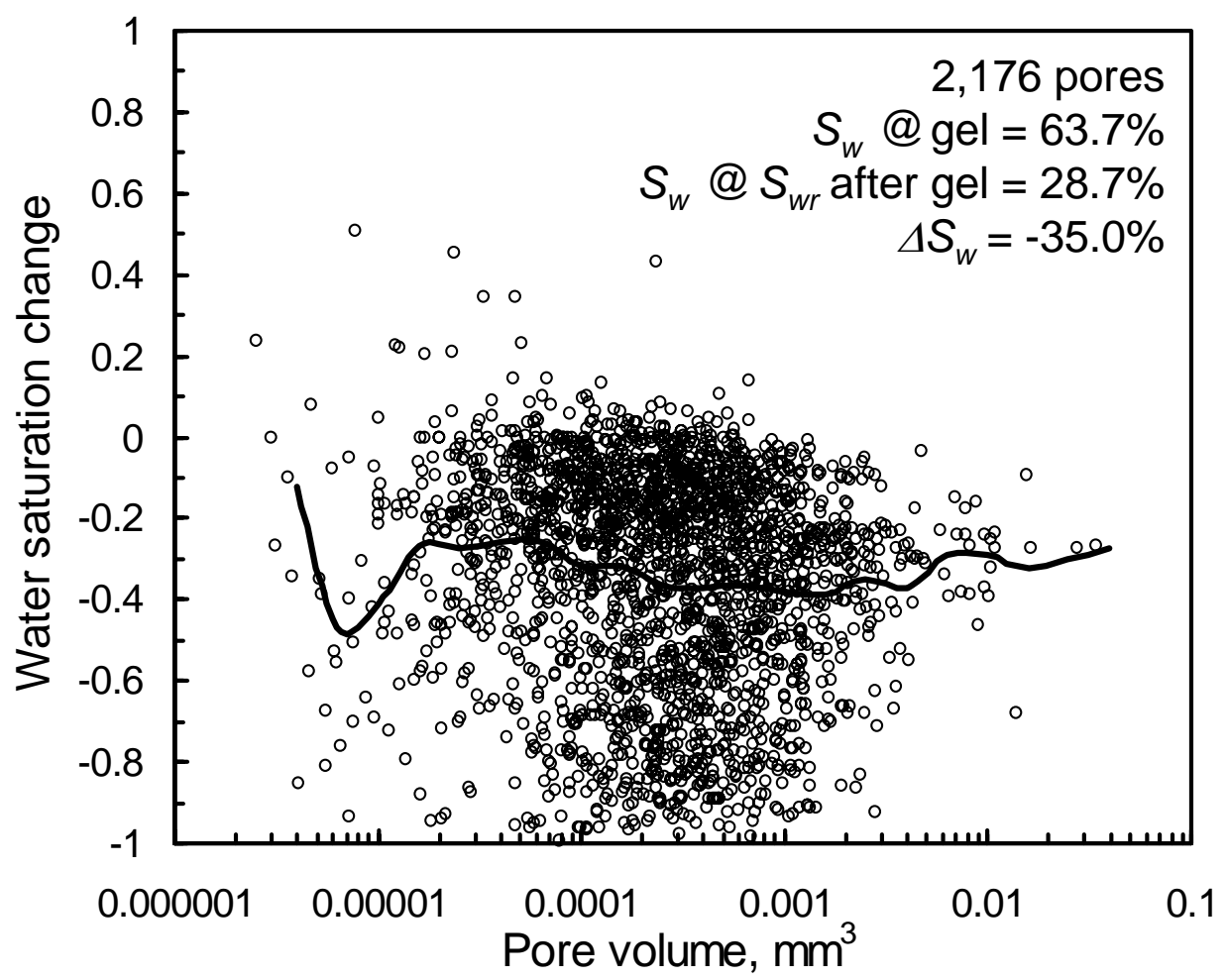

Fig. 26-Oil flooding to $S_{w r}$ after gel placement in Berea.

Fig. 27 provides additional insight into the process of reducing gel volume during oil injection. This plot shows the 300 pores (1/7 of total) that experienced the greatest increase in oil saturation during the process of oil injection after gel placement. Before gel placement, these pores were nearly full of oil at $S_{w r}$ and were nearly full of water at $S_{o r}$. Thus, oil and water both flowed freely into and filled these pores before gel placement. They were also easily accessible to oil after gel.

$S_{w r}$ in Berea Was Higher after Gel Placement than before. Overall water saturation was higher at $S_{w r}$ after gel placement (28.7\%) than before gel placement (16.0\%). (See Table 3 and Fig. 28.) From Fig. 28, 86.1\% of the pores had higher $S_{w r}$ values after gel placement than before gel. Presumably, gel accounted for this increase. (By itself, XMT cannot distinguish between water and gel.) In the previous section, we estimated that oil injection reduced gel volume by $55 \%$. Fig. 28 suggests that the remaining gel was widely distributed, although it was most likely to be found in medium to small pores. Fig. 28 also shows that few pores had lower $S_{w r}$ values after gel placement than before gel. 


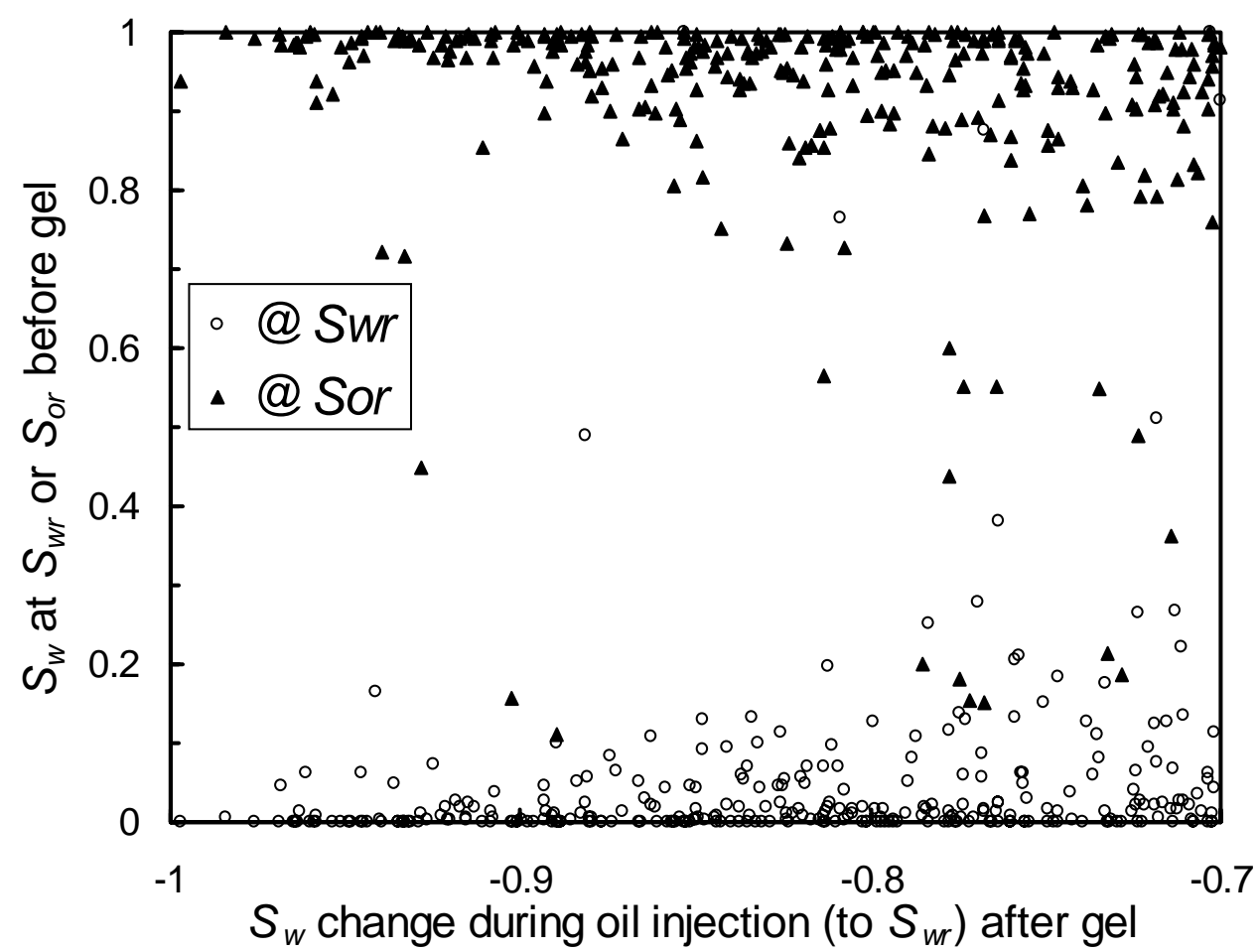

Fig. 27-Oil damaged gel most in pores that were easily filled by oil or water before gel.

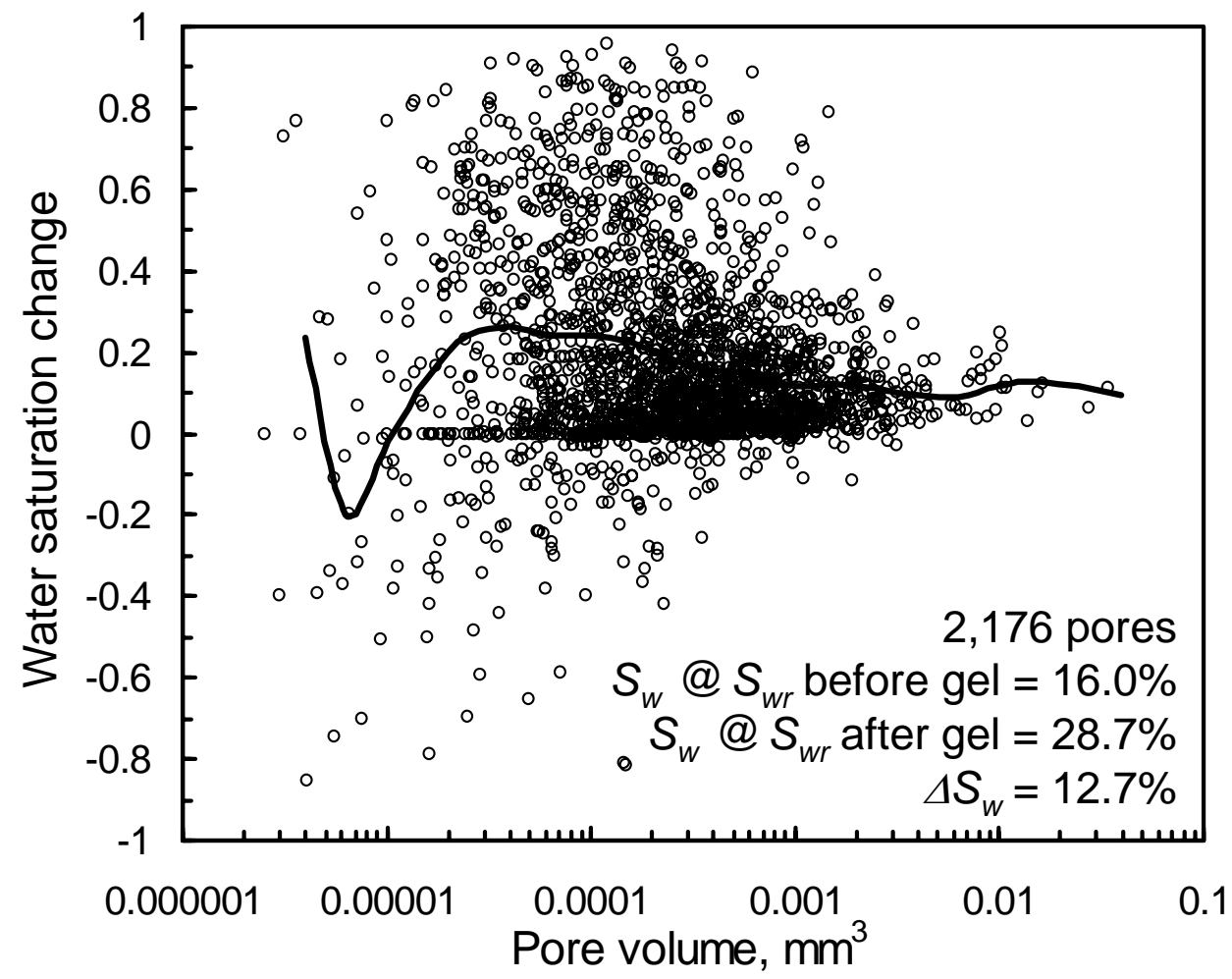

Fig. 28-Changes in Berea: $S_{w r}$ before gel to $S_{w r}$ after gel. 
On the other hand, many pores had nearly the same water saturation before and after gel placement (see the cluster of data points near zero change in water saturation in Fig. 28). In particular, $46 \%$ of the pores changed less than 10 saturation percentage points for the transition from $S_{w r}$ before gel placement to $S_{w r}$ after gel placement.

Oil Was Trapped in Berea during Subsequent Water Flow. During the transition from $S_{w r}$ after gel placement to $S_{\text {or }}$ after gel placement, the average increase in $S_{w}$ was 20.3\%. Fig. 29 reveals that a wide range of changes occurred for most pore sizes and the average saturation change was not particularly sensitive to pore size (although the average saturation changes were close to zero for the smaller pores). Interestingly, 22.6\% of the pores gained oil even though water was injected. Evidently, a significant degree of rearrangement occurred for water and oil saturations during this flood.

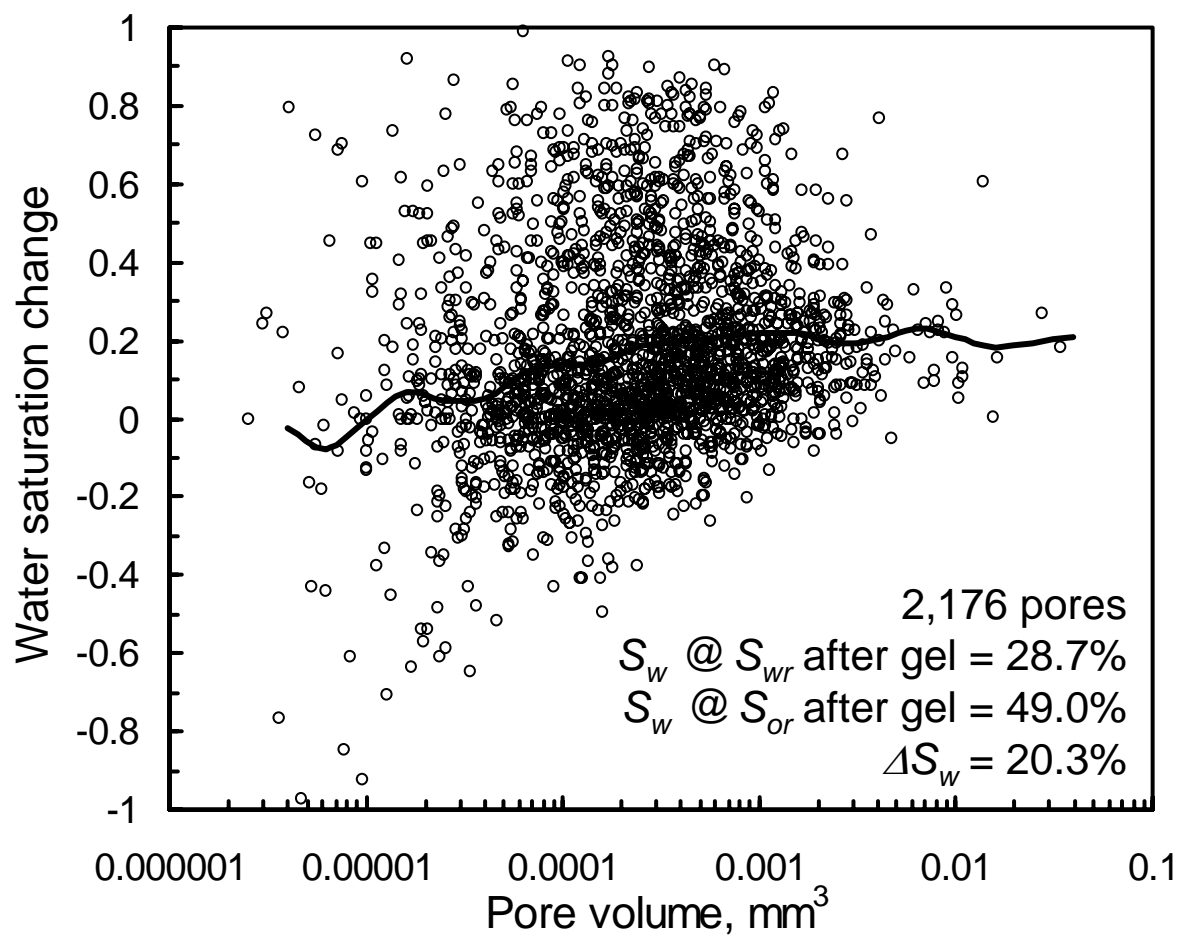

Fig. 29—Changes in Berea: $S_{w r}$ after gel to $S_{\text {or }}$ after gel.

During oil injection after gel placement, the oil residual resistance factor $\left(F_{\text {rro }}\right.$, permeability reduction) was 15 . During subsequent water injection, the water residual resistance factor $\left(F_{r r w}\right)$ was 1,220 . Thus, the gel reduced permeability to water 81 times more than to oil. As mentioned earlier, much of the gel was destroyed or reduced in volume during oil injection after gel placement. Why was the final permeability to water so much lower than that to oil? Previous analysis $^{15,16}$ indicated that the gel trapped significantly more residual oil. Our new analysis confirmed this conclusion, which indicated that $S_{\text {or }}$ jumped from $18.4 \%$ before gel placement to $51 \%$ after gel placement (i.e., $S_{w}$ decreased from $81.6 \%$ to $49 \%$; see Table 3 and Fig. 30 ). With many pores permanently occupied by oil, water was forced to flow through narrow films and through the gel itself-explaining the large water residual resistance factor (i.e., 1,220). In 
contrast, oil pathways remained relatively free from constriction by the gel, so the oil residual resistance factor was much less (i.e., 15).

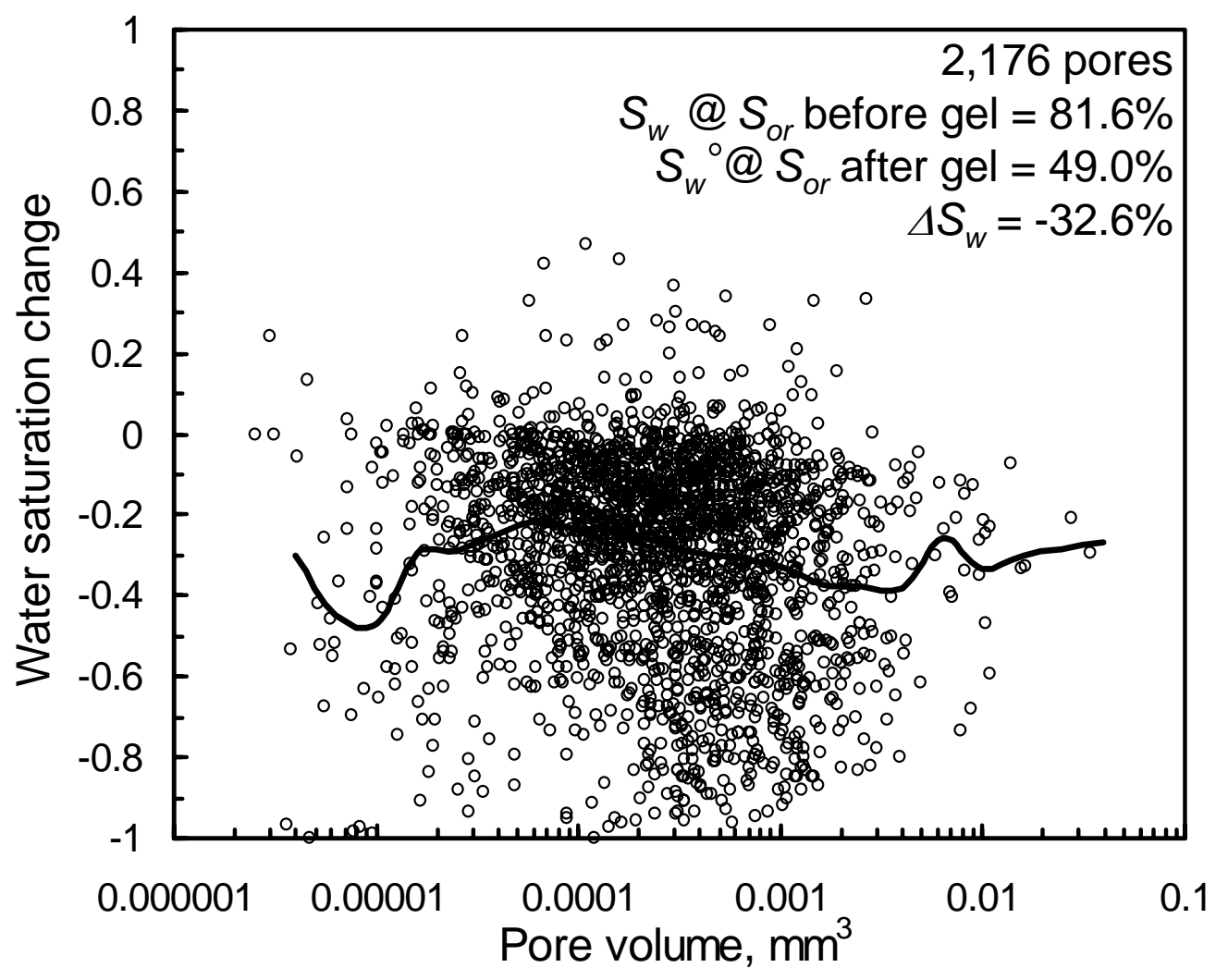

Fig. 30 - Changes in Berea: $S_{\text {or }}$ before gel to $S_{\text {or }}$ after gel.

At $S_{\text {or }}$ after gel placement, 93.3\% of the pores had higher oil saturations than at $S_{\text {or }}$ before gel placement. Fig. 30 reveals that a wide range of changes occurred for all pore sizes and that the average change was not sensitive to pore size.

In Polyethylene, Reduction of Gel Volume Occurred Mainly in Small Pores. As in Berea, gel appeared to form in all aqueous pore spaces of polyethylene (because permeability to water was in the $\mu \mathrm{d}$ range immediately after gel formation). When oil was injected after gel placement in polyethylene, the oil residual resistance factor was 24, and the overall $S_{w r}$ value was $83.5 \%$ (Fig. 31 and Table 3). For comparison, the overall $S_{w r}$ value was only $16.5 \%$ before gel placement (Fig. 22 and Table 3). Presumably, the difference (67 saturation percentage points) was due to gel that was not destroyed or dehydrated during oil injection. Put another way, oil injection reduced the gel volume by 16.3 saturation percentage points (99.8\%-83.5\%). This loss was substantially less than that seen in Berea (35 saturation percentage points from Table 3). If the losses could be attributed entirely to gel dehydration, the gel would have been concentrated by factors of 2.2 in Berea (i.e., 63.7/28.7) and only 1.2 in polyethylene (i.e., 99.8/83.5). 


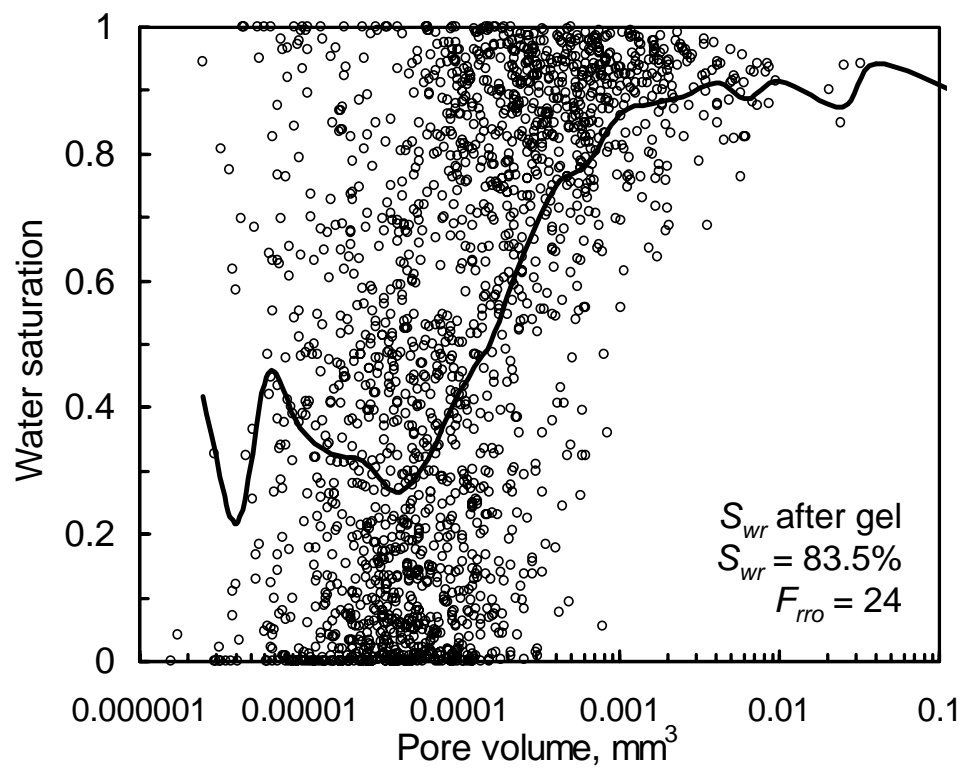

Fig.31-Polyethylene @ $S_{w r}$ after gel.

The oil saturation increased 63 saturation percentage points for pores that were smaller than $10^{-4}$ $\mathrm{mm}^{3}$ but only by 11 saturation percentage points for pores that were larger than $10^{-3} \mathrm{~mm}^{3}$ (see Fig. 32). Thus, compared to Berea, reduction of gel volume during oil injection into gel-filled porous polyethylene was more likely in small pores and less likely in large pores. As with our Berea experiments, the pressure gradients were not allowed to exceed $35 \mathrm{psi} / \mathrm{ft}$ during any stage of the polyethylene experiments. So again, it seems unlikely that reduction of gel volume occurred because of exposure to excessive pressure gradients. If high pressure gradients were responsible, gel damage should have been greater in larger pores than in smaller pores.

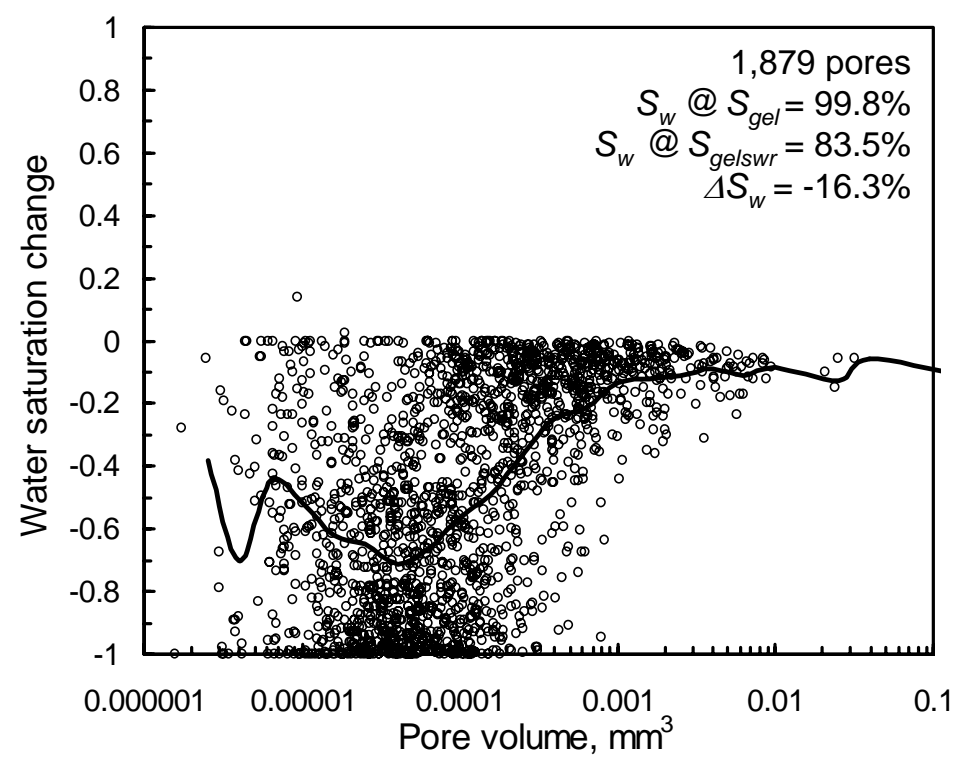

Fig. 32-Oil flooding to $S_{w r}$ after gel placement in polyethylene. 
If the losses could be attributed entirely to gel dehydration, the gel would have been concentrated by factors of 2.8 in small polyethylene pores and 1.1 in large polyethylene pores.

In Polyethylene, $\boldsymbol{S}_{w r}$ after Gel Placement Looked Like $\boldsymbol{S}_{\text {or }}$ before Placement. A comparison of Figs. 21, 23, and 31 suggests that the saturation distributions at $S_{w r}$ after gel placement in polyethylene were very similar to those at $S_{\text {or }}$ before gel placement. Why should this similarity occur? Two factors contribute. First, as mentioned earlier, injected oil entered and destroyed (or reduced the volume of) gel preferentially in the small pores where residual oil was located before gel placement. Second, subsequently injected water displaced most oil from the smaller pores. (Since the larger pores were permanently filled with gel, no displacement apparently occurred in the larger pores.) It is interesting that water could displace oil from the small pores after gel placement but not before gel placement. As mentioned earlier, the pressure gradients for the post-gel floods were less than those for the pre-gel floods. Therefore, at present, we have no explanation for this behavior.

The oil residual resistance factor $\left(F_{\text {rro }}\right)$ was 24 . The mobile oil flow follows films and smallest pores. One might have expected much higher resistance to flow for low oil saturations and such narrow flow paths.

In Polyethylene, Additional Oil Was Not Trapped during Subsequent Water Injection. After the oil injection step associated with Fig. 32, water was injected to drive the core to $S_{o r}$. The final saturations are plotted in Fig. 33. Notice the similarity between Figs. 25 and 33. In both cases, very little oil remained in the core $(0.3 \%$ or less). The small oil saturation that was present generally existed in the smallest pores.

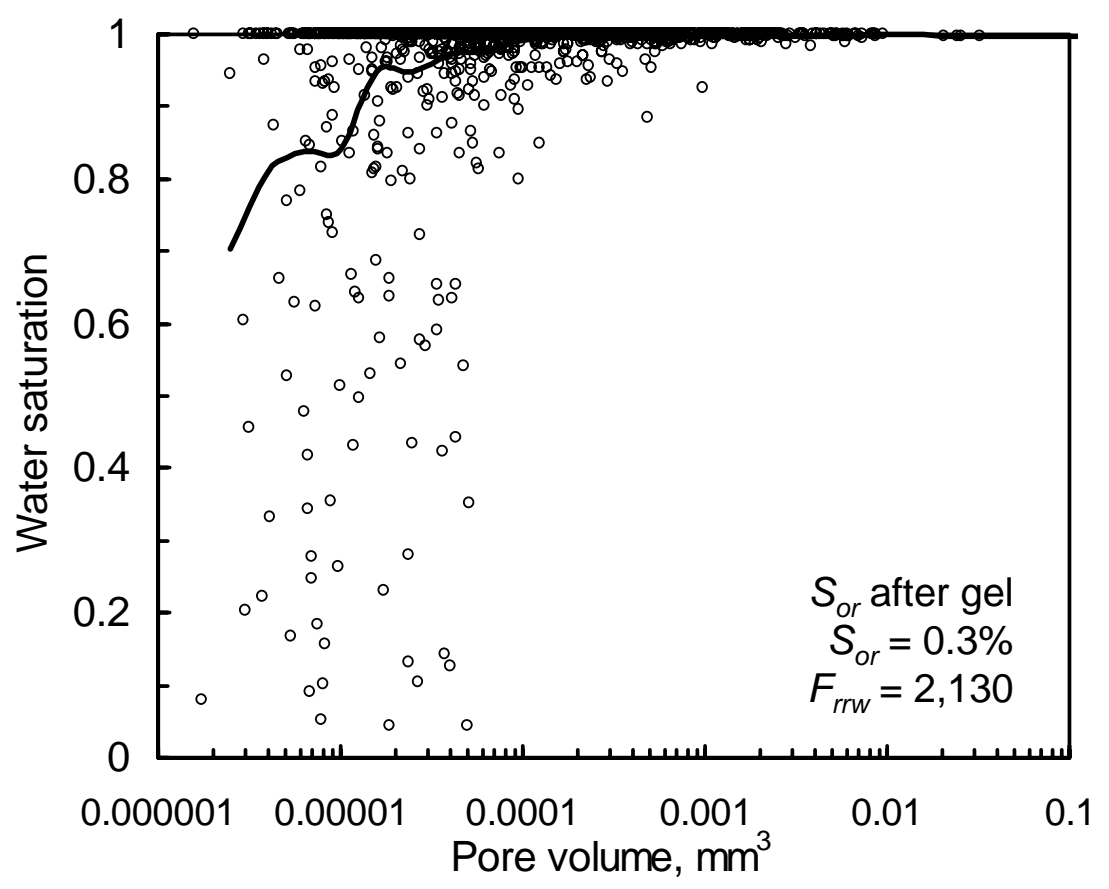

Fig. 33-Polyethylene @ $S_{\text {or }}$ after gel. 
The water residual resistance factor $\left(F_{r r w}\right)$ was 2,130. Based on the $S_{w}$ changes, the primary flow path for water is expected to be through the previously open oil paths, especially if little or no residual oil blocks the paths. However, if this were the case, $F_{r r w}$ would not be expected to be 89 times greater than $F_{\text {rro. }}$. On the other hand, the high water residual resistance factor could be explained if the paths closed up. Near the end of this chapter, we will suggest that paths open during oil injection by partial dehydration of the gel. During subsequent water injection, the paths could partially close when the gel re-hydrates.

\section{Connectivity of Phases}

Before Gel Placement, the Injected Phase Was Highly Connected. Using the new analysis, we determined the connectivity of the fluid phases in porous media. Not surprisingly, for all cases, nearly $100 \%$ of the injected phase was continuous or contained by the largest phase volume. This observation held regardless of the fluid that wetted the porous medium. (Details can be found in Ref. 2.) The fact that we could detect that nearly $100 \%$ of the injected phase was connected suggests that few very thin films were associated with the injected phase-whether it was the wetting phase or not. Since our voxel size was $4.1 \mu \mathrm{m}$, most films and connecting bridges must have been greater than $4.1 \mu \mathrm{m}$.

Most Residual Non-Wetting Blobs Were "Singlets". In Berea at $S_{\text {or }}$ before gel placement, 57\% of the residual oil blobs were "singlets," where each oil blob was associated with only one pore (Fig. 34). Similarly, in porous polyethylene at $S_{w r}$ before gel placement, $66 \%$ of the residual water blobs were singlets. These findings are consistent with previous microscopic analysis of residual oil in bead packs, where $65 \%$ of the blobs reportedly were singlets.

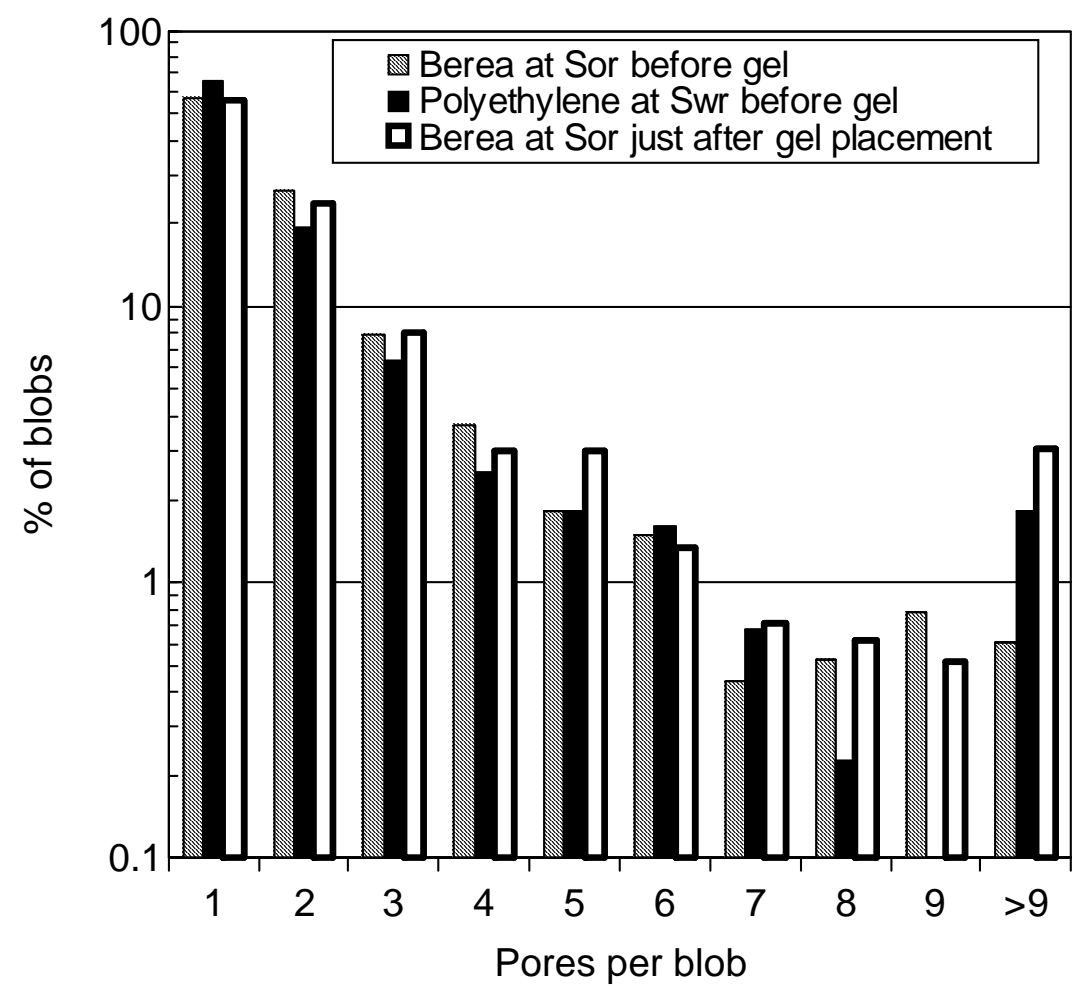

Fig. 34-Residual phase blob distributions. 
In Berea, we found $26 \%$ of the residual oil blobs were "doublets" (at $S_{\text {or }}$ before gel placement), where each blob was distributed between two pores (Fig. 34). Similarly, in porous polyethylene (at $S_{w r}$ before gel placement), 19\% of the residual water blobs were doublets. For comparison, Chatzis et al. ${ }^{19}$ quoted $20 \%$ of residual oil blobs were doublets in bead packs.

The fractions of blobs with greater numbers of pores per blob are shown in Fig. 34. The largest residual non-wetting-phase blob (before gel placement) involved 25 pores per blob in Berea and 20 pores per blob in porous polyethylene. In Berea, the largest oil blob $\left(0.00654 \mathrm{~mm}^{3}\right)$ accounted for $1.76 \%$ of the total residual water phase (within the small image volume). In polyethylene at $S_{w r}$, the largest water blob $\left(0.0204 \mathrm{~mm}^{3}\right)$ accounted for $4.15 \%$ of the total residual water phase.

In both Berea and polyethylene, the average pore size involved with triplets and doublets was about the same as that involved with singlets. For blobs with larger numbers of pores, the average pore size was typically two to three times the average pore size associated with the singlets.

Since oil was mobilized during gelant placement, we wondered whether the blob distribution was changed by the placement process. The blob distribution in Berea at $S_{\text {or }}$ immediately after gel placement is shown by the white bars in Fig. 34. A comparison with the hatched bars reveals that the distribution of blob sizes was little changed by the process of gel placement. The only significant difference was that gel placement induced the formation of a larger fraction of blobs that contained more than 9 pores $(0.6 \%$ before gel placement versus $3.1 \%$ just after gel placement).

Were Residual Wetting Blobs Connected by Thin Films? For a strongly-wetted porous medium, the residual wetting phase was expected to be nearly all connected. In other words, we expected a single water blob to exist at $S_{w r}$ in strongly water-wet Berea or a single oil blob to exist in strongly oil-wet polyethylene at $S_{o r}$. In polyethylene, the largest detected oil blob contained $36.2 \%$ of the total oil volume at $S_{\text {or } 1}$ and $46.1 \%$ of the total oil volume at $S_{\text {or } 2}$. Since the oil films were extremely thin (nanometer thicknesses) and our voxel size was $4.1 \mu \mathrm{m}$, we probably did not detect many of the connections between the residual oil blobs. The same logic likely applies to residual water blobs in Berea. The largest detected water blob accounted for $5.0 \%$ of the residual water in Berea at $S_{w r}$. Presumably, thin undetected water films connect most of the residual water blobs in Berea. Considering the results in the previous section, connecting films must be thicker when the wetting phase was injected than when it was residual.

After Gel, the Injected Phase Was Highly Connected. For all cases after gel placement, the largest detected blob for the injected phase contained a substantial portion of the total phase volume. In Berea at $S_{w r}$ after gel, the oil saturation was $71.3 \%$, and $96.1 \%$ of the injected oil was connected. This value emphasizes the widespread reduction of gel volume by oil throughout the image volume. Assuming that gel occupied all of the aqueous pore space when placed (63.7\% from Table 3), oil injection destroyed 55\% of the gel (35 saturation point increase in oil saturation). Fig. 28 suggests some resistance to gel destruction in the small- to moderate-sized pores (because many of these pores had post-gel water saturations that were greater than before gel). However, the figure also shows that for all size ranges, many pores had nearly the same saturations after gel as before gel. Presumably, gel formed in the aqueous pore space in most (if 
not all) pores. Therefore, oil injection caused widespread reduction in gel volume in most pores in order to reach $S_{w r}$ after gel (Fig. 26).

During water injection after gel placement in Berea, the final water saturation was $49.0 \%$, and $80.5 \%$ of the aqueous phase was contained within the largest blob. Although some water volume was contained in smaller blobs, we cannot discount the possibility that these blobs may be connected through thin undetected water films that follow pore walls. Also, our use of XMT cannot distinguish between free water and gel. Since the water saturation at $S_{w r}$ was $28.7 \%$ after gel placement, the final gel saturation may have been as high as $28.7 \%$. Assuming that the gel did not swell during final water injection, the free water saturation at $S_{\text {or }}$ after gel could have been at least $20.3 \%$ (i.e., $49.0 \%-28.7 \%$ ).

During oil injection after gel placement in polyethylene, the final oil saturation was $16.5 \%$, and $45.5 \%$ of the hexadecane oil was contained by the largest blob. Again, we suspect that most of the smaller blobs were connected by thin undetected oil films.

During water injection after gel placement in polyethylene, the final water saturation was 99.7\%, and $99.98 \%$ of that water was connected. Since $S_{w r}$ during the prior oil injection was $83.5 \%$, the final gel saturation may have been as much as $83.5 \%$ and the free water saturation may have been $16.2 \%$ (i.e., $99.7 \%-83.5 \%$ ).

After Gel, the Residual Phases Were Highly Connected. The most interesting observation during water injection after gel placement in Berea was that the residual oil was highly connected. $S_{\text {or }}$ after gel placement was $51.0 \%$, and $77.6 \%$ of that oil was contained within the largest oil blob. This blob was 122 times larger than the largest oil blob at $S_{\text {or }}$ before gel placement. This high degree of connection helps explain the relatively high permeability to oil after gel placement.

For water at $S_{w r}$ in Berea after gel placement, the water saturation was $28.7 \%$, and $25.7 \%$ of this water was included in the largest residual water blob. Since water was the wetting phase, we suspect that most (if not all) of the aqueous phase was actually connected, but that our XMT technique was simply not able to detect the thin film connections along the pore walls. Even so, it is interesting that the connected volume $\left(25.7 \%\right.$ of the total $\left.28.7 \% S_{w r}\right)$ was substantially larger than the connected volume noted at $S_{w r}$ before gel placement (5.0\% of the total $16.0 \% S_{w r}$ ). Perhaps with the higher $S_{w r}$ after gel placement, the connecting water film was thicker and easier to detect than before gel placement.

For oil at $S_{o r}$ in polyethylene after gel placement, the oil saturation was only $0.3 \%$, and $32.3 \%$ of this oil was included in the largest residual oil blob. Since oil was the wetting phase, we suspect that most (if not all) of the oil phase was actually connected, but that our XMT technique was simply not able to detect the thin film connections along the pore walls. In view of the low oil saturation and the difficulty in seeing the connecting water films in Berea, it is somewhat surprising that we could detect a relatively large residual oil blob in polyethylene.

For water at $S_{w r}$ in polyethylene after gel placement, $S_{w}$ averaged $83.5 \%$, and $99.8 \%$ of this water was connected. We suspect that this was probably one large gel blob. 
Higher Saturations Resulted in Greater Connectivity. Injection of the 20-cp gelant mobilized oil-decreasing the oil saturation for polyethylene and increasing the oil saturation for the image volume for Berea. The changes in connectivity qualitatively followed the trends expected from the saturation changes. In Berea, gelant injection caused oil saturation in the image volume to increase from $18.4 \%$ to $36.3 \%$, the largest oil blob grew from $1.76 \%$ to $11.8 \%$ of the total oil phase volume, and the largest water blob shrank from $97.9 \%$ to $95.0 \%$ of the total water phase volume. In polyethylene, gelant injection decreased oil saturation from $17 \%$ to $0.2 \%$, the largest oil blob shrank from $46.1 \%$ to $4.23 \%$, and the largest water blob grew from $99.8 \%$ to $99.985 \%$.

The correlation between oil saturation and blob connectivity continued to hold during oil injection after gel placement. In Berea, oil injection after gel placement caused oil saturation in the image volume to increase from $36.3 \%$ to $71.3 \%$, the largest oil blob grew from $11.8 \%$ to $96.1 \%$ of the total oil phase volume, and the largest water blob shrank from $95.0 \%$ to $25.7 \%$ of the total water phase volume. In polyethylene, oil injection after gel placement increased oil saturation from $0.2 \%$ to $16.5 \%$, the largest oil blob grew from $4.23 \%$ to $45.5 \%$, and the largest water blob contracted slightly from $99.985 \%$ to $99.78 \%$. In summary, the largest oil blob always grew when the oil saturation increased and shrank when the oil saturation decreased. Similarly, the largest water blob always grew when the water saturation increased and shrank when the water saturation decreased.

Properties of the Largest Oil Blob in Berea at $\boldsymbol{S}_{\text {or }}$ after Gel. At $S_{\text {or }}$ after gel placement in Berea, $77.6 \%$ of the oil in the image volume was contained in the largest residual oil blob. That blob had parts in $73 \%$ of the pores in the image volume (1,588 out of 2,176 pores). Thus, the blob was very widespread. As mentioned, it was 122 times larger than the largest oil blob that was present before gel placement. The pores that were involved with the largest oil blob had nearly the same distribution of pore sizes and water saturations as for all Berea pores in the image volume. For pores that participated with the largest oil blob, the average water saturation was $45 \%$, compared with $49 \%$ for all Berea pores in the image volume. The average pore size involved with the blob $\left(8.2 \times 10^{-4} \mathrm{~mm}^{3}\right)$ was somewhat larger than the average Berea pore $\left(3.5 \times 10^{-4} \mathrm{~mm}^{3}\right)$.

Why should gel allow such a large oil blob to exist? We speculated that the gel located in the extremities of individual pores (i.e., near pore walls, especially in the vicinity of greatest pore radius) might reduce the effective pore radius to more closely match the effective throat radius. Thus, the effective pore body/pore throat aspect ratio could be reduced to allow residual oil to remain connected through multiple pores. (In other words, with a lower aspect ratio, residual oil drops would be less inclined to snap off and become trapped as "singlets" in individual pores, as occurs at $S_{\text {or }}$ before gel placement.) This scenario is consistent with that suggested in Ref. 20. To test this hypothesis, we analyzed the largest oil blob (at $S_{o r}$ after gel placement) as if it were a porous medium (i.e., with the oil representing the pore space, and everything outside the oil blob acting as "rock"). We found the "pore bodies" in the oil blob had a size distribution that closely paralleled the distribution for the original Berea sandstone. The average and median "pore volumes" were $5.1 \times 10^{-4} \mathrm{~mm}^{3}$ and $1.8 \times 10^{-4} \mathrm{~mm}^{3}$, respectively, for the oil blob, and $6.2 \times 10^{-4} \mathrm{~mm}^{3}$ and $2.8 \times 10^{-4} \mathrm{~mm}^{3}$, respectively, for the original Berea.

The distributions of aspect ratios are compared in Fig. 35. Aspect ratio was defined as the effective pore radius divided by the effective throat radius. The effective pore radius was 
determined by assuming that the measured pore volume was spherical. The effective throat radius was determined by assuming that the measured throat area was circular. (In reality, although our pore volumes, throat areas, and shapes were known with reasonable accuracy, the pores were decidedly not spherical, and the throats were not circular.)

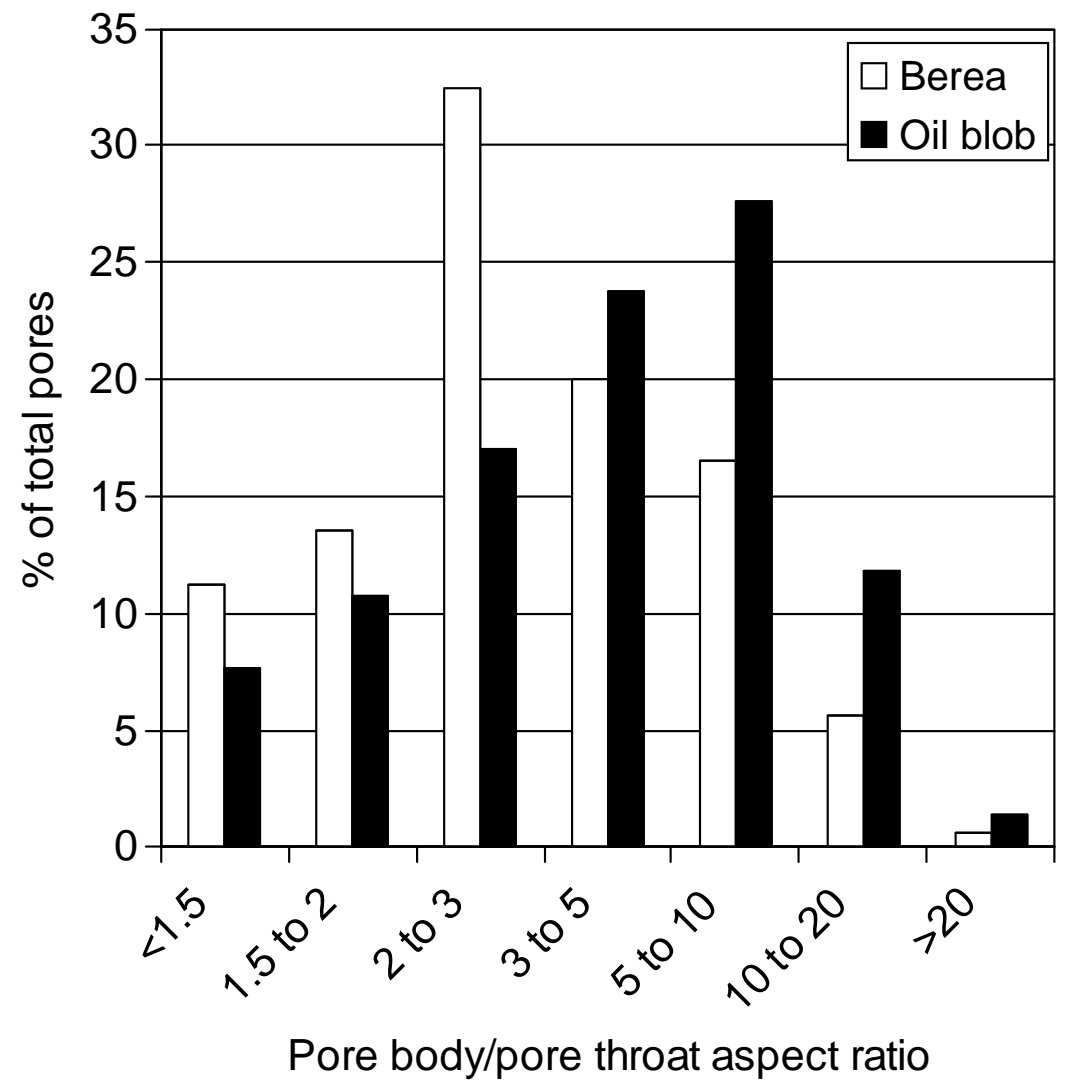

Fig. 35-Comparison of aspect ratios.

Contrary to our speculation, the gel did not reduce the effective pore body/pore throat aspect ratio. Instead, the average "aspect ratio" for the oil blob (5.5) was $31 \%$ greater than that for Berea sandstone (4.2). For Berea pores, the peak in the distribution occurs at values from 2 to 3. In contrast, for the oil blob, the distribution peaked at values from 5 to 10 .

The increase in aspect ratio associated with the presence of the gel might suggest that gel had a greater propensity to reside in pore throats than in pore bodies. However, the increased aspect ratio seems inconsistent with the existence of the large residual oil blob. With greater aspect ratios, why did the large oil blob not break up into many smaller blobs? A possible explanation is that water did not have access (or had limited access) to most of the pore throats after gel placement. With limited or no access, free water could not accumulate in pore throats to cause snap-off and form smaller oil blobs. The affinity of the gel to retain water could also explain why free-water films did not form and break up the largest oil blob. If gel absorbs the free water, little or no free water may be available to form films between oil drops. 
The distribution of coordination numbers for Berea and the largerst residual oil blob are compared in Fig. 36. Coordination number is the number of distinct exits from a given pore body. The average coordination number for "pores" in the oil blob (3.6) was $19 \%$ less than that for Berea sandstone (4.45). The peaks in the distributions occurred at a value of 3 in both cases. However, the oil blob had a much greater fraction of pores with low coordination numbers.

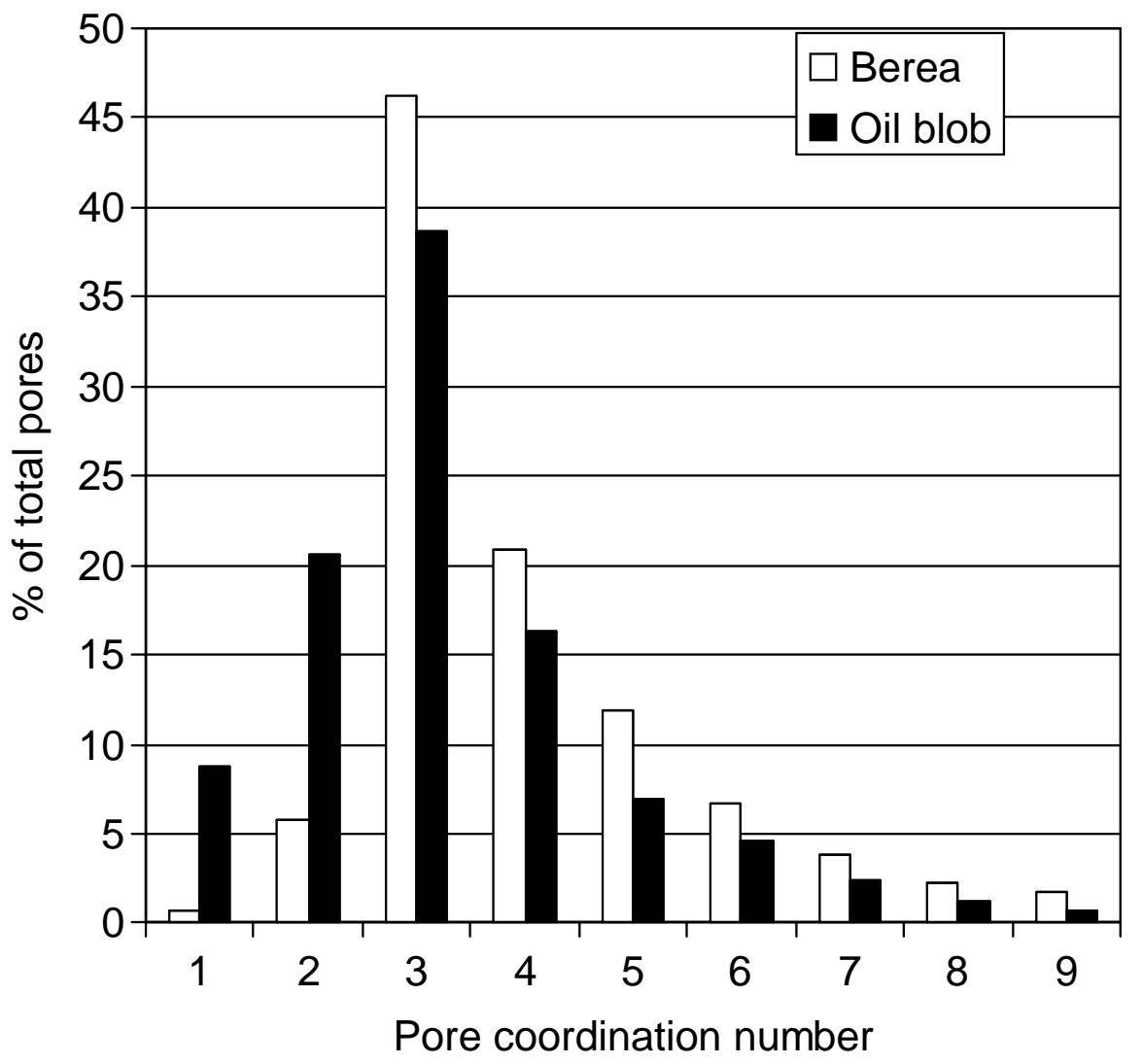

Fig. 36-Comparison of coordination numbers.

\section{Mechanistic Implications}

Water Injected First after Gel Placement. This section summarizes our current views of the mechanism for disproportionate permeability reduction for relatively "strong" (pore-filling) gels such as Cr(III)-acetate-HPAM. Immediately after placement and gelation, the water-based gel occupies all of the aqueous pore space. Residual oil may be trapped in pore centers in strongly water-wet rock such as Berea (Fig. 37). In strongly oil-wet porous media (e.g., porous polyethylene) low mobility "residual oil" may coat pore walls. If water or brine is injected after gel placement, it must flow through the gel itself (Fig. 37). Since the inherent permeability to water is in the microdarcy range for flow through the gel, a very large permeability reduction is observed. ${ }^{14}$ For rock with an initial permeability (before gel) around one darcy, the water residual resistance factor can be greater than 10,000. 

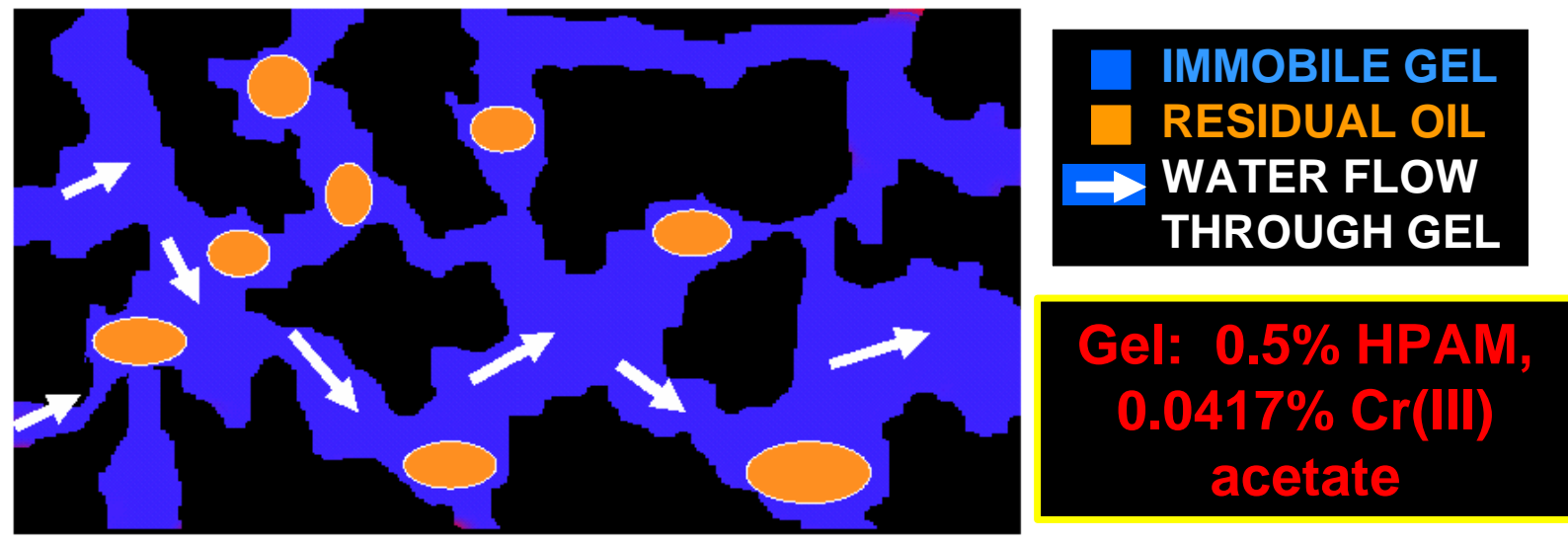

- $\mathrm{Cr}(\mathrm{III})$-acetate-HPAM gels fill all aqueous pore space.

Water must flow through the gel itself.

- Gel permeability to water is typically in the $\mu d$ range.

- Water residual resistance factor $\left(F_{r r w}\right)$ is typically $>10,000$.

Fig. 37—Water injected first after gel placement.

Oil Injected First after Gel Placement. This reduction created pathways for oil flow, thus restoring an important level of permeability to oil. Fig. 38 illustrates this process.

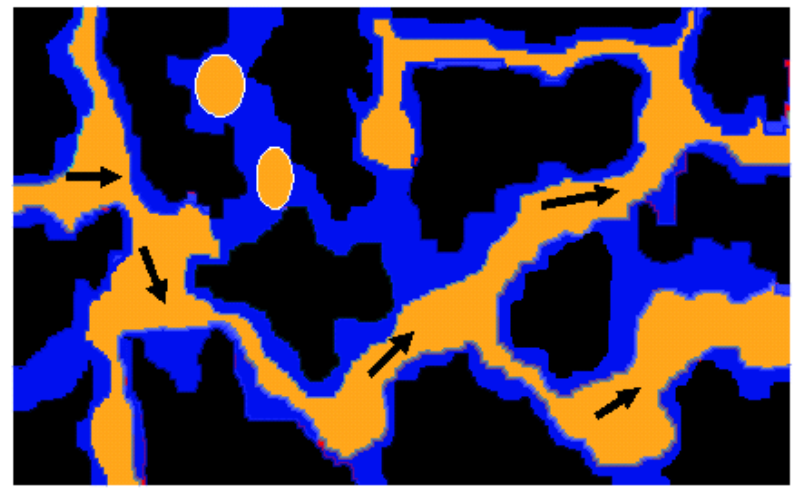

Berea $F_{\text {rro }}=15$

$S_{\text {gel }}=28.7 \%$

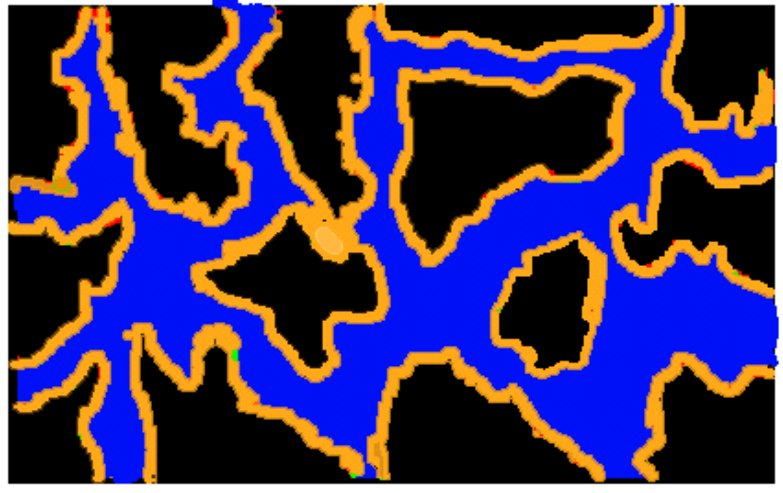

Polyethylene $F_{\text {rro }}=24$ $S_{g e l}=83.5 \%$

- Even with low pressure gradients, oil forces pathways through by destroying or dehydrating the gel.

- These oil pathways allow $k_{o}$ to be much higher than $\boldsymbol{k}_{w^{-}}$

- Even so, $k_{o}$ is lower than before gel placement.

Fig. 38-Oil injected first after gel placement. 
When oil is injected, how does this reduction in gel volume occur? Several possibilities come to mind, including oil (a) ripping through the gel, (b) concentrating or dehydrating the gel, (c) mobilizing the gel, or (d) chemically destroying the gel. Concerning the fourth possibility, our oil (hexadecane) is not reactive with any of the gel, brine, or rock components, so chemical destruction of the gel does not seem likely.

That leaves three mechanisms for active consideration. In one mechanism, oil ripped pathways through the gel. ${ }^{15,16,20}$ In the second mechanism, ${ }^{21-23}$ gel dehydrated (i.e., lost water and became more concentrated through compression.) Concerning the third mechanism, we have never observed gel production from our cores. However, it is possible that gel particles that were too small for us to detect were displaced from the core.

Our recent analysis supports the dehydration mechanism over the ripping or gel mobilization mechanisms. In particular, the apparent reduction in gel saturation during oil injection was insensitive to pore size in Berea (Fig. 26) and was greatest in small pores in porous polyethylene (Fig. 32). If ripping or gel mobilization were the dominant mechanisms, losses in gel volume should have been greatest in the largest pores. To explain, if gel failure (i.e., ripping or gel extrusion) occurred at a gel-rock interface or within the gel, a force balance suggests that the pressure gradient for gel failure should be inversely proportional to the pore radius. ${ }^{24,25}$ Thus, for a given applied pressure gradient, gel failure should occur dominantly in larger pores. Since this did not occur, our results argue against the ripping or gel mobilization mechanisms.

In contrast, the observed XMT results could be consistent with the dehydration mechanism. With a fixed pressure gradient applied through the porous medium, gel in all pores could be "squeezed" or dehydrated to the same extent, regardless of pore size.

Water Following Oil Flow after Gel Placement in Berea. If an oil zone that was treated with gel eventually waters out, our results indicate that the water residual resistance factors will be substantially greater than the residual resistance factors observed during the previous oil flow. What mechanism do we envision to explain this behavior? In strongly water-wet Berea sandstone, our results indicate that a significantly higher level of residual oil is trapped during water flow (Fig. 30 and Table 3). Even without the presence of gel, higher oil saturations necessarily lead to lower permeabilities to water. With higher oil saturations, water pathways would be more constricted. Considering the large ratio of $F_{r r w} / F_{r r o}(81)$, the primary pathways for water flow could conceivably be either thin water films and/or through the gel itself (Fig. 39).

When water was reinjected to establish $S_{\text {or }}$ after gel placement, gels conceivably could rehydrate and swell to some extent. Did this occur? Table 3 indicates that the water saturation (or the combined water plus gel saturation) in Berea changed from $63.7 \%$ immediately after gel placement, to $28.7 \%$ at $S_{w r}$ after gel to $49 \%$ at $S_{o r}$ after gel. If the decrease in $S_{w}$ from $63.7 \%$ to $28.7 \%$ during oil injection was entirely due to dehydration, the gel would have been concentrated by an average factor of 2.2. If the increase in $S_{w}$ from $28.7 \%$ to $49 \%$ during water injection was entirely due to rehydration, the gel would have swelled by a factor of 1.7 . 


\section{WATER FOLLOWING OIL AFTER GEL PLACEMENT WHY IS $F_{r r w}$ SO HIGH IN BEREA SANDSTONE?}
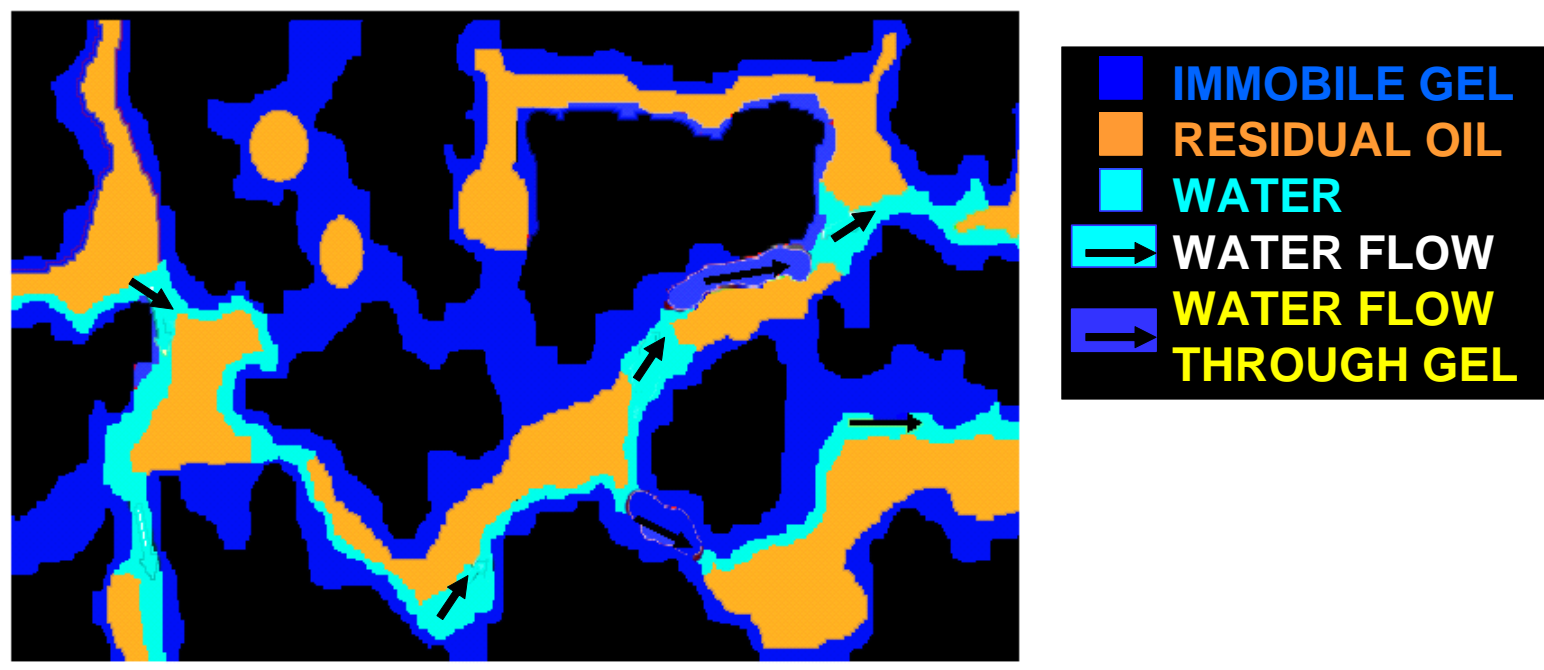

Gel traps more oil. $S_{o r}=51 \%, S_{g e l} \sim 29 \%, S_{w} \sim 20 \%$.

- Increased $S_{\text {or }}$ caused lower $k_{w^{\prime}} F_{r r w}=1,220$ (81X $F_{\text {rro }}$ !)

- ARE WATER FLOW PATHS VERY THIN FILMS?

O MUST WATER FLOW THROUGH THE GEL?

Fig. 39—Water flow following oil injection after gel placement in Berea.

Water Following Oil Flow after Gel Placement in Polyethylene. In contrast to the behavior in strongly water-wet Berea, gel does not appear to trap high levels of residual oil during water flow following oil flow after gel placement (Table 3 and Fig. 33). Nevertheless, our results in polyethylene indicated that the water residual resistance factors were still substantially greater than the residual resistance factors observed during the previous oil flow $\left(F_{r r w} / F_{r r o}=89\right)$. Similar to the case for Berea, the primary pathways for water flow could be either thin water films and/or through the gel itself (Fig 40).

Table 3 also indicates that the water saturation (or the combined water plus gel saturation) in polyethylene changed from $99.8 \%$ immediately after gel placement, to $83.5 \%$ at $S_{w r}$ after gel to $99.7 \%$ at $S_{\text {or }}$ after gel. If the decrease in $S_{w}$ from $99.8 \%$ to $83.5 \%$ during oil injection was entirely due to dehydration, the gel would have been concentrated by an average factor of $16 \%$-much less than observed in Berea. If the increase in $S_{w}$ from $83.5 \%$ to $99.7 \%$ during water injection was entirely due to rehydration, the gel would have swelled almost entirely back to its original size. Additional evidence of rehydration comes from the $F_{\text {rro }}$ and $F_{\text {rrw }}$ values for gel in the polyethylene core. The residual resistance factor increased from 24 during oil injection to 2,130 during brine injection. Since our earlier discussion suggested that oil and water may largely follow the same path, the high $F_{r r w}$ value could be explained by gel rehydration partially closing the path. 


\section{WATER FOLLOWING OIL AFTER GEL PLACEMENT (IN POLYETHYLENE)}
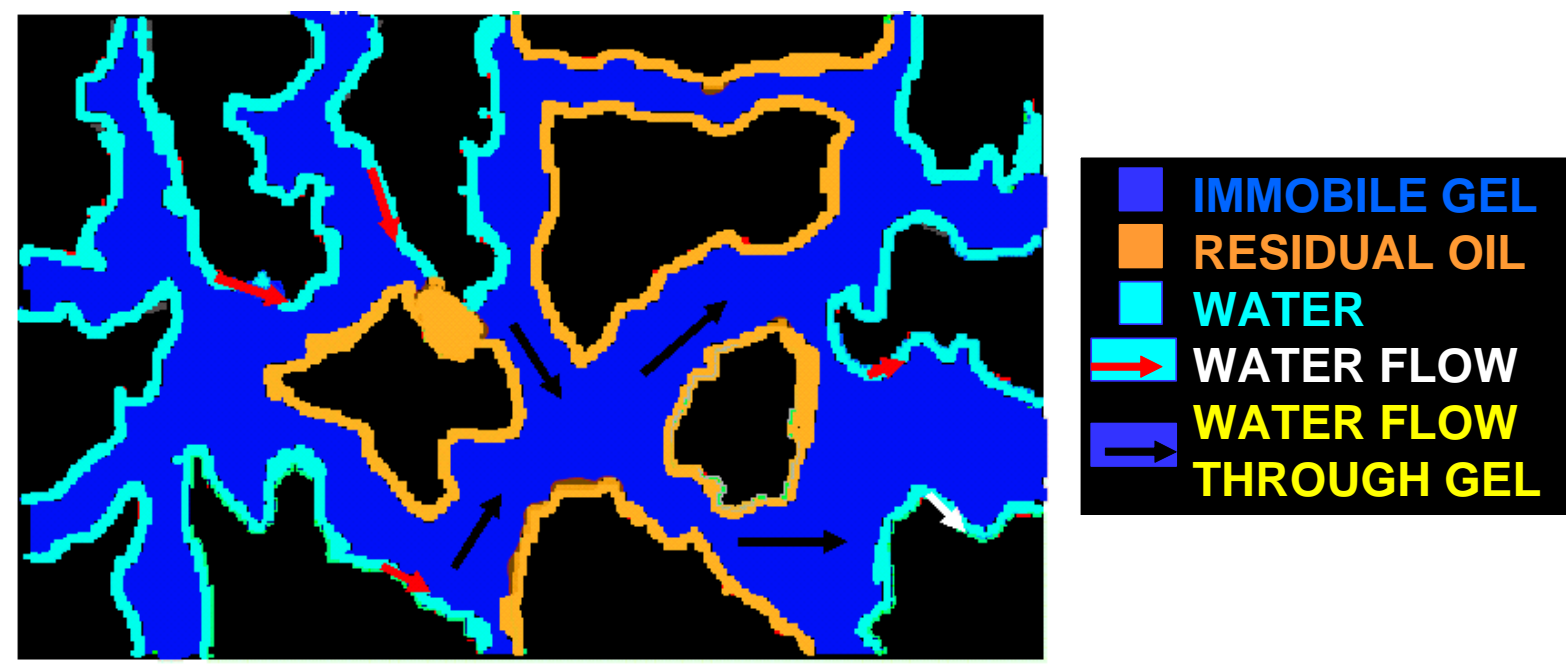

- Gel does not trap more oil. $S_{o r}=0.3 \%, S_{g e l} \sim 84 \%, S_{W} \sim 16 \%$.

- Water basically displaces the oil. $F_{\text {rrw }}=2,130$. (89X $F_{\text {rro }}$ !)

- Does gel re-hydrate and thus thin the water paths?

- Is water required to flow through the gel?

Fig. 40-Water flow following oil injection after gel placement in oil-wet polyethylene.

\section{Comparison with Results from the University of Kansas}

Researchers at the University of Kansas have strongly advocated dehydration as the dominant mechanism for re-establishing oil pathways through the gel. ${ }^{21-23}$ In their most recent work, ${ }^{22}$ they studied disproportionate permeability reduction provided by $\mathrm{Cr}$ (III)-acetate-HPAM gels in 4- to 5-darcy sandpacks. They found that "selectivity" $\left(F_{r r w} / F_{r r o}\right)$ increases with increasing polymer concentration. Using tracer studies with stilbene, they confirmed our finding of a high degree of connection for the oil phase. ${ }^{5,26}$ They also confirmed our finding that $S_{\text {or }}$ in strongly water-wet porous media was significantly higher after gel placement than before gel placement. ${ }^{5,15,16}$

As mentioned, the University of Kansas researchers argue exclusively in favor of a dehydration mechanism. However, substantial confusion exists about their definition of "dehydration." At least three different definitions of "dehydration" appear in their latest paper. ${ }^{23}$ The definition that we accept is: "Gel dehydration is a process of removing water from the GEL by imposing a pressure gradient on the gel." Necessarily, the polymer must become more concentrated by the dehydration process. Recognizing this as "Definition 1," Ref. 23 contains at least two other definitions. A second definition (from Tables 4-6 in Ref. 23) is: [increase in oil saturation during oil injection after gel placement] relative to [gel saturation immediately after gel placement]. The 
third definition is that "dehydration" simply means oil injection. This usage is extremely common throughout Ref. 23.

Ironically, a detailed analysis of their data ${ }^{23}$ indicates that the ripping and gel displacement mechanisms dominate over the dehydration mechanism. Analysis of Tables 5 and 6 in Ref. 23 reveal that the process of oil injection concentrated the gel by factors ranging from 1.24 to 2.54. So in most cases, the gel was not really concentrated all that much (certainly not by the factors of 20 or more that we see when gels are extruded through fractures ${ }^{27}$ ).

A key revelation from analysis of the data in Ref. 23 was that a significant amount of polymer was produced with the effluent during oil injection. Typically more than half the polymer was recovered! This indicates that a gel destruction or removal mechanism other than dehydration was very important-roughly equally in importance along with dehydration. Thus, removal of polymer from the core played an important role in establishing oil pathways and that removal of this polymer was not directly tied to dehydration. Instead, gel destruction or removal might be caused by (1) oil ripping the gel apart so it is basically just a polymer solution or (2) displacing gel from the core as very small particles (too small to detect).

To quantify the relative importance of dehydration versus the destruction/displacement mechanism, consider experiment TN003 from Ref. 23. The "fraction of gel dehydrated" was listed as $68.5 \%$ and fraction of polymer recovered was $45 \%$ (in Tables 4 and 5 of Ref. 23). In reality, oil injection created opened space in the gel equivalent to $59.7 \%$ of the original pore space (87.1-27.4 from Table 8 of Ref. 23). Recovery of $45 \%$ of the polymer suggests that $65.6 \%$ of the pore space that was opened by oil injection (i.e., $0.45 \times 87.1 / 59.7)$ was actually caused by destruction or removal of the gel—NOT by dehydration. Performing these calculations for all cases in Ref. 23 shows that destruction/removal of gel was AT LEAST as important as dehydration.

A close comparison of Tables 5 and 6 in Ref. 23 indicates that raising the oil-flooding pressure gradient from 20 to $50 \mathrm{psi} / \mathrm{ft}$ caused no apparent additional dehydration. (In all cases, the average remaining polymer concentration (in the core) decreased when the pressure gradient was increased from $20 \mathrm{psi} / \mathrm{ft}$ to $50 \mathrm{psi} / \mathrm{ft}$.) Instead, only the gel destruction/removal mechanisms were significant.

In summary, despite claims in support of dehydration, the data in Ref. 23 supports ripping or gel displacement mechanisms over a dehydration mechanism. We note that the permeability of the sandpacks were from 4 to 5 darcys in the work at the University of Kansas. In contrast, our Berea core had a permeability of 0.47 darcys. One would expect ripping or gel displacement mechanisms to become more important as the permeability increases for strongly water-wet porous media. Consequently, it is quite conceivable that the dehydration mechanism dominated in our 0.47-darcy Berea, while the ripping or gel displacement mechanisms dominated in the sandpacks investigated at the University of Kansas.

\section{Conclusions}

In previous work, we used X-ray computed microtomography to determine why a $\mathrm{Cr}(\mathrm{III})$ acetate-HPAM gel reduces permeability to water more than that to oil in strongly water-wet 
Berea sandstone and strongly oil-wet porous polyethylene cores. Our X-ray images were reanalyzed using a different method for segmenting the fluids (i.e., differentiating between water and oil). The following conclusions were reached.

1. During the transition from $S_{w r}$ to $S_{o r}$ in Berea before gel placement, pores in all detected size ranges experienced significant gains in water saturation. Pore size did not significantly influence the extent of the transition.

2. In contrast, in polyethylene before gel placement, oil was largely immobile in smaller pores.

3. Injection of our 20-cp gelant mobilized oil in both porous media even though the pressure gradients during gelant placement were less than those during previous floods.

4. Immediately after gel placement, an extremely high resistance $\left(F_{r r w}>10,000\right)$ to water flow occurs (in either Berea or polyethylene), presumably because impermeable gel occupies nearly all of the aqueous pore space.

5. During oil flow after gel placement in Berea, much of the gel was destroyed or experienced a reduction in volume, thus leading to a relatively high permeability to oil $\left(F_{r r o}=15\right)$. A 55\% reduction (on average) in gel volume occurred in pores of all detected size ranges. Gel volume was most likely to be reduced in pores that experienced the greatest saturation changes during floods before gel placement. After gel placement, $86.1 \%$ of the pores had higher $S_{w r}$ values than before gel. Presumably, gel accounted for this increase. The gel that remained was widely distributed.

6. At $S_{\text {or }}$ after gel placement in Berea, $93.3 \%$ of the pores had higher oil saturations than at $S_{\text {or }}$ before gel placement. The overall $S_{\text {or }}$ in Berea jumped from 18.4\% before gel placement to $51 \%$ after. The greater level of trapped oil greatly restricted water flow $\left(F_{r r w}=1,220\right)$. A wide range of saturation changes occurred for all pore sizes, and the average saturation change was insensitive to pore size.

7. In polyethylene, reduction in gel volume occurred mainly in small pores. Overall, oil injection apparently reduced gel volume by only $16.3 \%$. However, in pores smaller than $10^{-4}$ $\mathrm{mm}^{3}$, gel volume was reduced by $63.5 \%$.

8. The above observations suggest that reduction in gel volume was probably caused by a dehydration mechanism rather than a gel-ripping mechanism.

9. In polyethylene, the overall $S_{\text {or }}$ was significantly lower after gel placement than before gel placement $(0.3 \%$ versus $17.0 \%)$. Thus, oil trapping could not explain the large disproportionate permeability reduction seen in porous polyethylene $\left(F_{r r w} / F_{r r o}=2,130 / 24=89\right)$. Gel rehydration provides a viable explanation.

10. Before gel placement, at least $97.9 \%$ of the injected phase (oil or water) was connected.

11. Before gel placement, most residual non-wetting blobs were "singlets"-i.e., isolated within individual pores.

12. Changes in blob connectivity qualitatively followed the trends expected from the saturation changes. The largest oil blob always grew when the oil saturation increased and shrank when the oil saturation decreased. Similarly, the largest water blob always grew when the water saturation increased and shrank when the water saturation decreased.

13. In Berea at $S_{\text {or }}$ after gel placement, $77.6 \%$ of the residual oil was contained within the largest blob. This blob was 122 times larger than the largest oil blob at $S_{o r}$ before gel placement. Based on consideration of aspect ratios, we were surprised that this large blob could exist. The affinity of gel for water may have limited the formation of water films that would be needed to break the large oil blob into small blobs. 
14. Careful analysis of results during oil injection into gel-treated sandpacks (4- to 5-darcys) at the University of Kansas ${ }^{23}$ indicated that ripping or gel displacement mechanisms dominate over dehydration. One would expect ripping or gel displacement mechanisms to become more important as the permeability increases for strongly water-wet porous media. Consequently, it is quite conceivable that the dehydration mechanism dominated in our 0.47-darcy Berea, while the ripping or gel displacement mechanisms dominated in the sandpacks investigated at the University of Kansas. 


\section{PLUGGING FRACTURES: CEMENT VERSUS GELS}

Since cement is the most commonly used material for water shutoff, we wish to know when gels are preferred over cements during water shutoff applications. Cement is certainly expected to show mechanical and thermal stability that is superior to that of gels. However, gels are expected to penetrate much farther and into much tighter voids and fractures than cement. We wish to quantify the conditions under which these expectations hold.

In reviewing the cement literature, ${ }^{28,29}$ it is evident that the time interval is relatively short between cement mixing and when pumping becomes impractical. Although cement thickening or set times over 24 hours have been reported, typical set times are only a few hours. ${ }^{28-30}$ This fact significantly limits the volume of cement pumped and the distance of cement penetration. For gels, gelation times commonly range from an hour to a day. However, even after gelation, some gels can be extruded long distances into fractures and voids. ${ }^{27,31,32}$ Cases where gel were injected for one month have been reported. ${ }^{31,32}$

\section{Effective Viscosity}

Literature values (page 148 of Ref. 28) for the viscosity of cement slurries commonly were measured at two shear rates $\left(510 \mathrm{~s}^{-1}\right.$ and $\left.1020 \mathrm{~s}^{-1}\right)$ using a Fann viscometer. Fig. 41 plots measurements reported for Class $\mathrm{H}$ (solid triangles and solid line) and Class $\mathrm{G}$ (open triangles and dashed line) cement slurries. The cement slurries show shear-thinning behavior, with powerlaw exponents reportedly from 0.1 to 0.36 . (In Fig. 41, the power-law exponent, $n$, for a given curve would be one plus the slope of the curve. $n=1$ indicates Newtonian behavior.) For comparison, we measured the apparent viscosity of Class B cement by forcing the cement slurry through a 2.9-mm-ID tube at various rates (solid circles in Fig. 41). A regression indicated a power-law exponent around 0.65 , qualitatively confirming the shear-thinning nature of cement slurries. However, multiple viscosity measurements made over a broader range of shear rates reveal less extreme shear-thinning than that suggested by the limited two-point Fann measurements. Fig. 41 also shows apparent viscosities for Class B cement slurry in a 1.9-mm-ID tube (open circles).

For comparison, Fig. 41 also plots viscosities for a freshly prepared 1X [0.5\% Alcoflood 935 HPAM, $0.0417 \% \mathrm{Cr}(\mathrm{III})$ acetate, $\left.1 \% \mathrm{NaCl}, 0.1 \% \mathrm{CaCl}_{2}\right]$ gelant (open diamonds). These viscosities were measured using a Paar-Physica UDS-200 viscometer and exhibit low, nearNewtonian values $(n=0.92)$. Fig. 41 also plots apparent viscosities for a 1-day-old $1 \mathrm{X}$ formed gel (thick solid line). This relation was taken from Ref. 33 and describes behavior when the gel was extruded through fractures or tubes using a wide range of rates. In this case, extreme shearthinning was noted, the power-law exponent was 0.05 , and the pressure gradients during gel extrusion were almost independent of flow rate. 


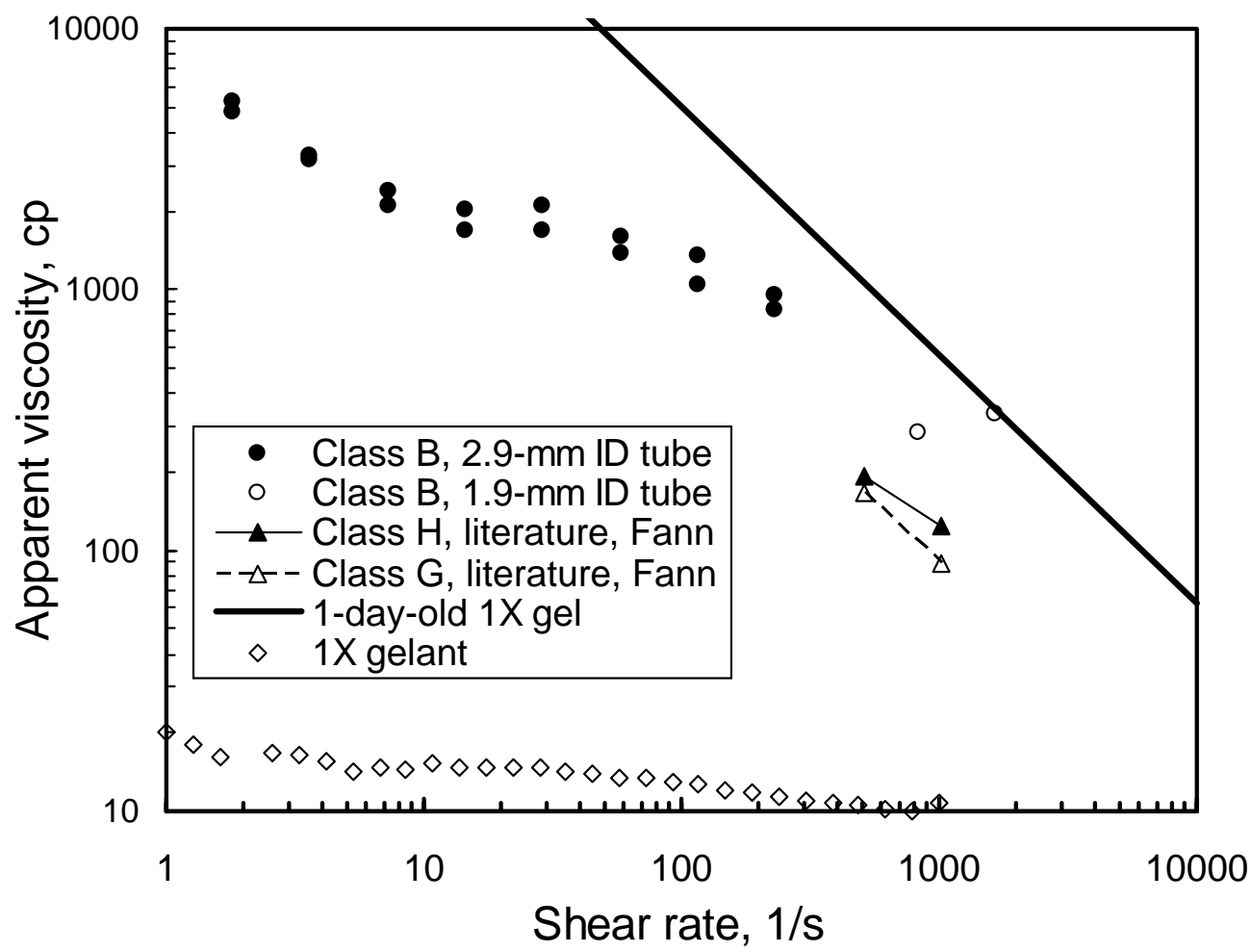

Fig. 41—Apparent viscosities for gelant, gel, and various cement slurries.

\section{Yield Stress}

Cement slurries reportedly behave as Bingham plastics and exhibit a yield stress. ${ }^{28}$ For the Class $\mathrm{H}$ and $\mathrm{G}$ cement slurries from Fig. 41, the yield stresses were 147 and $165 \mathrm{lbf} / 100 \mathrm{ft}^{2}$, respectively. If a yield stress is strictly required to initiate flow, then a force balance can be used to estimate the minimum pressure gradient needed for flow as a function of aperture (i.e., for a tube or fracture). In Fig. 42, the solid circles and dashed line plot this data for cement slurry with a yield stress of $165 \mathrm{lbf} / 100 \mathrm{ft}^{2}$. For comparison, the open circles and thick solid line show the behavior observed experimentally for our 1-day-old $1 \mathrm{X} \mathrm{Cr}(\mathrm{III})$-acetate-HPAM gel. ${ }^{25}$

Fig. 42 suggests that a cement slurry should have little problem in penetrating into fractures or tubes with apertures as small as $1 \mathrm{~mm}$. However, our experimental evidence indicates greater limitations than those suggested by Fig. 42. For example, Class B cement slurry showed steadystate flow through a 1.9-mm-ID tube for shear rates from 1,000 to 2,000 $\mathrm{s}^{-1}$ (open circles in Fig. 41). More specifically, during slurry injection at $825 \mathrm{~s}^{-1}\left(16,000 \mathrm{~cm}^{3} / \mathrm{hr}\right.$ or $\left.444,000 \mathrm{ft} / \mathrm{d}\right)$, the pressure gradient was stable at $10.9 \mathrm{psi} / \mathrm{ft}$ (equivalent to $283 \mathrm{cp}$ in Fig. 41). However, when the injection rate was reduced to $8,000 \mathrm{~cm}^{3} / \mathrm{hr}$, pressure gradients rose continuously to high values (not shown in Fig. 41). Raising the rate back to at $16,000 \mathrm{~cm}^{3} / \mathrm{hr}$ re-established a stable pressure gradient of $10.9 \mathrm{psi} / \mathrm{ft}$. Subsequent lowering of the rate to $8,000 \mathrm{~cm}^{3} / \mathrm{hr}$ again resulted in progressive plugging. This rate-dependent phenomenon is not described by yield-stress, Bingham-plastic, or shear-thinning explanations. Achieving a flux of $444,000 \mathrm{ft} / \mathrm{d}$ in a $100-\mathrm{ft}-$ high, two-wing, 2-mm-wide fracture would require a slurry injection rate of 72 barrels per minute (BPM). In field applications, cement slurry injection rates usually do not exceed 10 BPM 
for primary cementing ${ }^{28-30}$ and 2 BPM for remedial cementing. ${ }^{30}$ Therefore, under practical $^{3}$ conditions, we do not expect cement slurries to penetrate significantly into fractures or void spaces with apertures of $2 \mathrm{~mm}$ or less.

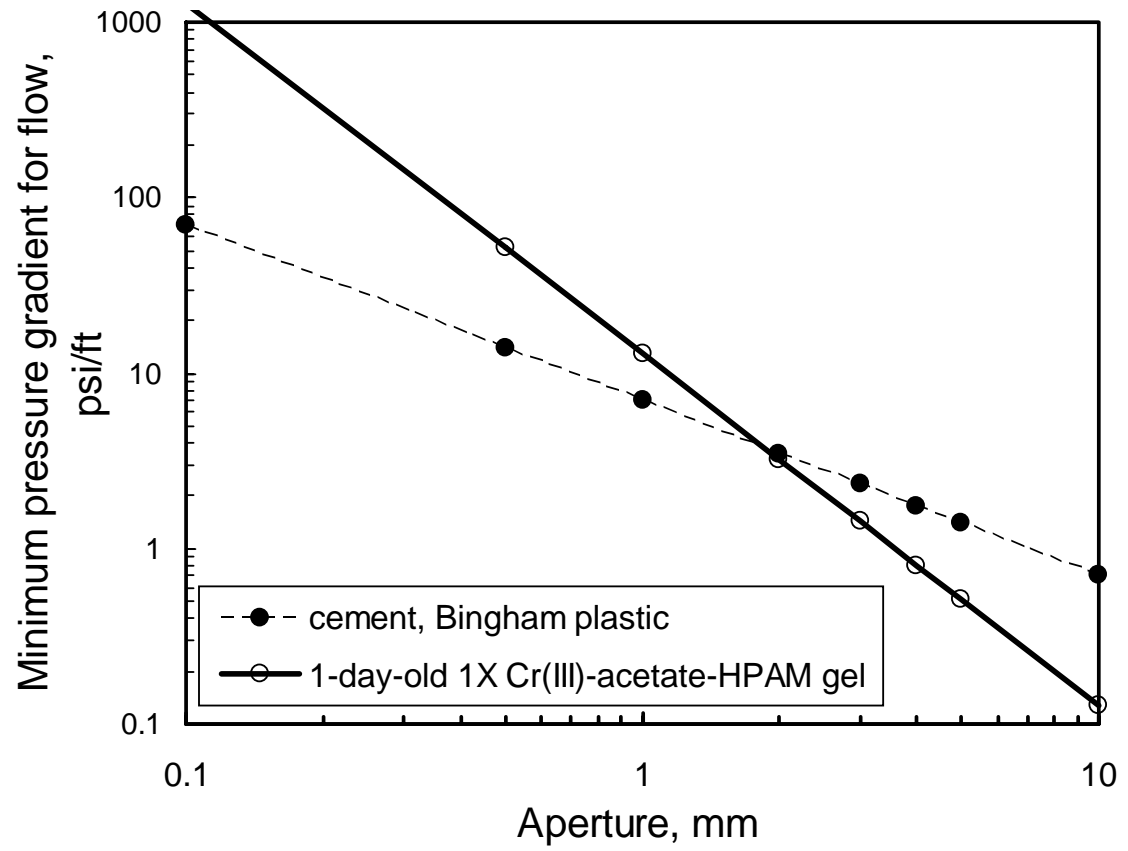

Fig. 42-Minimum pressure gradient for flow for cement and formed gel.

The latter conclusion is consistent with our experiments where Class $\mathrm{B}$ and $\mathrm{H}$ cement slurries were extruded through fractured Berea cores. Fig. 43 shows results from three experiments where cement slurries were extruded through 4-mm-wide fractures in Berea cores. The results reveal progressive plugging, especially after one fracture volume of slurry injection. Why were pressure gradients stable during extrusion through 2.9-mm-ID tubes (Fig. 41) but not in 4-mmwide fractures? The probable answer is that water can leak off through the fracture faces, create a filter cake that restricts flow, and ultimately lead to a screen out. In contrast, this process is less likely to happen in a tube since water cannot leak off.

The bottom line is that cement should not be expected to penetrate very far into fractures or voids with apertures of $4 \mathrm{~mm}$ or less. In contrast, formed gels can extrude fairly readily into fractures that are at least 0.5-mm wide (solid line in Fig. 42). Partially formed gels exhibit lower pressure gradients and may be able to penetrate into even tighter fractures. ${ }^{34}$ Of course, gelants (i.e., gel formulations before reaching the gelation time) flow readily through virtually any open fracture and most porous media of moderate to high permeability. ${ }^{14}$ 


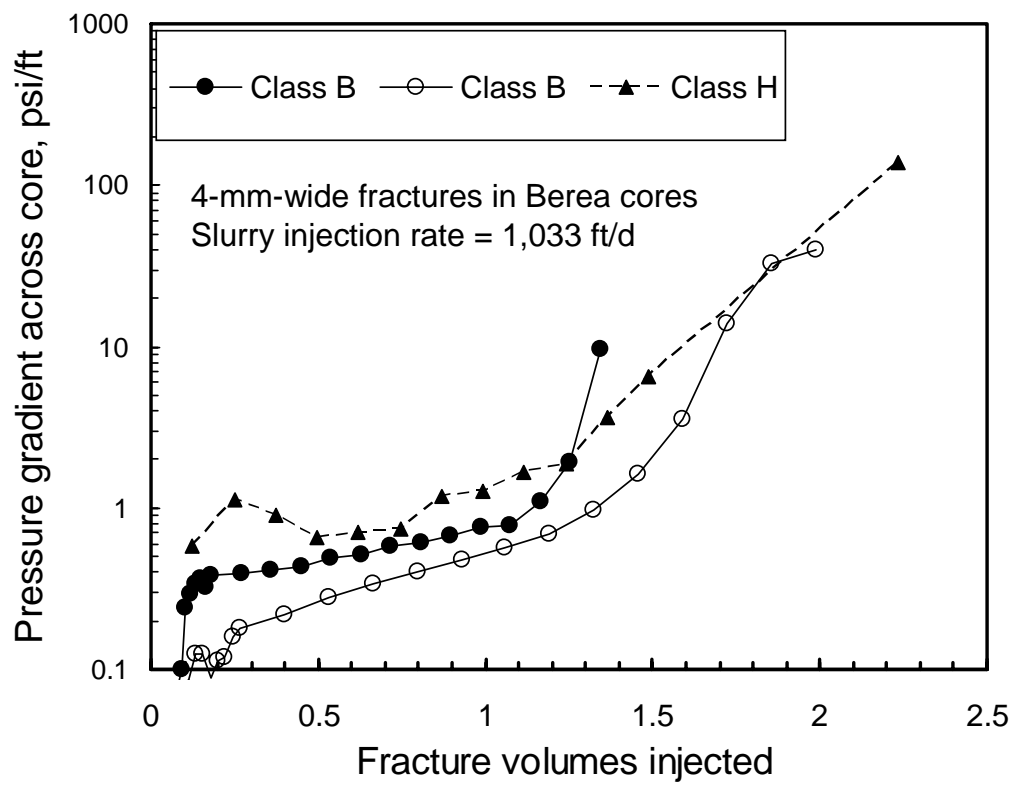

Fig. 43—Pressure gradients during cement slurry extrusion through 4-mm-wide fractures.

Incidentally, micro-fine cements have been used in place of more coarsely ground cements (e.g., Class $\mathrm{H}$ ) to allow penetration into tighter voids and fractures. However, because these micro-fine cements are composed of smaller particles, the set times for the cement slurries tend to be significantly shorter (i.e., 1/3) than those of conventional cements. ${ }^{30}$

\section{Ability to Plug Fractures}

For the experiments described in Fig. 43, brine was injected after cement placement and curing to establish how effectively the fractures were plugged. Special fittings and ports allowed the collection of the fluid that flowed through the porous rock (matrix) separate from fluid that flowed through the fracture. In all cases, the 3.8-cm-high fractures were completely plugged. All injected brine was forced to flow only through the porous Berea. Even with brine pressure gradients up to $235 \mathrm{psi} / \mathrm{ft}$, there was no evidence that the cement in the fracture was breached. In contrast, the highest breaching pressure gradient that we have observed for gel in a 4-mm-wide fracture is $26 \mathrm{psi} / \mathrm{ft}^{25}$

In one case described in Fig. 43, the 122-cm-long fractured core was split open after the experiment. Cement filled the entire length, width, and height of the fracture. During the process of forcing the cemented fracture open, the point of failure was at the cement-rock interface for more than $95 \%$ of the fracture. Thus, the cement-cement bond and the rock-rock bond were generally stronger than the cement-rock bond.

\section{Gravity Segregation}

During one experiment, the outlet end of the fracture was open so we could observe flow out of the vertically oriented 3.8-cm-high fracture. First breakthrough of the cement slurry was noted at 0.75 fracture volumes. This cement breakthrough occurred in the bottom part of the fracture. After breakthrough, the level of cement in the fracture gradually rose during the next 1.3 fracture 
volumes of injection until the entire 3.8-cm-high fracture was filled with cement. Thus, gravity segregation was evident during the placement process.

When cement slurry is injected into a vertical fracture to displace a less dense fluid, the orientation of the displacement front will be near vertical if viscous forces dominate over gravity forces. The displacement front will be near horizontal if gravity forces dominate over viscous forces. If viscous and gravity forces are of the same magnitude, the orientation of the displacement front will lie somewhere in between. The gravity number, $G$, provides a measure of the ratio of viscous to gravity forces.

$G=k \Delta \rho g \sin \theta /\left[1.0133 \times 10^{6} \mu u\right]$

In this equation, the parameters are expressed in Darcy units. Fig. 44 plots the minimum slurry injection rate into a 100-ft-high two-wing fracture so that viscous forces match gravity forces. Two slurry viscosities are considered, $100 \mathrm{cp}$ and 1,000 cp. The slurry density is about twice that of water. In order for the displacement front to be near vertical, the slurry injection rate must be several times the values indicated by the curves in this plot.

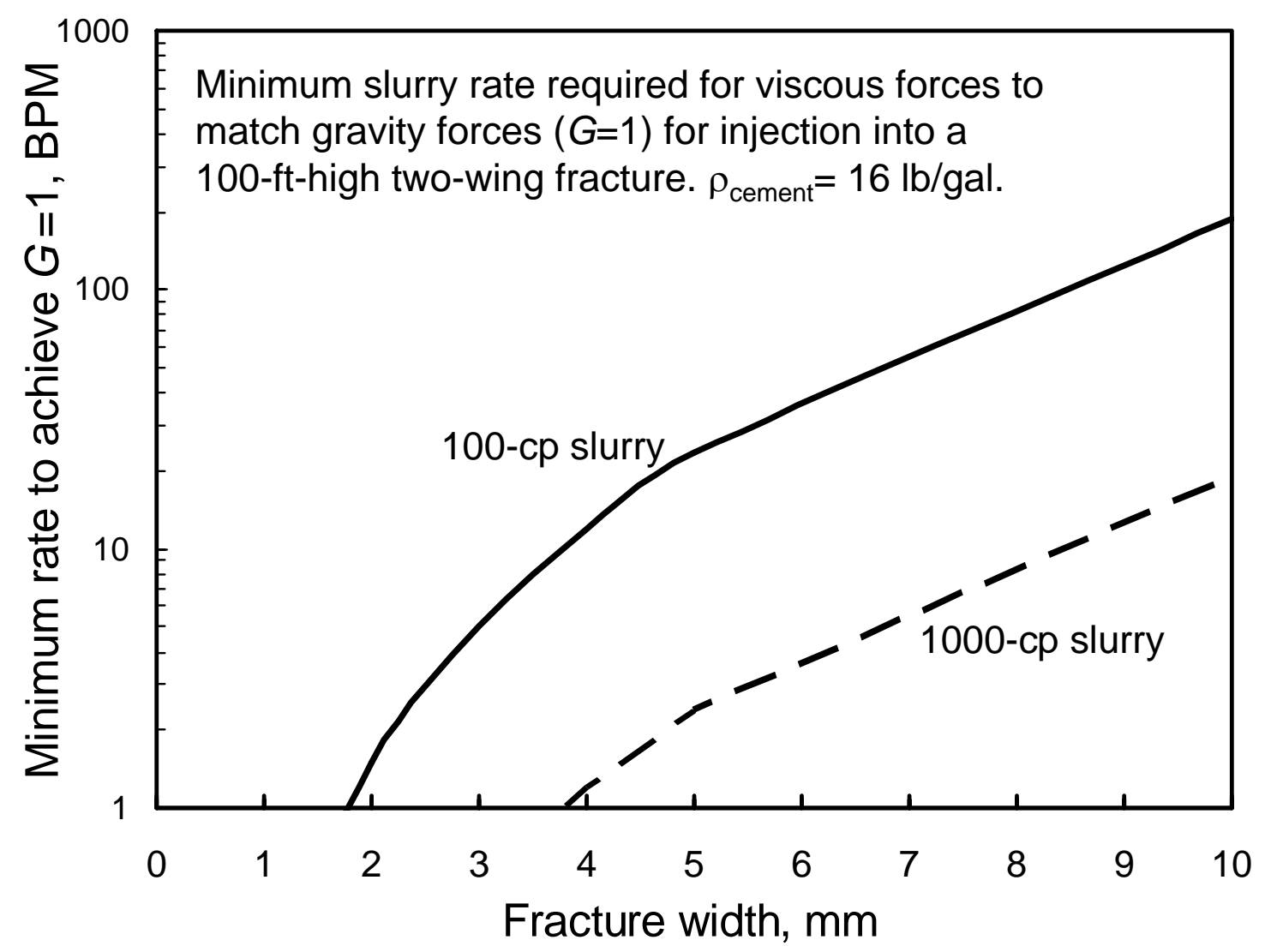

Fig. 44—Minimum rates for viscous and gravity forces to match for cement slurries. 
Observations from the previous section indicate that cement will not penetrate far into fractures or voids with apertures of $4 \mathrm{~mm}$ or less. For fractures or voids that are wider than $4 \mathrm{~mm}$, Fig. 44 suggests that the displacement profile will not be near vertical for practical cement slurry placement rates $(<10 \mathrm{BPM})$. For a given injection rate, the orientation of the displacement front inclines more toward the horizontal as the aperture increases. Because the displacement front is inclined, the upper part of any vertical fracture will be open (cement free) except near the wellbore.

In summary, cement cannot be expected to completely fill (top to bottom) a vertical fracture of any width, except near the wellbore. For vertical fractures with apertures less than $4 \mathrm{~mm}$, the cement slurry will simply not penetrate very far into the fracture. For vertical fractures with apertures greater than $4 \mathrm{~mm}$, the slurry may penetrate a substantial distance into the bottom part of the fracture. However, except near the wellbore, the upper part of the fracture will remain open.

Foamed cement has been suggested as a means to overcome the limitations that gravity segregation imposes. ${ }^{30}$ Foamed cements with densities less than water are claimed, although foamed cements used in in-depth field applications to date have generally been significantly more dense than water. ${ }^{30}$ Conceptually, foamed cement slurries with the same density as water could be placed long distances into voids and fractures and fill the void channel top to bottom. However, the relatively short set times of these slurries still limit their distance of penetration. Further work is needed to properly assess the potential of foamed cement.

\section{Cost}

On a per volume basis, material costs for cements are usually considerably more than gels. Conventional cements range from $\$ 28$ to $\$ 84$ per barrel (based on pumped volumes), ${ }^{30}$ whereas gels made from high-molecular-weight HPAM typically cost from $\$ 8$ to $\$ 20$ per barrel (based on pumped volumes). ${ }^{36}$ For gel treatments, total treatment costs are typically about twice the chemical costs. Foamed cements commonly command a $10 \%$ cost premium over conventional cements, and micro-fine cements often cost 2-3 times more than conventional cements. 


\section{GELS IN FRACTURES}

Gel compositions used for conformance control usually contain more than $90 \%$ water-and frequently more than $99 \%$ water. For example, much of our research focused on an aqueous gel that contained $0.5 \%$ Ciba Alcoflood $935^{\mathrm{TM}}$ HPAM (molecular weight $\approx 5 \times 10^{6}$ daltons; degree of hydrolysis $5 \%$ to $10 \%$ ), $0.0417 \% \mathrm{Cr}(\mathrm{III})$ acetate, $1 \% \mathrm{NaCl}$, and $0.1 \% \mathrm{CaCl}_{2}$. The gelation time for this formulation is about 5 hours at $41^{\circ} \mathrm{C}$. In this report, this formulation (after aging 24 hours) is called our standard $1 \mathrm{X} \mathrm{Cr}(\mathrm{III})$-acetate-HPAM gel. Also, unless stated otherwise, our brine contained $1 \% \mathrm{NaCl}$, and $0.1 \% \mathrm{CaCl}_{2}$, and the temperature was $41^{\circ} \mathrm{C}$.

\section{Gelant/Gel Properties during Placement}

Effective Viscosities. Gels can be placed in fractures as gelants, ${ }^{37}$ formed gels, ${ }^{27,38}$ or partially formed gels. ${ }^{34,35}$ Gelants (the fluid solution of crosslinker and polymer that exists before gelation) flow readily into fractures and medium to high permeability rock, exhibiting relatively low pressure gradients. However, gelants often experience problems with gravity segregation in fractures. ${ }^{39}$ Also, when gelants contact reservoir fluids or rock minerals, compositional changes can occur that interfere with gelation. ${ }^{37,40}$ Alternatively, formed gels (i.e., the crosslinked product of gelation) can be extruded into fractures during the placement process. Formed gels have significantly fewer problems with gravity segregation and chemical interference than gelants. However, formed gels exhibit water loss and higher pressure gradients during placement that may affect their distance of propagation along a fracture or into a fracture system. ${ }^{27,38}$ In wide fractures, gravity segregation can be a problem even with formed gels.

Fig. 45 illustrates the differences in effective viscosities (in a 1-mm-wide fracture) for gelants, formed gels, and an intermediate category-partially formed gels. ${ }^{34,35}$ (The $x$-axis plots the time from gelant preparation until injection into a fracture core.) For our $1 \mathrm{X} \mathrm{Cr}(\mathrm{III})$-acetate-HPAM gelant, the effective viscosity in the fracture was roughly $20 \mathrm{cp}$ - the same value shown by a polymer solution that contained $0.5 \%$ HPAM, but no crosslinker. The effective viscosity remains at this level until the gelation time-about 5 hours for this particular formulation at $41^{\circ} \mathrm{C}$.

Between 4 and 16 hours, the effective viscosity rises rapidly from 22 to 1,270 cp (Fig. 45). In this period, the formulation is labeled a "partially formed gel." In field applications, formulations are often in this state during part of the placement process. We envision two advantages associated with partially formed gels. ${ }^{34,35}$ First, the polymers have undergone sufficient crosslinking so that they do not penetrate significantly into porous rock. ${ }^{39}$ (Consequently, any gel that forms stays in the fracture or void feature and causes minimum damage to the porous rock.) Second, the effective viscosity of the gel formulation is significantly less than that of "fully formed" gels, so a relatively high injectivity can be maintained during placement.

After 16 hours, the effective viscosity is quite high and increases relatively slowly (i.e., from 1,270 to 2,300 cp over a 9-day period). In this period, we label the gel as a "formed gel" or "fully formed gel." In several field projects involving injection of large gel volumes, the formulations were in this state during most of the placement process. ${ }^{32,33,41}$ In the formed-gel state, the formulation extrudes through the fractures and voids during the placement process. Under the proper circumstances, pressure gradients are stable during gel extrusion (see Fig. 46). Of course, if the fracture is too narrow and/or the gel is too rigid, progressive plugging or screen-outs can 
occur. In the gelant state, the formulation flows (typically in laminar flow) following conventional fluid dynamics. In the partially-formed-gel state, flow experiences a transition from that of a conventional fluid with an increasing fraction of suspended gel particles to that of an extruding gel.

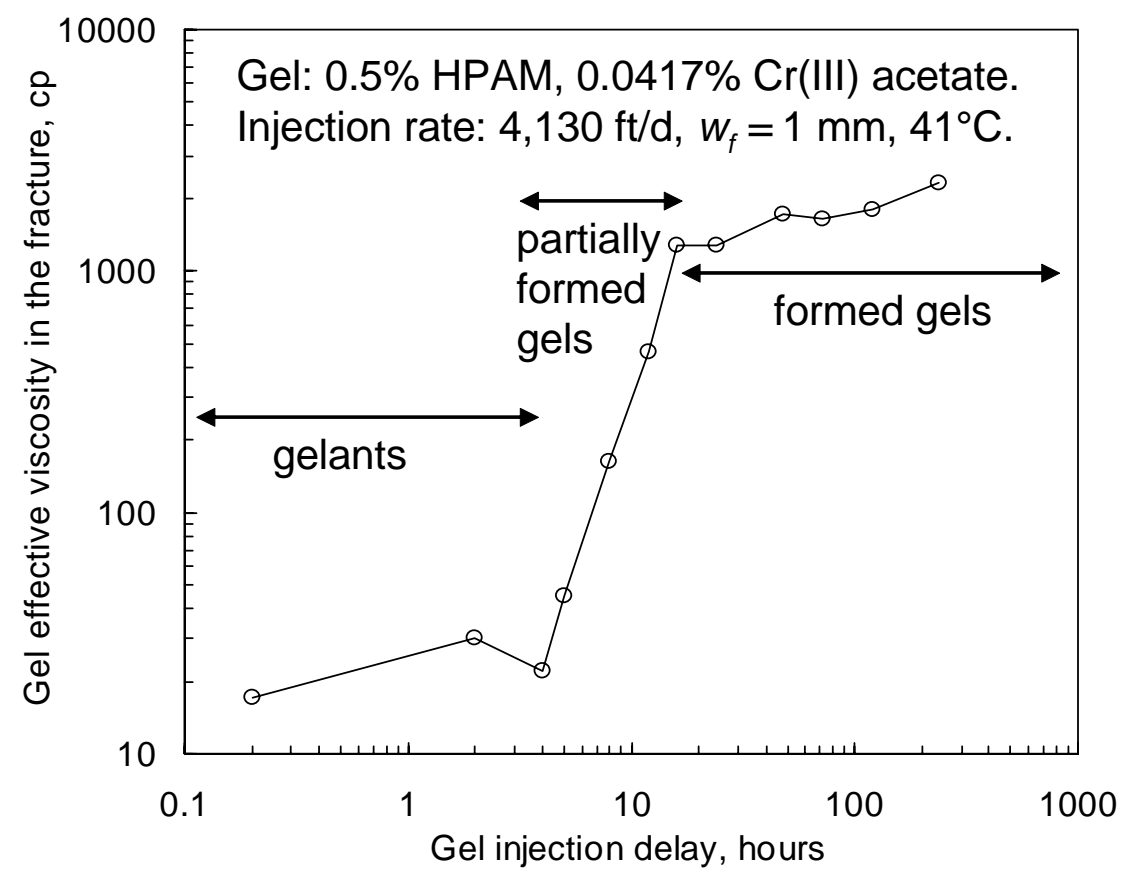

Fig. 45-Effective viscosities for gelants and gels in 1-mm-wide fractures.

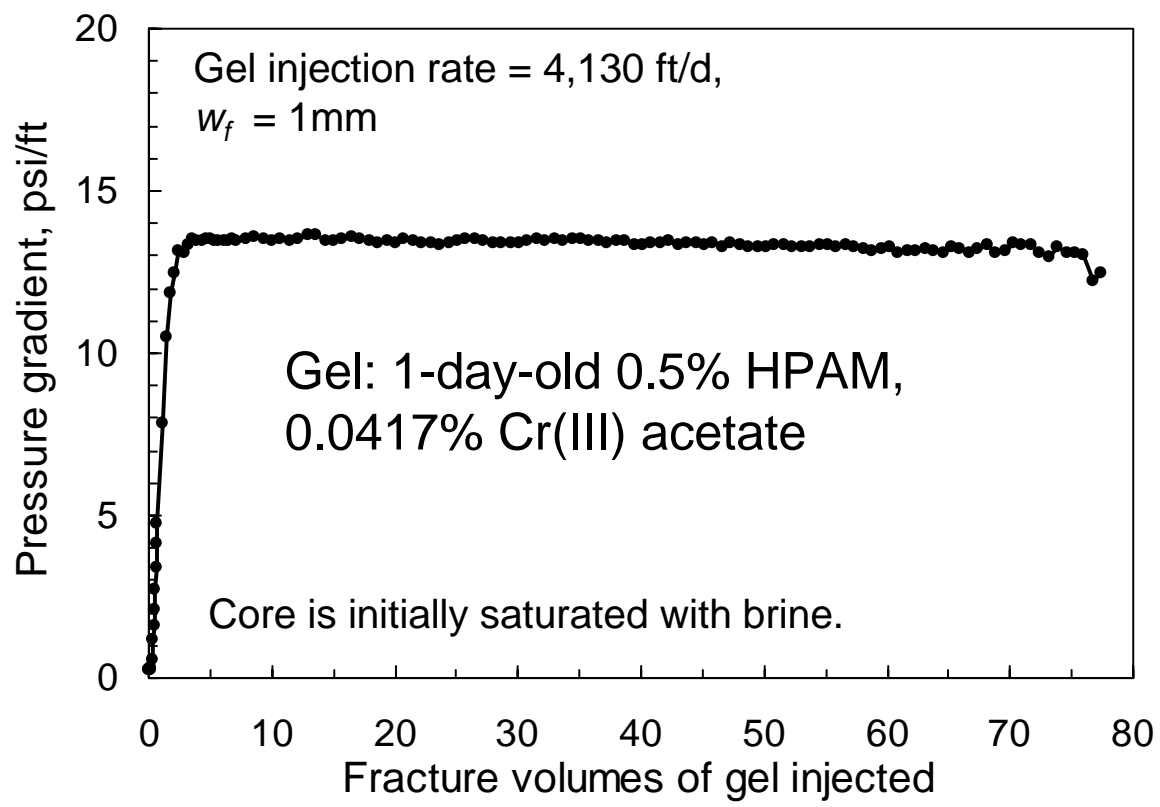

Fig. 46-Stable pressure gradients during gel extrusion. 
Leakoff. During flow of a gelant through a fracture or void feature, the formulation may flow (leakoff) into the adjacent porous rock. Depending on the extent of the leakoff and the particular circumstances, this material may significantly damage the flow capacity of the porous rock when the gel forms. Fig. 47 shows leakoff rates associated with the experiments reported in Fig. 45. This figure indicates relatively low leakoff rates for gelant during these experiments-primarily because the pressure difference that drives the leakoff (i.e., between the fracture and the porous rock) was relatively low.

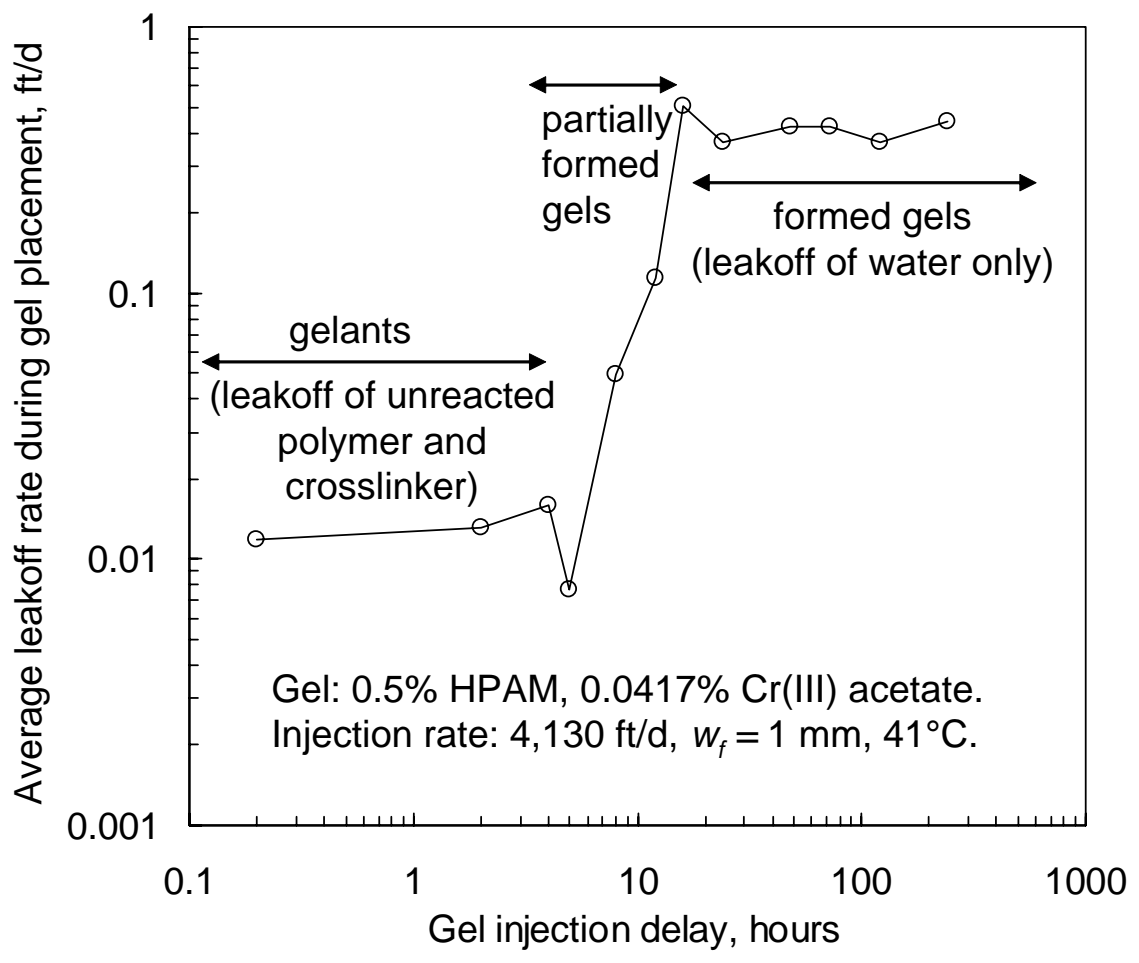

Fig. 47-Leakoff rates for gelants and gels in 1-mm-wide fractures.

At the other end of the time scale, formed gels extrude through fractures. During this process, formed gels dehydrate-i.e., water (or brine) leaves the gel and leaks off through the fracture faces into the porous rock. ${ }^{27,38}$ The crosslinked polymer remains behind in the fracture, becoming increasingly concentrated with time and gel throughput (i.e., crosslinked polymers do not flow through porous rock after gelation). Dehydrated gel usually becomes immobile at the point in the fracture where dehydration occurs. During placement, the only gel that generally moves through the fracture has basically the same composition, appearance, and properties as the injected gel. ${ }^{27,38}$ However, small bits of the dehydrated gel can erode to join the flowing gel.

Since only brine leaks off during extrusion of formed gels, the rock matrix is not damaged. Partially formed gels present an intermediate case. We presume that any gel particles (crosslinked polymer) that form will not penetrate into the porous rock. On the other hand, any un-reacted gelant that is present could leakoff and cause damage to the porous rock. Based on the leakoff behavior of the gelant (Fig. 47), we suspect that damage caused by partially formed gels 
to porous rock is no greater than that for gelants. However, additional work may be needed to prove this point.

Behavior Versus Rate. As mentioned, the pressure gradients required to extrude gels through fractures are greater than those for gelant flow. Depending on conditions, the effective viscosity of formed gels in fractures are typically $10^{3}$ to $10^{6}$ times greater than those for gelants. ${ }^{27,38,39}$ However, useful gels do not show progressive plugging during extrusion through fractures. A minimum pressure gradient is required to extrude a given gel through a fracture. Once this minimum pressure gradient is exceeded, the pressure gradient during gel extrusion is insensitive to the flow rate. ${ }^{27}$ Table 4 illustrates this concept by showing results from four identical corefloods where 80 fracture volumes (4 liters) of our standard 24-hour-old $1 \mathrm{X} \mathrm{Cr}$ (III)-acetateHPAM gel were extruded through a 1-mm-wide fracture at rates (flux in the fracture) ranging from 413 to 33,100 ft/d. Considering the wide rate variation, the pressure gradients did not vary much (18 to $40 \mathrm{psi} / \mathrm{ft}$ ).

Table 4-Gels dehydrate during extrusion.

\begin{tabular}{|c|c|c|c|c|}
\hline Injection flux, ft/d & 413 & 1,030 & 4,130 & 33,100 \\
\hline Average $d p / d l, \mathrm{psi} / \mathrm{ft}$ & 28 & 29 & 40 & 18 \\
\hline Gel breakthrough, fracture volumes & 15 & 6.0 & 4.0 & 1.7 \\
\hline Average gel dehydration, C/Co & 27 & 17 & 11 & 4 \\
\hline
\end{tabular}

The rate of gel front propagation increases significantly with increasing injection rate. ${ }^{27}$ Note in Table 4 that gel breakthrough decreased from 15 to 1.7 fracture volumes as flux increased from 413 to $33,100 \mathrm{ft} / \mathrm{d}$. Gel has less time to dehydrate as the injection rate increases. With a lower level of dehydration (concentration), the gel propagates a greater distance for a given total volume of gel injection. This result has important consequences for field applications. It suggests that gels should be injected at the highest practical rate in order to maximize penetration into the fracture system. On the other hand, in wide fractures or near the end of gel injection, gel dehydration may be desirable to form rigid gels that are less likely to washout after placement. In these applications, reduced injection rates may be appropriate. ${ }^{27}$ Note in Table 4 that the average concentration of residual gel in the fracture (relative to the concentration of the injected gel) decreased from 27 to 4 as flux increased from 413 to 33,100 ft/d.

Behavior Versus Fracture Width. For a Cr(III)-acetate-HPAM gel, the pressure gradient required for extrusion varys inversely with the square of fracture width (Fig. 48). In contrast, a force balance predicts that the pressure gradient should vary inversely with fracture width. ${ }^{24}$ Although the origin of this behavior has not been definitively identified, it is directly linked to the extremely strong apparent shear-thinning behavior during extrusion. ${ }^{24}$ Note from Fig. 48 that the pressure gradient for gel extrusion is not sensitive to the permeability of the porous medium that contains the fracture (i.e., from 1.5 to $10,000 \mathrm{md}$ ). 


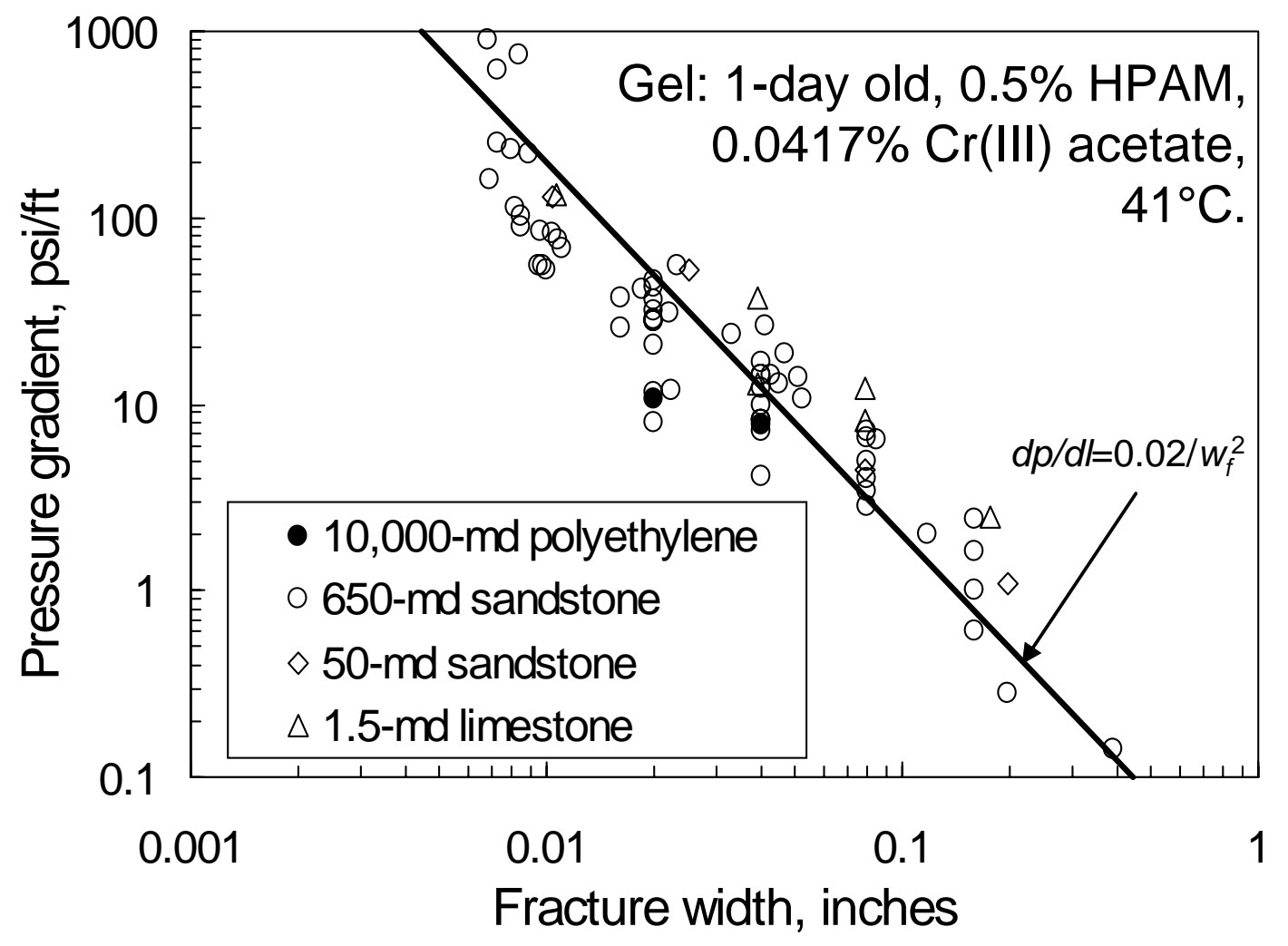

Fig. 48-Effect of fracture width on gel extrusion pressure.

A new model was developed to describe water leakoff from gels during extrusion through fractures. ${ }^{38}$ The rate of gel dehydration varies inversely with the square root of time. Fresh (mobile) gel wormholes through concentrated gel. ${ }^{27,38}$ Early in the process of gel injection, the wormhole pattern is very branched, with a significant fraction of the fracture area contacted by the wormholes. As additional gel volumes are injected, the wormholes become less branched, and a diminished fraction of the fracture area is contacted by the wormholes. This behavior is not surprising since the dehydrated gel becomes increasingly concentrated and less mobile and the mobility ratio (mobility of fresh gel divided by mobility of concentrated gel) increases with gel throughput. Fig. 49 illustrates the wormhole patterns that develop during the gel extrusion process. In this figure, our 1-day-old $1 \mathrm{X} \mathrm{Cr}(\mathrm{III})$-acetate HPAM gel wormholes through dehydrated gel that is 12 times more concentrated. The fracture dimensions were $15 \times 15 \times 0.1 \mathrm{~cm}$.

The leakoff behavior and pressure gradients during gel extrusion are not sensitive to temperature from $20^{\circ} \mathrm{C}$ to $80^{\circ} \mathrm{C}^{38}$ Elastic modulus is also insensitive to temperature. ${ }^{24}$ In contrast, the viscosity of water decreases by a factor of approximately three as temperature rises from $20^{\circ} \mathrm{C}$ to $80^{\circ} \mathrm{C}$. 


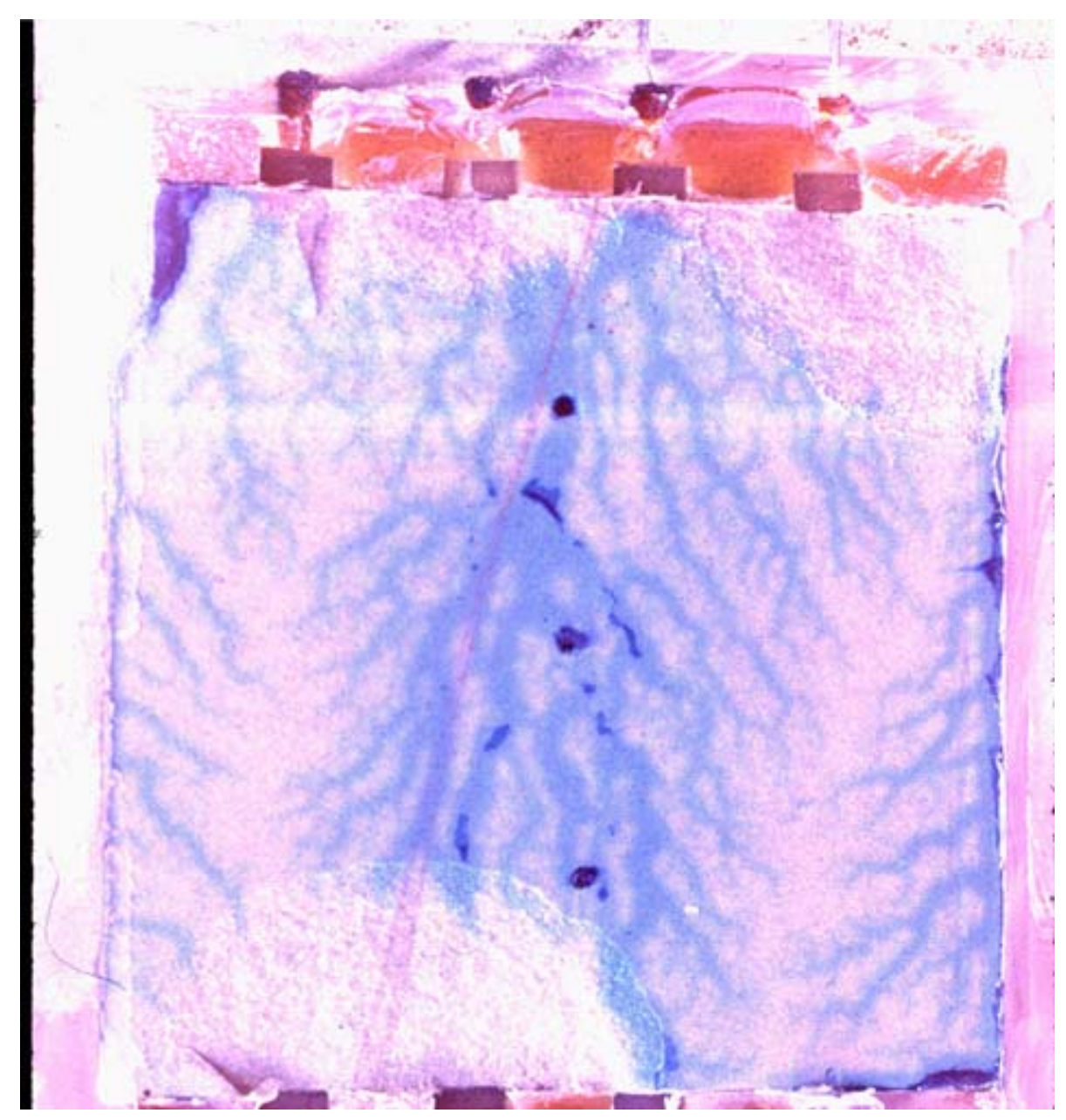

Fig. 49—Wormhole pattern during gel extrusion.

For gel compositions between $1 \mathrm{X}$ and $3 \mathrm{X}$, the leakoff behavior is not sensitive to polymer concentration. ${ }^{38}$ (The " $\mathrm{X}$ " multiplier refers to the HPAM and chromium concentrations relative to those in our standard $1 \mathrm{X}$ gel. The HPAM/Cr(III)-acetate ratio was fixed at 12/1.) In these experiments, the gels were aged for one day at $41^{\circ} \mathrm{C}$ before injection at 4,130 ft/d into 6-in.-long, 1.5-in.-diameter Berea cores that each contained a 0.04-in.-wide fracture. Pressure gradients during gel extrusion increase approximately with the square of polymer content in the gel. ${ }^{38}$ This behavior parallels that for measurements of elastic modulus versus gel composition. ${ }^{24}$ However, based on force balance considerations, the pressure gradients during gel extrusion through fractures are much greater (i.e., 87 times greater) than expected from measurements of elastic modulus. $^{24}$

Ganguly et al. ${ }^{37}$ studied gel rupture in tubes. Their gel was placed as gelant in 0.094-in. to 0.30in. diameter plastic tubes. The gel contained $0.75 \%$ Alcoflood 935 HPAM, $0.0417 \% \operatorname{Cr}(\mathrm{III})$ acetate, $1 \% \mathrm{NaCl}$ and was aged for 6-8 days at room temperature. During brine injection after gel formation, the pressure required to rupture the gel varied almost linearly with the ratio of tube length to inner tube diameter. ${ }^{37}$ Stated another way: the pressure gradient for gel rupture varied 
inversely with the tube diameter. This result was expected based on a simple force balance. ${ }^{24}$ In fact, given that the elastic modulus of the gel was $17.6 \mathrm{~Pa}(0.0025 \mathrm{psi})^{24,38}$, the experimental data of Ganguly et al. were quantitatively consistent with predictions from a simple force balance. A key difference exists between placement with gelants (i.e., as in Ganguly's work) versus placement with formed gels. With gelant placement, the entire fracture cross-section (ideally) is filled with a low-concentration, homogeneous gel. In contrast, with placement of formed gels, most of the fracture cross-section is filled with concentrated immobile gel. Only small wormholes contain the low-concentration gel that can be readily mobilized.

\section{Brine Injection Displaces a Small Fraction of the Gel}

A key finding from our studies to date was that only a small fraction of the gel in a fracture was displaced when brine (or oil) was injected after gel placement. In all our experiments, less than $10 \%$ (and often less than 1\%) of the gel was displaced during brine flow after gel placement. This result was not surprising since an extremely unfavorable mobility ratio exists when high mobility brine is forced through a fracture with very low mobility oil. This result was observed regardless of whether the gel as placed as a gelant, a partially formed gel, or as a fully formed gel. $^{25,34}$

Our first studies of gel failure during brine injection after gel placement, ${ }^{25}$ indicated that the point of gel failure occurred in the wormhole pathways that formed during gel extrusion. Also, the pressure gradient at which the gel was first breached by the brine was about the same as the pressure gradient exhibited during gel placement. Note in Fig. 50 that the peak pressure gradient during first brine injection after gel placement (i.e., first breach of the gel) was about the same as the pressure gradient during gel placement in four of the five fracture sections. (This was a 1mm-wide fracture where a 1-day-old $1 \mathrm{X}$ gel had previously been extruded into place.)

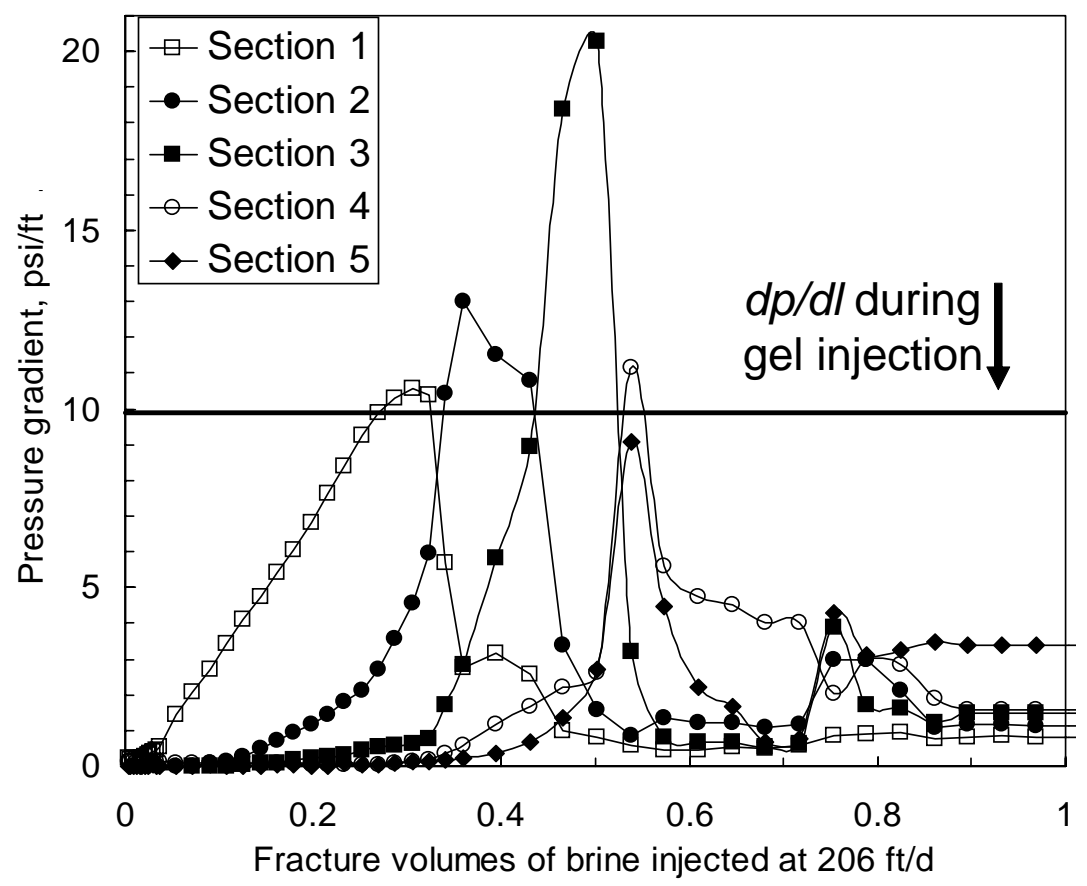

Fig. 50—Pressure gradients in 5 fracture sections during brine injection after gel placement. 


\section{Influence of Injection Delay}

Higher Injectivities for Gelants and Partially Formed Gels. An important objective in this work is to find a material that will exhibit minimum resistance to flow during placement in fractures and yet very high resistance to washout after placement. From Fig. 45 and Table 5, we know that formulations in the early stages of gelation are much more fluid than formed gels. Of course, lower effective viscosity implies higher injectivity during field applications. Table 5 compares the effect of injection delay (time from gelant mixing until injection into a fracture) for our $1 \mathrm{X} \mathrm{Cr}(\mathrm{III})$-acetate-HPAM gel when injected into 4-ft-long, 1-mm-wide fractures at 2,000 $\mathrm{cm}^{3} / \mathrm{hr}(4,130 \mathrm{ft} / \mathrm{d})$.

Table 5-Effect of injection delay. $w_{f}=1 \mathrm{~mm}, L_{f}=4 \mathrm{ft}$, $1 \mathrm{X}$ gel, gel rate $=2,000 \mathrm{~cm}^{3} / \mathrm{hr}$, brine rate $=100 \mathrm{~cm}^{3} / \mathrm{hr}, 41^{\circ} \mathrm{C}$

\begin{tabular}{|c|c|c|c|c|c|c|}
\hline $\begin{array}{c}\text { Injection } \\
\text { delay, } \\
\text { hours }\end{array}$ & $\begin{array}{c}\text { Gel } \\
\text { placement } \\
d p / d l, \\
\mathrm{psi} / \mathrm{ft}\end{array}$ & $\begin{array}{c}\text { Effective } \\
\text { viscosity of } \\
\text { gel in } \\
\text { fracture, } \mathrm{cp}\end{array}$ & $\begin{array}{c}\text { Brine } \\
\text { breaching } \\
d p / d l, \\
\mathrm{psi} / \mathrm{ft}\end{array}$ & $\begin{array}{c}\text { Stabilized } \\
\text { brine } \\
d p / d l, \\
\mathrm{psi} / \mathrm{ft}\end{array}$ & $\begin{array}{c}\text { Stabilized } \\
\text { brine } F_{\text {rrw }}\end{array}$ & $\begin{array}{c}\text { Matrix } \\
\text { flow, } \\
\%\end{array}$ \\
\hline 0.2 & 0.13 & 17 & 1.30 & 0.53 & 2050 & 8 \\
\hline 2 & 0.23 & 30 & 1.39 & 1.08 & 4170 & 12 \\
\hline 4 & 0.17 & 22 & 3.80 & 1.72 & 6640 & 20 \\
\hline 5 & 0.35 & 45 & 3.60 & 1.78 & 6870 & 18 \\
\hline 8 & 1.25 & 162 & 3.20 & 2.8 & 10800 & 18 \\
\hline 12 & 3.6 & 466 & 7.30 & 0.57 & 2200 & 7 \\
\hline 16 & 9.8 & 1270 & 5.20 & 2.6 & 10040 & 42 \\
\hline 24 & 9.9 & 1280 & 8.20 & 2.29 & 8840 & 21 \\
\hline 48 & 13.3 & 1720 & 2.00 & 0.62 & 2400 & 10 \\
\hline 72 & 12.8 & 1660 & 2.37 & 1.07 & 4130 & 26 \\
\hline 120 & 13.8 & 1780 & 2.76 & 0.22 & 850 & 4 \\
\hline 240 & 17.8 & 2300 & 3.60 & 0.68 & 2630 & 4 \\
\hline
\end{tabular}

Breaching the Gel during Brine Flow. Is the resistance to washout sensitive to the state of the formulation during placement? After gel placement (and shut in to allow gel maturation), brine was injected at $100 \mathrm{~cm}^{3} / \mathrm{hr}$. The fourth column in Table 5 shows that the pressure gradient $(d p / d l)$ required for brine to first breach the gel ranged from 1.3 to $8.2 \mathrm{psi} / \mathrm{ft}$ as the gel injection delay increased from 0.2 to 24 hours. For longer injection delays (2 to 10 days), the breaching pressure gradient ranged from 2 to $3.6 \mathrm{psi} / \mathrm{ft}$. Except for injection delays between 12 and 24 hours, the breaching pressure gradients in Table 5 were quite comparable. One could argue that higher injectivity (30 to 100 fold) associated with gelants and partially formed gels offsets the higher breaching pressure gradients associated with use of 24-hour-old gels. ${ }^{34}$

For the 24-hour old gel (Fig. 50), the breaching pressure gradient during brine injection was roughly the same as the pressure gradient when the gel was extruded into place. However, a comparison of the second and fourth columns in Table 5 reveals that the breaching pressure gradient was significantly greater than the gel placement pressure gradient for the gelants and partially formed gels (injection delays less than 12 hours) and was significantly less than the gel placement pressure gradient for gel injection delays of two days or greater. 
Gels Substantially Reduced Fracture Flow Capacity. The next to last column in Table 5 lists residual resistance factors $\left(F_{r r w}\right)$ or the factors by which the gel reduced permeability to brine in the fractures. These values were measured after brine injection (3 to 10 fracture volumes) at a rate of $100 \mathrm{~cm}^{3} / \mathrm{hr}(206 \mathrm{ft} / \mathrm{d})$. In all cases, the flow capacity of the fracture was reduced substantially (by factors ranging from 850 to 10,800). This fact was consistent with our observation that brine injection displaced only a small fraction of gel from the fracture.

Fractures Retained Significant Flow Capacity after Gel Breach. During corefloods, we routinely monitored the fraction of the fluid that was produced from the fracture versus the matrix. Prior to brine breaching gel in the fracture, all brine was produced from the matrixindicating effective healing of the fracture by the gel. The last column in Table 5 indicates the fraction of brine flow through the matrix after the gel was breached by brine injection at 100 $\mathrm{cm}^{3} / \mathrm{hr}$. Higher values indicate more efficient plugging of the fracture. For all cases in Table 5, a significant fraction $(>50 \%)$ of the final flow remained through the fracture.

\section{Using More Concentrated Gels}

A common approach toward improving gel resistance to washout is to increase the polymer content of the gel. Table 6 shows the effects of increased polymer content on gel properties in fractures. The " $X$ " multiplier indicates the polymer concentration in the gel. A $1 \mathrm{X}$ gel contained 0.5\% Alcoflood 935 HPAM, a 2X gel contained 1\% HPAM, and a 3X gel contained 1.5\% HPAM. In this table, the first two data rows were performed with "fully formed" 24-hr-old gels that were injected at $2,000 \mathrm{~cm}^{3} / \mathrm{hr}$ into 1 -mm-wide, 4 -ft-long fractures. The last three data rows were performed with "partially formed" gels that were injected at $8,000 \mathrm{~cm}^{3} / \mathrm{hr}$ into 1 -mm-wide, 2-ft-long fractures. In all cases, after gel placement and shut-in, brine was injected at $100 \mathrm{~cm}^{3} / \mathrm{hr}$. (Incidentally, for studies in this chapter, pressures were measured across the middle sections of the fractures, thus eliminating end effects associated with the entrance and exit sections of the core. This fact explains minor reporting differences from data in Refs. 34 and 35.)

For the fully formed (24-hr-old) gels, the placement pressure gradient increased substantially with increased polymer content, but the breaching pressure gradient (for brine) did not increase in proportion. The stabilized $F_{r r w}$ values were about the same for the $1 \mathrm{X}$ and $2 \mathrm{X}$ gels. Thus, no clear advantage is apparent for injecting a 24-hr-old 2X gel over a 24-hr-old 1X gel.

Table 6-Effect of gel polymer concentration. $w_{f}=1 \mathrm{~mm}$, brine rate $=100 \mathrm{~cm}^{3} / \mathrm{hr}, 41^{\circ} \mathrm{C}$

\begin{tabular}{|c|c|c|c|c|c|}
\hline Gel & $\begin{array}{c}\text { Gel } \\
\text { placement } \\
d p / d l, \\
\mathrm{psi} / \mathrm{ft}\end{array}$ & $\begin{array}{c}\text { Effective } \\
\text { viscosity of } \\
\text { gel in } \\
\text { fracture, cp }\end{array}$ & $\begin{array}{c}\text { Brine } \\
\text { breaching } \\
d p / d l, \\
\mathrm{psi} / \mathrm{ft}\end{array}$ & $\begin{array}{c}\text { Stabilized } \\
\text { brine } \\
d p / d l, \\
\mathrm{psi} / \mathrm{ft}\end{array}$ & $\begin{array}{c}\text { Stabilized } \\
\text { brine } F_{r r w}\end{array}$ \\
\hline 24-hr-old 1X & 9.9 & 1281 & 8.2 & 2.3 & 8842 \\
\hline 24-hr-old 2X & 48 & 6210 & 13.8 & 1.9 & 7220 \\
\hline & & & & & \\
\hline 7-hr-old 1X & 1.0 & 32 & 5.6 & 1.8 & 6950 \\
\hline 2.5-hr-old 2X & 2.5 & 81 & 27.8 & 2.1 & 7950 \\
\hline 1-hr-old 3X & 3.7 & 120 & 62 & 1.3 & 5020 \\
\hline
\end{tabular}


For the partially formed gels, the placement pressure gradients increased with increased polymer content (as expected), but the placement pressure gradients and effective viscosities were reasonably low (much lower than those for the 24-hr-old gels). Most importantly, the breaching pressure gradient (for brine injection) increased significantly with increased polymer concentration (from 5.6 to 62 as polymer increased from $1 \mathrm{X}$ to $3 \mathrm{X}$ ). Interestingly, after breaching the gel, the final stabilized pressure gradients and $F_{r r w}$ values were not sensitive to polymer content. This result suggests that a $3 \mathrm{X}$ gel will more effectively keep a fracture in a "healed" condition. However, once the gel has been breached, the plugging ability of the $3 \mathrm{X}$ gel is not significantly better than the $1 \mathrm{X}$ gel.

\section{Exploiting Placement (Extrusion) Rate}

We investigated whether washout could be reduced by controlling gel injection rate to form concentrated gels during placement. (Here, we are talking explicitly about formed gels extruding through fractures. We are not investigating the effects of rate on gelant placement.) Maximizing gel injection rate minimizes water loss and maximizes the distance of gel propagation along a fracture. $^{27,38}$ In contrast, as injection rate decreases, the concentration increases for the gel deposited in the fracture. This gel should be increasingly resistant to washout as it becomes more concentrated.

A key difference exists between this idea and the case where a concentrated gel was placed by injecting a 24-hr-old 2X gel. The pressure gradient for gel extrusion increased significantly with increased concentration of the injected gel (see Table 6). Thus, pressure gradients can be very high when injecting a 24-hr-old $2 \mathrm{X}$ gel. In the new concept, the injected gel would have a relatively low polymer concentration (e.g., a $1 \mathrm{X}$ gel). For a given fracture width and composition of the injected gel, the pressure gradient is insensitive to injection rate. ${ }^{27}$ Therefore, by lowering the injection rate, a concentrated gel can be placed in the fracture without resorting to high pressure gradients.

To test this idea, three corefloods were performed (in 1-mm-wide fractures) that were identical except for the gel placement rate. These floods used the same procedures as those described earlier, but using gel placement rates of $400,2,000$ or $16,000 \mathrm{~cm}^{3} / \mathrm{hr}$ (effective fluxes of 826 , 4,130, or 33,100 ft/d). ${ }^{25}$ Pressure gradients during gel placement averaged 16.7, 9.9, and 7.1 $\mathrm{psi} / \mathrm{ft}$, respectively (Table 7). Consistent with earlier findings, ${ }^{27}$ the pressure gradient was fairly insensitive to rate, considering the 40-fold difference in placement rates. Of course, it is interesting that the extrusion pressure gradient actually decreased with increased injection rate. This effect may result from a combination of (1) more constricted flow paths at the lower rates (caused by deposition of more concentrated gels) and (2) greater mechanical degradation of the gel at the higher rates.

After placement during brine injection at $100 \mathrm{~cm}^{3} / \mathrm{hr}$, the pressure gradient at which brine first breached the gel increased (from 7.3 to $12.3 \mathrm{psi} / \mathrm{ft}$ ) as the gel placement rate decreased (fourth column in Table 7). However, the effect was not dramatic. The stabilized $F_{r r w}$ value and the final matrix flow fraction were significantly greater for the lowest gel placement rate (sixth and seventh column in Table 7). This latter effect may be attributed to the deposition of very concentrated gel (17 times more concentrated than the injected $1 \mathrm{X}$ gel) for the lowest placement rate. This behavior contrasts with that noted in Table 6. Apparently, injection of a concentrated 
partially formed gel provided a high breaching pressure gradient, but did not provide an improved plugging ability once the gel was breached. In contrast, using rate control to place a concentrated (dehydrated) gel provided an improved plugging ability once the gel was breached, but did not provide a high breaching pressure gradient. These observations will be investigated further in our future work.

Table 7-Effect of gel placement (extrusion) rate. $L_{f}=4 \mathrm{ft}$, 24-hr-old $1 \mathrm{X}$ gel, brine rate $=100 \mathrm{~cm}^{3} / \mathrm{hr}, 41^{\circ} \mathrm{C}$

\begin{tabular}{|c|c|c|c|c|c|c|c|}
\hline $\begin{array}{c}\text { Gel } \\
\text { placement rate, } \\
\mathrm{cm}^{3} / \mathrm{hr}(\mathrm{ft} / \mathrm{d})\end{array}$ & $\begin{array}{c}\text { Gel } \\
\text { placement } \\
d p / d l, \\
\text { psi/ft }\end{array}$ & $\begin{array}{l}\text { Effective } \\
\text { viscosity } \\
\text { of gel in } \\
\text { fracture, cp }\end{array}$ & $\begin{array}{c}\text { Brine } \\
\text { breaching } \\
d p / d l, \\
\text { psi/ft }\end{array}$ & $\begin{array}{c}\text { Stabilized } \\
\text { brine } \\
d p / d l, \\
p s i / f t\end{array}$ & $\begin{array}{l}\text { Stabilized } \\
\text { brine } F_{r r w}\end{array}$ & $\begin{array}{c}\text { Matrix } \\
\text { flow, } \\
\%\end{array}$ & $\begin{array}{c}\text { Final } \\
C / C_{o} \\
\text { in the } \\
\text { fracture }\end{array}$ \\
\hline \multicolumn{8}{|c|}{$w_{f}=1 \mathrm{~mm}$} \\
\hline $400(826)$ & 16.7 & 10800 & 12.3 & 6.2 & 23900 & 52 & $17 X$ \\
\hline $2000(4130)$ & 9.9 & 1280 & 8.2 & 2.3 & 8840 & 21 & $3 X$ \\
\hline $16000(33100)$ & 7.1 & 115 & 7.3 & 2.2 & 8490 & 19 & $1 \mathrm{X}$ \\
\hline \multicolumn{8}{|c|}{$w_{f}=2 \mathrm{~mm}$} \\
\hline $400(413)$ & 2.8 & 14500 & 5.6 & 0.74 & 22900 & 27 & $3 X$ \\
\hline $2000(2065)$ & 4 & 4140 & 1.2 & 0.27 & 8340 & 11 & $1 \mathrm{X}$ \\
\hline
\end{tabular}

A second set of experiments were performed in 2-mm-wide fractures, using gel placement rates of 400 and 2,000 $\mathrm{cm}^{3} / \mathrm{hr}$. Comparison of the last two rows of Table 7 reveals that reduction in placement rate significantly increased (1) the breaching pressure gradient during brine flow after gel placement, (2) the $F_{r r w}$ value, and (3) the fraction of brine flowing through the matrix. Consequently, rate reduction during placement merits further study.

\section{Using Combinations of High and Low Mw Polymers}

We investigated using combinations of high and low molecular weight (Mw) polymers in $\mathrm{Cr}$ (III)-acetate-HPAM gels to reduce the flow capacity of fractures (at $41^{\circ} \mathrm{C}$ ). The specific objective of these experiments was to identify formulations that will flow readily into fractures and then effectively plug the fractures during brine flow after placement-especially in wider fractures (2- to 4-mm widths). Table 8 shows the compositions investigated. The gels contained both high and low molecular weight polymers. The high molecular weight (Mw) polymer was Ciba Alcoflood $935^{\mathrm{TM}}$ HPAM (hydrolyzed polyacrylamide), with a nominal Mw of $5 \times 10^{6}$ daltons. The low Mw polymer was Ciba Alcoflood 254-S ${ }^{\mathrm{TM}}$ HPAM, with a nominal Mw of 500,000 daltons. Both polymers were 5-10 mole\% hydrolyzed.

Strategy. The strategy of mixing high and low Mw HPAM polymer in gel formulations is based on the following premises. ${ }^{42}$ First, there is an upper concentration limit for incorporating relatively high Mw HPAM into polymer-gel formulations. This upper concentration limit is set by the upper viscosity limit that can be tolerated during pumping and placement of the gel formulations. The second premise is that any gel formulated for fracture water-shutoff purposes should contain as much high Mw polymer as practical. More gel strength per unit weight or unit cost is attained at low polymer concentrations by incorporating high Mw polymer rather than low 
Mw polymer. However, as the concentration of high Mw polymer increases above a threshold value, addition of low Mw polymer imparts improved gel strength and stability that are comparable to addition of the same amount of high Mw polymer. In this situation, both polymer chains are long enough to form effective crosslinks within the gel network. In concept, the low Mw polymer imparts a minor increase in viscosity to the gelant solution, while substantially improving the gel strength and stability.

Table 8-Use of high and low Mw polymers in gels.

Brine rate $=100 \mathrm{~cm}^{3} / \mathrm{hr}, 41^{\circ} \mathrm{C}$

\begin{tabular}{|c|c|c|c|c|c|c|c|c|}
\hline Row & $\begin{array}{c}w_{f}, \\
\mathrm{~mm}\end{array}$ & $\begin{array}{c}\text { High } \\
\text { Mw } \\
\text { polymer, } \\
\% \\
\end{array}$ & $\begin{array}{c}\text { Low } \\
\text { Mw } \\
\text { polymer, } \\
\% \\
\end{array}$ & $\begin{array}{c}\text { Gel } \\
\text { placement } \\
d p / d l, \\
\text { psi/ft }\end{array}$ & $\begin{array}{l}\text { Effective } \\
\text { viscosity } \\
\text { of gel in } \\
\text { fracture, } \\
\text { cp } \\
\end{array}$ & $\begin{array}{c}\text { Brine } \\
\text { breaching } \\
d p / d l, \\
\text { psi/ft }\end{array}$ & $\begin{array}{c}\text { Stabilized } \\
\text { brine } \\
d p / d l, \\
\text { psi/ft }\end{array}$ & $\begin{array}{l}\text { Stabilized } \\
\text { brine } F_{r r w}\end{array}$ \\
\hline \multicolumn{9}{|c|}{ Cases placing gelants. $L_{f}=4 \mathrm{ft}$, gel rate $=2000 \mathrm{~cm}^{3} / \mathrm{hr}$} \\
\hline 1 & 1 & 0.5 & 0.0 & 0.13 & 17 & 1.3 & 0.53 & 2050 \\
\hline 2 & 1 & 0 & 5.5 & 0.55 & 71 & 23.7 & 4 & 15400 \\
\hline 3 & 1 & 0 & 5.5 & 1.37 & 177 & 52 & 13.2 & 51000 \\
\hline \multicolumn{9}{|c|}{ Cases placing partially formed gels. $L_{f}=2 \mathrm{ft}$, gel rate $=8000 \mathrm{~cm}^{3} / \mathrm{hr}$. } \\
\hline 4 & 1 & 1.5 & 0 & 3.7 & 120 & 62 & 1.3 & 5020 \\
\hline 5 & 1 & 1.5 & 0 & 2.9 & 94 & 58.7 & 0.11 & 425 \\
\hline 6 & 1 & 1.5 & 2.0 & 15.3 & 495 & 78.6 & 17.4 & 67200 \\
\hline 7 & 2 & 1.5 & 2.0 & 2.4 & 621 & 31.4 & 4.2 & 130000 \\
\hline 8 & 2 & 1.5 & 2.0 & 2.1 & 543 & 5.8 & 1.9 & 59700 \\
\hline 9 & 4 & 1.5 & 2.0 & 0.73 & 1510 & 22.2 & 0.47 & 116000 \\
\hline 10 & 4 & 1.5 & 4.0 & 0.13 & 269 & 4.2 & 0.29 & 71700 \\
\hline 11 & 4 & 1.5 & 4.0 & 0.8 & 1660 & 15.2 & 0.08 & 18500 \\
\hline 12 & 4 & 3.0 & 2.0 & 0.62 & 1280 & 18.9 & 0.52 & 128500 \\
\hline \multicolumn{9}{|c|}{ Cases placing 24-hr-old gels. $L_{f}=4 \mathrm{ft}$, gel rate $=2000 \mathrm{~cm}^{3} / \mathrm{hr}$. } \\
\hline 13 & 2 & 0.5 & 0 & 4.0 & 4140 & 1.2 & 0.3 & 8340 \\
\hline 14 & 2 & 0.5 & 2.5 & 21.2 & 21900 & 3.1 & 1.3 & 39200 \\
\hline 15 & 4 & 0.5 & 0 & 2.8 & 23200 & 1.9 & 0.3 & 74100 \\
\hline 16 & 4 & 0.5 & 2.5 & 6.8 & 56300 & 8.6 & 5.0 & 1236000 \\
\hline
\end{tabular}

Gelants with Only Low Mw Polymer. Recently, some oil producers and gel vendors explored using gels made from low molecular weight (Mw) polymers to plug fractures. In many cases, gels made with high Mw HPAM were injected first, followed by gelants made with low Mw HPAM near the end of the treatment. Because the low Mw gels were considerably more concentrated than the high Mw gels, they were hoped to provide more effective plugging of the near-wellbore portion of fractures. Low $\mathrm{Mw}$ gels (e.g., MARASEAL ${ }^{\mathrm{SM}}$ ) were originally developed to provide total fluid shutoff in matrix (personal communication with R.D. Sydansk). How well these formulations can perform in fractures is a topic that requires additional research. 
Two experiments were performed injecting gelants into 1-mm-wide fractures, where the gelant contained 5.5\% low Mw polymer (MARASEAL ${ }^{\mathrm{SM}}$ ). As expected, the gelants exhibited relatively low pressure gradients and effective viscosities during placement (Rows 2 and 3 of Table 8). (For comparison, Row 1 shows results for a $1 \mathrm{X}$ gelant prepared using high Mw polymer.) After gelation, the gel provided high breaching pressures (up to $52 \mathrm{psi} / \mathrm{ft}$ ) during first brine flow after gel placement. However, the gelant extensively invaded the porous rock during placement, effectively shutting off flow through the matrix. After breaching the gel, virtually all brine flow was through the fracture. If the objective is to provide a high breaching pressure in the fracture without substantially damaging the matrix, the $3 \mathrm{X}$ partially formed gel would be a better choice (see the last data row of Table 6 or Rows 4 and 5 of Table 8). On the other hand, if the objective is to shut off both flow through the fracture and matrix, the MARASEAL formulation (prepared with 5.5\% low Mw polymer) provided higher stabilized $F_{r r w}$ values than the $3 \mathrm{X}$ partially formed gel (prepared with high Mw polymer). Thus, the MARASEAL formulation might be deemed more effective than the $3 \mathrm{X}$ partially formed gel for total shutoff applications. However, we should note that gravity segregation could compromise effective placement of low viscosity gelants in vertical fractures. Gravity segregation may not be as important in our laboratory studies as in field applications.

Partially Formed Gels with 1.5\% High Mw and 2\% Low Mw Polymer. Four experiments were performed where 2\% low Mw polymer was added to the 3X gelant (with 1.5\% high Mw polymer). These formulations were placed as partially formed gels (Rows 6 to 9 in Table 8). Note that the placement pressure gradients and viscosities (in a 1-mm-wide fracture) were four to five times greater than those for the 3X partially formed gel (compare Row 6 with Rows 4 and 5 in Table 8). Thus, contrary to our hope, addition of the low Mw polymer did increase gelant viscosity noticeably. However, the viscosity increase was substantially less than that expected if $2 \%$ of additional high Mw polymer had been added.

Rows 7 to 9 (in Table 8) show behavior for the formulation in 2- and 4-mm-wide fractures. During placement, pressure gradients and effective viscosities were reasonably low. During brine injection after gel placement, the breaching pressure gradients were the highest that we have observed in 2- and 4-mm-wide fractures. After breaching the gel, the stabilized $F_{r r w}$ values were respectable. It would be interesting to compare the performance of a partially formed gel that contained 3.5\% high Mw polymer (possible future work).

More Concentrated Partially Formed Gels. Additional experiments were performed in 4-mmwide fractures using partially formed gels with 4\% low Mw polymer (i.e., Rows 10 and 11 in Table 8) or with 3\% high Mw polymer (Row 12). The performances of these formulations were comparable, but not superior to those of the formulation with 1.5\% high Mw polymer and 2\% low Mw polymer. Consequently, no apparent benefits were gained by using the more concentrated formulations.

Fully Formed Gels in 2- and 4-mm-Wide Fractures. Experiments were also performed in 2and 4-mm-wide fractures where 24-hr-old gels were extruded into place. In two of these experiments, the gel contained 0.5\% high Mw polymer and 2.5\% low Mw polymer (Rows 14 and 16 in Table 8). During placement, the pressure gradients were the highest that we have noted 
in fractures with these widths. During brine flow after placement, the breaching pressure gradients were respectable but low compared with other values in Table 8 associated with use of partially formed gels. The stabilized $F_{r r w}$ values were good, especially in the 4-mm-wide fracture.

Summary. In summary, use of gelants with high concentrations of low Mw polymers (such as MARASEAL) appears appropriate for total shutoff of both matrix and fractures with widths of 1 $\mathrm{mm}$ or less. More work is needed to establish its effectiveness in wider fractures. A concern exists about gravity segregation during placement of low viscosity fluids in vertical fractures.

Use of partially formed gels with both high and low Mw polymers allows relatively low pressure gradients during placement and the highest gel breaching pressure gradients (observed to date) during brine flow after gel placement. However, the polymer concentrations are quite high $(>3 \%)$ and therefore relatively expensive. If high stabilized $F_{r r w}$ values are required, injection of formed gels may be the most effective approach, especially in wide fractures.

\section{Using Secondary Crosslinking Reactions}

Another method to control gel washout involves use of secondary gelation reactions. The concept is to inject a gel that undergoes two separate crosslinking reactions. The first (primary) reaction is timed to take place before entry into the fracture. The second crosslinking reaction occurs after the gel has been placed. The first reaction forms a crosslinked polymer that will not enter the porous rock but will be sufficiently fluid to exhibit relatively low pressure gradients during extrusion. The second reaction strengthens the gel and significantly increases the gel's resistance to washout. The crosslinker for the second reaction should not gel with any component that leaks off into the porous rock. In this way, damage to the porous rock is minimized.

In a test of this concept, the primary reaction involved 0.5\% Alcoflood 935 HPAM crosslinked with $0.5 \%$ formaldehyde and $0.5 \%$ resorcinol. (The gel also contained $1 \% \mathrm{NaCl}$ and $0.1 \% \mathrm{CaCl}_{2}$. Gel injection occurred at 2,000 $\mathrm{cm}^{3} / \mathrm{hr}$ or $4,130 \mathrm{ft} / \mathrm{d}$.) During two baseline experiments, 80 fracture volumes $\left(3,700 \mathrm{~cm}^{3}\right)$ of this 24 -hr-old gel were extruded through 4 -ft long, 1-mm wide fractures. The second and third data rows in Table 9 show results from these experiments. The first data row provides a comparison with the behavior of our standard $1 \mathrm{X}$ gel, where chromium was the crosslinker. As with our other experiments, brine was injected at $100 \mathrm{~cm}^{3} / \mathrm{hr}$ after gel placement and shut-in.

For an experiment represented by the fourth data row in Table 9, five fracture volumes of chromium crosslinker [0.417\% $\mathrm{Cr}(\mathrm{III})$ acetate] were injected immediately after placing 80 fracture volumes of the 24-hr-old resorcinol-formaldehyde-HPAM gel. The fifth data row shows the complementary experiment where five fracture volumes of resorcinol-formaldehyde crosslinker ( $0.5 \%$ resorcinol, $0.5 \%$ formaldehyde) were injected immediately after placing 80 fracture volumes of our standard 24-hr-old 1X Cr(III)-acetate-HPAM gel.

A comparison of the first five data rows in Table 9 indicate that the gel placement pressure gradients and the breaching pressure gradients (during brine flow after gel placement) were similar. The stabilized $F_{r r w}$ values varied significantly, although the data suggests that using chromium as a secondary crosslinker might have some benefit over resorcinol-formaldehyde. 
Table 9-Effect of secondary reactions.

$L_{f}=4 \mathrm{ft}, 0.5 \%$ high Mw HPAM, Gel injection delay $=24 \mathrm{hrs}$, brine rate $=100 \mathrm{~cm}^{3} / \mathrm{hr}, 41^{\circ} \mathrm{C}$

\begin{tabular}{|c|c|c|c|c|c|c|}
\hline $\begin{array}{l}\text { Primary } \\
\text { crosslinker }\end{array}$ & $\begin{array}{l}\text { Secondary } \\
\text { crosslinker }\end{array}$ & $\begin{array}{c}\text { Gel } \\
\text { placement } \\
d p / d l, \\
\text { psi/ft }\end{array}$ & $\begin{array}{l}\text { Effective } \\
\text { viscosity of } \\
\text { gel in } \\
\text { fracture, cp }\end{array}$ & $\begin{array}{c}\text { Brine } \\
\text { breaching } \\
d p / d l, \\
\text { psi/ft } \\
\end{array}$ & $\begin{array}{c}\text { Stabilized } \\
\text { brine } \\
d p / d l, \\
\text { psi/ft } \\
\end{array}$ & $\begin{array}{l}\text { Stabilized } \\
\text { brine } F_{r r w}\end{array}$ \\
\hline \multicolumn{7}{|c|}{$w_{f}=1 \mathrm{~mm}$, gel rate $=2000 \mathrm{~cm}^{3} / \mathrm{hr}$} \\
\hline $\mathrm{Cr} *$ & none & 9.9 & 1280 & 8.2 & 2.29 & 8840 \\
\hline $\mathrm{RF}^{* *}$ & none & 17 & 2200 & 4.4 & 4.38 & 16900 \\
\hline $\mathrm{RF}^{* *}$ & none & 4.5 & 582 & 3.7 & 1.23 & 4750 \\
\hline $\mathrm{RF}^{* *}$ & $\mathrm{Cr}^{*}$ & 16.6 & 2150 & 7.2 & 6.64 & 25600 \\
\hline $\mathrm{Cr}^{*}$ & $\mathrm{RF}^{* *}$ & 8.3 & 1070 & 7.4 & 0.15 & 579 \\
\hline \multicolumn{7}{|c|}{$w_{f}=2 \mathrm{~mm}$, gel rate $=2000 \mathrm{~cm}^{3} / \mathrm{hr}$. } \\
\hline $\mathrm{Cr}^{*}$ & none & 4 & 4140 & 1.2 & 0.27 & 8340 \\
\hline $\mathrm{RF}^{* *}$ & $\mathrm{Cr}^{*}$ & 1.2 & 1240 & 2.6 & 0.11 & 3400 \\
\hline \multicolumn{7}{|c|}{$w_{f}=2 \mathrm{~mm}$, gel rate $=400 \mathrm{~cm}^{3} / \mathrm{hr}$. } \\
\hline $\mathrm{Cr}^{*}$ & none & 2.8 & 14500 & 5.6 & 0.74 & 22900 \\
\hline $\mathrm{RF}^{* *}$ & $\mathrm{Cr}^{*}$ & 0.87 & 4500 & 4.4 & 4.37 & 135000 \\
\hline
\end{tabular}

Additional experiments were performed in 2-mm-wide fractures using resorcinol-formaldehyde as the primary crosslinker and chromium as the secondary crosslinker. One set was performed at $2,000 \mathrm{~cm}^{3} / \mathrm{hr}$ (middle data rows of Table 9), while a second set was performed at $400 \mathrm{~cm}^{3} / \mathrm{hr}$ (last data rows of Table 9). Overall, the behavior did not reveal a major benefit with using secondary crosslinkers. However, we are in the early stages of investigating this concept, and we suspect that future experiments will provide more promising results.

\section{Swelling Polymers}

This section reviews our work investigating the use of swelling polymers to plug fractures. ${ }^{2}$ Three types of dried or particle-form polymers were examined, including (1) Alcoflood 935 HPAM (our standard high Mw polymer used in our 1X gel), (2) Alcosorb polymers (provided by Ciba), and (3) Diamond Seal or Polycrystal (provided by Halliburton). Results from the experiments are summarized in Table 10. For comparison, the first three data rows in Table 10 list results for our standard 24-hr-old Cr(III)-acetate-HPAM gel in 1-, 2-, and 4-mm-wide fractures.

Alcoflood 935. In particular, suspensions of powder-form polymers (Alcoflood 935 HPAM) were quickly prepared and injected before they had a chance to dissolve fully. Hopefully, the partially dissolved polymer "fisheyes" would lodge and swell to plug the fracture. Several experiments were performed to investigate this idea. These experiments used 1-mm-wide (0.04in.) fractures in 4-ft-long Berea sandstone cores. All mixtures had total polymer concentration of $0.5 \%$ and contained $1 \% \mathrm{NaCl}$ and $0.1 \% \mathrm{CaCl}_{2}$. The polymer or gel placement rate was 2,000 $\mathrm{cm}^{3} / \mathrm{hr}$ or $4,130 \mathrm{ft} / \mathrm{d}$, and the temperature was $41^{\circ} \mathrm{C}$. 
Table 10-Use of swelling polymers.

$L_{f}=4 \mathrm{ft}$, gel rate $=2000 \mathrm{~cm}^{3} / \mathrm{hr}$, brine rate $=100 \mathrm{~cm}^{3} / \mathrm{hr}, 41^{\circ} \mathrm{C}$

\begin{tabular}{|c|c|c|c|c|c|c|}
\hline $\begin{array}{l}w_{f}, \\
\mathrm{~mm}\end{array}$ & & $\begin{array}{c}\text { Gel } \\
\text { placement } \\
d p / d l, \\
\text { psi/ft }\end{array}$ & $\begin{array}{l}\text { Effective } \\
\text { viscosity } \\
\text { of gel in } \\
\text { fracture, } \\
\text { cp }\end{array}$ & $\begin{array}{c}\text { Brine } \\
\text { breaching } \\
d p / d l, \\
\text { psi/ft }\end{array}$ & $\begin{array}{l}\text { Stabilized } \\
\text { brine } \\
d p / d l, \\
\text { psi/ft }\end{array}$ & $\begin{array}{l}\text { Stabilized } \\
\text { brine } F_{r r w}\end{array}$ \\
\hline 1 & 24-hr-old 1X gel & 9.9 & 1280 & 8.2 & 2.29 & 8840 \\
\hline 2 & 24-hr-old 1X gel & 4 & 4140 & 1.2 & 0.27 & 8340 \\
\hline 4 & 24-hr-old 1X gel & 2.8 & 23200 & 1.9 & 0.30 & 74100 \\
\hline \multicolumn{7}{|c|}{ Cases where $0.5 \%$ Alcoflood 935 was used in particulate form } \\
\hline 1 & No $\mathrm{Cr}$ & $0.3^{*}$ & 39 & 0.08 & 0.04 & 151 \\
\hline 1 & $+0.0513 \% \mathrm{CrCl}_{3}$ & $1.5^{*}$ & 194 & 7.8 & 5.89 & 22700 \\
\hline 1 & $+0.0513 \% \mathrm{CrCl}_{3}$ on fly & $0.26^{*}$ & 34 & 7 & 0.22 & 849 \\
\hline \multicolumn{7}{|c|}{ Cases where 2.5\% Diamond Seal was used in particulate form } \\
\hline 2 & Diamond Seal only & $14.2^{*}$ & 14700 & 18.2 & 3.95 & 122000 \\
\hline 2 & $+1 \mathrm{X}$ gelant, 1-day wait & 7.8 & 8070 & 19.1 & 1.79 & 55300 \\
\hline 4 & Diamond Seal only & 2.61 & 21600 & 3.8 & 1.76 & 435000 \\
\hline 4 & $+1 \mathrm{X}$ gelant, 1-day wait & $4.1^{*}$ & 33900 & 17.4 & 2.25 & 556000 \\
\hline 4 & +1X gelant, 1-hr wait & $1.8^{*}$ & 14900 & 7.2 & 4.13 & 1020000 \\
\hline \multicolumn{7}{|c|}{ Cases where $0.5 \%$ Alcosorb was used in particulate form with $0.0513 \% \mathrm{CrCl}_{3}$} \\
\hline 4 & Alcosorb 400 & $1.6 *$ & 13200 & 6.2 & 6.00 & 1480000 \\
\hline 4 & Alcosorb AB3C & $1.5^{*}$ & 12400 & 11.4 & 11.4 & 2820000 \\
\hline
\end{tabular}

*Particles showed substantial gravity segregation prior to injection and plugging behavior upon entering the fracture.

In the first experiment (referred to as "No Cr" in Table 10), powder-form polymer was rapidly added to a swirling vortex of brine, placed in our ISCO pumps, and injected into a fractured core. Only 15 minutes elapsed between the first addition of polymer to the brine and the start of injection.

In the second experiment (referred to as “+0.0513\% $\mathrm{CrCl}_{3}$ ”), the procedure was identical to that for the first experiment, except that sufficient $\mathrm{CrCl}_{3}$ was added immediately after polymer addition to make the $\mathrm{CrCl}_{3}$ concentration $0.0513 \%$.

In the third experiment (referred to as “ $+0.0513 \% \mathrm{CrCl}_{3}$ on fly”), the procedure was identical to that for the second experiment, except that the polymer and $\mathrm{CrCl}_{3}$ mixtures/solutions were pumped separately and plumbed to mix just before entering the fractured core. Again, the final $\mathrm{CrCl}_{3}$ concentration was $0.0513 \%$. 
Alcosorb Polymers. Our initial polymer choice (Alcoflood 935) may not have been optimum for this application. Therefore, we wished to study polymers that were designed more specifically to swell after contacting water. For this application, Ciba (Jim Sutphen) kindly provided two polymers, Alcosorb 400 ${ }^{\mathrm{TM}}$ and AlcosorbAB3C $\mathrm{C}^{\mathrm{TM}}$. For each polymer, we prepared formulations that contained $0.5 \%$ polymer, $0.0513 \% \mathrm{CrCl}_{3}, 1 \% \mathrm{NaCl}$, and $0.1 \% \mathrm{CaCl}_{2}$. These formulations were injected immediately after preparation. (The typical delay time between chromium addition and injection into the fracture was 10 to 15 minutes.) All experiments were performed at $41^{\circ} \mathrm{C}$. Results from these studies are summarized in the last two data rows in Table 10.

PolyCrystal or Diamond Seal. Halliburton indicated that they also had a swelling polymer, called PolyCrystal or Diamond Seal ${ }^{\mathrm{TM}}$. This material is a dehydrated crystal of a copolymer. (The exact composition was not specified.) A field application of this material is discussed in Ref. 43. Prentice Creel of Halliburton was kind enough to provide us with a sample of this material. We tested this material using the same procedures described above, except that the formulations contained $2.5 \%$ Diamond Seal, $1 \% \mathrm{NaCl}$, and $0.1 \% \mathrm{CaCl}_{2}$ in water. This concentration of Diamond Seal was selected because we observed the material to swell by a factor of 40 when placed in our brine. Thus, 2.5\% Diamond Seal left little free water standing with the gel, and gravity segregation was hoped not a be problem.

The dry Diamond Seal granules were typically $2 \mathrm{~mm}$ to $4 \mathrm{~mm}$ in diameter. Thus, we chose to inject the Diamond Seal formulations into 2-mm- and 4-mm-wide fractures (both 4-ft long and 1.5-in. high). We felt that 1-mm-wide fractures were too narrow for the material to propagate effectively, although this limitation probably could have been circumvented by simply grinding the dry granules to a smaller size.

For two cases in Table 10 (one each in 2- and 4-mm-wide fractures), 2.5\% Diamond Seal was injected with no other additives. In two other cases (also, one each in 2- and 4-mm-wide fractures), 2.5\% Diamond seal was mixed with our standard $1 \mathrm{X}$ gelant and allowed to age 24 hours before injection into the fractured core. In a final case, 2.5\% Diamond seal was mixed with our standard $1 \mathrm{X}$ gelant and allowed to age one hour before injection into the fractured core. Results are shown in the middle data rows of Table 10.

Summary of Swelling Polymer Results. We compared the behavior of three types of swelling polymers with that of our standard 1-day-old 1X Cr(III)-acetate-HPAM gel (that was prepared using Alcoflood 935). The three swelling polymers included (1) undissolved Alcoflood 935 [with or without Cr(III) crosslinker], (2) Alcosorb polymers with $\mathrm{CrCl}_{3}$, and (3) Diamond Seal [with and without $1 \mathrm{X}$ gel]. The undissolved Alcoflood 935 and the Alcosorb polymers showed significant problems with gravity segregation. Although the Diamond Seal used five times the concentration of the Alcoflood 935 and Alcosorb polymers, problems with gravity segregation were less evident in beaker tests. Nevertheless, gravity segregation was evident during some of the corefloods. The third column in Table 10 indicates reasonable pressure gradients during most of the corefloods. However, most of these values reflect flow of brine that was largely devoid of the swelling polymer. Commonly, the swelling polymer settled to the bottom of the pump barrel and was the last material injected in a given experiment. The sudden onset of severe plugging was evident in all but two of the tests with swelling polymers (indicated by the asterisks in Table 10), and some degree of progressive plugging was seen in all tests. (Chapter 7 of Ref. 2 shows this behavior for 
the various cases.) Thus, these swelling polymers should not be expected to propagate very far into fractures. They will probably screen out at any constrictions that are encountered.

During first brine injection after polymer or gel placement, all three types of swelling polymers showed promise in requiring significant pressure gradients for the brine to first breach the polymer or gel. In 1-mm-wide fractures, the breaching pressure gradients were $8.2 \mathrm{psi} / \mathrm{ft}$ for the $1 \mathrm{X}$ Alcoflood 935 gel and 7.8 psi/ft for an undissolved Alcoflood 935 polymer that was mixed with $\mathrm{CrCl}_{3}$. In 2-mm-wide fractures, the breaching pressure gradients were $1.2 \mathrm{psi} / \mathrm{ft}$ for the $1 \mathrm{X}$ Alcoflood 935 gel and $18.2 \mathrm{psi} / \mathrm{ft}$ for the Diamond Seal. In 4-mm-wide fractures, the breaching pressure gradients were $1.9 \mathrm{psi} / \mathrm{ft}$ for the $1 \mathrm{X}$ Alcoflood 935 gel, $17.4 \mathrm{psi} / \mathrm{ft}$ for Diamond Seal mixed with $1 \mathrm{X}$ gelant, and $11.4 \mathrm{psi} / \mathrm{ft}$ for Alcosorb $\mathrm{AB} 3 \mathrm{C}$ with $\mathrm{CrCl}_{3}$. A more detailed analysis of these results can be found in Ref. 2 .

\section{Incorporating Particulates}

Polypropylene Fibers. A set of experiments was performed incorporating 0.5\% Forta SuperSweep $^{\mathrm{TM}}$ polypropylene fibers into our standard 1X Cr(III)-acetate-HPAM gelant [with 0.5\% HPAM and $0.0417 \% \mathrm{Cr}(\mathrm{III})$ acetate]. The fibers were roughly 0.5-in. (13-mm) long. Once dispersed in brine or gelant, these fibers exhibited the least gravity segregation of any particulate that we have tested to date. After incorporation of the fiber, the formulations were aged for 24 hours at $41^{\circ} \mathrm{C}$, and then extruded $\left(3,700 \mathrm{~cm}^{3}\right.$ total gelant volume) through one of three fractured cores using an injection rate of 2,000 $\mathrm{cm}^{3} / \mathrm{hr}$. These Berea cores were $4-\mathrm{ft}(122-\mathrm{cm})$ long and had smooth-face fracture widths of $1 \mathrm{~mm}, 2 \mathrm{~mm}$, or $4 \mathrm{~mm}$. During placement in the 1-mm-wide fracture, moderate plugging behavior (i.e., steady increase in pressure) was noted at the fracture inlet, but stable pressure gradients were observed throughout the remainder of the fractureaveraging about $10 \mathrm{psi} / \mathrm{ft}$. This stabilized pressure gradient was similar to that for gel without the fibers (Table 11). When extruding the fiber formulation into 2-mm-wide and 4-mm-wide fractures, pressure gradients at the fracture entrance were greater than in the remainder of the fracture, but these entrance pressures did not increase with throughput. For the remainder of the fracture, placement pressure gradients were consistent with gel formulations that did not contain fibers (3 psi/ft and $1.6 \mathrm{psi} / \mathrm{ft}$, respectively). (See second column of Table 11.)

During brine injection after gel placement in the 1-mm-wide fracture, the pressure gradient required to first breach the gel was quite high $(>100 \mathrm{psi} / \mathrm{ft})$ in the first fracture section. However, it was quite low for the middle fracture sections (1.9 psi/ft from the fourth column of Table 11). For comparison, the $1 \mathrm{X}$ gel without fibers exhibited a breaching pressure gradient of $8.2 \mathrm{psi} / \mathrm{ft}$ in the middle sections of a 1-mm-wide fracture.

The pressure gradients required to first breach the gel were 9.4, and $5.9 \mathrm{psi} / \mathrm{ft}$, for fracture widths of 2 and $4 \mathrm{~mm}$, respectively. These values were significantly greater than those for formulations that were placed without the fiber. After first breach of the gel, the flow capacity of the fracture after gel placement was substantially less than that before gel placement. In the 2-mm and 4-mmwide fractures, the stabilized $F_{r r w}$ values were significantly greater for formulations with fibers than without fibers.

In summary, the main advantage associated with use of the polypropylene fibers is their resistance to gravity segregation after dispersion in brine or gelant. In fractures with widths of at 
least $2 \mathrm{~mm}$, they did not exhibit progressive plugging during placement and showed placement pressure gradients similar to gel formulations without the fiber. The presence of the fiber significantly increased the gel's resistance to first breach by brine flow in 2- and 4-mm-wide fractures. The breaching pressure gradients were not as large as for some concentrated gels (with 3.5\%-5.5\% polymer, Table 8). However, their material requirements and costs (i.e., polymer and/or particulate concentrations) were substantially lower than those for concentrated gels.

Table 11-Use of particulates.

Brine rate $=100 \mathrm{~cm}^{3} / \mathrm{hr}, 41^{\circ} \mathrm{C}$

\begin{tabular}{|c|c|c|c|c|c|}
\hline $\begin{array}{c}w_{f}, \\
\mathrm{~mm}\end{array}$ & $\begin{array}{c}\text { Gel placement } \\
d p / d l, \mathrm{psi} / \mathrm{ft}\end{array}$ & $\begin{array}{c}\text { Effective viscosity } \\
\text { of gel in fracture, } \\
\text { cp }\end{array}$ & $\begin{array}{c}\text { Brine } \\
\text { breaching } \\
d p / d l, \mathrm{psi} / \mathrm{ft}\end{array}$ & $\begin{array}{l}\text { Stabilized brine } \\
d p / d l, \mathrm{psi} / \mathrm{ft}\end{array}$ & $\begin{array}{l}\text { Stabilized } \\
\text { brine } F_{r r w}\end{array}$ \\
\hline \multicolumn{6}{|c|}{ 24-hr-old 1X gel [0.5\% high Mw HPAM, 0.0417\% Cr(III) acetate], Gel rate=2000 cm $3 / \mathrm{hr}$} \\
\hline 1 & 9.9 & 1280 & 8.2 & 2.29 & 8840 \\
\hline 2 & 4 & 4140 & 1.2 & 0.27 & 8340 \\
\hline 4 & 2.8 & 23200 & 1.9 & 0.30 & 74100 \\
\hline \multicolumn{6}{|c|}{ 24-hr-old 1 X gel with $0.5 \% 1 / 2$ " fibers, Gel rate $=2000 \mathrm{~cm}^{3} / \mathrm{hr}$} \\
\hline 1 & 9.9 & 1280 & 1.9 & 1.82 & 7030 \\
\hline 2 & 3 & 3100 & 9.4 & 3.3 & 102000 \\
\hline 4 & 1.6 & 13200 & 5.9 & 2.43 & 600000 \\
\hline \multicolumn{6}{|c|}{ 0.5-hr 1.5\% high Mw HPAM, 2\% low Mw HPAM, 2.5\% 1/8” fibers, Gel rate=8000 $\mathrm{cm}^{3} / \mathrm{hr}$} \\
\hline 4 & 0.6 & 1220 & 14.4 & 0.87 & 215000 \\
\hline
\end{tabular}

Partially Formed Gels with Fiberglass. We also investigated the effect of incorporating 2.5\% chopped fiberglass strands (each typically 1/8-in. or 3-mm long) into a partially formed gel (0.5hr-old) with 1.5\% high Mw HPAM and 2\% low Mw HPAM. During placement in a 4-mm-wide fracture (with smooth faces), the effective viscosity of this partially formed gel formulation was $1,220 \mathrm{cp}$ - similar to values for partially formed gel without the fiberglass strands. Pressure gradients were fairly stable during gel placement, and no screen-out behavior was observed. During first brine injection after gel placement, the pressure gradient required to first breach the gel was $14.4 \mathrm{psi} / \mathrm{ft}$ in the middle sections of the fracture (last row of Table 11). The stabilized $F_{r r w}$ value was 215,000. These values were somewhat greater than those for the formulation without fiberglass (middle row of Table 8), but they were not as high as we had hoped. Upon opening the fracture at the end of the experiment, the fiberglass strands were evenly distributed along the fracture.

\section{Effect of a Constriction}

The above experiment was performed using a 4-mm-wide fracture with smooth-sawed faces. The real value of adding the fiberglass strands became evident in fractures with variable widths (i.e., constrictions). Two experiments were performed using fractures that were 4-mm wide for the first 15 inches of the fracture but narrowed to $0.5 \mathrm{~mm}$ for the last 9 inches. In these cases, the partially formed gel contained 1.5\% Alcoflood 935 [crosslinked with $\operatorname{Cr}(\mathrm{III})$ acetate] and 2.5\% fiberglass. Problems with gravity segregation of the fiberglass were noted in both experiments. 
Nevertheless, the small fraction of fiberglass that remained suspended screened out at the entrance to the $0.5-\mathrm{mm}$ portion of the fracture and effectively plugged the fracture. During brine injection after gel placement, all fluid flowed through the porous rock, with little flow through the fracture. The gel/fiberglass plug withstood pressure gradients of at least $75 \mathrm{psi} / \mathrm{ft}$. The plug withstood the same pressure gradient when the flow direction was reversed. Evidently, the plug was lodged very effectively in the constriction.

As suggested during the discussion of the swelling polymers, screen-outs can play an important role in the effectiveness of a fracture-plugging material. This will be an important area for our future work.

\section{Disproportionate Permeability Reduction in Fractures}

In Ref. 25, we reported that the pressure gradient required to first breach gel in a fracture when injecting oil was about the same as that when injecting brine. To date, we have found no evidence to the contrary, although additional studies are certainly warranted.

After breaching the gel with either brine or oil, we have observed a number of cases where the stabilized permeability to oil in the fracture was noticeably (up to 166 times) greater than that to brine. ${ }^{2,25,34,35}$ However, in all cases, the permeability reduction to oil was substantial (by factors ranging from 42 to 42,000). The permeability reductions are sufficiently large that the flow capacity of the fracture to both oil and water would be dramatically reduced. Thus, based on our observations to date, disproportionate permeability reductions within the fracture itself are not currently of practical interest. In contrast, disproportionate permeability reduction in the porous rock next to fracture faces is eminently useful and exploitable for fractures that cut through both water and hydrocarbon zones. ${ }^{7-9}$

We should leave some hope that value could be found for disproportionate permeability reduction in fractures. Recall that all breaching pressure gradients reported in this chapter were measured at a fixed injection rate of $100 \mathrm{~cm}^{3} / \mathrm{hr}$. Also, recall from our studies of disproportionate permeability reduction in porous rock, that oil forced pathways through gel even with relatively low pressure gradients. In concept, oil could force a pathway (e.g., by dehydration) through gel in a fracture, given sufficient time. It remains to be established whether this concept can be practically implemented in field applications.

\section{Tight Fractures}

Partially Formed Gel. Although much of our current work investigates how to effectively plug moderate to wide fractures, we also wondered how narrow a fracture could be plugged with a partially formed gel. Using a closed, sawed-surface fracture, brine injection data was used to estimate a fracture width of $0.052 \mathrm{~mm}$. This is the tightest fracture that we have investigated to date. Interestingly, we found that a 5-hr-old partially formed gel [containing 0.5\% Alcoflood 935 and $0.0417 \% \mathrm{Cr}(\mathrm{III})$ acetate at $41^{\circ} \mathrm{C}$ ] could not be forced into the fracture, even with pressure gradients up to $65 \mathrm{psi} / \mathrm{ft}$. In some cases, this behavior may be desirable-in particular, if gel is prevented from entering narrow secondary fractures where oil flows, but gel readily penetrates into wider fractures that are the primary conduits for water. 
24-hr-Old Low Concentration Gels. We wondered whether low concentrations of gel might show value in penetrating into and plugging tight fractures more effectively than conventional gels with higher concentrations. (Baojun Bai et al. performed preliminary work investigating this idea. ${ }^{54,55}$ ) In one set of experiments, we examined the use of a 24 -hr-old gel that contained $0.15 \%$ Alcoflood 935, $0.0125 \% \mathrm{Cr}(\mathrm{III})$ acetate, $1 \% \mathrm{NaCl}$ and $0.01 \% \mathrm{CaCl}_{2}$. Using our standard procedure, $3,700 \mathrm{~cm}^{3}$ of this gel were extruded through fractures at $2,000 \mathrm{~cm}^{3} / \mathrm{hr}$. Three fracture widths were examined, including $0.15 \mathrm{~mm}, 0.5 \mathrm{~mm}$, and $1 \mathrm{~mm}$. (All fractures had smooth-sawed faces.) Pressure gradients and effective viscosities were low during gel placement, ranging from 3 to $12 \mathrm{cp}$ (Table 12). After gel placement and shut-in, brine was injected at $100 \mathrm{~cm}^{3} / \mathrm{hr}$. Unfortunately, in all three fractures, the pressure gradients for breaching the gel were quite low. The stabilized $F_{r r w}$ values were also low, especially in the tightest fracture. Finally, placement of the gel caused no significant diversion of brine flow toward the matrix (i.e., nearly $100 \%$ of the post-placement brine flow occurred through the fractures). Thus, our first experiments were not as promising as we had hoped.

Table 12-Use of low-concentration gels in tight fractures.

$L_{f}=4 \mathrm{ft}$, 24-hr-old gel, gel rate $=2000 \mathrm{~cm}^{3} / \mathrm{hr}$, brine rate $=100 \mathrm{~cm}^{3} / \mathrm{hr}, 41^{\circ} \mathrm{C}$

\begin{tabular}{|c|c|c|c|c|c|c|}
\hline $\begin{array}{c}\text { Gel } \\
w_{f}, \mathrm{~mm}\end{array}$ & $\begin{array}{c}\text { placement } \\
d p / d l, \\
\mathrm{psi} / \mathrm{ft}\end{array}$ & $\begin{array}{c}\text { Effective } \\
\text { viscosity } \\
\text { of gel in } \\
\text { fracture, cp }\end{array}$ & $\begin{array}{c}\text { Brine } \\
\text { breaching } \\
d p / d l, \\
\mathrm{psi} / \mathrm{ft}\end{array}$ & $\begin{array}{c}\text { Stabilized } \\
\text { brine } \\
d p / d l, \\
\mathrm{psi} / \mathrm{ft}\end{array}$ & $\begin{array}{c}\text { Stabilized } \\
\text { brine } F_{r r w}\end{array}$ & $\begin{array}{c}\text { Matrix } \\
\text { flow, } \\
\%\end{array}$ \\
\hline $0.15 \%$ high Mw HPAM, $0.0125 \%$ Cr(III) acetate \\
\hline 0.15 & 7.4 & 3 & 0.25 & 0.21 & 3 & 0 \\
\hline 0.5 & 0.27 & 4 & 0.13 & 0.11 & 53 & 0 \\
\hline 1 & 0.096 & 12 & 0.088 & 0.063 & 243 & 0 \\
\hline \multicolumn{7}{|c|}{$0.2 \%$ high Mw HPAM, $0.0167 \%$ Cr(III) acetate } \\
\hline 0.1 & 31.0 & 7 & 20.0 & 8.8 & 40 & 100 \\
\hline 0.5 & 0.21 & 3 & 0.076 & 0.056 & 27 & 7 \\
\hline 1 & 0.028 & 4 & 0.056 & 0.036 & 138 & 0 \\
\hline
\end{tabular}

In a second set of experiments, the polymer concentration was $0.2 \%$ instead of $0.15 \%$. These experiments were repeated in three similar fractures. Results are also shown in Table 12. As with the $0.15 \%$ HPAM gel, effective viscosities were relatively low during gel placement (3 to $7 \mathrm{cp}$ ) in 0.1 to $1 \mathrm{~mm}$ wide fractures. During brine injection after gel placement in the 0.5 and $1 \mathrm{~mm}$ wide fractures, the pressure gradient to breach the gel was very low, and the stabilized pressure gradient after gel breach was also very low. Furthermore, the gel was ineffective in diverting flow away from the fracture and into the matrix. In contrast, in the $0.1 \mathrm{~mm}$ wide fracture, the gel breaching pressure gradient was reasonably high, $20 \mathrm{psi} / \mathrm{ft}$. (However, the pressure gradient for gel breaching by brine was less than the pressure gradient during gel placement, $31 \mathrm{psi} / \mathrm{ft}$ ). Also, the stabilized pressure gradient during brine flow ( $8.8 \mathrm{psi} / \mathrm{ft})$ was substantially greater than the other values in Table 12. Finally, for this case, the gel effectively diverted all flow away from the fracture and into the matrix (last column of Table 12). Thus, for the right polymer concentration and fracture width, use of low concentrations of polymer gels may have value in plugging tight fractures. More work remains to investigate this idea. 


\section{Conclusions}

In cases where gels are intended to plug fractures, our ultimate goal is to identify a material that will (1) exhibit low pressure gradients and effective viscosity during placement, (2) not suffer from significant gravity segregation during placement, (3) provide a high pressure gradient for breaching of the gel during brine flow after gel placement, (4) provide high resistance to brine flow if the gel is breached, and (5) provide performance that is insensitive to fracture aperture (or as an ideal alternative-selectively plug wide fractures in preference to narrow fractures).

Gelants and partially formed gels show low viscosities and pressure gradients during placement. Use of gelants with high concentrations of low Mw polymers appears appropriate for total shutoff of both matrix and fractures with widths of $1 \mathrm{~mm}$ or less. More work is needed to establish its effectiveness in wider fractures. Concern exists about gravity segregation during placement in vertical fractures. Gelants can penetrate significantly into (and potentially damage) porous rock, whereas this concern is mitigated for partially formed gels. With proper placement, concentrated gelants and partially formed gels can provide high breaching pressure gradients after gel placement. Gels with combinations of high and low molecular weight polymers received particular emphasis during our investigations. These materials offer advantages for convenient formulation during field applications. Like other materials, they provide mixed performance with respect to stabilized permeability reduction after gel placement, and are fairly expensive when concentrated formulations must be used.

Formed gels generally provide high pressure gradients and effective viscosities during placement. The disadvantage that this presents with respect to injectivity is partially offset by reduced problems with gravity segregation. Rate control during placement has shown potential in placing very concentrated, washout-resistant gels in fractures, even though low concentration gels were injected. If high stabilized $F_{r r w}$ values are required, injection of formed gels may be the most effective approach, especially in wide fractures.

Preliminary experiments with secondary crosslinking reactions did not reveal any performance breakthroughs. However, this area is worthy of additional study.

Swelling polymers commonly showed gravity segregation and abrupt screen-out behavior in fractures. These properties impose placement limitations, especially when deep penetration is desired. Nevertheless, they also show sufficient potential to warrant further investigation.

Gels that incorporated density-matched fiber particulates showed significant potential in strengthening the gel's resistance to breach after gel placement. As with some other materials, key issues associated with their use include relatively high effective viscosities during placement and screen-outs limiting depth of penetration in fractures. On the other hand, clever exploitation of screen-outs could significantly improve the cost effectiveness of some materials in certain circumstances.

All materials investigated to date showed significant performance variations with fracture width. High pressure gradients and limited distance of penetration are common problems in tight 
fractures. Gravity segregation and low resistance to breaching are common problems in wide fractures. These will be key issues to address in future work.

Although gels can exhibit disproportionate permeability reduction in fractures, the levels of permeability reduction for oil flow are too high to allow practical exploitation in most circumstances. In contrast, disproportionate permeability reduction provided by gels that form in porous rock (adjacent to the fractures) has considerable potential in fractured systems. 


\section{FUTURE WORK}

This chapter summarizes future work that remains to be performed under a new project, “Aperture-Tolerant, Chemical-Based Methods to Reduce Channeling.” From our current project, a need has become evident for means to reliably reduce water flow from fractures, fracture-like features, and void pathways with a wide range of apertures.

\section{Problem Statement}

Many methods have been implemented to improve sweep efficiency in reservoirs and reduce excess water production. For wells that are not fractured and where impermeable barriers prevent cross flow between adjacent strata, cement plugs, cement squeezes, sand plugs, packers, and bridge plugs are frequently used. However, these methods generally treat only the wellbore. They are usually ineffective if fluids can cross flow vertically out beyond the wellbore (e.g., if a vertical fracture is present). Cement, sand, ultra-fine cement, and foamed cement can penetrate into wide fractures and voids. However, they typically gravity segregate when placed, leaving the top portions of the channel open and often negating the benefits of the treatment.

Polymer floods can also effectively improve sweep efficiency, especially in reservoirs with moderately viscous oils. ${ }^{17,44-46}$ However, fractures and fracture-like features can allow expensive polymer solutions to simply channel between injection and production wells. If those fractures could be plugged before commencing polymer injection, the polymer flood could be much more efficient. ${ }^{47}$ This type of problem may be a factor with almost any type of EOR flood. ${ }^{31,32,48-50}$

In many cases, gels have effectively mitigated channeling through fractures, fracture-like features, and voids. Gels have reduced channeling through fractures in waterfloods ${ }^{31,48}$ and gas floods ${ }^{32,41,49,50}$. Gels have also reduced water production in wells where fractures, fracture-like features, and voids connect to an underlying aquifer. ${ }^{9,51-53}$ Although many gel treatments have been quite successful, many important questions exist concerning how best to design and implement them. Current methods are very sensitive to the aperture of the fracture or void. Unfortunately, these apertures are usually not known in field applications. Thus, a particular need exists for treatments that are not sensitive to the aperture of the fracture or void.

\section{Objectives of Future Work}

The goal of the new project is to develop aperture-tolerant, chemical-based methods to reduce channeling through voids (e.g., fractures, vugs, karst) during hydrocarbon production. One objective is to develop materials that can be effectively placed and will consistently minimize flow through voids with a wide range of apertures. A second objective is to develop methods to minimize water entry into voids from the surrounding rock. This aspiration requires chemicals (i.e., gels, polymers) that predictably and controllably reduce the permeability to water much more than that to hydrocarbon.

\section{Scope of Future Work}

We will fulfill the project objectives during a three-year effort, using two parallel activities. One effort will develop gel-based materials that readily penetrate a predictable distance into voids and then set up to effectively resist washout in voids with a wide range of apertures (e.g., fracture widths). Within this activity, we will investigate blocking-agent placement and washout 
properties as a function of (1) gelant/formed-gel composition and placement rate, (2) secondary crosslinking reactions that strengthen the gel after placement, and (3) reactive and non-reactive particulate compositions. The second effort will utilize polymers and gels that selectively damage porous rock to inhibit water flow into voids. If water does not enter the void, it won't channel to production wells. This effort will include (1) pore-level studies using X-ray computed microtomography to confirm the mechanism for disproportionate permeability reduction and (2) mechanistic corefloods to identify conditions of maximum disproportionate permeability reduction and reproducibility. Both tasks will involve laboratory and theoretical studies. Also, both tasks will incorporate analyses of selected field applications to evaluate the efficacy and mechanism of action for different gel treatment approaches.

\section{Questions to Be Addressed}

The following questions will be addressed in our future work:

1. When using void-plugging materials:

(a) how much reduction in flow capacity is needed?

(b) how far must the blocking agent penetrate into the void channel?

(c) what strength properties must the blocking agent possess to resist washout?

2. To what extent can we maximize resistance to washout for blocking agents while minimizing the required pressure gradients during placement by:

(a) optimization of placement rate and gel composition?

(b) use of secondary crosslinking reactions?

(c) use of reactive and non-reactive particulates?

3. For void-plugging materials, are lab and field observations consistent?

4. When using disproportionate permeability reducers:

(a) how much should the gel/polymer reduce permeability to water versus to hydrocarbon?

(b) how far should the blocking agent penetrate into the porous rock adjacent to the void channel?

(c) how far should the blocking agent penetrate along a void?

5. Is the mechanism for disproportionate permeability reduction different for adsorption-based polymers versus gels and for different types of porous media?

6. Can disproportionate permeability reduction be optimized by adjusting the elastic properties or the inherent gel permeability?

7. For disproportionate permeability reducers, are lab and field results consistent? 


\section{NOMENCLATURE}

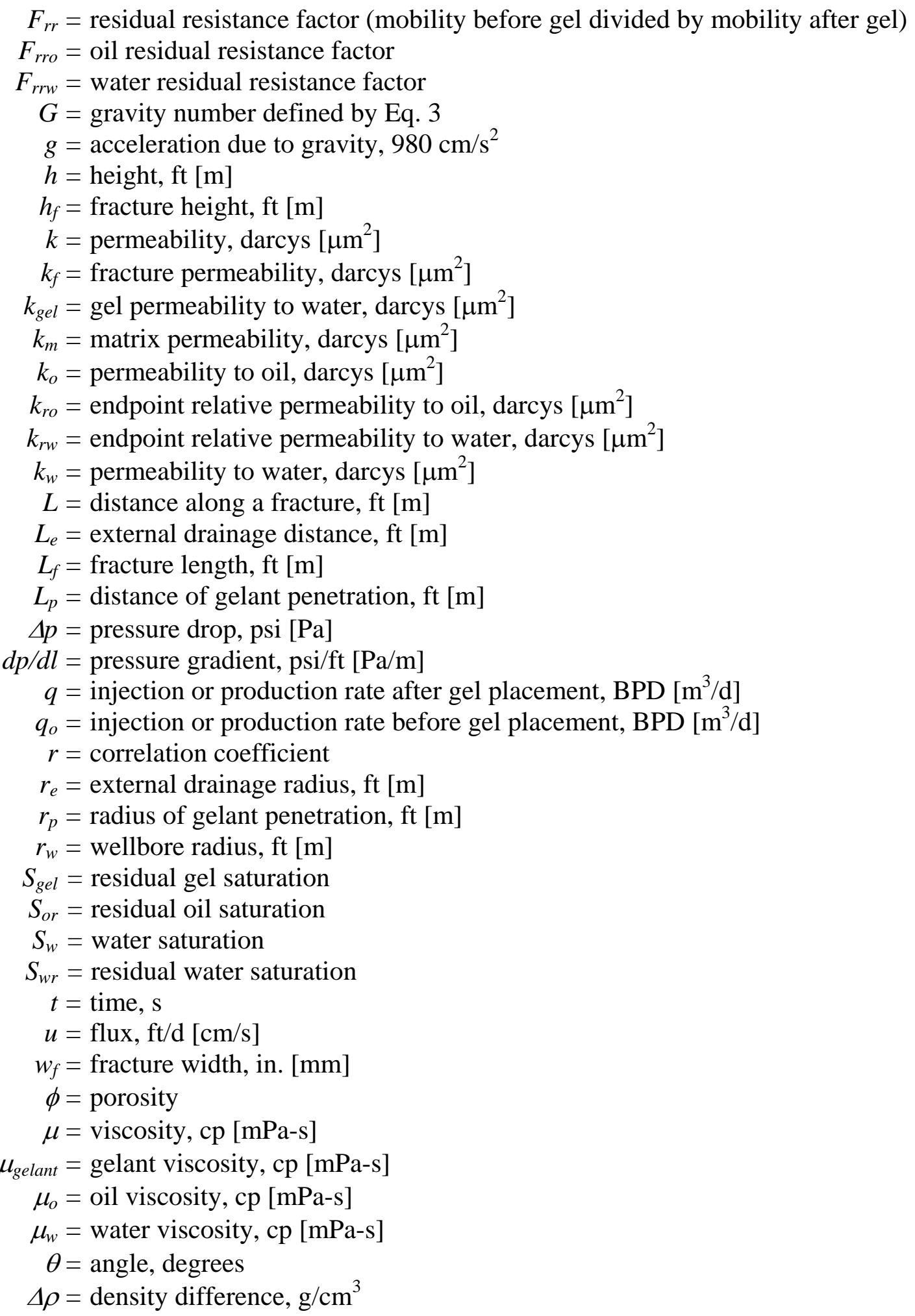




\section{REFERENCES}

1. Seright, R.S.: “Conformance Improvement Using Gels,” Annual Technical Progress Report (U.S. DOE Report DOE/BC/15316-2), U.S. DOE Contract DE-FC26-01BC15316 (Sept. 2002).

2. Seright, R.S.: “Conformance Improvement Using Gels,” Annual Technical Progress Report (U.S. DOE Report DOE/BC/15316-4), U.S. DOE Contract DE-FC26-01BC15316 (Sept. 2003).

3. Liang, J., Lee, R.L., and Seright, R.S.: "Placement of Gels in Production Wells," SPE Production \& Facilities (Nov. 1993) 276-284; Transactions AIME 295.

4. Seright, R.S.: "Placement of Gels to Modify Injection Profiles," paper SPE/DOE 17332 presented at the 1988 SPE/DOE Enhanced Oil Recovery Symposium, Tulsa, OK, April 1720.

5. Seright, R.S., Prodanovic, M., and Lindquist, W.B.: "X-Ray Computed Microtomography Studies of Disproportionate Permeability Reduction,” paper SPE 89393 presented at the 2004 SPE/DOE Symposium on Improved Oil Recovery, Tulsa, OK, April 17-21.

6. Zaitoun A. and Kohler, N.: "Two-Phase Flow through Porous Media: Effect of an Adsorbed Polymer Layer,” paper SPE 18085 presented at the 1988 SPE Annual Technical Conference and Exhibition, Houston, TX, Oct. 2-5.

7. http://baervan.nmt.edu/randy/

8. Seright, R.S., Liang, J., and Seldal, M.: "Sizing Gelant Treatments in Hydraulically Fractured Production Wells,” SPE Production \& Facilities (Nov. 1998) 223-229.

9. Marin, A., Seright, R., Hernandez, M., Espinoza, M., Mejias, F.: “Connecting Laboratory and Field Results for Gelant Treatments in Naturally Fractured Production Wells,” paper SPE 77411 presented at the 2002 SPE Annual Technical Conference and Exhibition, San Antonio, TX, Sept. 29- Oct. 2.

10. Lane, R.H., and Sanders, G.S.: "Water Shutoff through Fullbore Placement of Polymer Gel in Faulted and Fractured Producers of the Prudhoe Bay Field,” paper SPE 29475 presented at the 1995 SPE Production Operations Symposium, Oklahoma City, OK, April 2-4.

11. Stanley, F.O., et al.: "Improving Hydrocarbon/Water Ratios in Producing Wells-An Indonesian Case History Study,” paper SPE 36615 presented at the 1996 SPE Annual Technical Conference and Exhibition, Denver, CO, Oct. 6-9.

12. Seright, R.S.: “Impact of Dispersion on Gel Placement for Profile Control," SPE Reservoir Engineering (Aug. 1991) 343-352.

13. Koval, E.J.: "A Method for Predicting the Performance of Unstable Miscible Displacement in Heterogeneous Media,” SPE Journal (June 1963) 145-154.

14. Seright, R.S.: "Effect of Rock Permeability on Gel Performance in Fluid-Diversion Applications,” In Situ (1993) 17, No. 4, 363-386.

15. Seright, R.S, Liang J., Lindquist, W.B., and Dunsmuir, J.H.: "Characterizing Disproportionate Permeability Reduction Using Synchrotron X-Ray Computed Microtomography,” SPE Reservoir Evaluation \& Engineering (Oct. 2002) 355-364.

16. Seright, R.S, Liang J., Lindquist, W.B., and Dunsmuir, J.H.: "Use of X-Ray Computed Microtomography to Understand Why Gels Reduce Permeabilty to Water More Than That to Oil,” J. Petroleum Science and Engineering, 39, Nos. 3-4 (Sept. 2003) 217-230. 
17. Wang, D., et al: "Study of the Mechanism of Polymer Solution with Visco-Elastic Behavior Increasing Microscopic Oil Displacement Efficiency and the Forming of Steady Oil Thread Flow Channels,” paper SPE 68723 presented at the 2001 SPE Asia Pacific Oil and Gas Conference and Exhibition, Jakarta, Indonesia, April 17-19.

18. Seright, R.S.: "Using Chemicals to Optimize Conformance Control in Fractured Reservoirs," Annual Technical Progress Report (U.S. DOE Report DOE/BC/15110-2), U.S. DOE Contract DE-AC26-98BC15110, (Sept. 1999) 21-28.

19. Chatzis, I., Morrow, N.R., and Lim, H.T.: "Magnitude and Detailed Structure of Residual Oil Saturation,” SPE Journal (April 1983) 311-326.

20. Al-Sharji, H.H., et al.: "Pore-Scale Study of the Flow of Oil and Water through Polymer Gels,” paper SPE 56738 presented at the 1999 SPE Annual Technical Conference and Exhibition, Houston, TX, Oct. 3-6.

21. Willhite, G.P., et al.: "Mechanisms Causing Disproportionate Permeability in Porous Media Treated With Chromium Acetate/HPAAM Gels,” SPE Journal (March 2002) 100-108.

22. Ganguly, S., et al.: "Effect of Flow Rate on Disproportionate Permeability Reduction," paper SPE 80205 presented at the 2003 SPE International Symposium on Oilfield Chemistry, Houston, TX, Feb. 5-7.

23. Nguyen, T.Q., et al.: "Effect of Composition of a Polyacrylamide-Chromium(III) Acetate Gel on the Magnitude of Gel Dehydration and Disproportionate Permeability Reduction,” paper SPE 89404 presented at the 2004 SPE/DOE Symposium on Improved Oil Recovery, Tulsa, OK, April 17-21.

24. Liu, J., and Seright, R.S.: "Rheology of Gels Used For Conformance Control in Fractures," SPE Journal (June 2001) 120-125.

25. Seright, R.S.: "Washout of Cr(III)-Acetate-HPAM Gels from Fractures,” paper SPE 80200 presented at the 2003 SPE International Symposium on Oilfield Chemistry, Houston, TX, Feb. 5-7.

26. Liang, J., Sun, H., Seright, R.S.: "Reduction of Oil and Water Permeabilities Using Gels," paper SPE 24195 presented at the 1992 SPE/DOE Symposium on Enhanced Oil Recovery, Tulsa, OK, April 22-24.

27. Seright, R.S.: "An Alternative View of Filter Cake Formation in Fractures Inspired by Cr(III)-Acetate-HPAM Gel Extrusion,” SPE Production and Facilities (Feb. 2003) 65-72.

28. Smith, D.K.: Cementing, SPE Monograph 4, Society of Petroleum Engineers, Richardson, TX (1987).

29. Sabins, F.L., and Sutton, D.L.: “The Relationship of Thickening Time, Gel Strength, and Compressive Strength of Oilwell Cements,” SPEPE (March 1986) 143-152.

30. Personal communication with Prentice Creel (Halliburton), March 10, 2004.

31. Sydansk, R.D. and Moore, P.E.: “Gel Conformance Treatments Increase Oil Production in Wyoming,” Oil \& Gas J. (Jan. 20, 1992) 40-45.

32. Hild, G.P. and Wackowski, R.K.: "Reservoir Polymer Gel Treatments To Improve Miscible CO2 Flood,” SPEREE (April. 1999) 196-204.

33. Seright, R.S.: "Use of Preformed Gels for Conformance Control in Fractured Systems," SPE Production \& Facilities (Feb. 1997) 59-65.

34. Sydansk, R.D., Al-Dhafeeri, A., Xiong, Y., Schrader, R., and Seright, R.S..: "Characterization of Partially Formed Polymer Gels for Application to Fractured Production Wells for Water-Shutoff Purposes," paper SPE 89401 presented at the 2004 SPE/DOE Symposium on Improved Oil Recovery, Tulsa, OK, April 17-21. 
35. Sydansk, R.D., Al-Dhafeeri, A., Xiong, Y., and Seright, R.S..: "Polymer Gels Formulated with a Combination of High and Low Molecular-Weight Polymers Provide Improved Performance for Water-Shutoff Treatments in Fractured Production Wells," paper SPE 89402 presented at the 2004 SPE/DOE Symposium on Improved Oil Recovery, Tulsa, OK, April 17-21.

36. Personal communication with R.D. Sydansk, April 11, 2002.

37. Ganguly, S., et al.: "The Effect of Fluid Leakoff on Gel Placement and Gel Stability in Fractures,” SPE Journal (Sept. 2002) 309-315.

38. Seright, R.S.: “Gel Propagation through Fractures," SPE Production \& Facilities (Nov. 2001) 225-231.

39. Seright, R.S.: “Gel Placement in Fractured Systems,” SPE Production \& Facilities (Nov. 1995) 241-248.

40. McCool, C.S., Green, D.W., and Willhite, G.P.: “Fluid/Rock Interactions Between Xanthan/Chromium(III) Gel Systems and Dolomite Core Material," SPE Production \& Facilities (Aug. 2000) 159-167.

41. Borling, D.C.: "Injection Conformance Control Case Histories Using Gels at the Wertz Field $\mathrm{CO}_{2}$ Teriary Flood in Wyoming, USA,” paper SPE 27825 presented at the 1994 SPE/DOE Symposium on Improved Oil Recovery, Denver, CO, April 17-20.

42. Southwell, G.P. and Sydansk, R.D.: "Permeability or Fluid Mobility Reduction Treatment for a Hydrocarbon-Bearing Formation Using a Dual Molecular Weight Polymer Gel," U.S. Patent 6,025,304 (2000).

43. Green, C., Creel, P., McDonald, S., Ryan, T.: "Utilization of a Crystallized Hydrating Copolymer to Modify an Injectivity Problem in a Horizontal $\mathrm{CO}_{2}$ WAG Injector in the South Cowden Unit, Ector County, Texas-Post treatment Coil Tubing Acidizing StimulationCase History,” Southwestern Petroleum Short Course, Lubbock, TX (2003).

44. Maitin, B.K.: "Performance Analysis of Several Polyacrylamide Floods in North German Oil Fields," paper 24118 presented at the 1992 SPE/DOE Symposium on Improved Oil Recovery, Tulsa, OK, April 22-24.

45. Koning, E.J.K., Mentzer, E., and Heemskerk, J.: "Evaluation of a Pilot Polymer Flood in the Marmul Field, Oman,” paper SPE 18092 presented at the 1988 SPE Annual Technical Conference and Exhibition, Houston, TX, Oct. 2-5.

46. Putz, A.G., Bazin, B., and Pedron, B.M.: "Commercial Polymer Injection in the Courtenay Field, 1994 Update," presented at the 1994 SPE Annual Technical Conference and Exhibition, New Orleans, LA, Sept. 25-28.

47. DuBois, B.M.: "North Stanley Polymer Demonstration Project, Third Annual and Final Report,” Report BETC/RI-78/19, U.S. Dept. of Energy, Washington, D.C. (Nov. 1978).

48. O’Brien, W.J., Stratton, J.J., and Lane, R.H.: "Mechanistic Reservoir Modeling Improves Fissure Treatment Gel Design in Horizontal Injectors, Idd El Shargi North Dome Field, Qatar”, paper SPE 56743 presented at the 1999 SPE Annual Technical Conference and Exhibition, Houston, TX, Oct. 5-8.

49. Woods, P. et al: "In Situ Polymerization Controls $\mathrm{CO}_{2} /$ Water Channeling at Lick Creek", SPE/DOE paper 14958 presented at the 1986 SPE/DOE Symposium on Enhanced Oil Recovery, Tulsa, OK, April. 20-23.

50. Wagner, O.R., Weisrock, W.P., and Patel, C.: "Field Application of Lignosulfonate Gels to Reduce Channeling, South Swan Hills Miscible Unit, Alberta, Canada,” SPE paper 15547 presented at the 1986 Annual Technical Conference and Exhibition, New Orleans, LA, Oct. 
5-8.

51. Moffitt, P.D.: "Long-Term Production Results of Polymer Treatments in Production Wells in Western Kansas,” JPT (April 1993) 356-62.

52. Kintzele, M.J.: "Polymer Treatments Brighten Production Profiles of Rocky Mountain Wells," American Oil \& Gas Reporter (Feb. 1998) 108-119.

53. Southwell, G.P. and Posey, S.M.: "Applications and Results of AcrylamidePolymer/Chromium(III) Carboxylate Gels,” paper SPE 27779 presented at the 1994 SPE/DOE Symposium on Improved Oil Recovery, Tulsa, OK, April 17-20.

54. B. Bai et al.: "Preformed Particle Gel for Conformance Control: Factors Affecting its Properties and Applications," paper SPE 89389 presented at the 2004 SPE/DOE Symposium on Improved Oil Recovery, Tulsa, OK, April 17-21.

55. B. Bai et al.: "Preformed Particle Gel for Conformance Control: Transport Mechanism Through Porous Media," paper SPE 89468 presented at the 2004 SPE/DOE Symposium on Improved Oil Recovery, Tulsa, OK, April 17-21. 


\section{APPENDIX A: Program To Model Coreflood Results}

C .... program DPR Model 5 5/7/04

REAL MUO,MUW,KO,KW,QO, PVN,DPVO,T1,KT

REAL PVMARK

PARAMETER (MUO=3,MUW=1,KO=0.1,KW=0.00026)

PARAMETER $(\mathrm{PA}=14.7 * 12 * 2.54, \mathrm{~PB}=14.7)$

PARAMETER $($ FLEN $=3 . * 2.54$, SMAX $=0.632, \mathrm{SMIN}=0.432)$

PARAMETER $(\mathrm{NL}=40, \mathrm{NV}=1)$

PARAMETER (DLEN=FLEN/NL)

DIMENSION PO(0:NL),PN(0:NL),SO(0:NL),SN(0:NL)

DIMENSION QOO(0:NL),QON(0:NL),QWO(0:NL),QWN(0:NL)

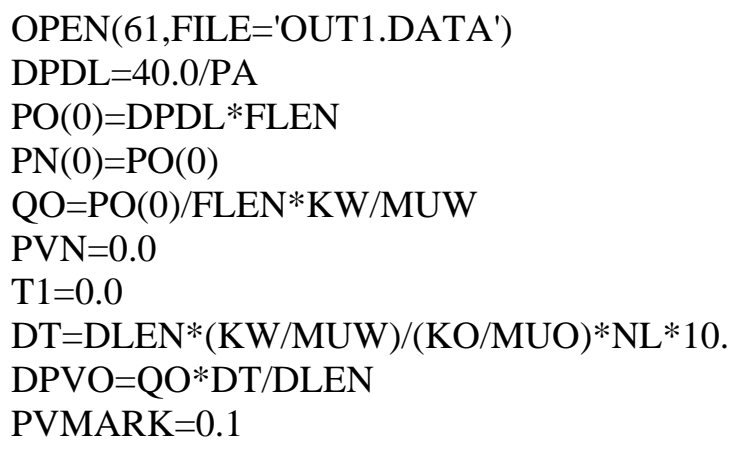

15 DO $150 \mathrm{~J}=1,500000$

$\mathrm{T} 1=\mathrm{T} 1+\mathrm{DT}$

DO 20 I=1,NL

IF(I.LE.J) THEN

QWO(I-1) $=0.0$ 


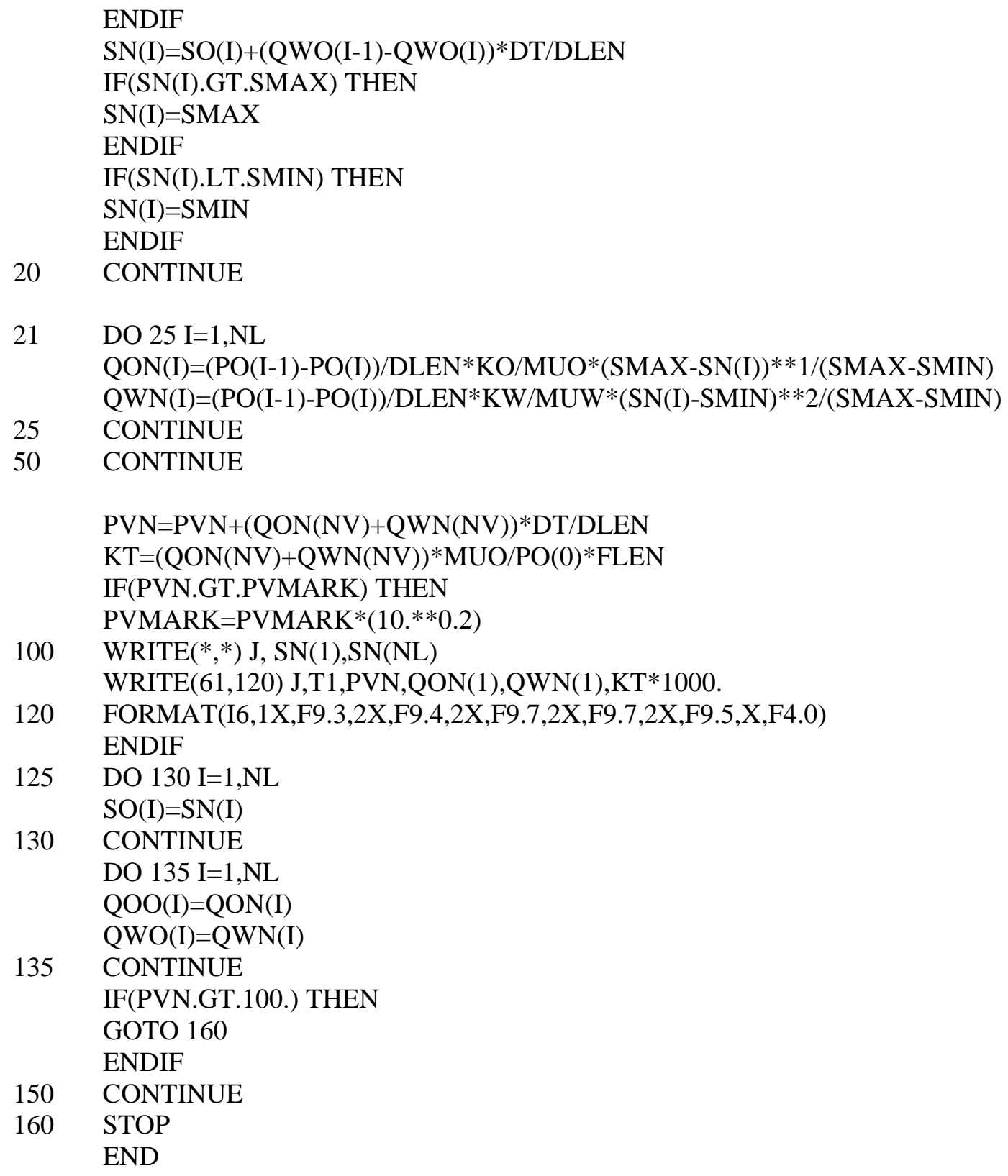




\section{APPENDIX B: Program to Predict Oil Productivity In Fractured Production Wells}

C .... program DPR Model 8FL 5/17/04

REAL MUO,MUW,KO,KW,QO, PVN,DPVO, T1,KT

REAL PVMARK

PARAMETER (MUO=3,MUW=1,KO=0.1,KW=0.00026)

PARAMETER $(\mathrm{PA}=14.7 * 12 . * 2.54, \mathrm{~PB}=14.7)$

PARAMETER $(\mathrm{FLEN}=1 . * 12 . * 2.54, \mathrm{SMAX}=0.632, \mathrm{SMIN}=0.432)$

PARAMETER $(\mathrm{LE}=500 * 12 . * 2.54)$

PARAMETER $(\mathrm{PW}=0 . / 14.7, \mathrm{PE}=100 . / 14.7)$

PARAMETER $(\mathrm{AF}=4 . *(100 . * 12 . * 2.54) * * 2)$

PARAMETER $(\mathrm{PVT}=\mathrm{AF} * 0.2 * \mathrm{FLEN})$

PARAMETER $(\mathrm{NL}=100, \mathrm{NV}=1)$

PARAMETER (DLEN=FLEN/NL)

DIMENSION PO(0:NL),PN(0:NL),SO(0:NL),SN(0:NL)

DIMENSION QOO(0:NL),QON(0:NL),QWO(0:NL),QWN(0:NL)

OPEN(61,FILE='OUT1.DATA')

$\mathrm{KT}=\mathrm{KW}$

$\mathrm{DPDL}=(\mathrm{PE}-\mathrm{PW}) / \mathrm{FLEN} *(\mathrm{FLEN} / \mathrm{KT}) /(\mathrm{FLEN} / \mathrm{KT}+(\mathrm{LE}-\mathrm{FLEN}) / \mathrm{KO})$

$\mathrm{QTO}=\mathrm{KO} *(\mathrm{PE}-\mathrm{PW}) /(\mathrm{MUO} * \mathrm{LE}) * \mathrm{AF}^{*} 3600 * 24 . /(350 * 454$.

$\mathrm{DP}=\mathrm{PE}-\mathrm{PW}$

$\mathrm{PO}(0)=\mathrm{DPDL} * \mathrm{FLEN}$

$\mathrm{PN}(0)=\mathrm{PO}(0)$

$\mathrm{QO}=\mathrm{PO}(0) / \mathrm{FLEN} * \mathrm{KW} / \mathrm{MUW}$

$\mathrm{PVN}=0.0$

$\mathrm{T} 1=0.0$

$\mathrm{DT}=\mathrm{DLEN} *(\mathrm{KW} / \mathrm{MUW}) /(\mathrm{KO} / \mathrm{MUO}) * \mathrm{NL} * 100$.

$\mathrm{DPVO}=\mathrm{QO} * \mathrm{DT} / \mathrm{DLEN}$

$\mathrm{PVMARK}=0.0001$

WRITE $(*, *) ' * * * *$ DATA IN FILE, OUT1.DAT **** '

WRITE(61,*) ' *** DPR MODEL 8FL 5/17/04 ko^1/kw^2***'

WRITE $(61, *)$

WRITE(61,5) MUO,MUW,FLEN/(12.*2.54),DLEN,KO,KW,DPDL*PA,SMAX,SMIN,DPVO

5 FORMAT (15X,'Oil cp=',F5.3,2X,'Water cp=',F5.3,2X,'Lpo(ft)=',F4.1,

$+\quad$ /15X,'DLEN $(\mathrm{cm})=$ ', F9.6,2X,'KO darcys= ',F5.4,2X,

$+\quad$ /15X,'KW darcys= ',F5.4,2X,'dp/dl (psi/ft)= ',F6.1,

$+\quad$ /15X,'SMAX= ',F5.3,2X,'SMIN= ',F5.3,' DPVO= ',F9.7)

WRITE(61,7) QTO,DP*14.7

7 FORMAT (15X,'Original BOPD=',F9.0,2X,'dP, psi=',F7.1)

WRITE $\left(61,{ }^{*}\right)$

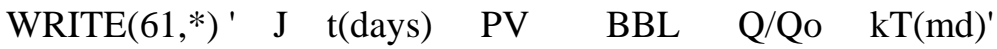

DO $10 \mathrm{I}=1, \mathrm{NL}$

$\mathrm{PO}(\mathrm{I})=\mathrm{DPDL} * \mathrm{FLEN} *(\mathrm{NL}-\mathrm{I}) / \mathrm{NL}$

$\mathrm{SO}(\mathrm{I})=$ SMAX

$\mathrm{QOO}(\mathrm{I})=0.0$

$\mathrm{QWO}(\mathrm{I})=\mathrm{QO}$

10 CONTINUE 
$\mathrm{QOO}(0)=\mathrm{DPDL} * \mathrm{KW} / \mathrm{MUW}$

$\mathrm{QWO}(0)=0.0$

15 DO $150 \mathrm{~J}=1,500000$

$\mathrm{T} 1=\mathrm{T} 1+\mathrm{DT}$

$\mathrm{DPDL}=(\mathrm{PE}-\mathrm{PW}) / \mathrm{FLEN} *(\mathrm{FLEN} / \mathrm{KT}) /(\mathrm{FLEN} / \mathrm{KT}+(\mathrm{LE}-\mathrm{FLEN}) / \mathrm{KO})$

DO $20 \mathrm{I}=1$, NL

IF(I.LE.J) THEN

QWO(I-1) $=0.0$

ENDIF

$\mathrm{SN}(\mathrm{I})=\mathrm{SO}(\mathrm{I})+(\mathrm{QWO}(\mathrm{I}-1)-\mathrm{QWO}(\mathrm{I})) * \mathrm{DT} / \mathrm{DLEN}$

IF(SN(I).GT.SMAX) THEN

$\mathrm{SN}(\mathrm{I})=\mathrm{SMAX}$

ENDIF

IF(SN(I).LT.SMIN) THEN

$\mathrm{SN}(\mathrm{I})=\mathrm{SMIN}$

ENDIF

20 CONTINUE

21 DO $25 \mathrm{I}=1, \mathrm{NL}$

$\mathrm{QON}(\mathrm{I})=\mathrm{DPDL} * \mathrm{KO} / \mathrm{MUO} *(\mathrm{SMAX}-\mathrm{SN}(\mathrm{I}))^{* *} 1 /(\mathrm{SMAX}-\mathrm{SMIN})$

$\mathrm{QWN}(\mathrm{I})=\mathrm{DPDL} * \mathrm{KW} / \mathrm{MUW}^{*}(\mathrm{SN}(\mathrm{I})-\mathrm{SMIN}) * * 2 /(\mathrm{SMAX}-\mathrm{SMIN})$

25 CONTINUE

50 CONTINUE

$\mathrm{PVN}=\mathrm{PVN}+(\mathrm{QON}(\mathrm{NV})+\mathrm{QWN}(\mathrm{NV})) * \mathrm{DT} / \mathrm{DLEN}$

$\mathrm{KT}=(\mathrm{QON}(\mathrm{NV})+\mathrm{QWN}(\mathrm{NV})) * \mathrm{MUO} / \mathrm{DPDL}$

$\mathrm{BBL}=\mathrm{PVT} * \mathrm{PVN} /(454 . * 350$.

$\mathrm{BPD}=(\mathrm{QON}(1)) /(\mathrm{QTO} /(\mathrm{AF} * 3600 . * 24 . /(350 . * 454))$.

IF(PVN.GT.PVMARK) THEN

PVMARK=PVMARK $*(10 . * * 0.2)$

100 WRITE $(*, *)$ J, SN(1),SN(NL)

WRITE(61,120) J,T1/(24.*3600.),PVN,BBL,BPD,KT*1000.

120 FORMAT(I6,1X,F9.4,2X,F9.4,2X,F9.1,3X,F7.5,3X,F6.2)

ENDIF

125 DO $130 \mathrm{I}=1, \mathrm{NL}$

$\mathrm{SO}(\mathrm{I})=\mathrm{SN}(\mathrm{I})$

130 CONTINUE

DO $135 \mathrm{I}=1, \mathrm{NL}$

$\mathrm{QOO}(\mathrm{I})=\mathrm{QON}(\mathrm{I})$

$\mathrm{QWO}(\mathrm{I})=\mathrm{QWN}(\mathrm{I})$

135 CONTINUE

IF(PVN.GT.1000.) THEN

GOTO 160

ENDIF

150 CONTINUE

160 STOP

END 


\section{APPENDIX C: Program to Predict Oil Productivity in Unfractured Production Wells}

C .... program DPR Model 8FR 5/17/04

REAL MUO,MUW,KO,KW,QO,PVN,T1,KT

REAL PVMARK,DV,DRI,DPI

PARAMETER (MUO=3,MUW=1,KO=0.1,KW=0.00026)

PARAMETER $(\mathrm{PA}=14.7 * 12 . * 2.54, \mathrm{~PB}=14.7)$

PARAMETER $($ SMAX $=0.632, \mathrm{SMIN}=0.432)$

PARAMETER $(\mathrm{PW}=0 . / 14.7, \mathrm{PE}=100 . / 14.7)$

PARAMETER (RPO=3.*12.*2.54,RWELL=0.5*12.*2.54)

PARAMETER $(\mathrm{H}=10 . * 12 * 2.54, \mathrm{PVT}=\mathrm{H} * 0.2 * 3.14 *(\mathrm{RPO} * * 2-\mathrm{RWELL} * * 2))$

PARAMETER $(\mathrm{RE}=500 . * 12 . * 2.54)$

PARAMETER $(\mathrm{NL}=100, \mathrm{NM}=\mathrm{NL}-1, \mathrm{NK}=\mathrm{NL}+1)$

DIMENSION PO(0:NL),PN(0:NL),SO(0:NL),SN(0:NL)

DIMENSION QOO(0:NL),QON(0:NL),QWO(0:NK),QWN(0:NK)

DIMENSION R(0:NL)

OPEN(61,FILE='OUT1.DATA')

$\mathrm{KT}=\mathrm{KW}$

$\mathrm{QTO}=2 * 3.14 * \mathrm{H} * \mathrm{KO} *(\mathrm{PE}-\mathrm{PW}) /(\mathrm{MUO} * \mathrm{LOG}(\mathrm{RE} / \mathrm{RWELL})) * 3600 . * 24 . /(350 * 454$.

$\mathrm{DP}=\mathrm{PE}-\mathrm{PW}$

$\mathrm{PO}(0)=\mathrm{PW}$

$\mathrm{PN}(0)=\mathrm{PW}$

$\mathrm{PO}(\mathrm{NL})=\mathrm{PW}+\mathrm{DP} *(\mathrm{LOG}(\mathrm{RPO} / \mathrm{RWELL}) / \mathrm{KT}) /(\mathrm{LOG}(\mathrm{RPO} / \mathrm{RWELL}) / \mathrm{KT}+\mathrm{LOG}(\mathrm{RE} / \mathrm{RPO}) / \mathrm{KO})$

$\mathrm{QO}=2 * 3.14 * \mathrm{H}^{*} \mathrm{KT} *(\mathrm{PO}(\mathrm{NL})-\mathrm{PW}) /(\mathrm{MUO} * \mathrm{LOG}(\mathrm{RPO} / \mathrm{RWELL}))$

$\mathrm{PVN}=0.0$

$\mathrm{T} 1=0.0$

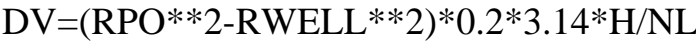

$\mathrm{DT}=\mathrm{DV} *(\mathrm{KW} / \mathrm{MUW}) /(\mathrm{KO} / \mathrm{MUO}) * 1$.

PVMARK $=0.0001$

$\mathrm{R}(0)=\mathrm{RWELL}$

$\mathrm{R}(\mathrm{NL})=\mathrm{RPO}$

WRITE $(*, *))^{\prime * * * *}$ DATA IN FILE, OUT1.DAT **** '

WRITE(61,*) ' *** DPR MODEL 8F Radial 5/17/04 ko^1/kw^2***'

WRITE $(61, *)$

WRITE(61,5) MUO,MUW,RPO/(12.*2.54),DV/350./454.,KO,KW,DP*PB,SMAX,SMIN

5 FORMAT (15X,'Oil cp=',F5.3,2X,'Water cp=',F5.3,2X,'Rpo(ft)=',F4.1,

$+\quad$ /15X,'DV (BBL) = ', F9.4,2X,'KO darcys= ',F5.4,2X,

$+\quad$ /15X,'KW darcys= ',F5.4,2X,'dP (psi)= ',F6.1,

$+\quad$ /15X,'SMAX= ',F5.3,2X,'SMIN= ',F5.3)

WRITE(61,7) QTO,DP*14.7

7 FORMAT (15X,'Original BOPD=',F9.0,2X,'dP psi=',F7.1)

WRITE $(61, *)$

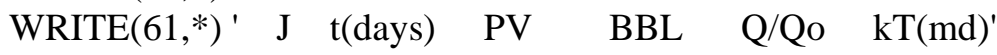

DO $10 \mathrm{I}=1, \mathrm{NM}$

$\mathrm{R}(\mathrm{I})=(\mathrm{R}(\mathrm{I}-1) * * 2+\mathrm{DV} * 0.2 /(3.1416)) * *(0.5)$

$\mathrm{PO}(\mathrm{I})=\mathrm{PW}+(\mathrm{PO}(\mathrm{NL})-\mathrm{PW}) * \mathrm{LOG}(\mathrm{R}(\mathrm{I}) / \mathrm{RWELL}) / \mathrm{LOG}(\mathrm{RPO} / \mathrm{RWELL})$ 
DO 12 I=1,NL

$\mathrm{SO}(\mathrm{I})=\mathrm{SMAX}$

$\mathrm{QOO}(\mathrm{I})=0.0$

$\mathrm{QWO}(\mathrm{I})=\mathrm{QO}$

12 CONTINUE

$\mathrm{QWO}(\mathrm{NK})=0.0$

15 DO $150 \mathrm{~J}=1,500000$

$\mathrm{T} 1=\mathrm{T} 1+\mathrm{DT}$

$\mathrm{PO}(\mathrm{NL})=\mathrm{PW}+\mathrm{DP} *(\mathrm{LOG}(\mathrm{RPO} / \mathrm{RWELL}) / \mathrm{KT}) /(\mathrm{LOG}(\mathrm{RPO} / \mathrm{RWELL}) / \mathrm{KT}+\mathrm{LOG}(\mathrm{RE} / \mathrm{RPO}) / \mathrm{KO})$

DO $20 \mathrm{I}=1, \mathrm{NL}$

$\mathrm{PO}(\mathrm{I})=\mathrm{PW}+(\mathrm{PO}(\mathrm{NL})-\mathrm{PW}) * \mathrm{LOG}(\mathrm{R}(\mathrm{I}) / \mathrm{RWELL}) / \mathrm{LOG}(\mathrm{R}(\mathrm{NL}) / \mathrm{RWELL})$

$\mathrm{SN}(\mathrm{I})=\mathrm{SO}(\mathrm{I})+(\mathrm{QWO}(\mathrm{I}+1)-\mathrm{QWO}(\mathrm{I})) * \mathrm{DT} / \mathrm{DV}$

IF(SN(I).GT.SMAX) THEN

$\mathrm{SN}(\mathrm{I})=\mathrm{SMAX}$

ENDIF

IF(SN(I).LT.SMIN) THEN

$\mathrm{SN}(\mathrm{I})=\mathrm{SMIN}$

$\mathrm{QWO}(\mathrm{I})=0.0$

ENDIF

20 CONTINUE

21 DO $25 \mathrm{I}=1, \mathrm{NL}$

$\mathrm{DPI}=\mathrm{PO}(\mathrm{I})-\mathrm{PO}(\mathrm{I}-1)$

$\mathrm{DRI}=\mathrm{LOG}(\mathrm{R}(\mathrm{I}) / \mathrm{R}(\mathrm{I}-1))$

QON(I)=DPI $2 * 3.14 * \mathrm{H} / \mathrm{DRI} *$ KO/MUO $*(\mathrm{SMAX}-\mathrm{SN}(\mathrm{I})) * * 1 /($ SMAX-SMIN)

$\mathrm{QWN}(\mathrm{I})=\mathrm{DPI} * 2 * 3.14 * \mathrm{H} / \mathrm{DRI} * \mathrm{KW} / \mathrm{MUW}^{*}(\mathrm{SN}(\mathrm{I})-\mathrm{SMIN}) * * 2 /(\mathrm{SMAX}-\mathrm{SMIN})$

25 CONTINUE

50 CONTINUE

$\mathrm{PVN}=\mathrm{PVN}+(\mathrm{QON}(\mathrm{NL})+\mathrm{QWN}(\mathrm{NL})) * \mathrm{DT} / \mathrm{PVT}$

$\mathrm{KT}=(\mathrm{QON}(\mathrm{NL})+\mathrm{QWN}(\mathrm{NL})) /(2 * 3.14 * \mathrm{H}) * \mathrm{MUO} * \mathrm{LOG}(\mathrm{RPO} / \mathrm{RWELL}) /(\mathrm{PO}(\mathrm{NL})-\mathrm{PW})$

$\mathrm{BBL}=\mathrm{PVT} * \mathrm{PVN} /(454 . * 350$.)

$\mathrm{BPD}=(\mathrm{QON}(\mathrm{NL})) /(\mathrm{QTO} /(3600 * 24 . /(350 . * 454))$.

IF(PVN.GT.PVMARK) THEN

PVMARK=PVMARK* $(10 * * 0.2)$

100 WRITE $(*, *)$ J, SN(1),SN(NL)

WRITE(61,120) J,T1/(24.*3600.),PVN,BBL,BPD,KT*1000.

120 FORMAT(I6,1X,F9.4,2X,F9.4,2X,F9.1,3X,F7.5,3X,F7.2)

ENDIF

125 DO $130 \mathrm{I}=1, \mathrm{NL}$

$\mathrm{SO}(\mathrm{I})=\mathrm{SN}(\mathrm{I})$

130 CONTINUE

DO $135 \mathrm{I}=1, \mathrm{NL}$

$\mathrm{QOO}(\mathrm{I})=\mathrm{QON}(\mathrm{I})$

$\mathrm{QWO}(\mathrm{I})=\mathrm{QWN}(\mathrm{I})$

135 CONTINUE

IF(PVN.GT.1000.) THEN

GOTO 160

ENDIF

150 CONTINUE

160 STOP

END 


\section{APPENDIX D: Technology Transfer}

\section{Presentations}

On August 25, 2004, we presented the PTTC Workshop, "Polymer and Polymer-Gel Water Shutoff Treatments: What It Takes to Be Successful and Illustrative Field Applications", at the Texas Bureau of Economic Geology facility in Houston, TX.

On June 24, 2004, we presented the talk, "Excess Water Production: Fix It or Live with It?" at the SPE Forum "Enhancing Value of Mature Fields", Broomfield, CO.

June 1-5, 2004, we presented the short course, "Water Shutoff" at PetroChina in Daqing City, China.

On April 21, 2004, we presented the paper, "X-Ray Computed Microtomography Studies of Disproportionate Permeability Reduction," at the 2004 SPE/DOE Symposium on Improved Oil Recovery, Tulsa, OK.

On April 20, 2004, we presented the paper, "Characterization of Partially Formed Polymer Gels for Application to Fractured Production Wells for Water-Shutoff Purposes," at the 2004 SPE/DOE Symposium on Improved Oil Recovery, Tulsa, OK.

On April 20, 2004, we presented the paper, "Polymer Gels Formulated with a Combination of High and Low Molecular-Weight Polymers Provide Improved Performance for Water-Shutoff Treatments in Fractured Production Wells," at the 2004 SPE/DOE Symposium on Improved Oil Recovery, Tulsa, OK.

On April 16, 2004, we presented the short course, "Water Shutoff" at the SPE/DOE IOR Meeting in Tulsa, OK.

On April 1, 2004, we presented the talk, "Using Gels to Reduce Excess Water Production in Fractured Production Wells”, at the PTTC San Juan Produced Water Forum, Farmington, NM.

On December 13-17, 2003, we presented the short course, "Water Shutoff" at the Kuwait Oil Company, Kuwait City, Kuwait.

On October 21, 2003, we presented the talk, "Polymer Gels for Water Shutoff and for Use during $\mathrm{CO}_{2}$ Flooding” for the SPE Gulf Coast Study Group in Houston, TX.

On October 18, 2003, we presented the short course, "Water Shutoff", at the 2003 SPE International IOR Conference in Kuala Lumpur, Malaysia. 
On July 31, 2003, we made a presentation "Water Shutoff Using CC/AP Gels in Fractured Producers" at the North Midcontinent PPTC workshop, "Reducing Water Production Using Gelled Polymers,” that was held in Wichita, KS.

On February 27, 2003, we participated in the Oxy Permian Conformance Workshop that was held at Oxy’s Midland, TX office.

On February 6, 2003, we presented SPE paper 80200, "Washout of Cr(III)-Acetate-HPAM Gels from Fractures," at the 2003 SPE International Symposium on Oilfield Chemistry in Houston, TX.

On January 23, 2003, we made a presentation "Causes and Treatments of Excessive Water Production - Science and Technology of Polymer Gel Treatments” at the West Coast PTTC workshop, "Water Reduction Through Polymer Treatments in Injection and Production Wells," that was held in Valencia, CA.

On December 5, 2002, we presented the talk, "A Strategy for Attacking Excess Water Production,” at the PRRC/PTTC Produced Water Workshop in Farmington, NM.

On December 5, 2002, we presented the talk, "Water Shutoff Using Polymer Gels in Fractured Producers,” at the PRRC/PTTC Produced Water Workshop in Farmington, NM.

On October 10, 2002, we held a project review at Shell’s offices in Rijswijk, Netherlands.

On October 8, 2002, we presented the talk “Treatment of Fracture Problems Using Gels," at the SPE Applied Technology Workshop, "Emerging Chemical Solutions for Water Control," in Copenhagen, Denmark.

On September 30, 2002, we presented SPE paper 77411, “Connecting Laboratory and Field Results for Gelant Treatments in Naturally Fractured Production Wells,” at the 2002 SPE Annual Technical Conference and Exhibition, in San Antonio, TX.

On August 5, 2002, we presented "Permeability Reduction Mechanisms using Microtomography," at the Gordon Research Conference, "Flow \& Transport In Permeable Media," at the Proctor Academy in Andover, NH.

On June 12, 2002, we held a project review at BP’s offices in Houston, TX.

On April 16, 2002, we presented SPE paper 75158, “An Alternative View of Filter Cake Formation in Fractures," at the 2002 SPE/DOE Symposium on Improved Oil Recovery, in Tulsa, OK.

On April 14, 2002, we presented the Short Course, "Water Shutoff," at the 2002 SPE/DOE Improved Oil Recovery Symposium in Tulsa, OK. 
On March 11, 2002, we presented the paper "Use of X-Ray Computed Microtomography to Understand Why Gels Reduce Permeabilty to Water More Than That to Oil," at the 7th International Symposium on Reservoir Wettability in Freycinet, Tasmania, Australia.

On March 8, 2002, we presented the talk “A New Model for Filter Cake Formation in Fractures” at the University of Tulsa, Department of Petroleum Engineering graduate seminar, Tulsa, OK.

On December 19, 2001, we held a project review at Shell’s offices in Rijswijk, Netherlands.

On October 1, 2001, we presented the talk, "Characterizing Disproportionate Permeability Reduction Using Synchrotron X-Ray Computed Microtomography,” at the 2001 SPE Annual Technical Conference and Exhibition in New Orleans, Louisiana.

\section{Web Site}

A description of our research group can be found at the following New Mexico PRRC web site: http://baervan.nmt.edu/randy. The site lists the publications of our group and allows viewing and downloads of all of our annual reports, most of our papers, and several important presentations.

\section{Papers and Publications}

Prodanovic, M., Lindquist, W.B, and Seright, R.S..: "3D Microtomography Study of Fluid Displacement in Rock Cores," Computational Methods in Water Resources XV Conference, Chapel Hill, NC, June 13-17.

Seright, R.S., Prodanovic, M., and Lindquist, W.B.: "X-Ray Computed Microtomography Studies of Disproportionate Permeability Reduction," paper SPE 89393 presented at the 2004 SPE/DOE Symposium on Improved Oil Recovery, Tulsa, OK, April 17-21.

Sydansk, R.D., Al-Dhafeeri, A., Xiong, Y., Schrader, R., and Seright, R.S..: "Characterization of Partially Formed Polymer Gels for Application to Fractured Production Wells for Water-Shutoff Purposes," paper SPE 89401 presented at the 2004 SPE/DOE Symposium on Improved Oil Recovery, Tulsa, OK, April 17-21.

Sydansk, R.D., Al-Dhafeeri, A., Xiong, Y., and Seright, R.S..: "Polymer Gels Formulated with a Combination of High and Low Molecular-Weight Polymers Provide Improved Performance for Water-Shutoff Treatments in Fractured Production Wells," paper SPE 89402 presented at the 2004 SPE/DOE Symposium on Improved Oil Recovery, Tulsa, OK, April 17-21.

Seright, R.S, Liang J., Lindquist, W.B., and Dunsmuir, J.H.: "Use of X-Ray Computed Microtomography to Understand Why Gels Reduce Permeabilty to Water More Than That to Oil,” J. Petroleum Science and Engineering, Vol. 39, Nos. 3-4 (Sept. 2003) 217-230.

Seright, R.S., Lane, R.H., and Sydansk, R.D.: “A Strategy for Attacking Excess Water Production,” SPE Production and Facilities (Aug. 2003) 158-169. 
Seright, R.S.: "An Alternative View of Filter Cake Formation in Fractures Inspired by Cr(III)Acetate-HPAM Gel Extrusion,” SPE Production and Facilities (Feb. 2003) 65-72.

Seright, R.S.: "Washout of Cr(III)-Acetate-HPAM Gels from Fractures," paper SPE 80200 presented at the 2003 SPE International Symposium on Oilfield Chemistry, Houston, TX, Feb. 57.

Seright, R.S, Liang J., Lindquist, W.B., and Dunsmuir, J.H.: "Characterizing Disproportionate Permeability Reduction Using Synchrotron X-Ray Computed Microtomography,” SPE Reservoir Evaluation \& Engineering, 5(5), (Oct. 2002) 355-364.

Marin, A., Seright, R., Hernandez, M., Espinoza, M., Mejias, F.: "Connecting Laboratory and Field Results for Gelant Treatments in Naturally Fractured Production Wells,” paper SPE 77411 presented at the 2002 SPE Annual Technical Conference and Exhibition, San Antonio, TX, Sept. 29-Oct. 2.

Seright, R.S.: "Conformance Improvement Using Gels," Annual Technical Progress Report (U.S. DOE Report DOE/BC/15316-2), U.S. DOE Contract DE-FC26-01BC15316 (Sept. 2002).

Seright, R.S.: “An Alternative View of Filter Cake Formation in Fractures,” paper SPE 75158 presented at the 2002 SPE/DOE Symposium on Improved Oil Recovery, Tulsa, OK, April 13-17.

Seright, R.S, Liang J., Lindquist, W.B., and Dunsmuir, J.H.: "Use of X-Ray Computed Microtomography to Understand Why Gels Reduce Permeabilty to Water More Than That to Oil," 7th International Symposium on Reservoir Wettability in Freycinet, Tasmania, Australia, March 12-15, 2002.

Seright, R.S.: “Gel Propagation Through Fractures,” SPE Production \& Facilities (Nov. 2001) 225-232.

Seright, R.S, Liang J., Lindquist, W.B., and Dunsmuir, J.H.: "Characterizing Disproportionate Permeability Reduction Using Synchrotron X-Ray Computed Microtomography,” paper SPE 71508 presented at the 2001 SPE Annual Technical Conference and Exhibition, New Orleans, LA, Sept. 30- Oct. 3.

Liang, J., and Seright, R.S.: "Wall-Effect/Gel Droplet Model of Disproportionate Permeability Reduction,” SPE Journal (September 2001) 268-272. 